\title{
Untersuchungen zur Chemotherapieresistenz von H8N8-Tumorzellen nach Cyclophosphamid-, Doxorubicin- und 5-Fluouraciltherapie im syngenen WAP-T-Mammakarzinom-Mausmodell
}

\author{
Dissertation \\ zur Erlangung des mathematisch-naturwissenschaftlichen Doktorgrades \\ "Doctor rerum naturalium" (Dr. rer. nat.) \\ der Georg-August-Universität Göttingen \\ im Promotionsprogramm Molekulare Medizin \\ der Georg-August University School of Science (GAUSS)
}

vorgelegt von

Oliver Reinhardt

aus

Heilbad Heiligenstadt

Göttingen 2019 


\section{Betreuungsausschuss:}

Betreuerin:

Zweitbetreuer:

Drittbetreuer:
Prof. Dr. Frauke Alves

Translationale Molekulare Bildgebung

Max-Planck-Institut für Experimentelle Medizin

und

Klinik für Hämatologie und Medizinische Onkologie

Universitätsmedizin Göttingen

und

Institut für Diagnostische und Interventionelle Radiologie Universitätsmedizin Göttingen

Prof. Dr. Michael Zeisberg

Klinik für Nephrologie und Rheumatologie

Universitätsmedizin Göttingen

Dr. Florian Wegwitz

Klinik für Allgemein-, Viszeral- und Kinderchirurgie

Universitätsmedizin Göttingen 


\section{Prüfungskommission:}

Referentin:

Prof. Dr. Frauke Alves

Translationale Molekulare Bildgebung

Max-Planck-Institut für Experimentelle Medizin

und

Klinik für Hämatologie und Medizinische Onkologie

Universitätsmedizin Göttingen

und

Institut für Diagnostische und Interventionelle Radiologie Universitätsmedizin Göttingen

Korreferent: $\quad$ Prof. Dr. Michael Zeisberg

Klinik für Nephrologie und Rheumatologie

Universitätsmedizin Göttingen

\section{Weitere Mitglieder der Prüfungskommission:}

Dr. Florian Wegwitz

Klinik für Allgemein-, Viszeral- und Kinderchirurgie

Universitätsmedizin Göttingen

Prof. Dr. Ralf Dressel

Institut für Zelluläre \& Molekulare Immunologie

Universitätsmedizin Göttingen

Prof. Dr. Luis Pardo

Onkophysiologie

Max-Planck-Institut für Experimentelle Medizin

Prof. Dr. Hubertus Jarry

Klinische und Experimentelle Endokrinologie

Universitätsmedizin Göttingen

Datum der mündlichen Prüfung: 27.08.2019 
Hiermit erkläre ich, die Dissertation mit dem Titel „Untersuchungen zur Chemotherapieresistenz von H8N8-Tumorzellen nach Cyclophosphamid-, Doxorubicin- und 5-Fluouraciltherapie im syngenen WAP-TMammakarzinom-Mausmodell" eigenständig angefertigt und keine anderen als die von mir angegebenen Quellen und Hilfsmittel verwendet zu haben.

Göttingen, den 31.05.2019 


\section{Inhaltsverzeichnis}

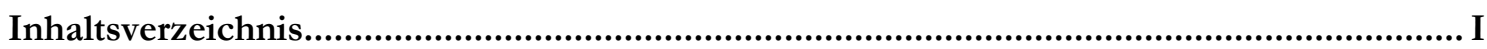

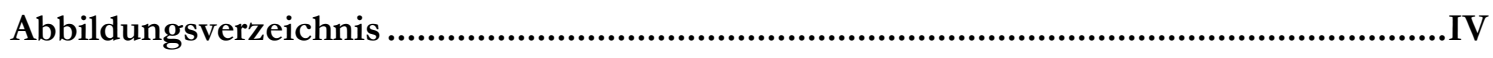

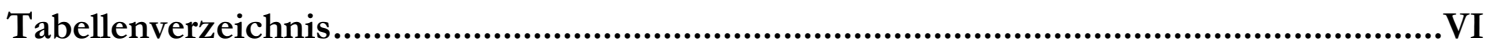

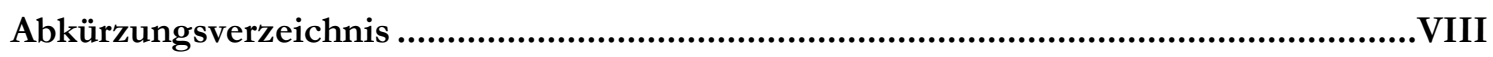

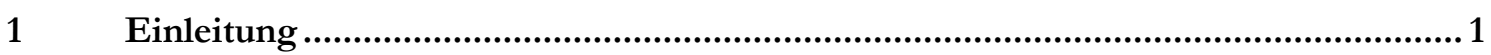

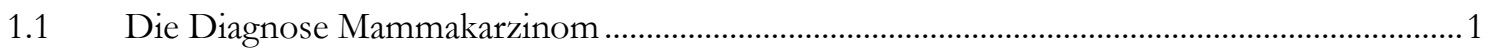

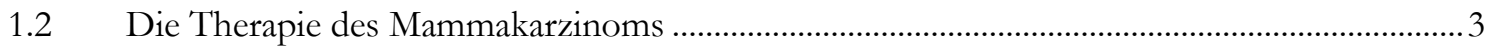

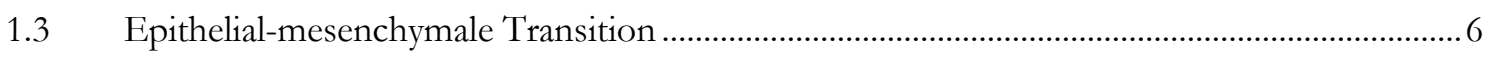

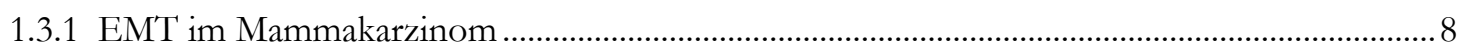

1.3.2 Signaltransduktion während der EMT im Mammakarzinom.................................................8

1.3.3 Krebsstammzellen und EMT im Mammakarzinom ..........................................................

1.3.4 Therapieresistenz und EMT im Mammakarzinom ................................................................ 10

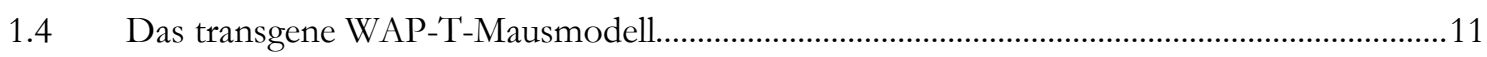

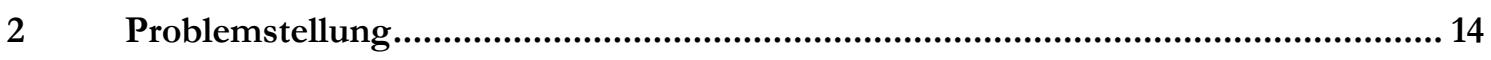

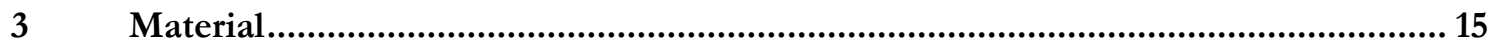

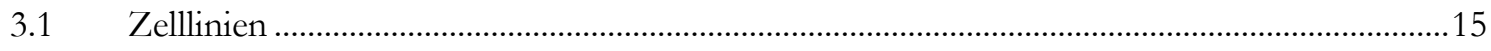

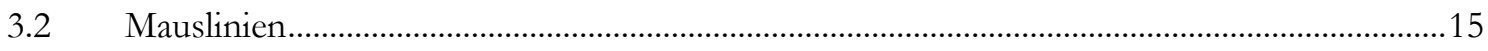

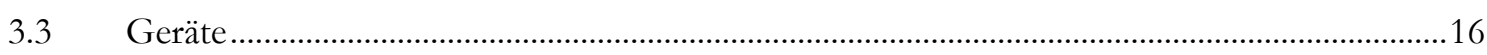

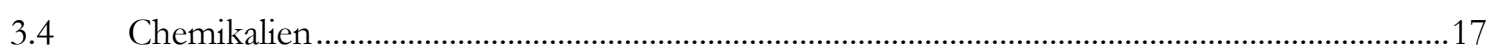

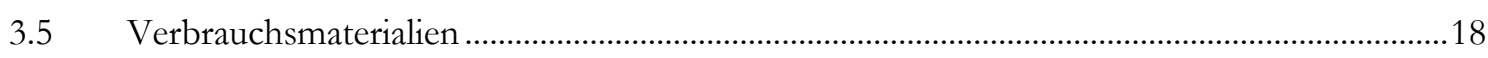

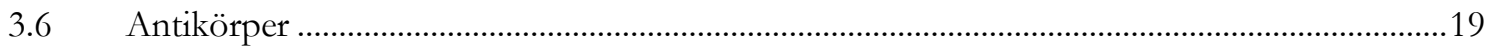

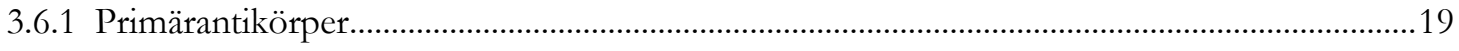

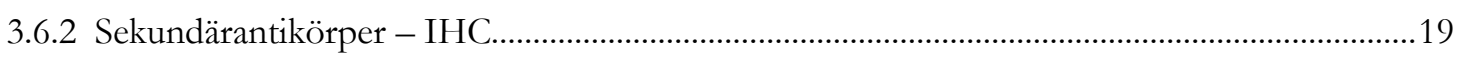

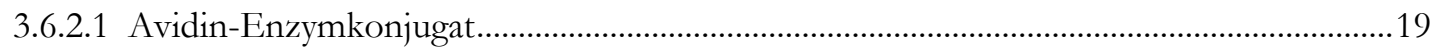

3.6.3 Sekundärantikörper - Immunfluoreszenz .......................................................................19

3.6.4 Konjugierte Antikörper - Durchflusszytometrie ..................................................................20

3.7 Oligonukleotide für PCR zur Genotypisierungs ................................................................22

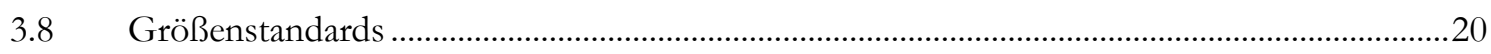

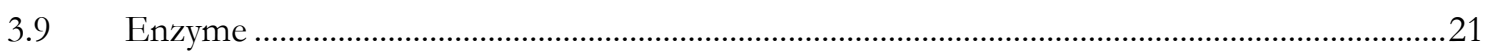

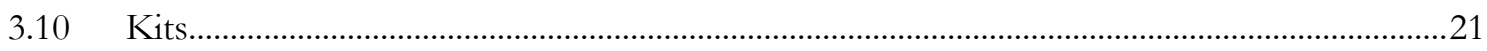

3.11 Software, Macros und Web-Browser-Anwendungen .........................................................21

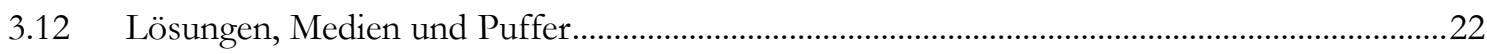

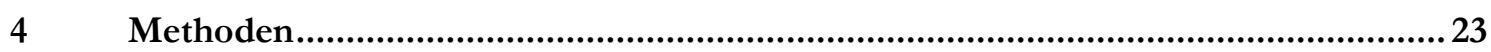

4.1 Arbeiten mit eukaryotischen Zellen ..................................................................................23

4.1.1 Kultivierung adhärent wachsender Zellen...............................................................................23

4.1.2 Kryokonservierung und Auftauen von Zellen...................................................................23 


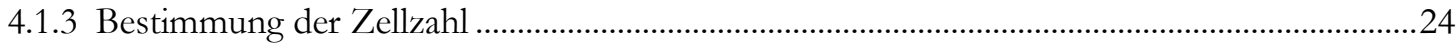

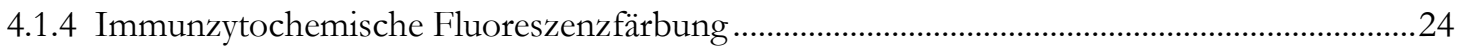

4.1.5 Zytotoxizitätsanalysen durch Impedanzmessungen ...........................................................25

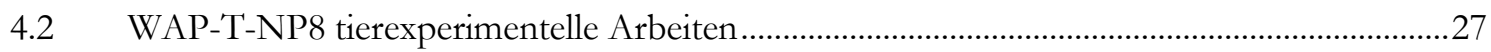

4.2.1 Zucht und Haltung der transgenen WAP-T-NP8-Mauslinie ..................................................27

4.2.2 Genotypisierung transgener WAP-T-NP8-Mäuse ..............................................................27

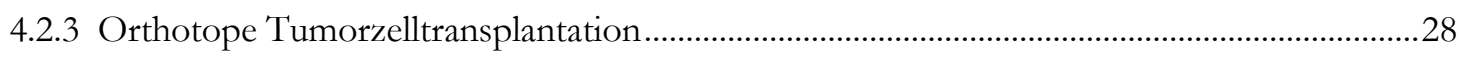

4.2.4 Bewertung des Therapieerfolgs nach RECIST-Kriterien ....................................................29

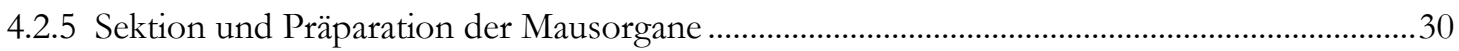

4.3 Histo- und immunhistologische Untersuchungen .............................................................. 31

4.3.1 Gewebefixierung und Herstellung von Paraffinblöcken.........................................................31

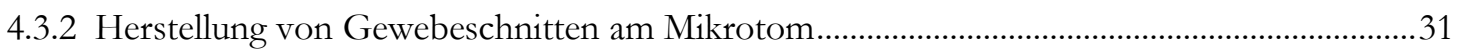

4.3.3 Entparaffinierung und Rehydrierung von Gewebeschnitten ................................................32

4.3.4 Histochemische Hämalaun-Eosin-Färbung ...........................................................................32

4.3.5 Histochemische Masson-Trichrom-Färbung .........................................................................33

4.3.5.1 Auswertung der Masson-Trichrom-Färbungen ............................................................33

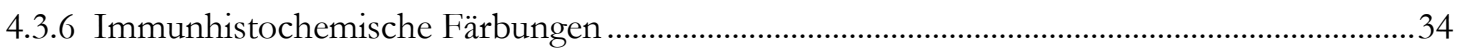

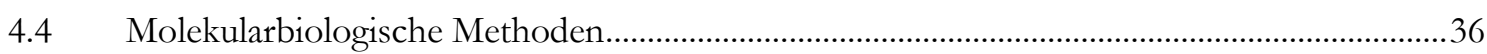

4.4.1 Extraktion genomischer DNA aus Ohrstanzenbiopsien .......................................................36

4.4.2 Genotypisierung von WAP-T-NP8-Mäusen mittels Standard-PCR.......................................37

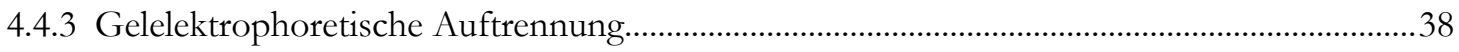

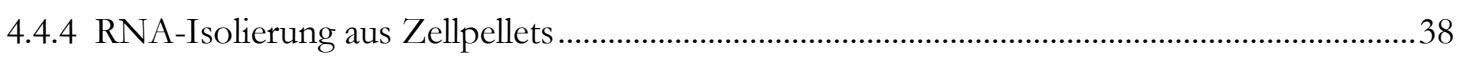

4.4.5 Bestimmung der RNA-Qualität und -Integrität ..........................................................................39

4.4.6 Illumina-Sequenzierung von generierten mRNA-Bibliotheken .............................................39

4.4.7 Analyse der sequenzierten mRNA-Bibliotheken................................................................40

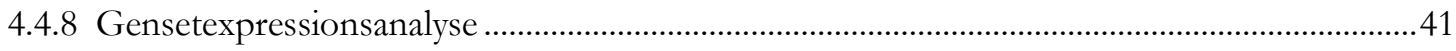

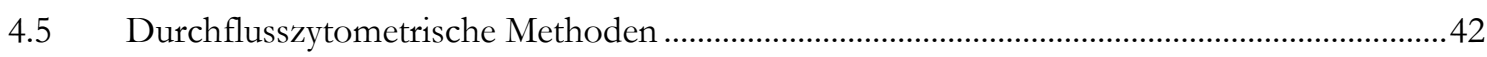

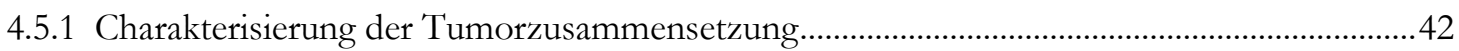

4.5.2 Isolierung von Tumorzellen durch negative Depletion ............................................................42

4.5.3 Antikörperfärbung zur Charakterisierung von Tumorzellen ................................................43

4.6 Abbildungen, Grafiken und statistische Methoden ............................................................44

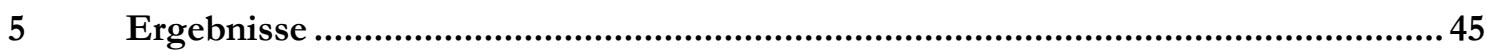

5.1 Auswirkung der CAF-Therapie auf das Tumorwachstum.......................................................45

5.1.1 Temporäre Reduzierung des Tumorvolumens nach CAF-Therapie .......................................46

5.1.2 Einordnung der Wachstumskinetiken nach RECIST-Kriterien ............................................49

5.2 Einfluss von CAF auf den Allgemeinzustand der Mäuse .....................................................51

5.2.1 CAF therapierte Mäuse zeigen schlechten Allgemeinzustände..................................................51

5.2.2 Bessere Therapieverträglichkeit bei gleicher Wirksamkeit durch Verringerung der Konzentration von Cyclophosphamid 
5.3 Auswirkungen der CAF-Therapie auf den Tumorphänotyp......................................................54

5.3.1 Veränderte Zusammensetzung und Histopathologie von Tumoren nach CAF-

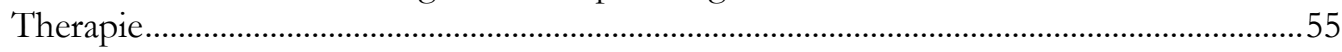

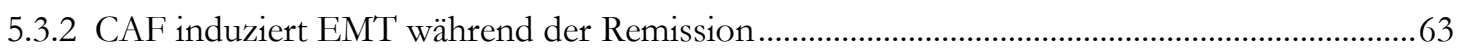

5.3.3 Tumorzellen in Remission haben Stammzellcharakter ...............................................................

5.4 Einfluss von CAF auf bereits CAF therapierte Tumore.............................................................. 80

5.4.1 Isolierte Tumorzellen behalten in vitro H8N8 Eigenschaften..................................................8

5.4.2 Erhöhte Resistenz bereits CAF therapierter retransplantierter Tumorzellen nach

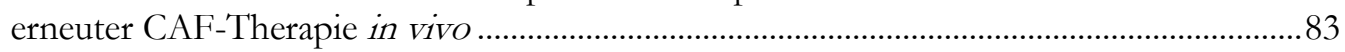

5.4.3 Isolierte, bereits CAF therapierte Tumorzellen besitzen gesteigerte CAF Resistenz in

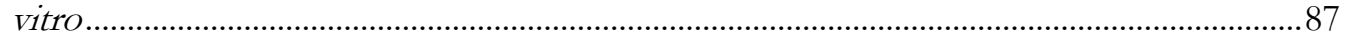

5.5 Kombinationstherapie aus CAF und Siltuximab...................................................................... 89

5.5.1 Gleiche Wirkung der CAF/S-Therapie und der CAF-Therapie auf die H8N8-

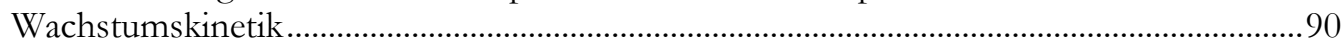

5.5.2 Schnellere Tumorvolumenreduzierung nach CAF/S-Therapie................................................94

5.5.3 Weniger Cd44+-Tumorzellen nach CAF/S-Therapie ……………………………………......95

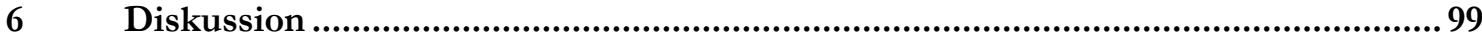

6.1 Wie wirkt sich die CAF-Therapie auf die Wachstumskinetik und den H8N8-

Tumorphänotyp aus? ................................................................................................................99

6.2 Welche Gene, Signalwege und Oberflächenmarker sind für die remittierten H8N8-

Tumorzellen charakteristisch und befähigen sie nach CAF-Therapie zum

Wiederwachstum?.

6.3 Wie wirkt sich die Hemmung von Interleukin-6 in Verbindung mit der CAF-Therapie auf Wachstumskinetik, Oberflächenmarker und CAF-Resistenz der Tumorzellen aus?.....111

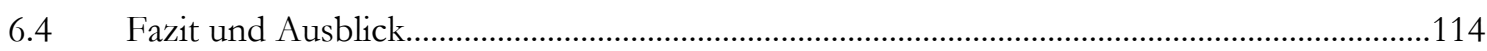

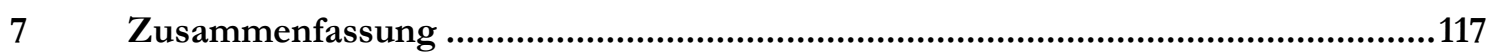

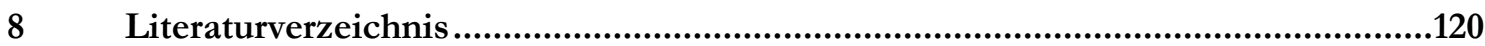

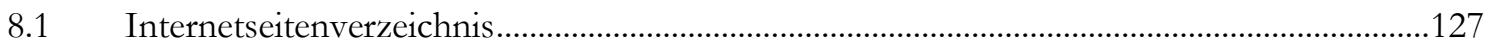

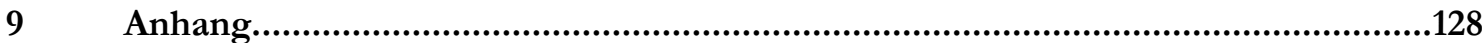




\section{Abbildungsverzeichnis}

Abbildung 1: Morphologische und physiologische Veränderungen während der EMT 7

Abbildung 2: NSP-96 Multiwell-Sensorplatte und schematische Darstellung der Impedanzmessung.....

Abbildung 3: Anatomie der Labormaus

Abbildung 4: Flussdiagramm mit den Bearbeitungsschritten zur Auswertung der MTS-Färbung....34

Abbildung 5: Schematische Darstellung der Sortierstrategie zur Isolierung der Tumorzellen ...........43

Abbildung 6: CAF-Behandlungsschema von H8N8 tumortragenden Mäusen........................................46

Abbildung 7: H8N8-Wachstumskinetiken von den zwei durchgeführten Transplantationen ...........48

Abbildung 8: Drei Phasen der H8N8-Wachstumskinetik nach CAF-Therapie .....................................49

Abbildung 9: Einfluss der CAF-Therapie auf Allgemeinzustand und Mausgewicht.............................52

Abbildung 10: $\mathrm{C}^{40} \mathrm{AF}-$ bzw. CAF-Behandlungsschema von H8N8 tumortragenden Mäusen ............53

Abbildung 11: Verträglichkeit und Wirkung der CAF-Therapie im Vergleich zu dem C40AFBehandlungsprotokoll .............................................................................................................54

Abbildung 12: Makroskopische Darstellung repräsentativer H8N8-Tumore der einzelnen

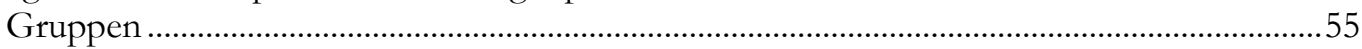

Abbildung 13: Zusammensetzung der H8N8-Tumore aus unterschiedlichen Zellpopulationen .......57

Abbildung 14: Darstellung der Zellzusammensetzung von Tumoren nach CAF-Therapie mittels chemischen und IHC-Färbemethoden in differenzierten Bereichen der Tumore

Abbildung 15: Darstellung der Zellzusammensetzung von Tumoren nach CAF-Therapie mittels chemischen und IHC-Färbemethoden in undifferenzierten Bereichen der Tumore.

Abbildung 16: Bildanalytische Quantifizierung der Kollagenanteile nach MTS-Färbung. . .62

Abbildung 17: Durch CAF induziert Synthese EMT-assozierter Markerproteine

Abbildung 18: Magnetische Seperation und Epcam FACS-Färbung der angereicherten Tumorzellen

Abbildung 19: Ergebnis der Sequenzierung der isolierten Tumorzell-mRNA und Analyse von EMT-Markergenen sowie EMT-TF

Abbildung 20: GSEA- und LEA-Analysen der sequenzierten Tumorzell-mRNA von H8N8Tumoren.

Abbildung 21: GSEA-Analyse vom Tnf- $\alpha$-Signalweg und Genexpression assoziierter Gene in H8N8-Tumorzellen nach CAF-Therapie .

Abbildung 22: GSEA-Analyse vom Il6-Jak1-Stat3-Signalweg und Genexpression assoziierter Proteine und Gene in isolierter Tumorzell-mRNA nach CAF Therapie

Abbildung 23: FACS-Analysen von Tumorzellen nach Färbung mit AK die mit einem Resistenz- und CSC-Phänotyp assoziiert sind.

Abbildung 24: Verstärkte Cd44- und verminderte Cd24-Expression in remittierten Tumoren nach CAF-Therapie.

Abbildung 25: Vermehrte Anzahl Cd44+Cd24-Tumorzellen im remittierten Tumor nach CAF sind assoziert mit der Expression von Resistenz- und Stammzellmarkern.

Abbildung 26: Relative Expression von Genen, die mit CSC-Eigenschaften und Pluripotenz assoziert sind, in H8N8-Tumorzellen nach CAF-Therapie 
Abbildung 27: Kultivierung von unbehandelten und CAF therapierten Tumorzellen kurz nach

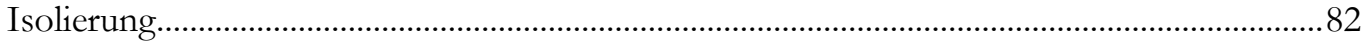

Abbildung 28: Expression von T-Ag, E-Cadherin und Vimentin nach CAF-Therapie in vitro........82

Abbildung 29: CAF-Behandlungsschema von H8N8T1, T2 und T3 tumortragenden Mäusen ........83

Abbildung 30: Wachstumskinetiken der Tumore aus den retransplantierten H8N8T1-, T2- und

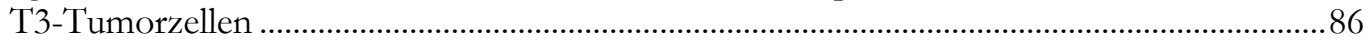

Abbildung 31: Nachweis der gesteigerten CAF-Resistenz in H8N8T2-Tumorzellen nach CAF-

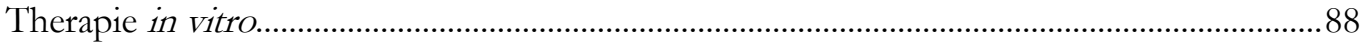

Abbildung 32: Behandlungsschema von H8N8 tumortragenden Mäusen zum Vergleich der CAF/S-Therapie mit der CAF-Therapie ............................................................................. 90

Abbildung 33: Wachstumskinetiken von H8N8-Tumoren nach CAF- und CAF/S-Therapie ..........93

Abbildung 34: Einfluss von Siltuximab bei CAF-Therapie auf Allgemeinzustand und Mausgewicht

Abbildung 35: Drei Phasen der H8N8-Wachstumskinetik nach CAF- und CAF/S-Therapie 94

Abbildung 36: Weniger Cd44+-Tumorzellen und veränderte Rezeptorexpression nach CAF/STherapie in FACS-Analysen. 97

Abbildung 37: Veränderte Cd44- und Cd24-Expression in Tumoren nach CAF/S-Therapie .98 


\section{Tabellenverzeichnis}

Tabelle 1: Isolierte unbehandelte und CAF therapierte remittierte und progressive H8N8Zelllinien.

Tabelle 2: In dieser Arbeit angegebene und verwendete Geräte ..............................................................16

Tabelle 3: In dieser Arbeit angegebene und verwendete Chemikalien ..................................................17

Tabelle 4: In dieser Arbeit angegebene und verwendete Verbrauchsmaterialien...................................18

Tabelle 5: In dieser Arbeit angegebene und verwendete unkonjugierte Primärantikörper ..................19

Tabelle 6: In dieser Arbeit angegebene und verwendete IHC Sekundärantikörper ..............................19

Tabelle 7: In dieser Arbeit angegebenes und verwendetes Avidin-Enzymkonjugat.............................19

Tabelle 8: In dieser Arbeit angegebene und für immunzytochemische Fluoreszenzfärbungen verwendete Sekundärantikörper

Tabelle 9: In dieser Arbeit angegebene und für die Durchflusszytometrie verwendete konjugierte Antikörper gegen Mausgewebe

Tabelle 10: In dieser Arbeit angegebene und verwendete Oligonukleotide für Standard-PCR..........20

Tabelle 11: In dieser Arbeit angegebener und verwendeter Größenstandard ........................................20

Tabelle 12: In dieser Arbeit angegebene und verwendete Enzyme.......................................................21

Tabelle 13: In dieser Arbeit angegebene und verwendete Kits

Tabelle 14: In dieser Arbeit angegebene und verwendete Software, Macros und Web-BrowserAnwendungen

Tabelle 15: Anwendungsangaben zu immunzytochemischen Primär- und Sekundärantikörpern.....25

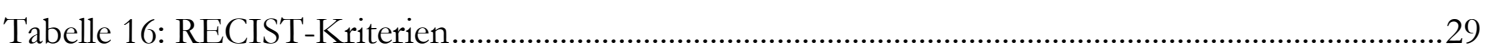

Tabelle 17: Programm für Gewebeentwässerung und Paraffininfiltration ............................................31

Tabelle 18: Absteigende Alkoholreihe zur Entparaffinierung und Rehydrierung von Gewebeschnitten

Tabelle 19: Aufsteigende Alkoholreihe zur Entwässerung HE gefärbter Gewebeschnitte...................32

Tabelle 20: Anwendungsangaben zu IHC Primär- und Sekundärantikörpern .......................................36

Tabelle 21: Reaktionsansatz für Standard-PCR zur SV40-Transgen und Notch-Identifizierung .......37

Tabelle 22: PCR-Programm für die Detektion des SV40-Transgens und Notch-

Positivkontrolle

Tabelle 23: Verwendete Barcodes des NEXTflex RNA-Seq Barcodes Kit für Illumina-

Sequenzierung.

Tabelle 24: Vergleich verschiedener Parameter der H8N8-Tumore bei Transplantationen 1 und 2 .......

Tabelle 25: Volumenveränderungen während der partiellen Remission, stabilen Erkrankung und progressiven Erkrankung nach CAF Therapie

Tabelle 26: Angaben zu CAF-Applikation und $\mathrm{V}_{\mathrm{T}}$ (ex vivo) der mittels FACS analysierten Tumore

Tabelle 27 Vergleich verschiedener Parameter nach Retransplantation von H8N8T1-, T2- und T3-Tumorzellen nach CAF-Therapie.

Tabelle 28: Verwendete CAF-Konzentrationen für Impedanzmessungen am CardioExcyte96 ........87

Tabelle 29: Plattenbelegungsplan der Impedanzmessungen am CardioExcyte96 
Tabelle 30: Vergleich verschiedener Parameter von H8N8-Tumoren nach CAF- und CAF/STherapie

Tabelle 31: Volumenveränderungen während der partiellen Remission, stabilen Erkrankung und progressiven Erkrankung nach CAF- und CAF/S-Therapie

Tabelle 32: Angaben zu Therapieapplikation und $\mathrm{V}_{\mathrm{T}}$ (ex vivo) der mittels FACS analysierten Tumore

Tabelle 33: EMT-Marker-Sequenzdaten der Tumorzell-mRNA der Gruppe CAF - Remission normiert gegen Tumorzell-mRNA der unbehandelten Tumore

Tabelle 34: EMT-Marker-Sequenzdaten der Tumorzell-mRNA der Gruppe CAF Progression normiert gegen Tumorzell-mRNA der unbehandelten Tumore.

Tabelle 35: Sequenzierdaten der Zielgene des Tnf- $\alpha$-Signalwegs der Tumorzell-mRNA der Gruppe CAF - Remission normiert gegen Tumorzell-mRNA der unbehandelten Tumore

Tabelle 36: Sequenzierdaten der Zielgene des Tnf- $\alpha$-Signalwegs der Tumorzell-mRNA der Gruppe CAF - Progression normiert gegen Tumorzell-mRNA der unbehandelten Tumore

Tabelle 37: Sequenzierdaten Il6-Rezeptor und -Zielgene des Il6-Jak1-Stat3-Signalwegs der Tumorzell-mRNA der Gruppe CAF - Remission normiert gegen Tumorzell-mRNA der unbehandelten Tumore...

Tabelle 38: Sequenzierdaten Il6-Rezeptor und -Zielgene des I16-Jak1-Stat3-Signalwegs der Tumorzell-mRNA der Gruppe CAF - Progression normiert gegen Tumorzell-mRNA der unbehandelten Tumore

Tabelle 39: Sequenzierdaten von Genen, die mit CSC-Eigenschaften und Pluripotenz assoziiert sind, der Tumorzell-mRNA der Gruppe CAF - Remission normiert gegen TumorzellmRNA der unbehandelten Tumore.

Tabelle 40: Sequenzierdaten von Genen, die mit CSC-Eigenschaften und Pluripotenz assoziiert sind, der Tumorzell-mRNA der Gruppe CAF - Progression normiert gegen Tumorzell-mRNA der unbehandelten Tumore. 


\section{Abkürzungsverzeichnis}

$\mathrm{ABC}$

ABCG2

ADAM10

ADAM17

AEC

AK

AKT2

ALDH1A3

ATP

Avidin-HRP

BCL1

BCL2

BCLXL

BCS

BMP

BSA

bspw.

bzw.

$\mathrm{C}^{40} \mathrm{AF}$

ca.

CAF

$\mathrm{CAF} / \mathrm{S}$

$\mathrm{CD}$

CD104

CD107a

CD120b

CD126

CD146

CD201

CD24

CD31

$\mathrm{CD} 44$

CD45

CD90.2

CD95

cDNA

CE96

$\mathrm{CGH}$

CSC

d.h.

DAPI

DCIS

DEPC

DICE

DMEM

DNA

DNER

D-Wasser

E2f

EBCTCG

EDTA

EM

EM1

$\mathrm{EM} 2 / 3$

EMT

EMT-TFs

EPCAM

ERBB2

ER- $\alpha$
ATP-binding cassette transporter

ATP-Binding-Cassette Subfamily-G member- 2

A Disintegrin und Metalloproteinase 10

A Disintegrin und Metalloproteinase 17

Aminoethylcarbazolsubstrats

Antikörper

thymoma viral proto-oncogene-2

Aldehyde Dehydrogenase Family-1, subfamily-A3

Adenosintriphosphat

Avidin-Meerrettichperoxidase-Konjugat

Cyclin-D1

$B$ cell leukemia/lymphoma 2

BCL2-like 1

Body Condition Score

bone morphogenetic protein

bovin serum albumin

beispielsweise

beziehungsweise

CAF mit verringerter Cyclophosphamidkonzentration

circa

Cyclophosphamid, Doxorubicin und 5-Fluouracil

$\mathrm{CAF}+$ Siltuximab-Therapie

cluster of differentiation

integrin-beta-4

lysosomal-associated membrane protein-1

tumor necrosis factor receptor superfamily, member- $1 \mathrm{~b}$

interleukin-6 receptor-alpha

melanoma cell adhesion molecule

endothelial protein $C$ receptor

lymphocyte antigen-52

platelet/endothelial cell adhesion molecule-1

lymphocyte antigen-24

leukocyte common antigen

thymus cell antigen-1

Fas - TNF receptor superfamily member-6

complementary DNA

CardioExcyte96

comparative genomic hybridization

cancer stem cell

das heißt

4',6-Diamidin-2-phenylindol

durctal carcinoma in situ

Diethyldicarbonat

Death Induced by Cd95R/L Elimination

high glucose Dulbecco's modified Eagle Medium

deoxyribonucleic acid

Delta/Notch-like EGF Repeat Containing

deionisiertem Wasser

E2f-Transkriptionsfaktor

Early Breast Cancer Trialists' Collaborative Group

Ethylendiamintetraessigsäure

Intermediärphänotyp

Intermediärphänotyp 1

Intermediärphänotyp $2 / 3$

epithelial-mesenchymale Transition

EMT-aktivierenden Transkriptionsfaktoren

epithelial cell adhesion molecule

Erb-B2 Rezeptortyrosinkinase

Estrogenrezeptor-alpha 


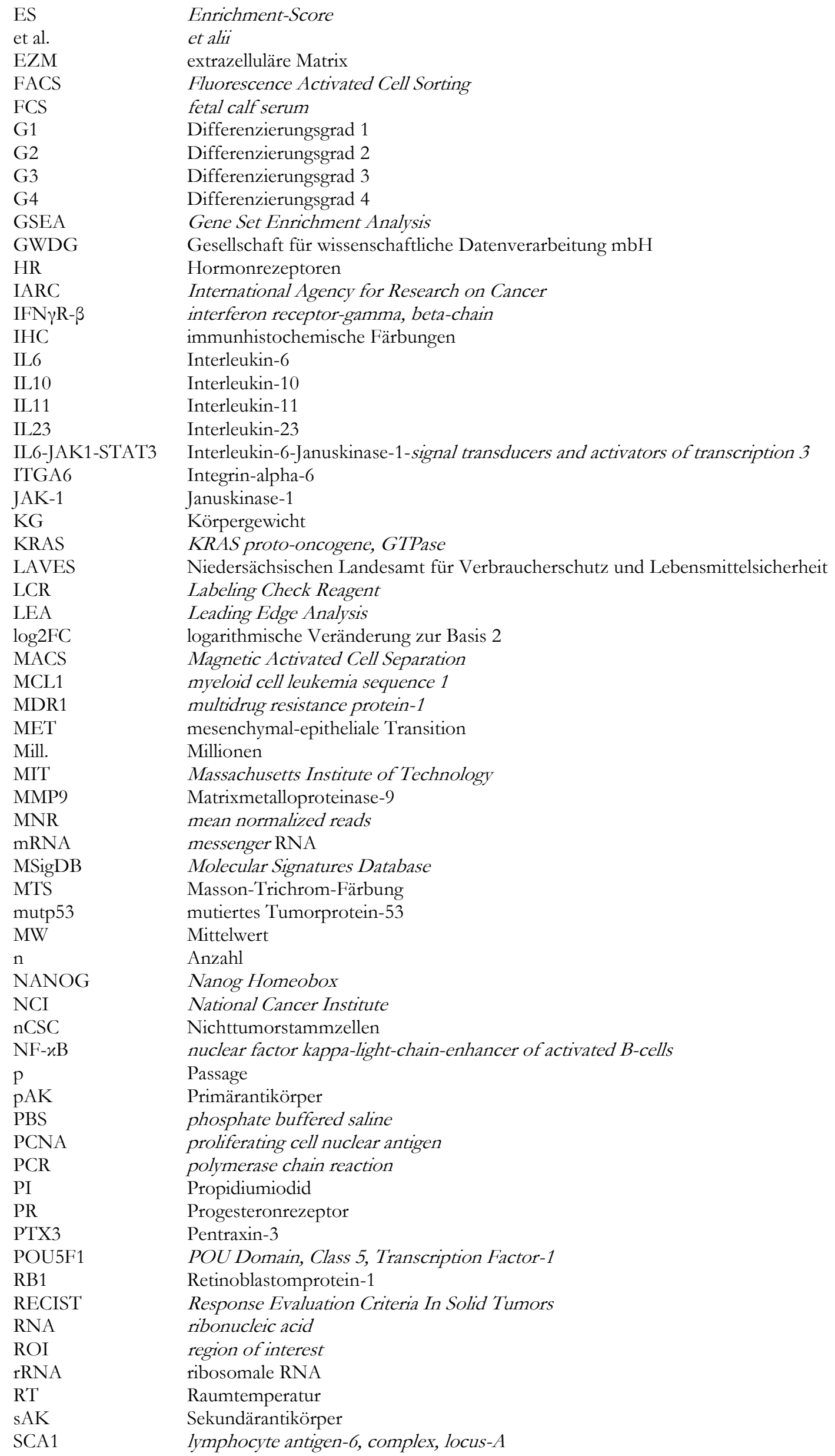




$\begin{array}{ll}\text { SD } & \text { Standardabweichung } \\ \text { SERD } & \text { Selective Estrogen Receptor Degrader } \\ \text { SHH } & \text { sonic hedgehog signaling molecule } \\ \text { siRNA } & \text { small interfering RNA } \\ \text { SOX2 } & \text { SRY (Sex Determining Region-Y)-box-2 } \\ \text { STAT } & \text { signal transducers and activators of transcription } \\ \text { SV40 } & \text { Simian-Virus-40 } \\ \text { TAF } & \text { tumorassoziierte Fibroblasten } \\ \text { T-Ag } & \text { großes T-Antigen } \\ \text { TAM } & \text { tumorassoziierte Macrophagen } \\ \text { TBE } & \text { Tris-Borat-EDTA-Puffer } \\ \text { TER119 } & \text { lymphocyte antigen-76 } \\ \text { TGF- } \beta & \text { transfoming growth factor beta } \\ \text { TNBC } & \text { triple negative breast bancer } \\ \text { TNF- } \alpha & \text { tumor necrosis factor alpha } \\ \text { TNM } & \text { Tumor-, Nodus- und Metastasenklassifizierung } \\ \text { TP53 } & \text { Tumorprotein-53 } \\ \text { Tsd. } & \text { Tausend } \\ \text { Tube } & \text { Eppendorf Reagenzgefäß } \\ \text { ÜN } & \text { über Nacht } \\ \text { UV } & \text { Ultraviolettstrahlung } \\ \text { VIM } & \text { Vimentin } \\ \text { V } & \text { Tumorvolumen } \\ \text { WAP } & \text { whey acidic protein } \\ & \end{array}$

In dieser Arbeit ist die Bezeichnung humaner Gene kursiv und in Großbuchstaben geschrieben (CDH1), das Genprodukt, also das von diesem Gen kodierte Protein, wird dagegen nicht kursiv geschrieben (CDH1) und ist so im Abkürzungsverzeichnis gelistet. Wird in dieser Arbeit ein murines Gen erwähnt, ist die Schreibweise ebenfalls kursiv, das Gensymbol beginnt jedoch mit einem Großbuchstaben, gefolgt von Kleinbuchstaben (Cdh1), das zugehörige Protein wird nicht kursiv geschrieben (Cdh1). 


\section{$1 \quad$ Einleitung}

Laut Schätzungen der Internationalen Agentur für Krebsforschung (IARC, International Agency for Research on Cancer) ist damit zu rechnen, dass die jährliche Anzahl diagnostizierter Krebserkrankungen vom Jahr 2018 bis 2040 weltweit um 61,2 \%, von ca. 18,1 auf ca. 29,5 Mill. ansteigt (Ferlay et al. 2019). Im Jahr 2018 waren 11,6 \% (ca. 2,1 Mill.) der weltweit diagnostizierten Krebserkrankungen Mammakarzinome (Bray et al. 2018) mit einer Inzidenz für Europa von 25,0 \% (ca. 522,5 Tsd.), einer Mortalität von 22,0 \% (ca. 137,7 Tsd.) und einer Fünfjahresprävalenz von 29,9 \% (ca. 2,1 Mill.). Damit ist das Mammakarzinom die dritthäufigste krebsbedingte Todesursache der europäischen Bevölkerung. Im Jahr 2018 verstarben in Deutschland ca. 19,4 Tsd. Menschen an einem Mammakarzinom. Damit ist diese Erkrankung die häufigste krebsbedingte Todesursache von Frauen in Deutschland (Bray et al. 2018; Ferlay et al. 2018; Ferlay et al. 2019).

\subsection{Die Diagnose Mammakarzinom}

Der Hauptrisikofaktor für Frauen, an einem Mammakarzinom zu erkranken, ist das Alter (Becker 2015). Weitere Risiken sind eine geringe Parität, eine kurze Stillphase und ein langer Zeitraum von der Menarche bis zum Klimakterium mit anschließender Menopause (Murawa et al. 2014; Dall und Britt 2017). Es mehren sich Hinweise, dass die hormonelle Kontrazeption ebenfalls das Mammakarzinomrisiko in bestimmten Fällen erhöhen kann (Mørch et al. 2017; White 2018). Diese Risikofaktoren erklären, dass die Wahrscheinlichkeit, speziell für Frauen der Industriestaaten, an einem Mammakarzinom zu erkranken, erhöht ist (Bray et al. 2018).

Zur Auswahl der bestmöglichen Therapie muss der Tumor in der Brust umfassend charakterisiert werden. Eine Tumorklassifikation beinhaltet die histopathologische Begutachtung und Einordnung der Mammakarzinome in Grad eins (G1) gut differenziert, Grad zwei (G2) mäßig differenziert, Grad drei (G3) schlecht differenziert oder Grad vier (G4) undifferenziert metastasierend (Elston und Ellis 1991). Außerdem wird der Tumor in das TNM-Klassifizierungssystem durch die folgenden drei Hauptkriterien eingestuft: i) Größe und Ausbreitung des Primärtumors (T), ii) Fehlen oder Vorhandensein von örtlichen oder benachbarten Lymphknotenmetastasen $(\mathrm{N})$ und iii) Vorhandensein von 
Fernmetastasen (M) (Harmer et al. 1968). Molekularbiologische Methoden ermöglichen eine weitere Charakterisierung der Tumore durch Bestimmung des Erb-B2-Rezeptortyrosinkinase-(ERBB2-), Estrogenrezeptor-alpha-(ER- $\alpha$-) und Progesteronrezeptor-(PR-) Status in Verbindung mit dem auf Genexpressionsprofilen basierenden molekularen Subtypen: i) Luminal A, ii) Luminal B, iii) basalähnlich und iv) normal-ähnlich (Prat und Perou 2011; Joshi und Press 2018).

In 50-75 \% der Fälle handelt es sich nach der Begutachtung der Histologie um ein invasives duktales Mammakarzinom, gefolgt von einem invasiven lobulären Mammakarzinom in 5-15\% der Fälle. Die restlichen Befunde machen seltene Histologien aus (Corben 2013). Bei ca. $70 \%$ der invasiven Mammakarzinome sind der ER- $\alpha$ und der PR, hier zusammengefasst als Hormonrezeptoren (HR), exprimiert (Joshi und Press 2018). Zwischen 15-20 \% der Mammakarzinome weisen eine verstärkte Aktivität oder Überexpression des epidermalen Wachstumsfaktorrezeptors ERBB2 auf und sind unbehandelt mit einer schlechten Prognose assoziiert (Piccart-Gebhart et al. 2005). Fünfzehn Prozent aller Mammakarzinome, die keinen der genannten Rezeptoren aufweisen, nennt man dreifach negative Mammakarzinome (TNBC, triple negative breast cancer) (Denkert et al. 2017). Patientinnen mit TNBC besitzen ein hohes Risiko, dass ein Fernrezidiv (Metastase) während der ersten drei bis fünf Jahre nach Diagnose und Primärtherapie auftritt (Foulkes et al. 2010). Die exakte molekularbiologische Pathophysiologie der TNBC ist bisher sehr schlecht verstanden (Waks und Winer 2019).

Bei den Fünfjahresüberlebensraten gibt es große Unterschiede, die entscheidend vom Differenzierungsgrad und dem Rezeptorstatus abhängen, bspw. liegt sie für G1-Tumore, die kleiner als $2 \mathrm{~cm}$ sind und einen negativen Lymphknotenbefund haben, für HR-positive Mammakarzinome bei 99 \%, für ERBB2-positive bei $94 \%$ und für TNBC bei $85 \%$. Die mittlere Gesamtüberlebenszeit für metastasierende G4-Mammakarzinome mit HR-positiven und ERBB2-positiven Rezeptortstatus beträgt ca. 5 Jahre und für TNBC 1 Jahr (Waks und Winer 2019). Nur $7 \%$ der Mammakarzinome sind zur Zeit der Diagnose bereits metastasiert (Lord et al. 2012). Schätzungen von 2017 für die USA gehen davon aus, dass drei von vier Frauen mit Mammakarzinomen, vormals als G1-G3 eingestuft, im Verlauf der Tumorprogression am metastasierenden G4-Mammakarzinom erkranken und dass aufgrund einer immer älter werdenden amerikanischen Gesellschaft die Anzahl an metastasierenden G4Mammakarzinomen in der Zukunft zunehmen wird (Mariotto et al. 2017). 


\subsection{Die Therapie des Mammakarzinoms}

Die jeweilige Therapie richtet sich nach der Subklassifikation des Mammakarzinoms und der Verfassung der Patientinnen. Generell unterscheiden sich die Behandlungsziele beim nicht metastasierenden (G1-G3) und beim metastasierenden (G4) Mammakarzinom. Bei nicht metastasierenden Mammakarzinomen erfolgt die Behandlung kurativ, d.h. mittels chirurgischer Eingriffe und der Kombination aus adjuvanter und/oder neoadjuvanter Radio- bzw. Chemotherapie wird versucht, die Mammakarzinome zu eliminieren. Die Therapie zielt auf die vollständige Entfernung der Tumorzellen aus dem Brustgewebe sowie aus den angrenzenden Lymphknoten, um das Risiko eines Lokoregional- oder Fernrezidivs zu minimieren. Das genaue Behandlungsprotokoll richtet sich nach dem Rezeptorstatus des Mammakarzinoms. Hormonrezeptorpositive Mammakarzinome werden mit einer endokrinen Therapie behandelt und in seltenen Fällen zusätzlich mit einer Chemotherapie. Gegen ERBB2-gerichtete Antikörper (AK), wie bspw. Trastuzumab, werden in Kombination mit Chemotherapeutika gegen ERBB2-positiv klassifizierte Mammakarzinome angewendet. Wenn diese auch HR-positiv sind, kommt zusätzlich eine endokrine Therapie in Frage. Zurzeit wird das TNBC vorzugsweise entweder mit einem auf Platin oder einem auf Taxol basierenden Chemotherapeutikum behandelt (Waks und Winer 2019).

Hauptbehandlungsziele beim metastasierenden G4-Mammakarzinom sind die Verlängerung der Lebenszeit und die palliative Symptomlinderung. Die Behandlung dieser Mammakarzinome richtet sich ebenfalls nach dem Rezeptorstatus; ein chirurgischer Eingriff und/oder eine Radiotherapie werden nur zur Symptomlinderung in Betracht gezogen (Waks und Winer 2019).

In dieser Arbeit wurde für die Behandlung muriner Mammakarzinome eine Chemotherapie bestehend aus den drei zytotoxischen Substanzen Cyclophosphamid, Doxorubicin und 5-Fluouracil (CAF) gewählt. Die CAF-Chemotherapie ist laut dem nationalen amerikanischen Krebsinstitut (NCI, National Cancer Institute) für die adjuvante Behandlung vom nichtmetastasierenden invasiven Mammakarzinom sowie der palliativen Behandlung vom rezidivierten metastasierenden Mammakarzinom zugelassen (NCI Thesaurus 2009) und kann durch zwei Darreichungsformen gegeben werden: i) Am ersten Behandlungstag werden alle CAF-Komponenten intravenös verabreicht. Eine Woche 
später wird 5-Fluoruracil allein appliziert, gefolgt von einer dreiwöchigen Ruhezeit. Über einen Zeitraum von drei bis vier Monaten wird dieser vierwöchige Zyklus vier- bis sechsmal wiederholt. ii) Während der ersten 14 Tage wird Cyclophosphamid täglich oral als Pille eingenommen. Doxorubicin und 5-Fluoruracil werden zusammen am ersten und achten Tag intravenös verabreicht, gefolgt von einer zweiwöchigen Ruhezeit. Über einen Zeitraum von vier bis fünf Monaten wird dieser vierwöchige Zyklus vier- bis sechsmal wiederholt. Eine Metastudie zum Vergleich adjuvanter Chemotherapien ergab, dass eine Behandlung mit drei Chemotherapiekomponenten, wie das CAF-Behandlungsprotokoll, gegenüber vergleichbaren Chemotherapien bestehend aus zwei Komponenten mit einem besseren Therapieergebnis assoziiert ist und die Rezidivwahrscheinlichkeit, verglichen mit unbehandelten Tumoren, reduziert wird (Early Breast Cancer Trialists' Collaborative Group (EBCTCG) 2012).

Cyclophosphamid wird in der Leber über das Cytochrom-P450-System durch Hydroxylierung in das zytotoxische Phosphoramidmustard umgewandelt und verursacht in den Zellen Vernetzungsverbindungen zwischen den Strängen der einzelnen Desoxyribonukleinsäuren (DNA, deoxyribonucleic acid) und sorgt so für Einzel- und Doppelstrangbrüche in sich schnell teilenden Zellen (Chang et al. 1993). Doxorubicin interkaliert in die DNA und Ribonukleinsäure (RNA, ribonucleic acid). Die DNA-Synthese wird dadurch gestört, Topoisomerase-2 gehemmt und über weitere Mechanismen erfolgt eine Radikalbildung (Dean 2009). Fünf-Fluoruracil wird bei der DNA-Replikation bzw. -Transkription aufgrund der Strukturähnlichkeit mit den Pyrimidinbasen Cytosin, Thymin und Uracil anstatt dieser in die DNA bzw. RNA eingebaut. Daraus resultiert eine fehlerhafte RNA-Synthese, Hemmung der Proteinbiosynthese und Thymidylatsynthase. Dies führt letztendlich dazu, dass DNA-Synthese und Zellteilung inhibiert werden (Morschhäuser 2003).

Derartige Chemotherapien können Tumore bis auf eine nicht mehr nachweisbare Größe reduzieren. Bei $40 \%$ der therapierten Patientinnen entwickelt sich allerdings ein Rezidiv nach ca. drei Jahren im Bereich des Primärtumors (Lokoregionalrezidiv) oder metastasiert an anderen Stellen des Körpers (Fernrezidiv) (Gerber et al. 2010). Nur die Tumorzellen, die am besten an den durch die Chemotherapie verursachten Selektionsdruck angepasst sind bzw. die Tumorzellen, welche sich am schnellsten und vorteilhaftesten auf die neue Situation einstellen, haben einen Überlebensvorteil gemäß der „survival of the fittest" Theorie (Darwin 1860). Solche Tumorzellen können teilweise Jahre in einer Art 
Nische verbleiben und auf die richtige Umgebung warten, bis das ausschlaggebende Signal eintritt, um das Wachstum des Rezidivs zu initiieren.

Die Chemotherapie verursacht paradoxerweise bei einigen Tumorzellen keinen Zelltod, sondern bewirkt intrinsische und extrinsische Veränderungen/Anpassungen. Resistente Tumorzellen erfahren einen Überlebensvorteil und sind eventuell Ausgangspunkt für eine erneute Tumorprogression (Middleton et al. 2018). Vorteilhafte intrinsische Veränderungen sind umfangreich untersucht und Studien zeigen, dass Chemotherapeutika die Expression antiapoptotischer Gene hochregulieren und Fähigkeiten zur Migration und Invasivität steigern (Wang et al. 2009; Quintavalle et al. 2011; Ren et al. 2015). Die Forschung über vorteilhafte extrinsische Anpassungen erfährt seit Beginn der 2000erJahre wachsende Aufmerksamkeit und ist im Fokus vielversprechender Untersuchungen. Resistente Tumorzellen können normale körpereigene Zellen manipulieren. Dieser Mechanismus kann vermutlich durch Chemotherapeutika ausgelöst oder verstärkt werden. Dadurch fungieren körpereigene Nichttumorzellen als eine Art „Komplize“ der Tumorzellen. Sie helfen dabei, Tumorzellen vor dem Immunsystem zu verstecken oder sorgen durch Ausschüttung von Zytokinen für eine progressionsfördernde Umgebung (Gilbert und Hemann 2011; De Palma und Lewis 2013; Ruffell und Coussens 2015). Eine weitestgehend akzeptierte Theorie besagt, dass einige Chemotherapeutika, wie u.a. Doxorubicin, das vermehrte Einwandern von Makrophagen, sogenannte tumorassoziierte Makrophagen (TAM), in den Tumor fördern (Nakasone et al. 2012). Tumore sind teilweise in der Lage, durch extrinsische Veränderungen die Genexpression der TAM zu manipulieren, wodurch sich die Eigenschaften der TAM von einem eigentlich bekämpfenden Tumorstatus in einen unterstützenden Tumorstatus verändert (Aras und Zaidi 2017; Mantovani et al. 2017; Zheng et al. 2017). Aus diesen Beobachtungen ergeben sich u.a. folgende Fragen: Wie verändert sich die Tumorzusammensetzung während der Tumorremission und wie sind die Tumorzellen charakterisiert, die den remittierten Tumor zu Beginn der Rezidivprogression ausmachen? Welche Rolle spielt die epithelialmesenchymale Transition (EMT) während der Rezidivprogression? Dieses Programm reguliert die Umwandlung von Tumorzellen und von normalen körpereigenen Nichttumorzellen von einem Phänotyp mit epithelialen hin zu einem mit mesenchymalen Eigenschaften, was ein verändertes Genexpressionsprofil zur Folge hat. Epithelial-mesenchymale Transition könnte das Bindeglied zwischen 
intrinsischen und extrinsischen Veränderungen/Anpassungen während der Therapie von Mammakarzinomen sein.

\subsection{Epithelial-mesenchymale Transition}

Die EMT ist ein äußert komplexes Programm und steuert neben physiologischen Prozessen auch pathologische Prozesse der Tumorprogression, -invasion und -metastasierung und gehört damit zu einen der klassischen Kennzeichen von Krebs (Hallmarks of Cancer) (Hanahan und Weinberg 2000; Taube et al. 2010). Es wurde erstmals bei Untersuchungen der Embryonalentwicklung beschrieben (Hay 1995; Shook und Keller 2003) und spielt, nach heutigem Kenntnisstand, auch bei der Geweberegeneration und während der Wundheilung eine wichtige Rolle (Haensel und Dai 2018).

Der EMT-Prozess geht immer mit ähnlichen fundamentalen physiologischen Veränderungen in den Zellen einher. Das Zytoskelett der Zellen wird komplett umorganisiert, was eine Morphologieveränderung zur Folge hat. Epitheliale platten-, quader- oder säulenförmige statische Zellen verwandeln sich in mesenchymale spindelförmig längliche dynamische Zellen. Dabei geht die apikal-basale Polarität durch Verlust epithelialer Zell-Zell-Verbindungen verloren und wird durch eine „,vorn-hinten“ Polarität ersetzt. Diese Umwandlung befähigt die Zellen, extrazelluläre Matrix (EZM) abzubauen und zu reorganisieren, wodurch Zellinvasion und -migration ermöglicht werden (Zavadil und Böttinger 2005; Shibue und Weinberg 2017).

Die Ausführung der EMT erfolgt durch Signaltransduktion der sogenannten EMT-aktivierenden Transkriptionsfaktoren (EMT-TF). Das sind hauptsächlich Transkriptionsfaktoren der Zink-FingerProteine (SNAI1, SNAI2, und SNAI3), der Zink-Finger-Enhancer-Box-Proteine (ZEB1 und ZEB2), der Helix-Loop-Helix-Proteine (TWIST1 und TWIST2) und der Forkhead-Box-Proteine (FOXC1 und FOXC2) (Puisieux et al. 2014; Chen et al. 2017). Hinzu kommt, dass die meisten EMT-TF parallel Funktionen in allen Phasen der Tumorprogression übernehmen, von der Entstehung, über Wachstum, Invasion, Dissemination, Metastasierung bis hin zur Resistenzentwicklung (Nieto et al. 2016; Shibue und Weinberg 2017; Brabletz et al. 2018). Diese Masterregulatoren steuern die Transkription EMT-assoziierter Gene durch Promotoraktivierung und -hemmung mittels Modifikationen an der Chromatinstruktur (Craene und Berx 2013). Daraus resultiert zum einen die Unterdrückung 
von E-Cadherin und Laminin-1, die mit einem epithelialen Phänotyp assoziiert sind und zum anderen die Hochregulierung von Fibronektin-1 und Vimentin, welches charakteristische Biomarker für einen mesenchymalen Phänotyp sind (Kalluri und Weinberg 2009; Shibue und Weinberg 2017). Dieser Prozess kennt nicht nur den epithelialen oder mesenchymalen Phänotyp, sondern auch Intermediärphänotypen, die die verändernden Zellen vorrübergehend im Verlauf der EMT einnehmen. Mit den morphologischen und physiologischen Veränderungen wandeln sich auch die Fähigkeiten und Eigenschaften der Zellen. Mit zunehmendem mesenchymalen Charakter steigt das invasive Verhalten und die Fähigkeit der Zellen, Metastasen- und Tumorentwicklung zu fördern, verbessert sich. Die tumorigene Fähigkeit der Zellen ist beim Intermediärphänotyp EM2/3 am größten (Abbildung 1). Zellen, die einen kompletten mesenchymalen Phänotyp aufweisen, müssen zunächst den Umkehrprozess der mesenchymal-epithelialen Transition (MET) initiieren, um die Fähigkeit eine Metastase im Gewebe zu entwickeln wiederzuerlangen. Parallel hierzu nimmt die Therapieresistenz der Zellen zu und ist am höchsten, wenn Zellen den Intermediärphänotyp EM2/3 bilden, die dann das Level der Therapieresistenz auf diesem Niveau bis zur vollständigen Umwandlung in den mesenchymalen Phänotyp halten (Abbildung 1) (Nieto et al. 2016; Shibue und Weinberg 2017).

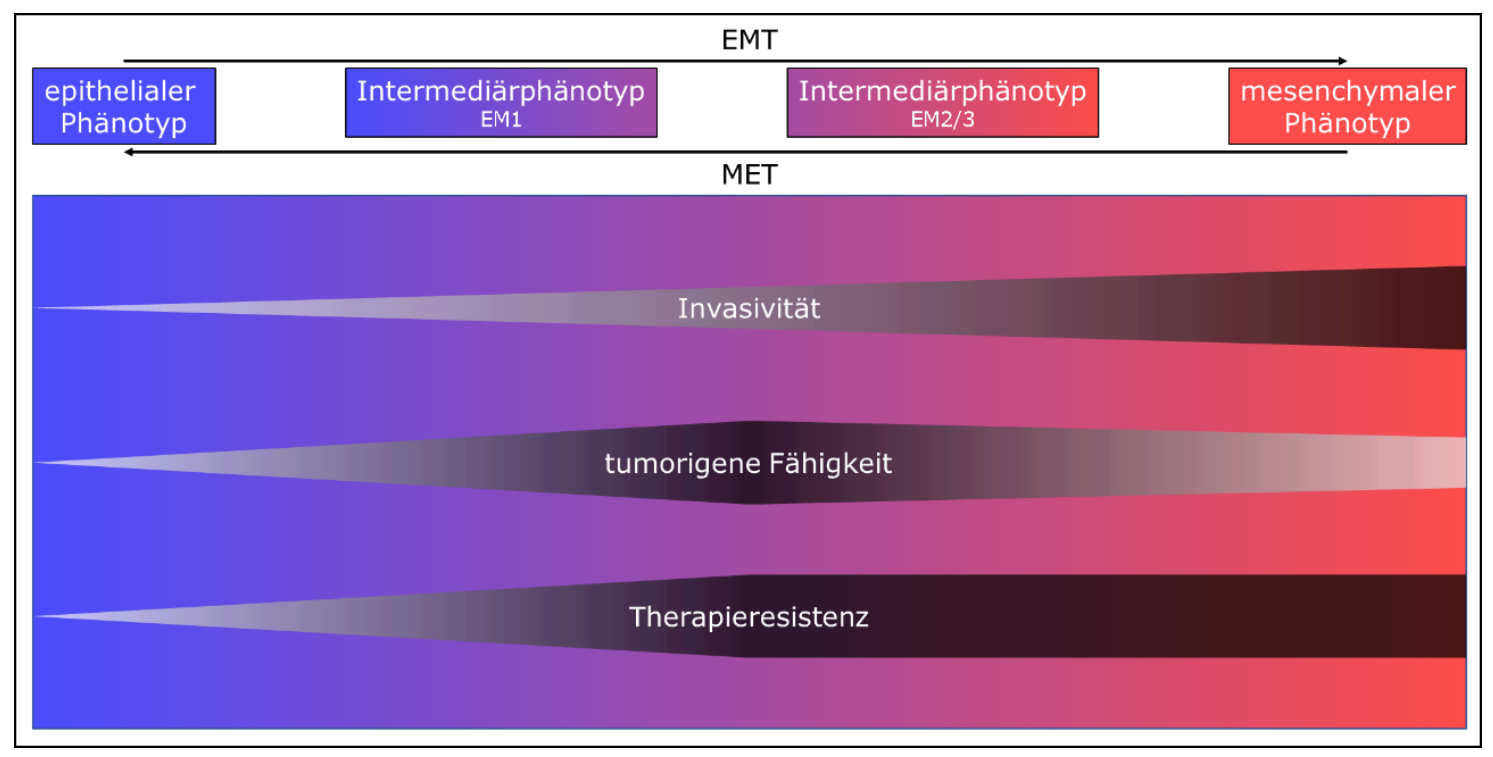

\section{Abbildung 1: Morphologische und physiologische Veränderungen während der EMT}

Graphische Darstellung der morphologischen und physiologischen Veränderungen, die die Mammakarzinomzellen im Verlauf der EMT durchlaufen. Das Profil der dargestellten Formen entspricht schematisch dem Grad an Invasivität, der tumorigenen Fähigkeit und dem Maß an Therapieresistenz. (Die Abbildung orientiert sich an Nieto et al. 2016 und Shibue und Weinberg 2017). 


\subsubsection{EMT im Mammakarzinom}

Histologische Studien ordnen basalähnliche Mammakarzinome, die vermehrt mesenchymale Eigenschaften und metastatische Fähigkeiten aufweisen, unter die aggressiveren Subtypen mit schlechter Prognose ein. Hierarchische Clusteranalysen basalähnlicher Tumore korrespondieren mit einer Reduktion epithelialer und der Hochregulierung mesenchymaler Markergene sowie der Überexpression von EZM-Proteinen und mit Invasivität assoziierte Gene (Sarrió et al. 2008; Prat und Perou 2011; Scimeca et al. 2016). Diese Ergebnisse stimmen mit denen von Micalizzi et al. überein, die eine Hochregulierung von EMT-Markergenen in TNBC zeigen (Micalizzi und Ford 2009). Molekularbiologische Untersuchungen bestätigten die histologischen Beobachtungen und charakterisieren basalähnliche Mammakarzinome und TNBCs als Mammakarzinome mit einem mesenchymaleren Phänotyp, verglichen mit nicht basalähnlichen Luminal A/B und ERBB2-positiven Mammakarzinomen (Al Saleh et al. 2011; Pomp et al. 2015). Analysen von 40 schlecht differenzierten infiltrierenden G3Mammakarzinombiopsien zeigten einen Zusammenhang zwischen Differenzierungsgrad, EMT und EMT-aktivierenden Signaltransduktionswegen. Scimeca et al. beobachtete vermehrt Zellen mit einer hochregulierten Genexpression von Vimentin (VIM), sonic hedgehog signaling molecule (SHH), KRAS proto-oncogene, GTPase (KRAS) und Pentraxin-3 (PTX3) in 40 G3-Biopsien, verglichen mit 30 benignen Läsionen und 30 gut differenzierten G1-Mammakarzinomen. Dieses Ergebnis deutet darauf hin, dass die Dedifferenzierung von G1/G2-Mammakarzinomen hin zu G3/G4-Mammakarzinomen ebenso wie die Dissemination und Metastasierung ein EMT-abhängiger Prozess ist (Scimeca et al. 2016).

\subsubsection{Signaltransduktion während der EMT im Mammakarzinom}

Aufgrund der hohen Varianz an EMT-TF überrascht es nicht, dass zahlreiche Signaltransduktionswege an der EMT-Aktivierung und der Umprogramierung epithelialer Zellen beteiligt sind (Gonzalez und Medici 2014; Felipe Lima et al. 2016). Obwohl die EMT-TF synergistisch zusammenarbeiten und ähnliche Signaltransduktionswege nutzen, kann die Hemmung eines EMT-TF ausreichen, um das gesamte EMT-Programm zu blockieren (Xie et al. 2004). 
Der am besten charakterisierte Signalweg der EMT-Aktivierung ist der transfoming growth factor beta (TGF- $\beta$-) Signalweg, der typischerweise durch die Liganden der TGF- $\beta$ Superfamilie (TGF- $\beta 1$, TGF- $\beta 2$ und TGF- $\beta 3$ ) und durch die sechs Isoformen des bone morphogenetic protein (BMP1BMP6) aktiviert wird. Der TGF- $\beta$-Signalweg zur EMT-Aktivierung in Tumoren wird größtenteils durch TGF- $\beta 1$, BMP2 und BMP4 induziert (Akhurst und Derynck 2001; Rothhammer et al. 2005; Kang et al. 2009).

Bezüglich der Rolle von EMT und Resistenzentwicklung im Mammakarzinom sind der tumor necrosis factor alpha-(TNF- $\alpha-)$ und der Interleukin-6-Januskinase-1-signal transducers and activators of transcription 3-(IL6-JAK1-STAT3-) Signalweg von Bedeutung. Der TNF- $\alpha$ ist als zentrales Zytokin in inflammatorischen, zellulären und homöostatischen Prozessen sowie in Vorgängen der Tumorprogression involviert. Durch die Zusammenarbeit mit anderen Signalwegen trägt TNF- $\alpha$ zur Hemmung von E-Cadherin und Aktivierung der Matrixmetalloproteinase-9 (MMP9) bei. Diese Kaskade fördert die EMT-vermittelte Verstärkung der Tumorinvasivität und -angiogenese (Polyak und Weinberg 2009). Analysen zeigen, dass eine TWIST1-vermittelte EMT-Aktivierung die Synthese des TNF- $\alpha$ hochreguliert und assoziiert mit einem gesteigertem Metastasierungspotential, einer erhöhten Tumorinvasivität und der gesteigerten Expression von Stammzelleigenschaften im Mammakarzinom ist (Li et al. 2012). Die durch IL6-induzierte JAK1-STAT3-Aktivierung trägt ebenso wie die TNF- $\alpha$ Aktivierung zum Erwerb neuer Fähigkeiten wie Invasivität und Metastasierung bei, die maßgeblich durch Induktion von EMT über das Schlüsselgen TWIST1 reguliert werden (Thomas et al. 2015).

\subsubsection{Krebsstammzellen und EMT im Mammakarzinom}

Kurze Mammakarzinomüberlebensraten konnten mit einer Anreicherung an Krebsstammzellen (CSC, cancer stem cells) im Mammakarzinom in Verbindung gebracht werden. Diesen Zellen wird die Fähigkeit zur Selbsterneuerung und Tumorgenese zugeschrieben. Sie sind in der Literatur zum einen oft beschrieben als positiv für das Zelloberflächenrezeptor-Glykoprotein CD44 (CD, cluster of differentiation), das Zell-Zell-Interaktionen, Zelladhäsion und -migration vermittelt sowie zum anderen als negativ für das Zelloberflächenrezeptor-Sialoglykoprotein CD24, welches Zellwachstum 
und -differenzierung moduliert (Al-Hajj et al. 2004). Die CD44+CD24-Mammakarzinomzellen zeigen Eigenschaften, welche sie zur Invasivität, Migration, Dissemination und Metastasierung befähigen. Eine vergleichende Analyse von isolierten $\mathrm{CD} 44{ }^{+} \mathrm{CD} 24-$ Zellen aus normalem humanen Mammagewebe und aus Mammakarzinomgewebe zeigt, dass die Expression von EMT-TF in Zellen mit stammzellähnlichen Eigenschaften erhöht ist (Polyak und Weinberg 2009; Sigurdsson et al. 2011). Die CSC-Eigenschaften verleihen Mammakarzinomzellen eine große phänotypische Plastizität. Dies ermöglicht ihnen im Primärtumor EMT durchzuführen (Kalluri und Weinberg 2009; Sigurdsson et al. 2011; Kotiyal und Bhattacharya 2014). Ein mit CSC-Eigenschaften verbundener Phänotyp wird auch mit einer erhöhten Resistenz gegenüber Apoptose assoziiert (Kotiyal und Bhattacharya 2014). In Biopsien therapierter Mammakarzinome nach neoadjuvanter Chemotherapie wurden vermehrt CD44+CD24-Tumorzellen mit einem EMT-typischen Genexpressionsprofil und CSC-Eigenschaften identifiziert, weshalb diese Zellen fähig sind das Wiederwachstum der Mammakarzinome zu initiieren (Kotiyal und Bhattacharya 2014; Felipe Lima et al. 2016).

\subsubsection{Therapieresistenz und EMT im Mammakarzinom}

Die EMT verleiht sowohl Zellen der Embryonalentwicklung als auch Mammakarzinomzellen über verschiedene Wege eine Resistenz gegenüber dem Zelltod. Diese EMT-vermittelte Resistenz wird auch während der Mammakarzinombehandlung durch Chemotherapeutika initiiert (Thiery et al. 2009; Singh und Settleman 2010). Verschiedene Mechanismen und Veränderungen werden hierfür verantwortlich gemacht, darunter: die verstärkte Expression von antiapoptotischen Genen und erhöhte Mengen an ATP-binding cassette transporter (ABC) in den Zellmembranen. Von ABC-Transmembranprotein-Transportern ist bekannt, dass sie den Efflux von Chemotherapeutika vermitteln und dadurch Mammakarzinomzellen Resistenzen verleihen (Feuerhake et al. 2000; Zhou et al. 2001). Diese Mechanismen werden auch den CSC zugeschrieben und geben einen Erklärungsansatz, warum diese im Vergleich zu normalen Nichttumorstammzellen (nCSC) durch eine konventionelle Chemotherapie nicht eliminiert werden (Al-Hajj et al. 2004). Ein weiteres Resistenzmerkmal, den CSC mit normalen Stammzellen teilen, ist die geringe Proliferationsrate beider Zelltypen (Potten und Loeffler 1990). 


\subsection{Das transgene WAP-T-Mausmodell}

In der präklinischen Onkologie ist es oft problematisch das richtige und klinisch relevante Tumormodell zu finden, um die komplexen biomedizinischen Prozesse des Mammakarzinoms und die systemische Interaktion mit dem tumortragenden Organismus und dessen Immunsystem ganzheitlich zu untersuchen. Mittlerweile steht eine Fülle von Mausmodellen für die Mammakarzinogenese und Tumorprogression zur Verfügung. Wegen der großen anatomischen und genotypischen Ähnlichkeiten zwischen Nagetieren und Menschen sowie der vergleichbaren Entwicklung der Mammae eignet sich die murine Mamma besonders gut als Modell zur Untersuchung des Mammakarzinoms und zur präklinischen Evaluierung von neuen Therapien (Medina 1996; Cardiff und Wellings 1999; McNally und Stein 2017)

Für die folgenden tierexperimentellen Arbeiten wurde die WAP-T-NP8-Mauslinie gewählt, die auf dem syngenen WAP-T-Mammakarzinom-Mausmodell basiert. Die immunkompetente WAP-TNP8-Mauslinie ist ein wertvolles System zur Untersuchung der Therapieeffektivität, weil es unkompliziert ist: i) Tumore zu generieren, ii) Therapeutika zu verabreichen, iii) die Entwicklung der Wachstumskinetik über die Vermessung der Tumore mittels Schieblehre zu verfolgen und iv) den Einfluss des Immunsystems in die Analysen mit einzubeziehen. Durch den Wirkmechanismus der frühen Genregion des Simian-Virus-40 (SV40) induzierte Adenokarzinome besitzen sowohl basalähnliche, als auch nicht basalähnliche Mammakarzinomeigenschaften und werden prinzipiell als dem humanen TNBC-ähnelnde Läsionen definiert (Gevensleben 2010; Otto et al. 2013b).

Die Transgenexpression des hier verwendeten WAP-T-Mausmodells kann durch eine gezielte Verpaarung induziert werden. Gegen Ende der Trächtigkeit wird die frühe Genregion des SV40-Genoms unter der Kontrolle des whey acidic protein (Wap-) Promotors in Epithelzellen der Mamma exprimiert (Schulze-Garg et al. 2000). Die Aktivierung des Wap-Promotors wird während der Laktation durch laktotrophe Hormone wie Prolaktin und Estrogen induziert (Pittius et al. 1988). Das SV40Polyomavirus transkribiert während einer frühen Phase der Replikation die folgenden Onkoproteine: das große T-Antigen (T-Ag), das kleine T-Antigen und das 17kT-Protein. Die transformierende Eigenschaft beruht hauptsächlich auf dem T-Ag (Goetz et al. 2001). Die Komplexbildung der Tumor- 
suppressorproteine Retinoblastomprotein-1 (Rb1) und Tumorprotein-p53 (Tp53) an das T-Ag simuliert eine Nullsituation und verursacht eine funktionelle Inaktivierung der Proteine (Sheng et al. 2000). Das Tp53 markiert einen wichtigen Kontrollpunkt bei der Arretierung von Zellen mit geschädigter DNA in der G1-Phase der Zellteilung. Durch die T-Ag-Komplexbildung kommt es zur Endoreplikation mit Bildung tetraploider und aneuploider Zellen (Ramel et al. 1995). Das Rb1 hemmt bei normaler Aktivität die Funktion des E2f-Transkriptionsfaktors. Dadurch bindet dieser an die DNA und aktiviert die Genexpression von Genen, die für die DNA-Synthese benötigt werden (Bartek et al. 1997). Die funktionelle Inaktivierung durch Komplexbildung hat den Eintritt der Zellen in die SPhase und eine gesteigerte Proliferationsrate zur Folge (Gevensleben 2010). Mit Beendigung der Involution exprimiert ein kleiner Anteil von Drüsenepithelzellen das T-Ag selbstständig und hormonunabhängig weiter (Schulze-Garg et al. 2000).Nach erfolgreicher Induktion entwickeln WAP-TMäuse intraepitheliale Neoplasien mit einer Morphologie ähnlich der von humanen duktalen Karzinomen in situ (DCIS, ductal carcinoma in situ). Die Neoplasien bilden kribriforme, solide, papillare und clingingtype-artige Strukturen mit der Fähigkeit zur Progression zu invasiven Adenokarzinomen. Es entstehen Karzinome vom gut differenzierten Typ (G1) mit zumeist tubulärem, trabekulärem oder papillarem Strukturen sowie mäßig (G2), schlecht (G3) und selten vom undifferenzierten metastasierenden Typ (G4) (Schulze-Garg et al. 2000; Wegwitz et al. 2010). Bereits intraepitheliale Neoplasien sind durch HR-negative Phänotypen gekennzeichnet. Immunhistochemische Färbungen (IHC) von Erbb2 wiesen eine starke membranöse und mäßige zytoplasmatische Färbung auf (Gevensleben 2010). Komparative genomische Hybridisierungs- (CGH, comparative genomic hybridization) und Genexpressionsanalysen zeigten weder eine Amplifikation des Erbb2-Gens noch eine Überexpression des Rezeptors im Vergleich zu morphologisch unverändertem Mammagewebe (Otto et al. 2013b).

Aus einem endogen induzierten Tumor der bitransgenen WAP-T-NP8xWAP-mutp53-H8-Mauslinie wurden H8N8-Mammakarzinomzellen isoliert, anschließend etabliert (Maenz et al. 2015) und nach orthotoper Transplantation in WAP-T-NP8-Mäuse ein transplantierbares Mammakarzinom-Mausmodell generiert, was zur Entwicklung von Mammakarzinomen eines epithelialen Phänotyps mit mesenchymalen Anteilen, die der Morphologie der parentalen Tumore entspricht und meist einen schlecht differenzierten Phänotypen (G3) abbildet (Wegwitz et al. 2010; Otto et al. 2013a; Maenz et 
al. 2015). Die H8N8-Tumorzellen wachsen nach orthotoper Transplantation aufgrund dem Akkumulieren weiterer genetischer Alterationen im H8N8-Genom durch eine T-Ag-vermittelte Inaktivierung des Tp53 und des Rb1 hormonunabhängig weiter (Wegwitz 2011). Das H8N8-WAP-T-Mamakarzinom-Transplantationsmausmodell eignet sich wegen der reproduzierbaren sich entwickelnden Mammakarzinome, der Gemeinsamkeiten zum humanen TNBC und der einfachen und schnellen Generierbarkeit sehr gut dafür, die Entwicklung von Therapieresistenzen und dem Wiederwachstum der Residualtumore nach CAF-Therapie im Mammakarzinom zu untersuchen. 


\section{Problemstellung}

Nach einer Brustkrebsdiagnose ist oft nicht der Primärtumor die Todesursache, sondern die Entstehung von Lokoregional- (Mamma) bzw. Fernrezidiven (Metastasen). Die Behandlungsform richtet sich nach dem individuellen Befund meist in Form einer adjuvanten oder neoadjuvanten Therapie und im Fall eines metastasierenden G4-Mammakarzinoms dient die Behandlung nur als palliative Symptomlinderung. Obwohl nur $7 \%$ der diagnostizierten Tumore zum Zeitpunkt der Diagnose bereits metastasiert sind, entwickeln drei von vier Frauen im Verlauf der Krankheit und $40 \%$ der therapierten Frauen innerhalb von ca. drei Jahren ein metastasierendes Mammakarzinom (Gerber et al. 2010; Lord et al. 2012; Mariotto et al. 2017).

Die Wirkung der Chemotherapie auf Tumorzelldifferenzierung ist beim Mammakarzinom noch nicht ausreichend untersucht. Besonders die Tumorzellplastizität und die damit verbundene Fähigkeit von Tumorzellen, auf eine Chemotherapie mit Mechanismen zur Resistenzentwicklung zu reagieren, ist noch nicht ausreichend untersucht. Das Ziel sollte sein, das Entstehen eines Rezidivs im Voraus zu verhindern, in dem resistente Tumorzellen identifiziert und charakterisiert werden, um die Mechanismen der Resistenzentwicklung zu entschlüsseln und passende Therapie zu entwickeln. Damit das erreicht werden kann, müssen die folgenden grundlegenden Fragen beantwortet werden:

1. Wie wirkt sich die CAF-Therapie auf die Wachstumskinetik und den H8N8-Tumorphänotyp aus?

2. Welche Gene, Signalwege und Oberflächenmarker sind für die remittierten H8N8-Tumorzellen charakteristisch und befähigen sie nach CAF-Therapie zum Wiederwachstum?

3. Wie wirkt sich die Hemmung von Interleukin-6 in Verbindung mit der CAF-Therapie auf Wachstumskinetik, Oberflächenmarker und CAF-Resistenz der Tumorzellen aus? 


\section{Material}

\subsection{Zelllinien}

Für orthotope Transplantationen wurde die murine H8N8-Mammakarzinom-Zelllinie von Prof. Dr. W. Deppert (Universitätsklinikum, Hamburg-Eppendorf) bezogen und von seiner Arbeitsgruppe aus einem undifferenzierten bitransgenen WAP-T-NP8xWAP-mutp53-H8-Tumor isoliert und etabliert (Schulze-Garg et al. 2000; Maenz et al. 2015).

Des Weiteren wurden in unserer Arbeitsgruppe Mammakarzinom-Zelllinien aus unbehandelten H8N8-Tumoren, aus CAF therapierten H8N8-Tumoren in Remission und aus CAF therapierten wieder gewachsenen H8N8-Tumoren in Progression isoliert und etabliert (Tabelle 1).

Tabelle 1: Isolierte unbehandelte und CAF therapierte remittierte und progressive H8N8-Zelllinien

\begin{tabular}{|c|c|c|c|}
\hline & Tumor & Zelllinie & Abkürzung \\
\hline \multirow{4}{*}{ unbehandelt } & 6163 & H8N8T1.1 & T1.1 \\
\hline & 6164 & H8N8T1.2 & T1.2 \\
\hline & 6165 & H8N8T1.3 & T1.3 \\
\hline & 6166 & H8N8T1.4 & T1.4 \\
\hline \multirow{3}{*}{ CAF - Remission } & 6172 & H8N8T2.1 & $\mathrm{T} 2.1$ \\
\hline & 6174 & H8N8T2.2 & $\mathrm{T} 2.2$ \\
\hline & 6173 & H8N8T2.3 & $\mathrm{T} 2.3$ \\
\hline \multirow{4}{*}{ CAF - Progression } & 6228 & H8N8T3.1 & T3.1 \\
\hline & 6230 & H8N8T3.2 & T3.2 \\
\hline & 6229 & H8N8T3.3 & T3.3 \\
\hline & 6231 & H8N8T3.4 & T3.4 \\
\hline
\end{tabular}

\subsection{Mauslinien}

Für orthotope Transplantationen wurde die monotransgene WAP-T-NP8-Mammakarzinom-Mauslinie von Prof. Dr. W. Deppert (Universitätsklinikum, Hamburg-Eppendorf) bezogen (Schulze-Garg et al. 2000). Zur Zucht dieser Tiere wurden weibliche Wildtyp BALB/c-Mäuse benutzt und von Janvier bezogen. 


\subsection{Geräte}

Tabelle 2: In dieser Arbeit angegebene und verwendete Geräte

\begin{tabular}{|c|c|}
\hline Geräte & Hersteller \\
\hline Achtkanalpipette (Lambda) & Corning GmbH, Kaiserslautern \\
\hline Agilent 2100 Bioanalyzer & Agilent Technologies, Santa Clara, CA, USA \\
\hline Brutschrank (BB6220) & Heraeus Holding GmbH, Hanau \\
\hline CardioExcyte 96 & Nanion Technologies GmbH, München \\
\hline CardioExcyte 96 Inkubationssystem & Nanion Technologies GmbH, München \\
\hline CCD-Digitalkamera (ORCA-ER) & Hamamatsu Photonics GmbH, Herrsching \\
\hline CCD-Sensorkamera (AxioCam MRc) & Carl Zeiss Microscopy GmbH, Jena \\
\hline Dampfgarer (Braun) & De'Longhi Deutschland GmbH, Frankfurt \\
\hline Einfrierbox (Mr. Frosty) & Thermo Fisher Scientific Corp., Waltham, MA, USA \\
\hline Einkanal-Multipipette (Multipette plus) & Eppendorf AG, Hamburg \\
\hline Einkanal-Pipetten (Reference 0,5-10 $\mu \mathrm{l})$ & Eppendorf AG, Hamburg \\
\hline Einkanal-Pipetten (Reference 100-1000 $\mu \mathrm{l})$ & Gilson, Inc., Middleton, WI, USA \\
\hline Einkanal-Pipetten (Reference 10-100 $\mu \mathrm{l}$ ) & Gilson, Inc., Middleton, WI, USA \\
\hline Fluorometer (Qubit) & Thermo Fisher Scientific Corp., Waltham, MA, USA \\
\hline Geldokumentationsanlage (Biometra Whatman) & Analytik Jena AG, Jena \\
\hline gentleMACS Dissociator & Miltenyi Biotec $\mathrm{GmbH}$, Bergisch Gladbach \\
\hline Gewebeinfiltrationsautomat (TP1020) & Leica Biosystems Nussloch GmbH, Nussloch \\
\hline Kühlplatte (EG1150C) & Leica Biosystems Nussloch GmbH, Nussloch \\
\hline Kühlschrank (Comfort) & Liebherr-International Deutschland $\mathrm{GmbH}$, Biberach \\
\hline Kühlschrank (glassline) & Liebherr-International Deutschland $\mathrm{GmbH}$, Biberach \\
\hline Kühlschrank (Premium) & Liebherr-International Deutschland $\mathrm{GmbH}$, Biberach \\
\hline Laborwaage (CP64) & Sartorius AG, Göttingen \\
\hline Laborwaage (LC2200S) & Sartorius AG, Göttingen \\
\hline MACSQuant Analyzer 10 & Miltenyi Biotec GmbH, Bergisch Gladbach \\
\hline Magnetrührer (RET basic) & IKA-Werke GmbH \& CO. KG, Staufen \\
\hline Mikroskop (Axiovert 200M) & Carl Zeiss Microscopy GmbH, Jena \\
\hline Mikrotom (RM2255) & Leica Biosystems Nussloch GmbH, Nussloch \\
\hline Mikrowelle & Sharp Deutschland GmbH, Köln \\
\hline Neubauer Zählkammer & Schuett-Biotec GmbH, Göttingen \\
\hline Niederspannungsversorger (P25 Power Pack) & Analytik Jena AG, Jena \\
\hline Paraffin-Gießstation (EG1160) & Leica Biosystems Nussloch GmbH, Nussloch \\
\hline Paraffin-Streckbad (1052) & GFL Gesellschaft für Labortechnik mbH, Burgwedel \\
\hline Pipettierhilfe (Pipetboy acu) & Integra Biosciences $\mathrm{GmbH}$, Biebertal \\
\hline Reinstwassersystem (Arium Pro) & Sartorius AG, Göttingen \\
\hline Schieblehre (Atorn Messschieber INOX) & Hahn+Kolb Werkzeuge GmbH, Ludwigsburg \\
\hline Schüttler (Rocking Platform) & VWR International GmbH, Darmstadt \\
\hline Schüttler (VXR Vibrax) & IKA-Werke GmbH \& CO. KG, Staufen \\
\hline Sequenzierautomat (HiSeq 4000) & Illumina, San Diego, CA, USA \\
\hline Spektrophotometer (DS11+) & DeNovix Inc., Wilmington, DE, USA \\
\hline Sterilwerkbank (HBB2448) & Heraeus Holding GmbH, Hanau \\
\hline Thermocycler (Biometra T3000) & Analytik Jena AG, Jena \\
\hline Thermomixer (5436) & Eppendorf AG, Hamburg \\
\hline Thermomixer (Comfort) & Eppendorf AG, Hamburg \\
\hline Thermomixer (Compact) & Eppendorf AG, Hamburg \\
\hline Tiefkühlschrank $-85^{\circ} \mathrm{C}$ (New Brunswick U570) & Eppendorf AG, Hamburg \\
\hline Tierohrknipser & LabArt UG \& Co. KG; Waldbüttelbrunn \\
\hline Tischzentrifuge (Stratagene Picofuge) & Agilent Technologies, Santa Clara, CA, USA \\
\hline Trockenschrank & Memmert GmbH + Co. KG, Schwabach \\
\hline UV-Transilluminator (Biometra) & Analytik Jena AG, Jena \\
\hline Vakuumpumpe (Biometra MP86) & Analytik Jena AG, Jena \\
\hline Vortexer (Vortex-Genie) & Scientific Industries Inc., Bohemia, NY, USA \\
\hline Wärmeplatte (Objektträger-Strecktisch) & Medax GmbH \& Co.KG, Neumünster \\
\hline Wasserbad & JULABO GmbH, Seelbach \\
\hline Zentrifuge (5415R) & Eppendorf AG, Hamburg \\
\hline Zentrifuge (5417R) & Eppendorf AG, Hamburg \\
\hline Zentrifuge (5424) & Eppendorf AG, Hamburg \\
\hline Zentrifuge (8510) & Eppendorf AG, Hamburg \\
\hline
\end{tabular}




\subsection{Chemikalien}

Tabelle 3: In dieser Arbeit angegebene und verwendete Chemikalien

\begin{tabular}{|c|c|}
\hline Chemikalie & Hersteller \\
\hline 5-Fluouracil & Medac GmbH, Wedel \\
\hline Agarose (low EEO) & NeoFroxx GmbH, Einhausen \\
\hline Antibody Diluent (Dako) & Agilent Tech., Santa Clara, CA, USA \\
\hline Borsäure & Merck KGaA, Darmstadt \\
\hline Bouin’s Lösung & Merck KGaA, Darmstadt \\
\hline bovin serum albumin & Merck KGaA, Darmstadt \\
\hline Bromphenol & Merck KGaA, Darmstadt \\
\hline Carprofen & Zoetis Schweiz GmbH, Delémont, CHE \\
\hline Chloroform & Merck KGaA, Darmstadt \\
\hline Cyclophosphamid & Baxter, Deerfield, Illinois \\
\hline Diethyldicarbonat-(DEPC-) Wasser & Thermo Fisher Scientific Corp., Waltham, MA, USA \\
\hline Dimethylsulfoxid & Merck KGaA, Darmstadt \\
\hline Doxorubicin & Stadapharma GmbH, Bad Vilbel \\
\hline Dulbecco's Modified Eagle Medium, high glucose & Thermo Fisher Scientific Corp., Waltham, MA, USA \\
\hline EB-Puffer & Qiagen AG, Hilden \\
\hline Eosin & Merck KGaA, Darmstadt \\
\hline Essigsäure & Merck KGaA, Darmstadt \\
\hline Ethanol & Merck KGaA, Darmstadt \\
\hline Ethylendiamintetraacetat (EDTA) & Merck KGaA, Darmstadt \\
\hline fetal calf serum & Thermo Fisher Scientific Corp., Waltham, MA, USA \\
\hline Formalin (4 \% Formaldehydlösung) & Merck KGaA, Darmstadt \\
\hline GelRed & Biotium Inc., Fremont, CA, USA \\
\hline Glycerol & Merck KGaA, Darmstadt \\
\hline Immersionsöl (Immersol 518N) & Carl Zeiss Microscopy GmbH, Jena \\
\hline Isopropanol & Merck KGaA, Darmstadt \\
\hline Ketamin & Medistar Arzneimittelvertrieb GmbH, Ascheberg \\
\hline Kohlenstoffdioxid $\left(\mathrm{CO}_{2}\right)$ & Hausversorgung \\
\hline MACS Storage Solution & Miltenyi Biotec GmbH, Bergisch Gladbach \\
\hline Mayers Hämalaun & Merck KGaA, Darmstadt \\
\hline Natriumchlorid $(\mathrm{NaCl})$ & Merck KGaA, Darmstadt \\
\hline Natriumchloridlösung $(0,9 \%)$ & B. Braun Melsungen AG, Melsungen \\
\hline Paraffin & Süsse Labortechnik, Gudensberg \\
\hline phosphate buffered saline & Thermo Fisher Scientific Corp., Waltham, MA, USA \\
\hline Prolong + DAPI & Thermo Fisher Scientific Corp., Waltham, MA, USA \\
\hline QIAzol Lysis Reagent & Qiagen AG, Hilden \\
\hline Salzsäure (HCl) & Merck KGaA, Darmstadt \\
\hline Sea Block Blocking Buffer & Thermo Fisher Scientific Corp., Waltham, MA, USA \\
\hline Siltuximab (Sylvant) & Janssen Biotech Inc., Horsham, PA, USA \\
\hline sodium dodecyl sulfate (SDS) & Serva Electrophoresis GmbH, Heidelberg \\
\hline Stickstoff $\left(\mathrm{N}_{2}\right)$ & Air Liquide Deutschland GmbH, Düsseldorf \\
\hline Target Retrieval Solution pH 6 (Dako) & Agilent Tech., Santa Clara, CA, USA \\
\hline Tris Puffer & Merck KGaA, Darmstadt \\
\hline Triton X-100 & Merck KGaA, Darmstadt \\
\hline Trypanblau & Merck KGaA, Darmstadt \\
\hline Trypsin-EDTA $(0,05 \% / 0,02 \%)$ & Merck KGaA, Darmstadt \\
\hline Tween 20 & Merck KGaA, Darmstadt \\
\hline Wasserstoffperoxid & Merck KGaA, Darmstadt \\
\hline Xylazin & Riemser Pharma GmbH, Greifswald \\
\hline Xylencyanol & Merck KGaA, Darmstadt \\
\hline Xylol & Merck KGaA, Darmstadt \\
\hline
\end{tabular}




\subsection{Verbrauchsmaterialien}

Tabelle 4: In dieser Arbeit angegebene und verwendete Verbrauchsmaterialien

\begin{tabular}{|c|c|}
\hline Verbrauchsmaterial & Hersteller \\
\hline Augensalbe (Bepanthen) & "Bayer Vital GmbH, Leverkusen \\
\hline Combitips advanced (Biopur $0,2 \mathrm{ml}$ ) & Eppendorf AG, Hamburg \\
\hline Combitips advanced (Biopur $0,5 \mathrm{ml}$ ) & Eppendorf AG, Hamburg \\
\hline Combitips advanced (Biopur 2,5 ml) & Eppendorf AG, Hamburg \\
\hline Combitips advanced (Biopur $5 \mathrm{ml}$ ) & Eppendorf AG, Hamburg \\
\hline Deckgläser (Menzel 12 mm) & Thermo Fisher Scientific Corp., Waltham, MA, USA \\
\hline Deckgläser (Menzel 24 mm x 24 mm) & Thermo Fisher Scientific Corp., Waltham, MA, USA \\
\hline Deckgläser (Menzel 24 mm x 36 mm) & Thermo Fisher Scientific Corp., Waltham, MA, USA \\
\hline Deckgläser (Menzel 24 mm x 50 mm) & Thermo Fisher Scientific Corp., Waltham, MA, USA \\
\hline Einbettkassetten (Rotilabo) & Carl Roth GmbH + Co. KG, Karlsruhe \\
\hline Eindeckmittel (Aquatex) & Merck KGaA, Darmstadt \\
\hline Eindeckmittel (Entellan) & Merck KGaA, Darmstadt \\
\hline Eindeckmittel (ProLong Gold mit DAPI) & Thermo Fisher Scientific Corp., Waltham, MA, USA \\
\hline Einmalhandschuhe (Peha-soft Nitril) & Paul Hartmann AG, Heidenheim \\
\hline Einmalkanülen (Microlance 3 17G) & Becton Dickinson GmbH, Heidelberg \\
\hline Einmalskalpellklingen (No.11) & Swann-Morton Limited, Sheffield, GBR \\
\hline Eppendorf Reagenzgefäße (Tubes 1,5 ml) & Eppendorf AG, Hamburg \\
\hline Eppendorf Reagenzgefäße (Tubes 2,0 ml) & Eppendorf AG, Hamburg \\
\hline Insulinspritzen (Micro-Fine U100 0,3 ml) & Becton Dickinson GmbH, Heidelberg \\
\hline Kryo-Gefäße (Cryo.s $2 \mathrm{ml})$ & Greiner Bio-One GmbH, Frickenhausen \\
\hline Rollenpflaster (Leukosilk) & BSN medical GmbH, Hamburg \\
\hline Mikrotom-Einwegklingen (Typ 819) & Leica Biosystems Nussloch GmbH, Nussloch \\
\hline Multiwellplatten (24-Well) & Greiner Bio-One GmbH, Frickenhausen \\
\hline Multiwellplatten (6-Well) & Greiner Bio-One GmbH, Frickenhausen \\
\hline Multiwellplatten (96-Well) & Greiner Bio-One GmbH, Frickenhausen \\
\hline Nahtmaterial (Ethicon 4-0 Vicryl) & Johnson \& Johnson Medical GmbH, Norderstedt \\
\hline Objektträger (Menzel Superfrost plus) & Thermo Fisher Scientific Corp., Waltham, MA, USA \\
\hline Pipettenspitzen $(10 \mu \mathrm{l})$ & Sarstedt AG \& Co. KG, Nümbrecht \\
\hline Pipettenspitzen $(100 \mu \mathrm{l})$ & Sarstedt AG \& Co. KG, Nümbrecht \\
\hline Pipettenspitzen $(1000 \mu \mathrm{l})$ & Sarstedt AG \& Co. KG, Nümbrecht \\
\hline Pipettenspitzen (ART Pipette Tips $1000 \mu \mathrm{l}$ ) & Thermo Fisher Scientific Corp., Waltham, MA, USA \\
\hline Pipettenspitzen (ART Pipette Tips $20 \mu \mathrm{l}$ ) & Thermo Fisher Scientific Corp., Waltham, MA, USA \\
\hline Pipettenspitzen (ART Pipette Tips $200 \mu \mathrm{l}$ ) & Thermo Fisher Scientific Corp., Waltham, MA, USA \\
\hline Serologische Pipetten $(2 \mathrm{ml})$ & Greiner Bio-One GmbH, Frickenhausen \\
\hline Serologische Pipetten $(25 \mathrm{ml})$ & Corning GmbH, Kaiserslautern \\
\hline Serologische Pipetten $(5 \mathrm{ml})$ & Greiner Bio-One GmbH, Frickenhausen \\
\hline Serologische Pipetten (50 ml) & Corning GmbH, Kaiserslautern \\
\hline Spritze ohne Kanüle (Plastipak 303172) & Becton Dickinson GmbH, Heidelberg \\
\hline Tierfutter & Ssniff-Spezialdiäten $\mathrm{GmbH}$, Soest \\
\hline Transparente NSP96-Multiwellsensorplatten & Nanion Technologies GmbH, München \\
\hline Ultra-Reinstwasser (Ampuwa) & Fresenius Kabi Deutschland GmbH, Bad Homburg \\
\hline Verschlussfolie (Parafilm M) & Bemis AG, Neenah, WI, USA \\
\hline Zellkulturflaschen (TC T175) & Sarstedt AG \& Co. KG, Nümbrecht \\
\hline Zellkulturflaschen (TC T25) & Sarstedt AG \& Co. KG, Nümbrecht \\
\hline Zellkulturflaschen (TC T75) & Sarstedt AG \& Co. KG, Nümbrecht \\
\hline Zellsieb (Cell Strainer $100 \mu \mathrm{m}$ ) & Corning GmbH, Kaiserslautern \\
\hline Zellsieb (Cell Strainer $40 \mu \mathrm{m})$ & Corning GmbH, Kaiserslautern \\
\hline Zentrifugenröhrchen (Falcon 15 ml) & Corning GmbH, Kaiserslautern \\
\hline Zentrifugenröhrchen (Falcon $20 \mathrm{ml}$ ) & Corning GmbH, Kaiserslautern \\
\hline Zentrifugenröhrchen (Falcon $50 \mathrm{ml}$ ) & Corning GmbH, Kaiserslautern \\
\hline
\end{tabular}




\subsection{Antikörper}

\subsubsection{Primärantikörper}

Tabelle 5: In dieser Arbeit angegebene und verwendete unkonjugierte Primärantikörper

\begin{tabular}{llll} 
Antikörper & Spezies & Klonalität & Hersteller \\
\hline \hline$\alpha$-Sma & Kaninchen & polyklonal & Abcam, Cambridge, GBR \\
Cd24 & Kaninchen & polyklonal & Abcam, Cambridge, GBR \\
Cd44 & Ratte & monoklonal & BioLegend Inc., San Diego, CA, USA \\
Cd45 & Ratte & monoklonal & BioLegend Inc., San Diego, CA, USA \\
E-Cadherin & Kaninchen & monoklonal & Cell Signaling Tech. Corp., Cambridge, GBR \\
Interleukin-6 & Kaninchen & polyklonal & Abcam, Cambridge, GBR \\
Pcna & Kaninchen & monoklonal & Abcam, Cambridge, GBR \\
T-Ag (R15) & Kaninchen & polyklonal & (Deppert und Pates 1979) \\
Tenascin-C & Ratte & monoklonal & R\&D Systems Inc., Minneapolis, MN, USA \\
Vimentin & Kaninchen & monoklonal & Abcam, Cambridge, GBR \\
Vimentin & Maus & monoklonal & Santa Cruz Biotechnology Inc., Dallas, TX, USA
\end{tabular}

\subsubsection{Sekundärantikörper - IHC}

Tabelle 6: In dieser Arbeit angegebene und verwendete IHC Sekundärantikörper

\begin{tabular}{llll} 
Antikörper & Reaktivität & Konjugat & Hersteller \\
\hline \hline Histofine Simple Stain & Kaninchen & Peroxidase & Nichire Biosciences Inc., Tokyo, JPN \\
Ziege-anti-Ratte-IgG (H\&L) & Ratte & Biotin & Abcam, Cambridge, GBR
\end{tabular}

\subsubsection{Avidin-Enzymkonjugat}

Tabelle 7: In dieser Arbeit angegebenes und verwendetes Avidin-Enzymkonjugat

\begin{tabular}{llll}
$\begin{array}{l}\text { Avidin- } \\
\text { Enzymkonjugat }\end{array}$ & Reaktivität & Konjugat & Hersteller \\
\hline \hline Avidin-HRP & Biotin & Peroxidase & Thermo Fisher Scientific Corp., Waltham, MA, USA
\end{tabular}

\subsubsection{Sekundärantikörper - Immunfluoreszenz}

Tabelle 8: In dieser Arbeit angegebene und für immunzytochemische Fluoreszenzfärbungen verwendete Sekundärantikörper

\begin{tabular}{|c|c|c|c|}
\hline Antikörper & Reaktivität & Konjugat & Hersteller \\
\hline $\begin{array}{l}\text { Esel-anti-Kaninchen-IgG } \\
(\mathrm{H}+\mathrm{L})\end{array}$ & Kaninchen & Alexa 488 & $\begin{array}{l}\text { Thermo Fisher Scientific Corp., Waltham, MA, } \\
\text { USA }\end{array}$ \\
\hline $\begin{array}{l}\text { Ziege-anti-Maus-IgG } \\
(\mathrm{H}+\mathrm{L})\end{array}$ & Maus & Alexa 546 & $\begin{array}{l}\text { Thermo Fisher Scientific Corp., Waltham, MA, } \\
\text { USA }\end{array}$ \\
\hline
\end{tabular}




\subsubsection{Konjugierte Antikörper - Durchflusszytometrie}

Tabelle 9: In dieser Arbeit angegebene und für die Durchflusszytometrie verwendete konjugierte Antikörper gegen Mausgewebe

\begin{tabular}{llll} 
Antikörper & Spezies & Konjugat & Hersteller \\
\hline \hline Cd104 & rekombinant human IgG1 & APC & Miltenyi Biotec GmbH, Bergisch Gladbach \\
Cd107a & rekombinant human IgG1 & APC & Miltenyi Biotec GmbH, Bergisch Gladbach \\
Cd120b & rekombinant human IgG1 & APC & Miltenyi Biotec GmbH, Bergisch Gladbach \\
Cd126 & rat IgG2bx & APC & Miltenyi Biotec GmbH, Bergisch Gladbach \\
Cd146 & rat IgG2ax & PE & Miltenyi Biotec GmbH, Bergisch Gladbach \\
Cd201 & rat IgG2bx & APC & Miltenyi Biotec GmbH, Bergisch Gladbach \\
Cd24 & rat IgG2bx & FITC & Miltenyi Biotec GmbH, Bergisch Gladbach \\
Cd24 & rat IgG2bx & APC-Vio770 & Miltenyi Biotec GmbH, Bergisch Gladbach \\
Cd31 & rekombinant human IgG1 & PE-Vio770 & Miltenyi Biotec GmbH, Bergisch Gladbach \\
Cd44 & rat IgG2bx & APC-Vio770 & Miltenyi Biotec GmbH, Bergisch Gladbach \\
Cd44 & rat IgG2bx & FITC & Miltenyi Biotec GmbH, Bergisch Gladbach \\
Cd44 & rat IgG2bx & VioBlue & Miltenyi Biotec GmbH, Bergisch Gladbach \\
Cd45 & rekombinant human IgG1 & VioBlue & Miltenyi Biotec GmbH, Bergisch Gladbach \\
Cd90.2 & rat IgG2b $x$ & APC & Miltenyi Biotec GmbH, Bergisch Gladbach \\
Cd95 & rekombinant human IgG1 & PE-Vio770 & Miltenyi Biotec GmbH, Bergisch Gladbach \\
Epcam & rat IgG1 & PE & Miltenyi Biotec GmbH, Bergisch Gladbach \\
Ifn $\gamma r-\beta$ & rekombinant human IgG1 & PE & Miltenyi Biotec GmbH, Bergisch Gladbach \\
LCR & & VioBlue & Miltenyi Biotec GmbH, Bergisch Gladbach \\
Sca1 & rat IgG2ax & PE-Vio770 & Miltenyi Biotec GmbH, Bergisch Gladbach \\
Ter119 & rat IgG2b $x$ & FITC & Miltenyi Biotec GmbH, Bergisch Gladbach
\end{tabular}

\subsection{Oligonukleotide für PCR zur Genotypisierungs}

Tabelle 10: In dieser Arbeit angegebene und verwendete Oligonukleotide für Standard-PCR

\begin{tabular}{|c|c|c|c|c|}
\hline Name & Sequenz & Richtung & Amplikon & Bindestelle \\
\hline AC-1 & $\begin{array}{l}\text { 5'-TAT GTC AGC AGA GCC TGT } \\
\text { AGA ACC AAA C-3' }\end{array}$ & Antisense & \multirow{2}{*}{765 bp } & \multirow{2}{*}{ SV40 T-Ag } \\
\hline DC-2 & $\begin{array}{l}\text { 5'-GAG AAA GGT AGA AGA CAF } \\
\text { CAA G-3` }\end{array}$ & Sense & & \\
\hline Notch4 fw & $\begin{array}{l}5^{\varsigma}-\mathrm{CTG} \text { CAC CTA GCT GCC AGA } \\
\text { TTC-3 }^{\circ}\end{array}$ & Antisense & \multirow{2}{*}{$480 \mathrm{bp}$} & \multirow{2}{*}{ Notch4Ex27-28 } \\
\hline Notch4 rev & $\begin{array}{l}5^{\varsigma}-\mathrm{CTG} \text { TCT GCT GGC CAA TAG } \\
\text { GAG-3` }^{\circ}\end{array}$ & Sense & & \\
\hline
\end{tabular}

\subsection{Größenstandards}

Tabelle 11: In dieser Arbeit angegebener und verwendeter Größenstandard

\begin{tabular}{ll} 
Größenstandard & Hersteller \\
\hline \hline 1 Kb DNA-Größenstandard & Thermo Fisher Scientific Corp., Waltham, MA, USA
\end{tabular}




\subsection{Enzyme}

Tabelle 12: In dieser Arbeit angegebene und verwendete Enzyme

\begin{tabular}{ll} 
Enzym & Hersteller \\
\hline \hline Proteinase-K & Qiagen AG, Hilden \\
Taq-DNA-Polymerase & Qiagen AG, Hilden
\end{tabular}

\subsection{Kits}

Tabelle 13: In dieser Arbeit angegebene und verwendete Kits

\begin{tabular}{ll} 
Kit & Hersteller \\
\hline \hline AEC Substrat Kit & Becton Dickinson GmbH, Heidelberg \\
Avidin/Biotin Blocking Kit & Thermo Fisher Scientific Corp., Waltham, MA, USA \\
CellTiter 96 AQueous One Solution MTS Kit & Promega GmbH, Mannheim \\
Masson Trichrom Kit & Merck KGaA, Darmstadt \\
NEXTflex Poly(A) Beads Kit & Bioo Scientific, Austin, TX, USA \\
NEXTflex Rapid Directional RNA-Seq Library & Bioo Scientific, Austin, TX, USA \\
Prep Kit & Bioo Scientific, Austin, TX, USA \\
NEXTflex RNA-Seq Barcodes Kit & Agilent Technologies, Santa Clara, CA, USA \\
RNA 6000 Pico Kit & Miltenyi Biotec GmbH, Bergisch Gladbach \\
Tumor Cell Isolation Kit, mouse & Miltenyi Biotec GmbH, Bergisch Gladbach \\
Tumor Dissociation Kit & \\
Tumor-Associated Fibroblast Isolation Kit, & Miltenyi Biotec GmbH, Bergisch Gladbach \\
mouse &
\end{tabular}

\subsection{Software, Macros und Web-Browser-Anwendungen}

Tabelle 14: In dieser Arbeit angegebene und verwendete Software, Macros und Web-Browser-Anwendungen

\begin{tabular}{|c|c|c|}
\hline $\begin{array}{l}\text { Software/Macro/In- } \\
\text { ternetanwendung }\end{array}$ & Domain & Hersteller/Entwickler \\
\hline DataControl96 & https://www.nanion.de/en/ & $\begin{array}{l}\text { Nanion Technologies GmbH, } \\
\text { München }\end{array}$ \\
\hline Fiji & https:// fiji.sc/ & \\
\hline FlowJo V10 & https://www.flowjo.com/ & $\begin{array}{l}\text { Becton Dickinson GmbH, } \\
\text { Heidelberg }\end{array}$ \\
\hline $\begin{array}{l}\text { Galaxy-GWDG-Ser- } \\
\text { ver }\end{array}$ & https://galaxy.gwdg.de/ & The Galaxy Project \\
\hline GraphPad Prism 8 & https://www.graphpad.com/ & $\begin{array}{l}\text { GraphPad Software, San } \\
\text { Diego, CA, USA }\end{array}$ \\
\hline GSEA & $\begin{array}{l}\text { http://software.broadinstitute.org/gsea/in- } \\
\text { dex.jsp }\end{array}$ & $\begin{array}{l}\text { Broad Institut, Cambridge, } \\
\text { MA, USA }\end{array}$ \\
\hline Inkscape & https://inkscape.org/ & Das Inkscape Projekt \\
\hline $\begin{array}{l}\text { Molecular Signatures } \\
\text { Database v } 6.2\end{array}$ & $\begin{array}{l}\text { http://software.broadinsti- } \\
\text { tute.org/gsea/msigdb/index.jsp }\end{array}$ & $\begin{array}{l}\text { Broad Institut, Cambridge, } \\
\text { MA, USA }\end{array}$ \\
\hline White Balance Macro & $\begin{array}{l}\text { https://github.com/pmascalchi/ImageJ_Auto- } \\
\text { white-balance-correction }\end{array}$ & Patrice Mascalchi \\
\hline Zotero & https://www.zotero.org/ & \\
\hline
\end{tabular}




\subsection{Lösungen, Medien und Puffer}

10x DNA-Puffer
$20 \%$ Glycerol
0,1 M EDTA
$0,2 \%$ Bromphenol
$0,2 \%$ Xylencyanol

DNA-Ladepuffer

$0,5 \mu \mathrm{l} 1 \mathrm{~Kb}$ DNA Größenstandard

7,5 $\mu$ l TE Puffer $\mathrm{pH} 8$

2,0 $\mu$ l 10x DNA Puffer

Gewebe-Lysispuffer

$200 \mathrm{mM} \mathrm{NaCl}$

$100 \mathrm{mM}$ Tris- $\mathrm{HCl}$

$5 \mathrm{mM}$ EDTA

$10 \mu \mathrm{l} / \mathrm{ml}$ Proteinase $\mathrm{K}$

$10 \%$ SDS

Phosphorwolframsäure/Molybdatophosphorsäure-Gemisch

2 Teile deionisiertes Wasser

1 Teil Phosphorwolframsäure

1 Teil Molybdatophosphorsäure

Tris-HCl-Puffer

$6,1 \mathrm{~g} / \mathrm{L}$ Tris

$9 \mathrm{~g} / \mathrm{L} \mathrm{NaCl}$

$\mathrm{pH} 7,6$ 10x TBE-Puffer

$108 \mathrm{~g}$ Tris

$55 \mathrm{~g}$ Borsäure

0,2 M EDTA

\section{Eosin-Färbelösung}

$5 \mathrm{~g}$ Eosin

$500 \mathrm{ml}$ destilliertes Wasser

1-2 Tropfen Essigsäure

Kryomedium

$90 \%$ FCS

$10 \%$ Dimethylsulfoxid

\section{TE-Puffer}

1,0 M Tris

$9 \mathrm{~g} / \mathrm{L} \mathrm{NaCl}$

0,2 M EDTA

$\mathrm{pH} 8$

Weigerts-Eisenhämatoxylin

1 Teil Weigerts-Eisenhämatoxylin-Lösung-A

1 Teil Weigerts-Eisenhämatoxylin-Lösung-B 


\section{Methoden}

\subsection{Arbeiten mit eukaryotischen Zellen}

\subsubsection{Kultivierung adhärent wachsender Zellen}

Die Kultivierung der parentalen H8N8-Zellen und der isolierten H8N8T1-T3-Tumorzellvarianten (Tabelle 1) erfolgte unter standardisierten Bedingungen bei $37^{\circ} \mathrm{C}, 5 \% \mathrm{CO}_{2}$ und einer relativen Luftfeuchtigkeit von $95 \%$ im Inkubator. Alle Zellkulturarbeiten wurden unter einer Sterilwerkbank und mit sterilen Materialien durchgeführt. Die Zellen wurden als Monolayer-Kultur in unbeschichteten Zellkulturflaschen in high glucose Dulbecco's modified Eagle Medium (DMEM) mit Zugabe von $10 \%$ fetalem Kälberserum (FCS, fetal calf serum) gehalten. Die Zellen wurden bei einer Konfluenz von 70-80\% passagiert und in Abhängigkeit der Wachstumsgeschwindigkeit zwei bis dreimal pro Woche im Verhältnis 1:10 umgesetzt. Für das Passagieren der Zellen wurden diese mit einer phosphatgepufferten Salzlösung (PBS, phosphate buffered saline) gewaschen und mit einer 0,05 \%igen Trypsin/0,02 \%igen EDTA-Lösung nach kurzer Inkubationszeit von ca. 3 min im Inkubator von der Zellkulturflasche gelöst. Nach 2 min Zentrifugieren bei $1200 \mathrm{rpm}$ und Raumtemperatur (RT) wurde das Pellet in frischem DMEM aufgenommen, die Zellzahl mit der Neubauer-Zählkammer bestimmt und in den entsprechenden Konzentrationen neu ausgesät.

\subsubsection{Kryokonservierung und Auftauen von Zellen}

Für die Kryokonservierung wurden die Zellen von einer ca. 80 \%igen konfluenten Zellkulturflasche mit einer 0,05 \%igen Trypsin/0,02 \%igen EDTA-Lösung abgelöst und für 2 min bei $1200 \mathrm{rpm}$ und RT zentrifugiert. Das Zellpellet wurde anschließend in $1 \mathrm{ml}$ kaltem Kryomedium, bestehend aus $90 \%$ FCS versetzt mit $10 \%$ Dimethylsulfoxid, resuspendiert und in Kryoröhrchen überführt. Die Kryoröhrchen wurden anschließend in einer isopropanolgefüllten Einfrierbox für mindestens $24 \mathrm{~h}$ bei $-80{ }^{\circ} \mathrm{C}$ langsam herabgekühlt, bevor sie im Stickstofftank bei $-196{ }^{\circ} \mathrm{C}$ aufbewahrt wurden. Kryokonservierte Zellen wurden im Wasserbad bei $37^{\circ} \mathrm{C}$ aufgetaut und sofort in DMEM überführt. Nach Zentrifugation für 2 min bei $1200 \mathrm{rpm}$ und RT wurde das Zellpellet im vorgewärmten DMEM resuspendiert und in einer Zellkulturflasche mit der gewünschten Konzentration ausgesät. 


\subsubsection{Bestimmung der Zellzahl}

Zur Bestimmung der Zellzahl wurde eine Neubauer-Zählkammer verwendet. Bei der Zählkammer befindet sich zwischen Glasplättchen und Objektträger ein definiertes Volumen, aufgrund dessen die Konzentrationsbestimmung einer Zellsuspension möglich war. Dazu wurden Zellen zuvor mit 0,05 \% Trypsin/0,02\% EDTA trypsiniert und in DMEM aufgenommen. Zum Zählen der Zellen wurden $10 \mu \mathrm{l}$ der Zellsuspension mit $10 \mu \mathrm{l}$ Trypanblau (Stammlösung 1:5 mit PBS verdünnt) vermischt und in den Spalt der Zählkammer pipettiert. Trypanblau wird nur von toten Zellen aufgenommen, wodurch ausschließlich ungefärbte, vitale Zellen für die Zählung berücksichtigt wurden. Die Kammer besteht aus neun großen Quadraten, die jeweils eine Fläche von $1 \mathrm{~mm}^{2}$ besitzen. Bei einer Tiefe von 0,1 mm ergibt dies ein Volumen von 0,1 $\mu$ l. Es wurden die vier Eckfelder mit je 16 Kleinquadraten ausgezählt. Dabei wurde darauf geachtet, dass Zellen auf den Außenlinien nicht doppelt gezählt wurden. Dafür wurden nur solche Zellen mitgezählt, die oben und links vom Betrachter auf den Linien lagen. Aus 4x16 ausgezählten Kleinquadraten wurde der Mittelwert genommen und wegen der vorangegangen 1:1 Verdünnung mit 2x104 multipliziert, um die Gesamtzellzahl pro ml zu erhalten.

\subsubsection{Immunzyłochemische Fluoreszenzfärbung}

Für den Nachweis des T-Ag und der Proteine E-Cadherin und Vimentin zur Charakterisierung der isolierten H8N8-Tumorzellvarianten wurden immunzytochemische Fluoreszenzfärbungen durchgeführt. Jeweils ein $12 \mathrm{~mm}$ Deckglas wurde in einem Well einer 24-Well-Multiwellplatte platziert und eine Zellsuspension mit einer Konzentration von 100000 Zellen/Well/500 $\mu \mathrm{l}$ (200 000 Zellen/ml) hinzugefügt.

Als die Zellen die benötigte Konfluenz erreichten, wurde das Medium abgenommen und die Deckgläser zweimal 5 min mit $1 \mathrm{ml} 37^{\circ} \mathrm{C}$ warmen PBS gewaschen, gefolgt von der 15 -minütigen Fixierung mit $500 \mu \mathrm{l} 4 \%$ igem Formalin. Hieran schlossen sich drei 5 min Waschschritte mit je $1 \mathrm{ml}$ PBS an. Mit je $1 \mathrm{ml}$ einer 1 \%igen Triton-X100-in-PBS-Lösung wurden die Zellen für 10 min permeabilisiert, gefolgt von drei Waschschritten mit je $1 \mathrm{ml}$ PBS für je 5 min. Um die Hintergrundfärbung durch 
unspezifische Bindungen zu minimieren wurde $1 \mathrm{~h}$ mit einer 0,5\%igen BSA-(bovin serum albumin-)in-PBS-Lösung geblockt und im Anschluss unverzüglich je $30 \mu \mathrm{l}$ des Primärantikörpers (pAK) in der benötigten Konzentration verdünnt in 0,5 \% BSA in PBS auf die Deckgläser pipettiert und für $1 \mathrm{~h}$ in einer feuchten Kammer inkubiert, gefolgt von drei Waschschritten mit je $1 \mathrm{ml}$ 0,1 \% Tween20 in PBS für je 5 min. Zur Detektion der pAK, die an die Zielepitope banden, wurden Sekundärantikörper (sAK) verwendet, die mit einem Fluorophor konjugiert waren und durch eine bestimmte Wellenlänge angeregt, Photonen einer bestimmten Wellenlänge emittieren. Der sAK wurde in der benötigten Konzentration in $0,5 \%$ BSA in PBS verdünnt und je $30 \mu \mathrm{l}$ auf die Deckgläser pipettiert und $1 \mathrm{~h}$ im Dunkeln in einer feuchten Kammer inkubiert. Nach erneutem dreimaligen Wa-

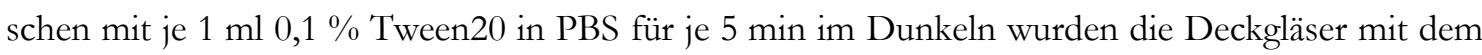
Eindeckmittel ProLong-Gold, welches zur Zellkernfärbung DAPI enthielt, luftdicht versiegelt. Alle Arbeitsschritte fanden bei RT statt. Die verwendeten AK und Konzentrationen sind in Tabelle 15 aufgelistet. Die angefertigten Immunfluoreszenzfärbungen von adhärenten Zellen wurden mithilfe eines Axiovert-200M-Mikroskops, das mit einer ORCA-ER-CCD-Digitalkamera ausgestattet war, aufgenommen.

Tabelle 15: Anwendungsangaben zu immunzytochemischen Primär- und Sekundärantikörpern

\begin{tabular}{lccccc} 
Antikörper & pAK/ & Konjugiert & Spezies & Reaktivität & Verdünnung \\
\hline \hline E-Cadherin & pAK & unkonjugiert & Kaninchen & & $1: 200$ \\
T-Ag (R15) & pAK & unkonjugiert & Kaninchen & & $1: 10000$ \\
Vimentin & pAK & unkonjugiert & Maus & & $1: 200$ \\
\hline Esel-anti-Kaninchen-IgG (H+L) & sAK & Alexa 488 & Esel & Kaninchen & $1: 500$ \\
Ziege-anti-Maus-IgG (H+L) & sAK & Alexa 546 & Ziege & Maus & $1: 500$
\end{tabular}

\subsubsection{Zyłotoxizitätsanalysen durch Impedanzmessungen}

Mit dem CardioExcyte96 (CE96) wurden Zytotoxizitätsanalysen über einen Zeitraum von vier Tagen durchgeführt. Durch Messung der Impedanz war es möglich in vitro zu untersuchen, ob Zellen, die bereits einmalig mit CAF therapiert wurden, bei einer erneuten CAF-Applikation eine geringere Toxizität aufweisen, also eine Resistenz gegenüber der CAF-Therapie entwickelt haben. Die Impedanzmessung beim CE96 beruht auf der Aufzeichnung sich verändernder Wechselstromwiderstände bei unterschiedlichen Zelldichten. Der gemessene Widerstand ergo die Impedanz wird größer, wenn der 
jeweilige Zelltyp durch Proliferation einen dichteren Zell-Monolayer mit mehr Adhäsionsverbindungen ausbildet. Zellen sterben durch Chemotherapeutika, wodurch der Zellverband gelockert wird und mehr Strom über das Medium fließt und die Impedanz abnimmt (Abbildung 2) (Doerr et al. 2015).

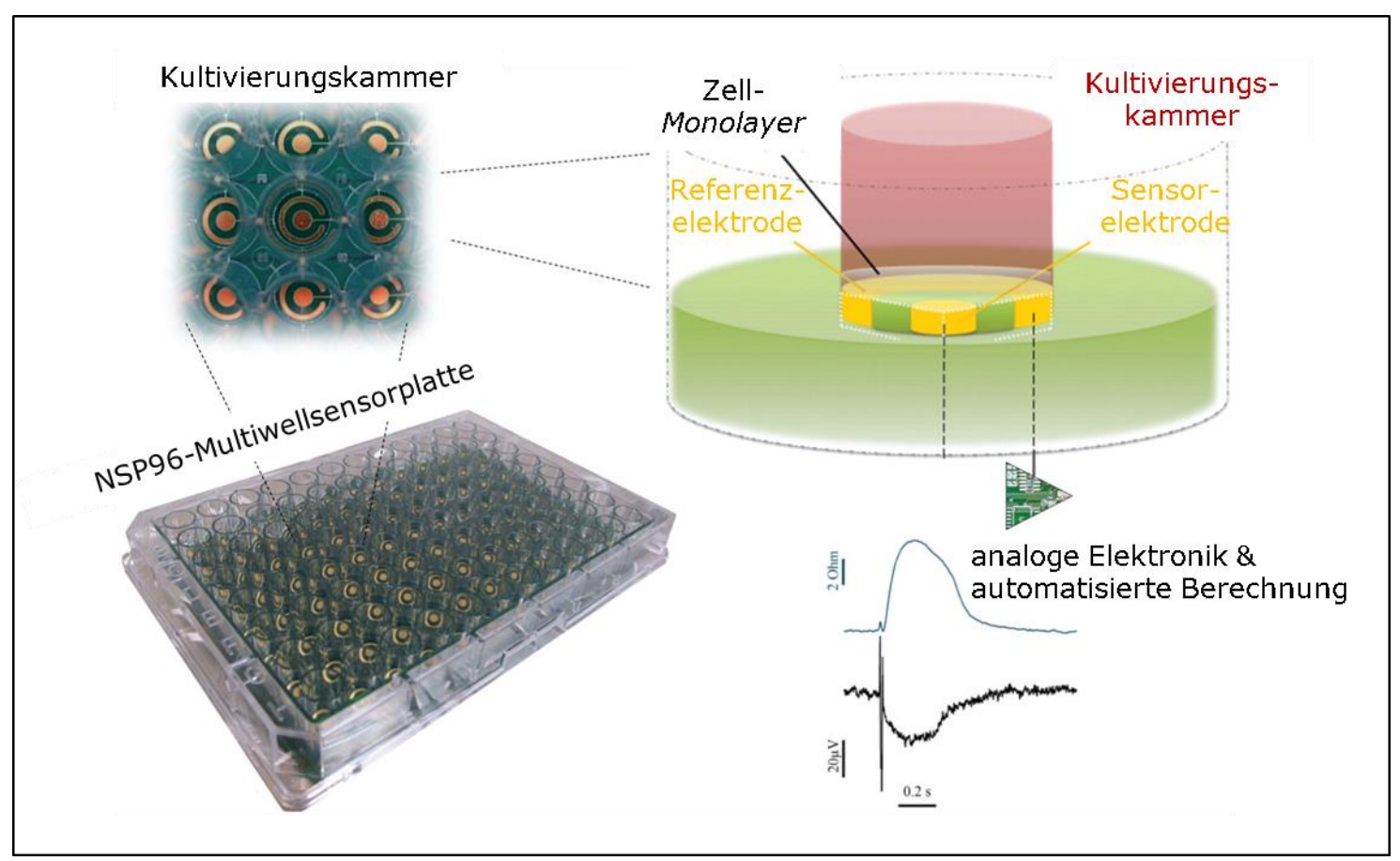

Abbildung 2: NSP-96 Multiwell-Sensorplatte und schematische Darstellung der Impedanzmessung

Die NSP-96 Multiwell-Sensorplatte besitzt 96 dieser schematisch dargestellten Sensorelektroden. In der Kultivierungskammer entstehende Zell-Monolayer verursachen einen Widerstand, welcher über die Elektroden gemessen wird. (Veränderte Abbildung aus Doerr et al. 2015)

Zu Beginn des Experiments wurden $200 \mu \mathrm{l}$ DMEM in die später verwendeten Wells pipettiert und eine Referenzmessung des Mediums für 5 s alle 5 min gestartet. In der Zwischenzeit wurde die Zellsuspension der benötigten Zelllinie mit der entsprechenden Konzentration vorbereitet. Anschließend wurde die Referenzmessung pausiert, das vorhandene Medium entfernt und je $200 \mu \mathrm{l}$ der Zellsuspension der jeweiligen Zelllinie in die Wells pipettiert. Nun wurde die Referenzmessung der unbehandelten Zellen zum Aufzeichnen der Basisimpedanz gestartet und im $1 \mathrm{~h}$ Intervall eine $5 \mathrm{~s}$ lange Messung vorgenommen. Für $48 \mathrm{~h}$ wurden das Zellwachstum und die damit verbundene Impedanzveränderung gemessen. Danach wurden die jeweiligen CAF-Konzentrationen in der doppelten Konzentration vorbereitet. Zur Behandlung der Zellen wurden $100 \mu$ l Medium verworfen und danach $100 \mu \mathrm{l}$ der jeweiligen CAF-Konzentration bzw. der Kontrollen zu den Zellen hinzugefügt. Das Berühren des Wellbodens mit dem intakten Zell-Monolayer sollte möglichst vermieden werden. Das Messintervall 
im CE96 wurde für die nächsten 48 h fortgesetzt. Die Zellen wurden während des kompletten Versuchs bei Standardbedingungen von $37^{\circ} \mathrm{C}, 5 \% \mathrm{CO}_{2}$ und einer relativen Luftfeuchtigkeit von $95 \%$ gehalten. Diese Bedingungen konnten durch das CE96-Inkubationssystem gewährleistet werden. Die Auswertung der Daten dieser Impedanzmessungen erfolgte mit der CE96-DataControl96-Software. Das CE96 wurde uns in Kollaboration mit der Herstellerfirma Nanion Technologies zur Verfügung gestellt und die Messungen sowie die Datenauswertung erfolgten in Zusammenarbeit mit Krisztina Juhasz von Nanion Technologies, München.

\subsection{WAP-T-NP8 tierexperimentelle Arbeiten}

\subsubsection{Zucht und Haltung der transgenen WAP-T-NP8-Mauslinie}

Die Haltungsbedingungen bestanden aus einem zwölfstündigen Hell-Dunkel-Rhythmus bei $22{ }^{\circ} \mathrm{C}$ und $55 \%$ relativer Luftfeuchtigkeit. Tierfutter und Wasser wurde den Tieren ad libitum gegeben. Die Tiere wurden entsprechend der Tierschutzversuchstierordnung gehandhabt. Das Erhalten der WAPT-NP8-Mauslinie erfolgte durch Verpaarung heterozygoter WAP-T-NP8-Männchen mit WildtypBALB/c-Weibchen. Somit konnte die Gefahr einer Akkumulation von Mutationen durch homozygote Verpaarung und eine unbeabsichtigte Induktion des Transgens bei Weibchen vermieden werden. Für die Durchführung der Versuche wurde ein Antrag beim Niedersächsischen Landesamt für Verbraucherschutz und Lebensmittelsicherheit (LAVES) unter der Tierantragsnummer 33.19-4250204-16/1621 genehmigt.

\subsubsection{Genotypisierung transgener WAP-T-NP8-Mäuse}

Für Genotypisierungen wurden Ohrstanzen, die bei der Kennzeichnung der Tiere anfielen, als Biopsie verwendet. Die Tiere wurden im Alter von drei bis vier Wochen durch einen Zahlencode mit einem Tierohrknipser markiert. Aus den Biopsien wurde im Anschluss genomische DNA aufgereinigt. Diese wurde mittels Standard-Polymerase-Kettenreaktion (PCR, polymerase chain reaction) vervielfältigt. In der vervielfältigten DNA wurde das T-Ag des SV40-Transgens durch Gelelektrophorese anhand der spezifischen Größe identifiziert. 


\subsubsection{Orthotope Tumorzelltransplantation}

Die orthotope Transplantation von $1 \times 10^{6}$ Tumorzellen in die rechte Mamma des abdominalen Mammapaars von syngenen WAP-T-NP8-Mäusen erfolgte nach intraperitonealer Applikation von 2,5-3 $\mu \mathrm{l} / \mathrm{g}$ Körpergewicht (KG) Ketamin/Xylazin-Kombinationsnarkose (Abbildung 3). Sie besteht aus $75 \mathrm{mg} / \mathrm{kg} \mathrm{KG} \mathrm{Ketamin} \mathrm{und} 15 \mathrm{mg} / \mathrm{kg} \mathrm{KG}$ Xylazin in einer 0,9\%igen Kochsalzlösung und wurde $24 \mathrm{~h}$ vor der orthotopen Transplantation angesetzt. Nach Eintreten der Narkose wurde den Tieren 1,2 $\mu \mathrm{l} / \mathrm{g} \mathrm{KG}$ des Schmerzmittels Carprofen mit einer Konzentration von 5 mg/kg KG subkutan in die Nackenfalte appliziert. Die Augen wurden vor Austrocknung mit Bepanthen-Augensalbe geschützt. Die narkotisierte Maus wurde zum Schutz vor Unterkühlung auf eine Wärmeplatte bei $37^{\circ} \mathrm{C}$ in Rückenlage gelegt und mit Leukosilk fixiert. Auf Höhe der rechten Mamille des abdominalen Mammapaars wurde rechts davon ein 3-4 mm kleiner Schnitt durchgeführt (Abbildung 3). Eine Zellzahl von $1 \times 10^{6}$ Tumorzellen wurde in $20 \mu \mathrm{l}$ PBS mittels einer $0,3 \mathrm{ml}$ U100-Insulinspritze aufgenommen. Nach vorsichtiger Trennung der Mamma vom Bindegewebe wurde die vorbereitete Zellsuspension mit der U100-Insulinspritze direkt in die leicht vorgelagerte Mamma injiziert. Die Spritze verblieb $5 \mathrm{~s}$ in der Injektionsstelle und wurde erst nach dieser Zeit entfernt, um ein Ausfließen der Zellsuspension zu vermeiden. Die Wunde wurde mit ein bis zwei Nähten mit resorbierbaren 4-0Vicryl-Nahtmaterial verschlossen. Die Transplantationsdauer betrug 5-10 min. Die Empfängertiere blieben 30-40 min unter Narkose. Transplantierte Tiere wurden dreimal wöchentlich während der gesamten Dauer des Experiments bis zum Sektionstag kontrolliert. Das $V_{\mathrm{T}}$ der Mammakarzinome wurde mittels einer Schieblehre vermessen und mit der folgenden Formel berechnet: $\mathrm{V}_{\mathrm{T}}=($ Länge x Breite x Höhe)/2 (Tomayko und Reynolds 1989). Die in dieser Arbeit applizierten Therapien wurden den Mäusen immer bei einem ungefähren $V_{T}$ von $500 \mathrm{~mm}^{3}$ einmalig intraperitoneal verabreicht und im Fall der CAF Therapie im Gemisch. 


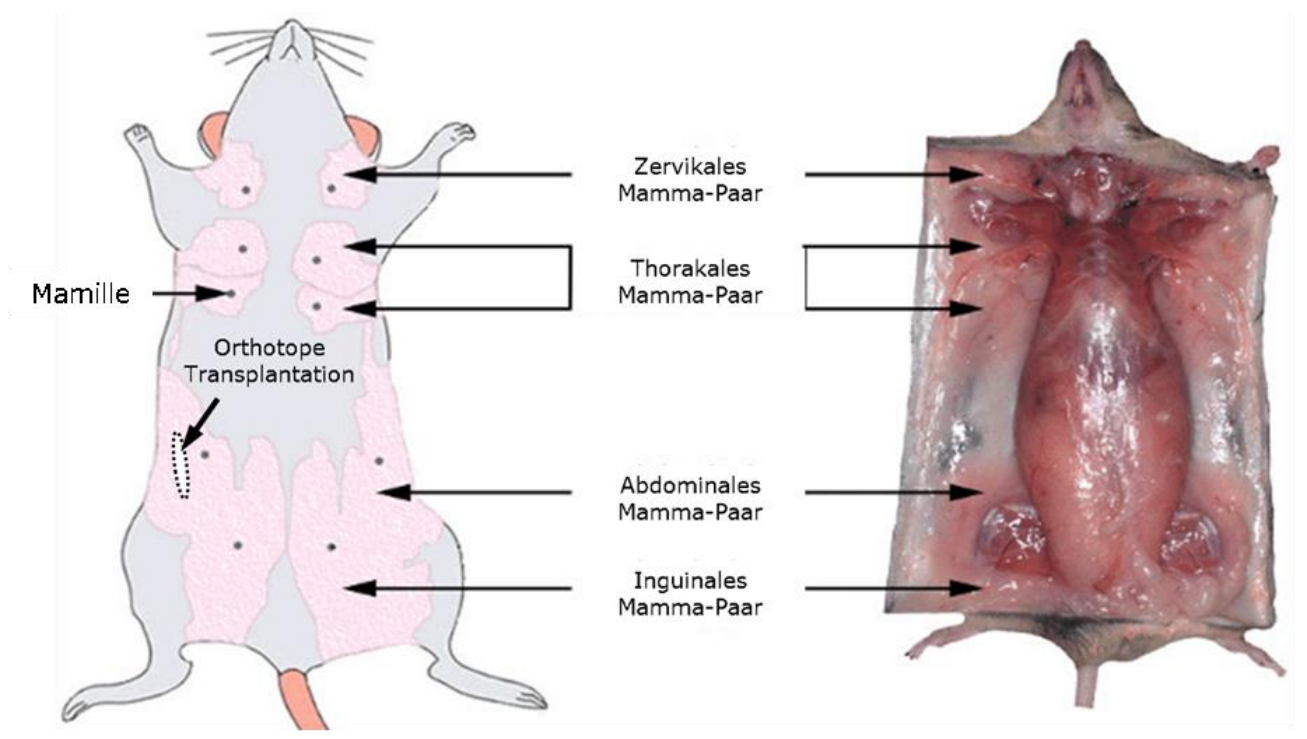

Abbildung 3: Anatomie der Labormaus

In der Abbildung rechts sind die verschiedenen Mammae der Labormaus während der Sektion dargestellt. Die thorakalen Mammae bestehen aus zwei zum Teil überlappenden Drüsen. Der Schnitt für die orthotope Transplantation ist rechts neben der rechten Mamille des abdominalen Mammapaars in der linken Abbildung schematisch dargestellt. (Veränderte Abbildung aus Honvo-Houéto und Truchet 2015)

\subsubsection{Bewertung des Therapieerfolgs nach RECIST-Kriterien}

Zur Bewertung der Behandlungserfolge nach Therapie der H8N8-Mammakarzinome mit der CAFTherapie wurden die RECIST-Kriterien angewendet (Schwartz et al. 2016). Die Kriterien für die Bewertung des Ansprechens der Behandlung bei soliden Tumoren (RECIST, Response Evaluation Criteria In Solid Tumors) wurden von einer internationalen Kollaboration erstmalig im Jahr 2000 (Therasse et al. 2000) und in einer überarbeiteten Verfassung 2009 (Eisenhauer et al. 2009) publiziert. In dieser Arbeit wurden die RECIST-Kriterien auf die mit der Schieblehre gemessenen und anschlieBend berechneten $\mathrm{V}_{\mathrm{T}}$ angewendet. Die durch die Therapien verursachten $\mathrm{V}_{\mathrm{T}^{-}}$Veränderungen wurden anhand der folgenden Kriterien klassifiziert (Tabelle 16).

\section{Tabelle 16: RECIST-Kriterien}

\begin{tabular}{ll} 
Kriterium & Erklärung \\
\hline \hline \multirow{2}{*}{ partielle Remission } & Das $\mathrm{V}_{\mathrm{T}}$ ist um mindestens 30\% verringert, verglichen mit dem $\mathrm{V}_{\mathrm{T}}$ zum Start der \\
& Therapie. \\
& Es ist weder das Kriterium der partiellen Remission noch das der progressiven \\
stabile Erkrankung & Erkrankung erfüllt. \\
& Das $\mathrm{V}_{\mathrm{T}}$ ist um mindestens $20 \%$ angewachsen, verglichen mit dem niedrigsten \\
progressive Erkrankung & $\mathrm{V}_{\mathrm{T}}$ zum Zeitpunkt der Remission.
\end{tabular}




\subsubsection{Sektion und Präparation der Mausorgane}

Zum Versuchsende wurden die Mäuse für die Sektion in einer mit Kohlenstoffdioxid gefluteten Kammer getötet. Anschließend wurden die Tumore herauspräpariert. Die Formalinfixierung von Tumoren erfolgte nach Einlegen in Einbettkassetten in $4 \%$ Formalin über Nacht (ÜN) bei $4{ }^{\circ} \mathrm{C}$ im Kühlschrank. Die Tumore wurden wie folgt präpariert: Jeweils vier unbehandelte Tumore, vier Tumore in Remission und vier Tumore in Progression nach CAF Therapie wurden komplett und unverzüglich nach Präparation in Magnetic Activated Cell Separation (MACS) Tissue Storage Solution überführt und am nächsten Tag für durchflusszytometrische Analysen dissoziiert. Die restlichen Tumore wurden halbiert. Die eine Hälfte des Tumors wurde formalinfixiert und die andere Hälfte je nach Größe auf ein bis drei 1,5 ml Eppendorf Reagenzgefäße (Tube) aufgeteilt und mit flüssigem Stickstoff eingefroren. formalinfixierte Proben wurden im Anschluss für histochemische und IHCFärbungen verwendet. Mit flüssigem Stickstoff eingefrorene Proben wurden im Anschluss für mRNA-Sequenzierungen verwendet.

Weiter wurden je vier unbehandelte Tumore und vier Siltuximab behandelte Tumore sowie drei CAF und drei $\mathrm{CAF}+$ Siltuximab $(\mathrm{CAF} / \mathrm{S})$ behandelte Tumore für durchflusszytometrische Analysen präpariert. Diesen Tumoren wurde ein zentrales Stück für histochemische und IHC-Färbungen entfernt und sofort formalinfixiert. Die verbleibenden Stücke wurden unverzüglich nach Präparation in MACS Tissue Storage Solution überführt und am nächsten Tag für durchflusszytometrische Analysen dissoziiert. Die restlichen Tumore wurden so präpariert wie die oben beschriebenen Tumore, welche nicht für durchflusszytometrische Analysen verwendet wurden.

Für durchflusszytometrische Analysen wurden die Tumore zunächst dissoziiert. Für die Herstellung einer Einzel-Zellsuspension wurden, die in MACS Tissue Storage Solution befindlichen Tumorproben, mit dem Tumor Dissociation Kit für Mausgewebe in Verbindung mit dem gentleMACS Dissociator bearbeitet. Während der einzelnen Bearbeitungsschritte wurde stets nach dem Herstellerprotokoll gearbeitet. Die Einzel-Zellsuspensionen konnten dann für Isolierungen oder durchflusszytometrische Analysen gefärbt werden. Je nach Verwendungszweck wurden 1x106 Zellen mit flüssigem Stickstoff eingefroren, in DMEM in Kultur genommen oder in MACS Tissue Storage Solution für weitere Analysen überführt. 


\subsection{Histo- und immunhistologische Untersuchungen}

\subsubsection{Gewebefixierung und Herstellung von Paraffinblöcken}

Zur Herstellung von Paraffinschnitten wurden formalinfixierte Gewebeproben für 10 min mit deionisiertem Wasser (D-Wasser) gewaschen, um Formalinreste zu entfernen. Die Proben wurden durch sequenzielle Inkubationsschritte für je 1,5 h in $60 \%, 70 \%, 80 \%, 90 \%, 95 \%, 100 \%$ Ethanol und Xylol entwässert. Diesem Prozedere folgte für 1,5 h die Infiltration mit flüssigem Paraffin. Entwässerung und Infiltration erfolgten im Gewebeinfiltrationsautomaten mit dem in Tabelle 17 abgebildeten Programm. Schließlich konnten die Gewebeproben in Paraffinblöcke mithilfe einer Paraffingießstation eingebettet werden. formalinfixiertes Gewebe in Paraffinblöcken wurde bei RT im Dunkeln gelagert.

Tabelle 17: Programm für Gewebeentwässerung und Paraffininfiltration

\begin{tabular}{lc} 
Schritt & Dauer \\
\hline \hline $60 \%$ Ethanol & $1,5 \mathrm{~h}$ \\
$70 \%$ Ethanol & $1,5 \mathrm{~h}$ \\
$80 \%$ Ethanol & $1,5 \mathrm{~h}$ \\
$90 \%$ Ethanol & $1,5 \mathrm{~h}$ \\
$100 \%$ Ethanol & $1,5 \mathrm{~h}$ \\
$100 \%$ Ethanol & $1,5 \mathrm{~h}$ \\
Xylol & $1,5 \mathrm{~h}$ \\
Paraffin & $1,5 \mathrm{~h}$
\end{tabular}

\subsubsection{Herstellung von Gewebeschnitten am Mikrotom}

Die Paraffinblöcke wurden zuerst für 30 min auf eine auf $-20^{\circ} \mathrm{C}$ vorgekühlte Kühlplatte gelegt. Die Herstellung der Gewebeschnitte erfolgte am Mikrotom mit einer Schnittdicke von $2 \mu \mathrm{m}$. Die Schnitte wurden sofort im Wasserbad bei ca. $45^{\circ} \mathrm{C}$ geglättet, auf Objektträger überführt und ÜN bei RT oder für 20 min bei maximal $65^{\circ} \mathrm{C}$ auf einer Wärmeplatte getrocknet. Nach diesem Schema behandelte Schnitte wurden entweder histochemisch oder IHC gefärbt bzw. bei RT in Objektträgerkästen aufbewahrt. 


\subsubsection{Entparaffinierung und Rehydrierung von Gewebeschnitten}

Für histochemische und IHC-Färbungen wurden Gewebeschnitte zuerst manuell entparaffiniert und rehydriert. Dafür wurde das Paraffin im Trockenschrank bei $60^{\circ} \mathrm{C}$ für $30 \mathrm{~min}$ geschmolzen, gefolgt von sequenziellen Inkubationsschritten in Xylol und einer absteigenden Alkoholreihe (Tabelle 18).

Tabelle 18: Absteigende Alkoholreihe zur Entparaffinierung und Rehydrierung von Gewebeschnitten

\begin{tabular}{ll} 
Schritt & Dauer \\
\hline \hline Xylol & $7 \mathrm{~min}$ \\
Xylol & $7 \mathrm{~min}$ \\
Propanol & $5 \mathrm{~min}$ \\
$98 \%$ Ethanol & $5 \mathrm{~min}$ \\
$75 \%$ Ethanol & $5 \mathrm{~min}$ \\
$60 \%$ Ethanol & $5 \mathrm{~min}$ \\
D-Wasser & $5 \mathrm{~min}$
\end{tabular}

\subsubsection{Histochemische Hämalaun-Eosin-Färbung}

Für die Begutachtung und Analyse der Morphologie einzelner Gewebe wurden Hämalaun-EosinFärbungen (HE) durchgeführt. Die HE-Färbung ist eine Standardfärbung in der Histologie und dient als Übersichtsfärbung. Hierbei werden Zellkerne durch Hämalaun dunkelblau bis violett und Zytoplasma, Kollagen, Keratin und Erythrozyten durch Eosin rot gefärbt. Entparaffinierte und rehydrierte Gewebeschnitte wurden im Anschluss an die absteigende Alkoholreihe für 5 min in Mayers Hämalaunlösung gefärbt, kurz mit D-Wasser abgespült und anschließend unter fließendem Leitungswasser 5 min gebläut. Daraufhin erfolgte eine 5 min Inkubation in alkoholischem Eosin. Dafür wurden $5 \mathrm{~g}$ Eosin in $500 \mathrm{ml}$ destilliertem Wasser gelöst und mit 1-2 Tropfen Essigsäure versetzt. Die Färbung wurde in D-Wasser gestoppt. Die gefärbten Gewebeschnitte wurden über eine aufsteigende Alkoholreihe mit einer abschließenden Inkubation in Xylol entwässert und mit dem xylolhaltigen Eindeckmittel Entellan und einem Deckglas luftdicht versiegelt (Tabelle 19).

Tabelle 19: Aufsteigende Alkoholreihe zur Entwässerung HE gefärbter Gewebeschnitte

\begin{tabular}{lc} 
Schritt & Dauer \\
\hline \hline D-Wasser & kurz \\
$60 \%$ Ethanol & kurz \\
$75 \%$ Ethanol & kurz \\
$98 \%$ Ethanol & $5 \mathrm{~min}$ \\
Propanol & $5 \mathrm{~min}$ \\
Xylol & $5 \mathrm{~min}$ \\
Xylol & $5 \mathrm{~min}$
\end{tabular}




\subsubsection{Histochemische Masson-Trichrom-Färbung}

Für die Begutachtung und Analyse der Kollagenanteile im Tumor wurden Masson-Trichrom-Färbungen (MTS) mittels dem Masson Trichrom Kit durchgeführt. Hierbei wurden Zellkerne durch Weigerts-Eisenhämatoxylin schwarz, Zytoplasma und Muskelgewebe durch Bieberichs-ScharlachrotSäurefuchsin-Lösung rot und Kollagen durch Anilinblau blau gefärbt. Entparaffinierte und rehydrierte Gewebeschnitte wurden im Anschluss an die absteigende Alkoholreihe ÜN in Bouin's-Lösung bei RT vorbehandelt, anschließend für 5 min unter fließendem Leitungswasser bis zur Entfärbung gespült. An die Entfärbung schloss sich die Kernfärbung für 5 min mit Weigerts-Eisenhämatoxylin an. Dafür wurde zunächst ein Teil Weigerts-Eisenhämatoxylin-Lösung-A mit einem Teil WeigertsEisenhämatoxylin-Lösung-B gemischt und für jede Färbung frisch angesetzt. Danach wurde 5 min in Leitungswasser und kurz in D-Wasser gespült. Nun kamen die Proben für 5 min in BieberichsScharlachrot-Säurefuchsin-Lösung und wurden nur kurz mit D-Wasser gespült. In der Zwischenzeit wurden zwei Teile D-Wasser mit je einem Teil Phosphorwolframsäure und einem Teil Molybdatophosphorsäure gemischt und die Proben darin 5 min inkubiert. Ohne Waschschritt kamen die Proben für 5 min in die Anilinblaulösung, gefolgt von 2 min in $1 \%$ iger Essigsäure und nach kurzem Abspülen mit bidestilliertem Wasser wurde erneut kurz mit D-Wasser gespült. Die gefärbten Gewebeschnitte wurden über eine aufsteigende Alkoholreihe mit einer abschließenden Inkubation in Xylol entwässert (Tabelle 19) und mit dem xylolhaltigen Eindeckmittel Entellan und einem Deckglas luftdicht versiegelt.

\subsubsection{Auswertung der Masson-Trichrom-Färbungen}

Die quantitative bildanalytische Auswertung des Prozentualen-Kollagenanteils an der Gesamttumorfläche der MTS gefärbten Probe wurde mit der Software Fiji durchgeführt. Die Bearbeitungsschritte waren so gewählt, dass blaue unspezifische Hintergrundfärbung bzw. falsch-positive Probenfärbung (Zelldebris) aus der analysierten Fläche herausgerechnet wurden. Die einzelnen Schritte sind im Flussdiagramm der Abbildung 4 dargestellt. Der eigentlichen Auswertung ging die Personalisierung des MTS Profils des Color Deconvolution Macros zum Aufspalten des Bildes in drei Farbkanäle mit Fiji voraus. Mit dem Color Deconvolution Macro war es möglich bis zu drei Regionen (ROI, 
region of interest) auszuwählen und spezifisch für diese Regionen den jeweiligen dort befindlichen Farbkanalmittelwert des Bildes als Referenzwert für die Aufspaltung in drei Kanäle zu verwenden. Das Macro gab die Javafarbwerte in einer Tabelle an. Diese Werte konnten als Referenzwerte für die MTS-Färbung in der colordeconvolution.txt Datei gespeichert werden und dienten als Grundlage für die Auswertung von MTS-Färbungen mit dem Color Deconvolution Macro zur Ermittlung des Kollagenanteils im Tumor.

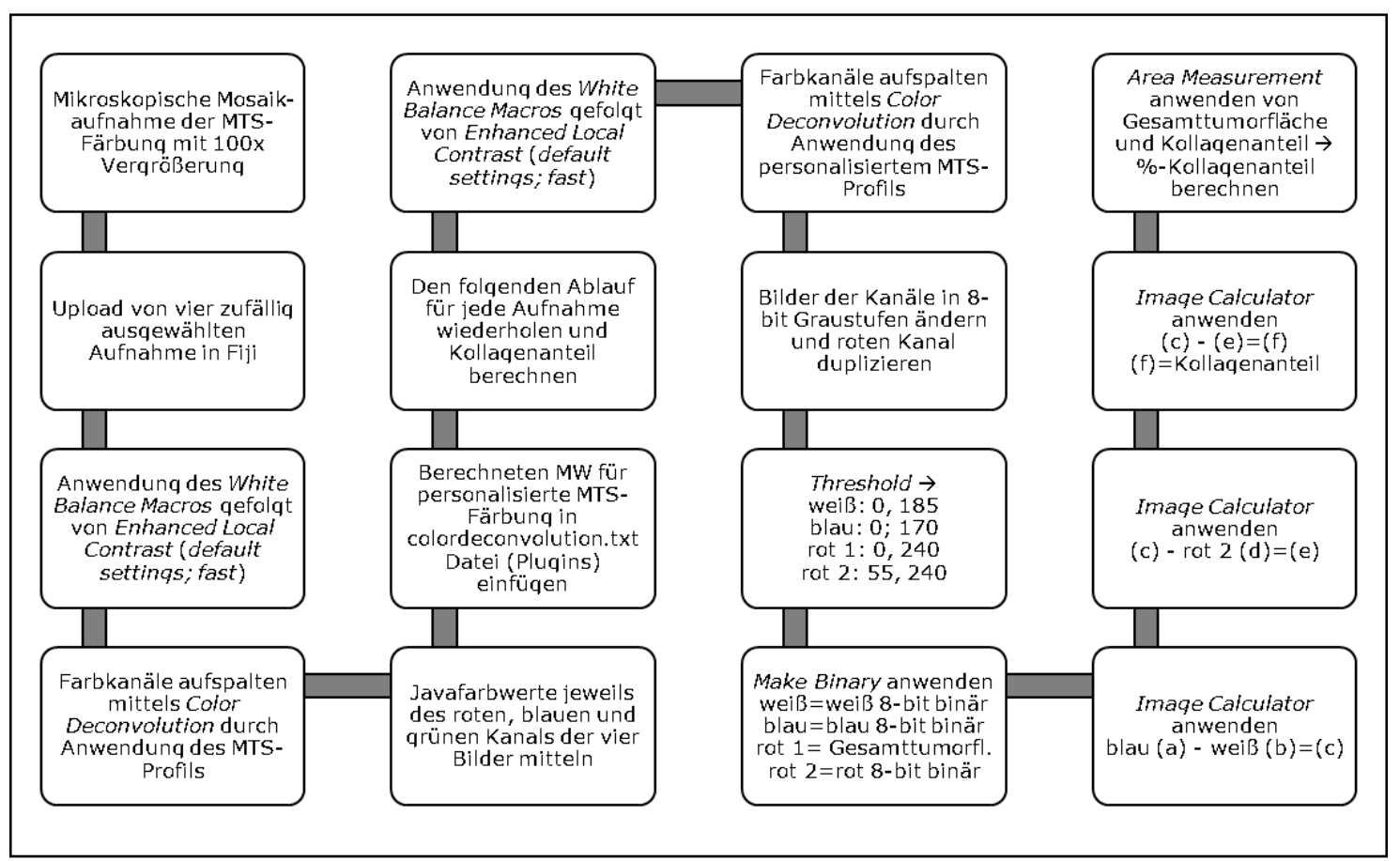

Abbildung 4: Flussdiagramm mit den Bearbeitungsschritten zur Auswertung der MTS-Färbung

Hier sind schrittweise die Bearbeitungsschritte und verwendeten Macros in der angewendeten Reihenfolge schematisch dargestellt. Zuerst wurde an vier zufällig ausgewählten mikroskopischen Mosaikaufnahmen (je ein Bild eines Tumors jeder Gruppe) Referenzwerte für den roten, blauen und grünen Farbkanal ermittelt. Dies ermöglichte anschließend jede Aufnahme mit dem errechneten personalisierten MTS-Profil zu analysieren, gefolgt von der Berechnung des Kollagenanteils an der Gesamttumorfläche.

\subsubsection{Immunhistochemische Färbungen}

Eine IHC-Färbung dient der Detektion von Zielproteinen in formalinfixierten Organen. Der Nachweis beruht auf der Affinität von pAK zu einem bestimmten Epitop eines Proteins. Hier wurden unkonjugierte pAK verwendet, die durch einen sAK sichtbar gemacht wurden. Dieser sAK ist an ein Detektionssystem gekoppelt. Das Detektionssystem basiert auf einer enzymatischkatalysierten Umwandlung des farblosen Aminoethylcarbazol-(AEC-) Substrats in ein farbiges Endprodukt durch 
Oxidation der am sAK gekoppelten Peroxidase. So können bereits sehr geringe Mengen an Zielprotein durch Bindung mehrerer sAK an einem pAK dargestellt werden. Einige sAK waren anstatt mit einer Peroxidase mit Biotin konjugiert und benötigten einen Zwischenschritt. Dieser sah vor, die Proben mit dem Avidin-Meerrettichperoxidase-Konjugat (Avidin-HRP) zu behandeln. Biotin besitzt vier Bindungsstellen, an dem das Avidin binden kann, wodurch eine noch geringere Menge des Zielproteins detektiert werden kann.

Die Fixierung des Gewebes durch 4 \% Formalin kann zu einer chemischen Veränderung der Antigene führen. Dies kann eine Maskierung der Epitope hervorrufen, sodass der AK unter Umständen sein Antigen nicht erkennt (Shi et al. 1991). Mit Hitze können die Epitope in vielen Fällen wieder demaskiert werden (Kim et al. 2004). Um Zielproteine besser für ihre AK zugänglich zu machen, wurden Gewebeschnitte für 20 min in einem Dampfgarer in 1x Citrat Puffer pH 6 (Target Retrieval Solution) gekocht. Nach 5 min Abkühlen in bidestilliertem Wasser auf Eis wurden die Schnitte zweimal 5 min in Tris-HCl-Puffer pH 7,6 gewaschen. Anschließend wurden die Proben 10 min bei RT mit 3 \%igem Wasserstoffperoxid behandelt, um die Wirkung von endogenen Oxydasen zu reduzieren und im Anschluss erneut zweimal mit Tris- $\mathrm{HCl} \mathrm{pH}$ 7,6 gewaschen. Wurden mit Biotin gekoppelte sAK verwendet, benötigten die Schnitte zwei weitere Vorbehandlungen. Zum einen eine 10 min Inkubation bei RT mit einem Avidinblock (Avidin/Biotin Blocking Kit) und zum anderen eine $10 \mathrm{~min}$ Inkubation mit einem Biotinblock (Avidin/Biotin Blocking Kit). Diese Vorbehandlungsschritte dienten der Blockierung von endogenem Biotin, Avidin und Biotin-bindenden-Proteinen. Nach erneutem zweimaligen Waschen mit Tris- $\mathrm{HCl}$ pH 7,6 wurden die einzelnen Gewebeschnitte für 20 min bei RT mit einem Lachsnormalserum (Sea Block Blocking Buffer) inkubiert, um unspezifische Bindungen und damit Hintergrundfärbung zu minimieren. Der pAK wurde in Antibody Diluent verdünnt und auf die Gewebeschnitte gegeben. Die Inkubation fand ÜN bei $4{ }^{\circ} \mathrm{C}$ in einer feuchten Kammer statt, gefolgt von zwei Waschschritten mit Tris-HCl pH 7,6. Zur Detektion der pAK wurden die Schnitte nun mit sAK in Tris-HCl pH 7,6 bei RT für $1 \mathrm{~h}$ inkubiert und erneut zweimal mit Tris-HCl pH 7,6 gewaschen. Handelte es sich bei dem sAK um einen Biotin gekoppelten sAK, so schloss sich nun eine Inkubationszeit von $1 \mathrm{~h}$ bei RT mit Avidin-HRP an. Das Avidin band an das Biotin des sAK und nach erneutem zweimaligen Waschen mit Tris- $\mathrm{HCl}$ pH 7,6 wurden die einzelnen Gewebeschnitte für 30 min bei RT mit dem AEC Substrat Kit inkubiert und die Farbreaktion mit D-Wasser 
gestoppt. Die am sAK oder avidinkonjugierte Peroxidase nutzt das AEC als Substrat und die enzymatische Reaktion bildet ein Endprodukt, welches verantwortlich für die braun-rote Färbung ist. Zur Gegenfärbung wurden die Gewebeschnitte 20 s in Mayers-Hämalaunlösung getaucht, kurz in DWasser gewaschen und anschließend für $5 \mathrm{~min}$ in Leitungswasser gebläut. Schließlich wurden die gefärbten Schnitte mit dem Eindeckmittel Aquatex und einem Deckglas luftdicht versiegelt. In der folgenden Tabelle 20 sind die verwendeten pAK und sAK sowie die benutzten Verdünnungen und individuellen Konjugationen aufgelistet. Histochemische und IHC gefärbte Gewebeschnitte wurden mithilfe eines Axiovert-200M Mikroskops, das mit einer AxioCam-MRc-CCD-Sensorkamera ausgestattet war, aufgenommen.

Tabelle 20: Anwendungsangaben zu IHC Primär- und Sekundärantikörpern

\begin{tabular}{|c|c|c|c|c|c|}
\hline Antikörper & $\mathrm{pAK} / \mathrm{sAK}$ & Konjugiert & Spezies & Reaktivität & Verdünnung \\
\hline Avidin-HRP & & Peroxidase & Huhn & Biotin & unverdünnt \\
\hline$\alpha-S m a$ & $\mathrm{pAK}$ & unkonjugiert & Kaninchen & & $1: 500$ \\
\hline $\mathrm{Cd} 24$ & $\mathrm{pAK}$ & unkonjugiert & Kaninchen & & $1: 100$ \\
\hline $\mathrm{Cd} 44$ & $\mathrm{pAK}$ & unkonjugiert & Ratte & & $1: 250$ \\
\hline $\mathrm{Cd} 45$ & $\mathrm{pAK}$ & unkonjugiert & Ratte & & $1: 250$ \\
\hline E-Cadherin & pAK & unkonjugiert & Kaninchen & & 1:100 \\
\hline Interleukin-6 & $\mathrm{pAK}$ & unkonjugiert & Kaninchen & & $1: 100$ \\
\hline Pcna & $\mathrm{pAK}$ & unkonjugiert & Kaninchen & & $1: 500$ \\
\hline T-Ag (R15) & $\mathrm{pAK}$ & unkonjugiert & Kaninchen & & 1:10000 \\
\hline Tenascin- $C$ & $\mathrm{pAK}$ & unkonjugiert & Ratte & & $1: 100$ \\
\hline Vimentin & $\mathrm{pAK}$ & unkonjugiert & Kaninchen & & $1: 500$ \\
\hline Histofine Simple Stain & sAK & Peroxidase & Ziege & Kaninchen & unverdünnt \\
\hline Ziege-anti-Ratte-IgG (H\&L) & sAK & Biotin & Ziege & Ratte & $1: 800$ \\
\hline
\end{tabular}

\subsection{Molekularbiologische Methoden}

\subsubsection{Extraktion genomischer DNA aus Ohrstanzenbiopsien}

Für die Extraktion von DNA aus Ohrstanzenbiopsien wurde das Gewebe mit $300 \mu$ l Gewebelysispuffer und $1,5 \mu$ Proteinase-K ÜN bei $56{ }^{\circ} \mathrm{C}$ und $600 \mathrm{rpm}$ auf dem Schüttler inkubiert. AnschlieBend wurden die Proben für 5 min bei 13000 g zentrifugiert. In neue Tubes wurden $250 \mu \mathrm{l}$ des Überstands transferiert und mit $600 \mu$ l eiskaltem 100 \%igem Ethanol versetzt, auf dem Vortex-Schüttler vermischt und für 10 min bei $13000 \mathrm{~g}$ zentrifugiert. Nachdem der Überstand verworfen wurde, konnte das Pellet in $500 \mu \mathrm{l} 70$ \%igem Ethanol gewaschen und für 5 min bei $13000 \mathrm{~g}$ zentrifugiert 
werden. Anschließend wurde der Überstand verworfen, kurz erneut abzentrifugiert und letzte Ethanolreste entfernt. Das Pellet wurde mit $100 \mu \mathrm{l}$ autoklaviertem Wasser bei $37^{\circ} \mathrm{C}$ und $300 \mathrm{rpm}$ für $1 \mathrm{~h}$ bei offenem Tube-Deckel gelöst. Die extrahierte DNA wurde bei $4{ }^{\circ} \mathrm{C}$ gelagert, nicht eingefroren und schnellstmöglich für die Genotypisierung verwendet.

\subsubsection{Genotypisierung von WAP-T-NP8-Mäusen mittels Standard-PCR}

Eine PCR ermöglicht die in vitro Amplifizierung von kurzen und spezifischen DNA-Sequenzen (Mullis und Faloona 1987). Das Prinzip dieser Reaktion beruht auf der komplementären Bindung zweier Oligonukleotidprimer (forward und reverse primer) an den Flanken der zu amplifizierenden DNA. Die Verwendung einer thermostabilen Taq-DNA-Polymerase ermöglicht die zyklische Denaturierung von DNA durch Erhitzen und die anschließende Verlängerung der Oligonukleotidprimer nach Abkühlung. Dadurch, dass die Primer jeweils an den Sense- und Antisense-Strang binden und verlängert werden, entstehen komplementäre Stränge, die dann als Matrix für den folgenden Elongationszyklus dienen.

Die Identifizierung des Transgens der frühen SV40-Region erfolgte zusammen mit einer Notch-PCR, die als Konzentrationskontrolle diente. In der Tabelle 21 sind die Reaktionsansätze der SV40- und der Notch-PCR aufgelistet. Die Reaktionen wurden mit einem Thermocycler und den in Tabelle 22 angegebenen Bedingungen durchgeführt. Als Positivkontrolle wurde isolierte DNA aus H8N8-Tumorgewebe aufgetragen. Isolierte DNA aus Gewebeproben einer Balb/c-Maus diente als Negativkontrolle und zur Kontrolle einer möglichen Kontamination der Reagenzien wurde Ampuwa-Wasser anstatt DNA eingesetzt.

Tabelle 21: Reaktionsansatz für Standard-PCR zur SV40-Transgen und Notch-Identifizierung

\begin{tabular}{l|ccc} 
& SV40-PCR & Notch-PCR & Volumen \\
\hline \hline 10x Reaktionspuffer $\left(+\mathrm{MgCl}_{2}\right)$ & & & $2,5 \mu \mathrm{l}$ \\
dNTPs $(10 \mathrm{mM})$ & & & $0,5 \mu \mathrm{l}$ \\
fw. Primer $(10 \mu \mathrm{m})$ & AC & Notch4 & $0,5 \mu \mathrm{l}$ \\
rev. Primer $(10 \mu \mathrm{m})$ & DC & Notch4 & $0,5 \mu \mathrm{l}$ \\
DNA $(100 \mathrm{ng} / \mu \mathrm{l})$ & & & $1 \mu \mathrm{l}$ \\
autoklaviertes Wasser & & & 18,7 \\
Taq-Polymerase $(5 \mathrm{U} / \mu \mathrm{l})$ & & & $0,3 \mu \mathrm{l}$ \\
\hline Endvolumen & & & $25 \mu \mathrm{l}$
\end{tabular}


Tabelle 22: PCR-Programm für die Detektion des SV40-Transgens und Notch-Positivkontrolle

\begin{tabular}{l|ccc} 
Schritt & Temperatur & Dauer & \\
\hline \hline initial Denaturierung & $95^{\circ} \mathrm{C}$ & $4 \mathrm{~min}$ & \\
\hline Denaturierung & $94^{\circ} \mathrm{C}$ & $45 \mathrm{~s}$ & \\
Hybridisierung & $60^{\circ} \mathrm{C}$ & $30 \mathrm{~s}$ & 35 Zyklen \\
Amplifikation & $72^{\circ} \mathrm{C}$ & $1 \mathrm{~min}$ & \\
\hline Termination & $72^{\circ} \mathrm{C}$ & $5 \mathrm{~min}$ & \\
\hline Programmende & $4{ }^{\circ} \mathrm{C}$ & $\infty$
\end{tabular}

\subsubsection{Gelelektrophoretische Auftrennung}

Die Agarose-Gelelektrophorese diente der analytischen Auftrennung von PCR-Amplifizierungsprodukten und der Qualitätsbestimmung von DNA-Proben. Die Produkte wurden auf einem Gel mit einer Konzentration von 1,3\% Agarose in 1x Tris-Borat-EDTA-Puffer (TBE), versetzt mit 0,1 $\mu \mathrm{l} / \mathrm{ml}$ GelRed, aufgetragen. Die Auftrennung der DNA erfolgte in einer horizontalen Elektrophoreseapparatur bei einer konstanten Spannung von $160 \mathrm{~V}$ für 30-45 min in 1x TBE-Puffer. Die zu untersuchenden Proben wurden mit $8 \mu$ DNA-Ladepuffer gemischt und im Agarosegel der Größe entsprechend aufgetrennt. Die Nukleinsäuren wurden mittels eines UV-Transilluminators sichtbar gemacht und mit einer Geldokumentationsanlage aufgenommen. Zur Größenbestimmung wurde ein $1 \mathrm{~kb}$ DNA-Größenstandard parallel aufgetragen.

\subsubsection{RNA-Isolierung aus Zellpellets}

Zur Isolierung von RNA aus einem Zellpellet mit 1×106 Zellen wurden $500 \mu \mathrm{l}$ Qiazol dem Zellpellet hinzugefügt und vorsichtig auf und ab pipettiert bis das Pellet vollständig resuspendiert war. Wenn es nötig war, wurde noch einmal etwas Qiazol hinzugefügt, um eine vollständige Resuspension zu gewährleisten. Um Nukleotidkomplexe zu dissoziieren wurde das Gemisch bei RT für 10 min unter dem Abzug inkubiert. Nach Zugabe von $100 \mu$ l Chloroform pro $500 \mu \mathrm{l}$ Qiazol wurden die Proben 15 s lang kräftig auf einem Vortexer geschüttelt, nochmals 10 min bei RT inkubiert und anschließend bei $4{ }^{\circ} \mathrm{C}, 12000 \mathrm{~g}$ für $10 \mathrm{~min}$ zentrifugiert.

Die obere wässrige Phase wurde anschließend in einem neuen Tube mit $200 \mu$ l Chloroform für $15 \mathrm{~s}$ kräftig auf einem Vortexer geschüttelt und im Anschluss erneut bei $4{ }^{\circ} \mathrm{C}, 12000 \mathrm{~g}$ für 5 min zentrifugiert. Die obere wässrige Phase wurde anschließend in einem Tube mit $500 \mu \mathrm{l}$ Isopropanol versetzt, invertiert und ÜN bei $-20{ }^{\circ} \mathrm{C}$ inkubiert. Durch erneute Zentrifugation bei $4{ }^{\circ} \mathrm{C}, 12000 \mathrm{~g}$ für $30 \mathrm{~min}$ 
wurde die RNA sedimentiert. Der Überstand wurde verworfen, das Pellet mit $1 \mathrm{ml}-20^{\circ} \mathrm{C}$ kaltem RNase freien $80 \%$ igem Ethanol gewaschen und wieder bei $4{ }^{\circ} \mathrm{C}, 12000 \mathrm{~g}$ für 10 min zentrifugiert. Der Überstand wurde verworfen und die Prozedur ein weiteres Mal wiederholt, gefolgt von einer weiteren Zentrifugation bei $4^{\circ} \mathrm{C}, 8000 \mathrm{~g}$ für $10 \mathrm{~min}$. Das RNA-Pellet wurde nach Abpipettieren des Ethanols bei RT 10 min getrocknet und in $50 \mu \mathrm{l}$ mit Diethyldicarbonat (DEPC) behandelten Wasser bei $50{ }^{\circ} \mathrm{C}$ für 10 min gelöst und konnte nun bei $-80^{\circ} \mathrm{C}$ gelagert werden.

Die Bestimmung der RNA-Konzentration wurde über eine photometrische Messung am Spektrophotometer vorgenommen. Zu Beginn der RNA-Konzentrationsmessung wurde mit DEPC-Wasser der Referenzwert des Lösungsmittels bestimmt und als Nullwert eingestellt. Auf die Messfläche des Gerätes wurde jeweils $1 \mu \mathrm{l}$ der gelösten RNA pipettiert und die Konzentration gemessen.

\subsubsection{Bestimmung der RNA-Qualität und -Integrität}

Zum Ausschluss degradierter RNA-Proben wurde die Qualität der RNA mit dem Agilent 2100 Bioanalyzer untersucht. Für diese Bestimmung wurde das Agilent RNA 600 Nano Kit verwendet und streng nach Herstellerangaben gearbeitet. Das Ergebnis wurde als ein gelähnliches Bild und als Elektropherogramm dargestellt und die Qualität bzw. Integrität der RNA ermittelt. Anhand des Elektropherogramms wurden degradierte RNA- oder auch DNA-Verunreinigungen visualisiert. Eine intakte RNA-Probe wies zwei eindeutige Markierungsspitzen auf, eine für die 18S rRNA (ribosomale RNA) und die andere für die 28S rRNA. Die einzusetzende RNA-Menge betrug zwischen 25$500 \mathrm{ng} / \mu \mathrm{l}$.

\subsubsection{Illumina-Sequenzierung von generierten mRNA-Bibliotheken}

Für die Sequenzierung wurden mRNA-Bibliotheken mithilfe des NEXTflex Rapid Directional RNASeq Library Prep Kits nach Herstellerprotokoll generiert. Es wurden zuerst die transkribierten messenger RNAs (mRNA) aus jeweils $1 \mu \mathrm{g}$ Gesamt-RNA-Isolat mit dem NEXTflex Poly(A) Beads Kit isoliert. Anschließend wurden die mRNA fraktioniert, in doppelsträngige complementary DNA (cDNA) konvertiert und mit einer Barcode beinhaltenden Adaptersequenzen, zur eindeutigen Kennzeichnung, versehen (Tabelle 23). Die mRNA-Bibliotheken wurden schließlich durch 12 Zyklen PCR 
amplifiziert. Die Fragmentgröße der hergestellten mRNA-Bibliothek wurde dann mit Hilfe des Agilent RNA 6000 Pico Kits in einem Agilent 2100 Bioanalyzer nach Herstellerangaben eingeschätzt. Die Konzentration der jeweiligen mRNA-Bibliothek wurde mit einem Fluorometer bestimmt. Für die Sequenzierungsreaktion wurden die mRNA-Bibliotheken schließlich äquimolar als 2 nM Lösung in EB-Puffer zusammen gemischt. Die Illumina-Sequenzierung erfolgte in einem HiSeq 4000 Sequenzierautomat der Serviceeinheit Transcriptome and Genome Analysis Laboratory (TAL) der Universität Göttingen.

Tabelle 23: Verwendete Barcodes des NEXTflex RNA-Seq Barcodes Kit für Illumina-Sequenzierung

\begin{tabular}{cc}
$\begin{array}{c}\text { NEXTflex } \\
\text { RNA-Seq Barcodes }\end{array}$ & Basensequenz \\
\hline \hline Barcode \#22 & CGTACG \\
Barcode \#26 & ATGAGC \\
Barcode \#27 & ATTCCT \\
Barcode \#37 & CGGAAT \\
Barcode \#38 & CTAGCT \\
Barcode \#41 & GCGCTA \\
Barcode \#42 & TAATCG \\
Barcode \#43 & TACAGC \\
Barcode \#35 & CATTTT \\
Barcode \#46 & TCCCGA \\
Barcode \#47 & TCGAAG \\
Barcode \#48 & TCGGCA
\end{tabular}

\subsubsection{Analyse der sequenzierten mRNA-Bibliotheken}

Die nach der Sequenzierung erhaltenen Rohdaten wurden als FASTQ-Datei auf die Web-Browserbasierte Galaxy-Plattform der GWDG (Gesellschaft für wissenschaftliche Datenverarbeitung mbH) hochgeladen (Goecks et al. 2010; Afgan et al. 2018). Anschließend wurde die Qualität der Sequenzen mit der FASTQC (V0.71) überprüft (Andrews 2010). Qualitativ schlechte Sequenzbereiche wurden entsprechend mit der FastQ-Trimmer-Galaxy-Anwendung (V1.0.0) vom 5'-Ende um 11 Basen getrimmt (Blankenberg et al. 2010). Alle so erhaltenen Sequenzen wurden mit der RNA-Star-GalaxyAnwendung (V2.5.2b-2) auf das Mausgenom (Mus_musculus.GRCm38.92) zugeordnet und ausgerichtet (Dobin et al. 2013). Mit der Galaxy-Anwendung Feature Counts (V1.6.0.2) wurde dann quantitativ bestimmt, wie viele Gensequenzfragmente (reads) eindeutig einem Gen des Referenzgenoms zugeordnet wurden (Liao et al. 2014). Diese reads wurden innerhalb der Gruppe gemittelt und anschließend gegen Referenzwerte normiert (MNR, mean normalized reads). Die Normalisierung und Analyse der differentielle Genexpression erfolgte mit der DESeq2-Galaxy-Anwendung (Love et al. 
2014). Diese Anwendung testet auf Grundlage der Varianz der eingespeisten Daten die differenzielle Genexpression. Der absolute Mittelwert des Expressionslevels wird für jedes Gen und jede Kondition berechnet. Weiter wird ein Mittelwert für jede Kondition allein berechnet. Für den Vergleich von zwei Konditionen wird die logarithmische Veränderung zur Basis 2 (log2FC, $\log 2$-Fold Change), der p- und korrigierte (adjusted) p-Wert für die statistische Signifikanz der berechneten Werte angegeben (Samborski 2013).

\subsubsection{Gensetexpressionsanalyse}

Bei der Gensetexpressionsanalyse (GSEA, Gene Set Enrichment Analysis) (V3.0) des Broad-Instituts vom MIT (Massachusetts Institute of Technology) handelt es sich um ein statistisches Verfahren für eine gewichtete Genexpression zum paarweisen Vergleich zweier Konditionen (Subramanian et al. 2005; Liberzon et al. 2011). Die Konditionen können beliebig zu Gengruppen zusammengestellt werden oder aus Datenbanken stammen.

In dieser Arbeit wurden die erhaltenen Datensätze mit drei Datensätzen der MSig-Datenbank (MSigDB, Molecular Signatures Database) (V6.2) verglichen. Dabei handelte es sich um die Datensätze des Halmark Gene Sets und aus diesem wurden die Gensets für EMT-, den TNF- $\alpha$ - und IL6JAK1-STAT3-Signalweg für eine genauere Charakterisierung des Datensatzes der Illumina-Sequenzierung verwendet (Liberzon et al. 2015).

Bei der GSEA wurde eine präferenzielle Verteilung von vorgegebenen Gensets an Genen im untersuchten Datensatz vorgenommen. Dem Programm wird eine Rangliste aus log2FC- und adjusted pWerten der exprimierten Gene vorgegeben. Aus diesen Daten berechnete das Programm einen Enrichment-Score (ES), diesem liegt eine gewichtete Statistik für das Maß der Anreicherung der Gengruppe zugrunde. Ein Genset war angereichert, wenn viele Gene aus diesem Genset einen hohen Rang in der Rangliste der hierarchischen Sortierung der Genliste einnahmen. Jedes hochregulierte Gen im Datensatz, welches auch im Referenzgenset vorkommt, wird kumulativ summiert. Sobald Gene im Datensatz die gegenteilige Expression beim Vergleich mit dem Referenzgenset aufweisen, nimmt der Rang durch negative Werte ab. Man spricht bis zum Wendepunkt des Maximums von der 
Leading Edge. Je mehr Gene der Gengruppe hochreguliert sind und einen hohen Rang in der Rangliste aufweisen, desto länger und höher ist die Leading Edge.

Die Datensätze des Halmark Gene Sets repräsentieren 50 Gensets in denen verschiedene Gene gesammelt sind, die bestimmte krebsspezifische Prozesse, Zustände und Signaltransduktionswege entsprechen. Mit der Leading Edge Analysis (LEA) ließen sich die normierten ES des gesamten Halmark Gene Sets miteinander vergleichen (Subramanian et al. 2005; Samborski 2013). Aus diesem Ergebnis war es möglich bestimmte hochregulierte Schlüsselgene zu identifizieren, die in vielen dieser 50 Gensets angereichert waren und damit zur Leading Edge beitrugen.

\subsection{Durchflusszytometrische Methoden}

\subsubsection{Charakterisierung der Tumorzusammensetzung}

Zur Charakterisierung der Tumorzusammensetzung wurden die Einzel-Zellsuspensionen mit einem AK-Cocktail aus Cd45-VioBlue (Cd45: leukocyte common antigen), Epcam-PE (Epcam: epithelial cell adhesion molecule), Cd90.2-APC (Cd90.2: thymus cell antigen-1), Cd31-PE-Vio770 (Cd31: platelet/endothelial cell adhesion molecule-1) und Ter119-FITC (Ter119: lymphocyte antigen-76) gefärbt und anschließend durchflusszytometrisch mittels Fluorescence Activated Cell Sorting (FACS) analysiert. Zum Ausschluss toter Zellen wurde mit Propidiumiodid (PI) gefärbt. Die AK-Färbungen wurden nach den Angaben des Herstellers durchgeführt. Die Durchflusszytometrie wurde am MACSQuant Analyzer 10 durchgeführt und die erhobenen Daten mit der FlowJo Software analysiert.

\subsubsection{Isolierung von Tumorzellen durch negative Depletion}

Um tatsächlich nur Tumorzellen durchflusszytometrisch und molekularbiologisch untersuchen zu können, mussten die Tumorzellen zunächst aus der Einzel-Zellsuspension isoliert werden. Dies wurde mittels MACS-Technologie basierender Depletion der Nichttumorzellen aus der Einzel-Zellsuspension erreicht. Dafür wurde das Tumor Cell Isolation Kit für Mausgewebe verwendet. Die magnetische Zellseparation wurde nach Herstellerangaben durchgeführt. Die Ergebnisse der negativen Depletion wurden durchflusszytometrisch am MACSQuant Analyzer 10 untersucht und mit der 
FlowJo Software analysiert. In der folgenden Abbildung 5 ist die angewendete Sortierstrategie dargestellt.

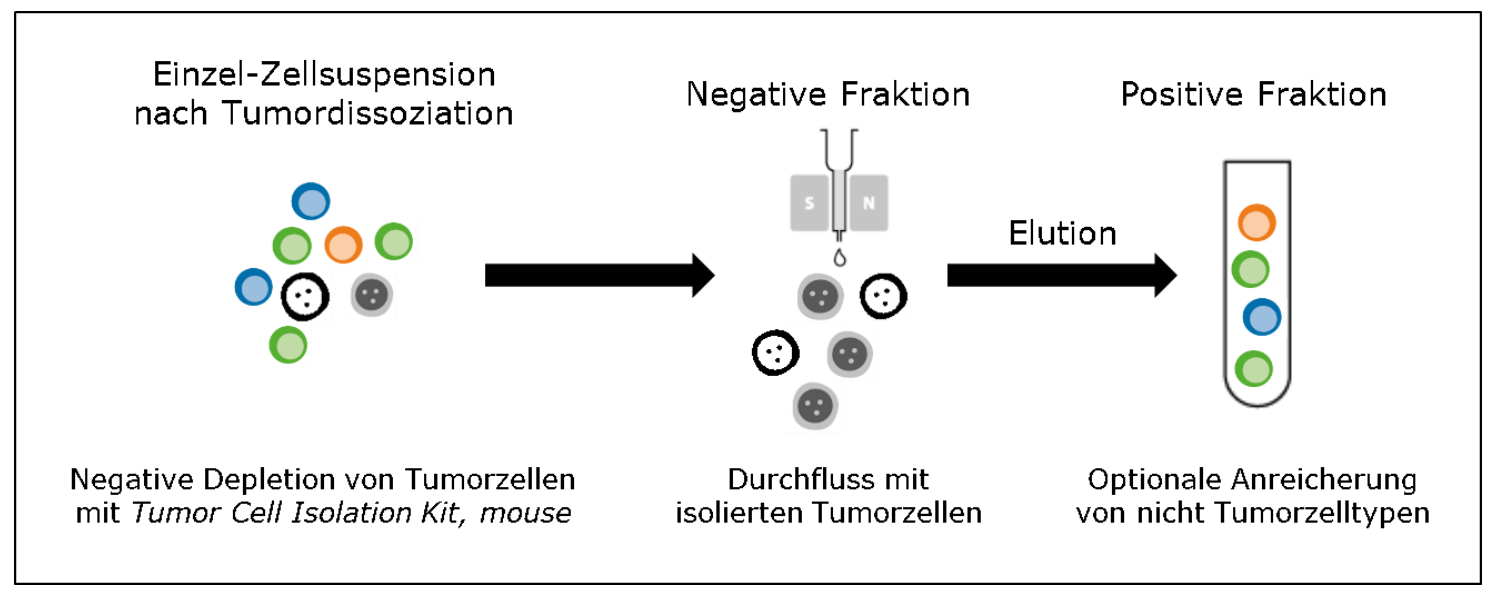

Abbildung 5: Schematische Darstellung der Sortierstrategie zur Isolierung der Tumorzellen

Dargestellt sind die Schritte zur Isolierung von Tumorzellen, die in Kollaboration mit David Agorku, Miltenyi Biotec GmbH durchgeführt wurde. Aus der dissoziierten Tumorzellsuspension wurden mittels Tumor Cell Isolation Kit, mouse Nichttumorzellen magnetisch markiert und auf magnetischen Säulen zurückgehalten, um über eine negative Depletion die Tumorzellen anzureichern.

\subsubsection{Antikörperfärbung zur Charakterisierung von Tumorzellen}

Zur Untersuchung von Oberflächenmolekülen und Charakterisierung der isolierten Tumorzellen wurden die Einzel-Zellsuspensionen mit den folgenden Antikörpern gefärbt: Cd44-VioBlue oder Cd44-APC-Vio770 (Cd44: lymphocyte antigen-24), Cd24-APC-Vio770 oder Cd24-FITC (Cd24: lymphocyte antigen-52), Cd95-PE-Vio770 oder Cd95-PE (Cd95: Fas - TNF receptor superfamily member-6), Cd201-APC (Cd201: endothelial protein C receptor), Cd107a-APC (Cd107a: lysosomalassociated membrane protein-1), Cd146-PE (Cd146: melanoma cell adhesion molecule), Sca1-PEVio77 (Sca1: lymphocyte antigen-6, complex, locus-A), Cd104-APC (Cd104: integrin-beta-4), Cd120b-APC (Cd120b: tumor necrosis factor receptor superfamily, member-1b), Cd126-APC (Cd126: interleukin-6 receptor-alpha) und anti-Ifn $\gamma \mathrm{r}-\beta-\mathrm{PE}$ (Ifn $\gamma \mathrm{r}-\beta$ : interferon receptor-gamma, betachain). Zum Ausschluss toter Zellen wurde mit PI gefärbt. Außerdem wurde den Färbungen noch das Labeling Check Reagent (LCR) hinzugefügt, um magnetisch markierte Zellen auszuschließen. Für die eigentliche Färbung wurde nach dem jeweiligen AK-Protokoll gearbeitet. Die Durchflusszytometrie wurde am MACSQuant Analyzer 10 durchgeführt und die erhobenen Daten mit der FlowJo Software Version 10 analysiert. 
Die Tumordissoziation, die durchflusszytometrischen Arbeiten und Analysen der Daten erfolgten in Kollaboration mit Miltenyi Biotec und wurde zusammen mit David Agorku, Miltenyi Biotec durchgeführt.

\subsection{Abbildungen, Grafiken und statistische Methoden}

Die graphischen Darstellungen, Diagramme und statistischen Auswertungen der erhobenen Daten erfolgte mit der GraphPad Prism Software (V8) und der Tabellenkalkulationssoftware Excel. Die Erstellung und Bearbeitung von Abbildungen wurden mit PowerPoint und den Open-Source-Softwaren Inkscape und Fiji (Schindelin et al. 2012) durchgeführt. Soweit nicht explizit eine andere Methode zur Berechnung der statistischen Signifikanz erwähnt ist, wurden die berechneten p-Werte mit dem ungepaarten Welch-t-Test zum Vergleich von zwei Gruppen ermittelt. Dabei wurde ein Wert von $\mathrm{p} \leq 0,05$ als statistisch signifikant und ein Wert von $\mathrm{p} \leq 0,01$ als statistisch hochsignifikant gewertet. 


\section{$5 \quad$ Ergebnisse}

Bei Mammakarzinom-Patientinnen ist normalerweise nicht der Primärtumor selbst die Todesursache, sondern eher die Entstehung eines lokoregionalen oder Fernrezidivs. So gehören zu einer erfolgreichen Therapie u.a. die vollständige Tumorresektion und die Eliminierung aller Tumorzellen durch die Kombination mit einer adjuvanten und/oder neoadjuvanten Strahlen- bzw. Chemotherapie, um das Zurückbleiben von Residualtumorzellen maximal zu minimieren. Da einzelne Tumorzellen Resistenzfähigkeiten erlangen oder besitzen, können diese Tumorzellen Ausgangspunkt für die Bildung eines lokoregionalen oder nach Dissemination in andere Organe für ein Fernrezidiv sein. Ziel der Arbeit war es, neue Erkenntnisse über die Entwicklung von Resistenzen nach Behandlung von H8N8-Mammakarzinomen mit der CAF-Chemotherapie im immunkompetenten syngenen WAP-TMammakarzinom-Mausmodell zu gewinnen. Dazu wurden histochemische und IHC, durchflusszytometrische sowie molekularbiologische Methoden eingesetzt, um CAF therapierte Mammakarzinomzellen angesichts von resistenzvermittelnden Signalwegen und Genexpressionen sowie der Anreicherung von Tumorzellen im remittierten Tumor, welche das Wiederwachsen der Residualtumore ermöglichen, zu charakterisieren.

\subsection{Auswirkung der CAF-Therapie auf das Tumorwachstum}

In diesem Teil der Arbeit wurden die Auswirkungen der CAF-Therapie auf das Tumorwachstum von H8N8-Mammakarzinomen im Mausmodell untersucht. Dazu wurden bei zwei unabhängigen Transplantationen jeweils $1 \times 10^{6}$ Zellen der murinen H8N8-Mammakarzinom-Zelllinie orthotop in die rechte Mamma des vierten Mammapaars von syngenen WAP-T-NP8-Mäusen transplantiert. Transplantierte Tiere wurden in die folgenden Gruppen eingeteilt: unbehandelt, CAF - Remission und CAF - Progression (Abbildung 6).

Unbehandelte Tiere der Transplantation $1(\mathrm{n}=12)$ wurden bei einem ungefährem $\mathrm{V}_{\mathrm{T}}$ von $500 \mathrm{~mm}^{3}$ seziert, die Tiere der Transplantation $2(n=10)$ wurden $a b$ diesem $V_{T}$ noch bis zu sieben Tage weiter beobachtet und spätestens bei einem $\mathrm{V}_{\mathrm{T}}$ von maximal $1000 \mathrm{~mm}^{3}$ seziert. Zu der Gruppe CAF Remission (Transplantation 1: $\mathrm{n}=8$ / Transplantation 2: $\mathrm{n}=3$ ) gehören Tiere, die spätestens sechs 
Tage nach CAF-Applikation seziert wurden. Die Gruppe CAF - Progression (Transplantation 1: $\mathrm{n}=4$ / Transplantation 2: $\mathrm{n}=7$ ) beinhaltet Tiere, die spätestens nach CAF-Therapie und progressiven Wiederwachstum bei einem $V_{\mathrm{T}}$ von maximal ca. $1000 \mathrm{~mm}^{3}$ seziert wurden. In beiden Gruppen, CAF Remission und CAF - Progression, sind Mäuse früher seziert wurden, wenn aufgrund der CAFTherapie ein Gewichtsverlust von maximal $20 \%$ erreicht war.

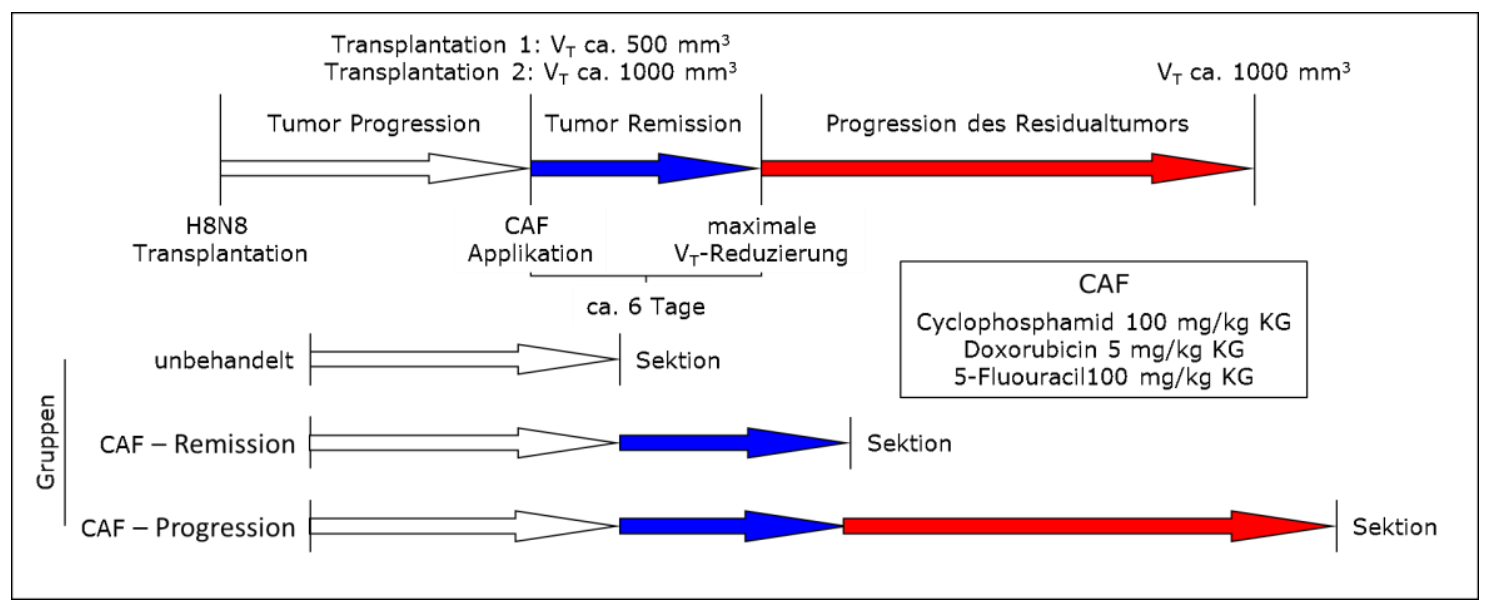

Abbildung 6: CAF-Behandlungsschema von H8N8 tumortragenden Mäusen

Behandlungsschema und Gruppeneinteilung von weiblichen nicht induzierten transgenen heterozygotenWAPT-NP8-Mäusen zur Untersuchung der Wirkung der CAF-Therapie auf das Tumorwachstum der H8N8-Tumore nach orthotoper Transplantation. Die Konzentrationen der CAF-Komponenten sind mit angegeben.

\subsubsection{Temporäre Reduzierung des Tumorvolumens nach CAF-Therapie}

Die Ergebnisse von zwei unabhängigen Transplantationen nach CAF-Therapie sind in Tabelle 24 und Abbildung 7 separiert dargestellt. Zur Beurteilung der Wirkung der CAF-Therapie sind die $\mathrm{V}_{\mathrm{T}}$ sechs und 12 Tage nach der CAF-Applikation der Tabelle 24 zu entnehmen. Die CAF-Therapie war kurze Zeit fähig das $\mathrm{V}_{\mathrm{T}}$ zu reduzieren, bis die CAF therapierten Residualtumorzellen das Wiederwachstum der Tumore initiierten. Das $\mathrm{V}_{\mathrm{T}}$ war sechs Tage nach der CAF-Therapie bei der Transplantation 1 auf 156,6 $\mathrm{mm}^{3}\left( \pm 39,58 \mathrm{~mm}^{3}\right)(\mathrm{MW}[ \pm \mathrm{SD}])$ und bei der Transplantation 2 auf 197,0 $\mathrm{mm}^{3}$ $\left( \pm 75,44 \mathrm{~mm}^{3}\right)$ reduziert. Nach dem die Residualtumore wieder wuchsen, war das $V_{\mathrm{T}} 12$ Tage nach der CAF-Therapie bei der Transplantation 1 noch auf $394,8 \mathrm{~mm}^{3}\left( \pm 163,41 \mathrm{~mm}^{3}\right)$ und bei der Transplantation 2 noch auf $237,1 \mathrm{~mm}^{3}\left( \pm 73,12 \mathrm{~mm}^{3}\right)$ reduziert. 


\section{Tabelle 24: Vergleich verschiedener Parameter der H8N8-Tumore bei Transplantationen 1 und 2}

Die hier mit der Schieblehre gemessenen und berechneten Werte beziehen sich auf das $\mathrm{V}_{\mathrm{T}}$ der Tumore in situ in den noch lebenden Mäusen von zwei unabhängigen Transplantationen. Die statistische Signifikanz (p-Wert) zum Vergleich von zwei Gruppen wurde mit dem ungepaarten Student-t-Test ermittelt.

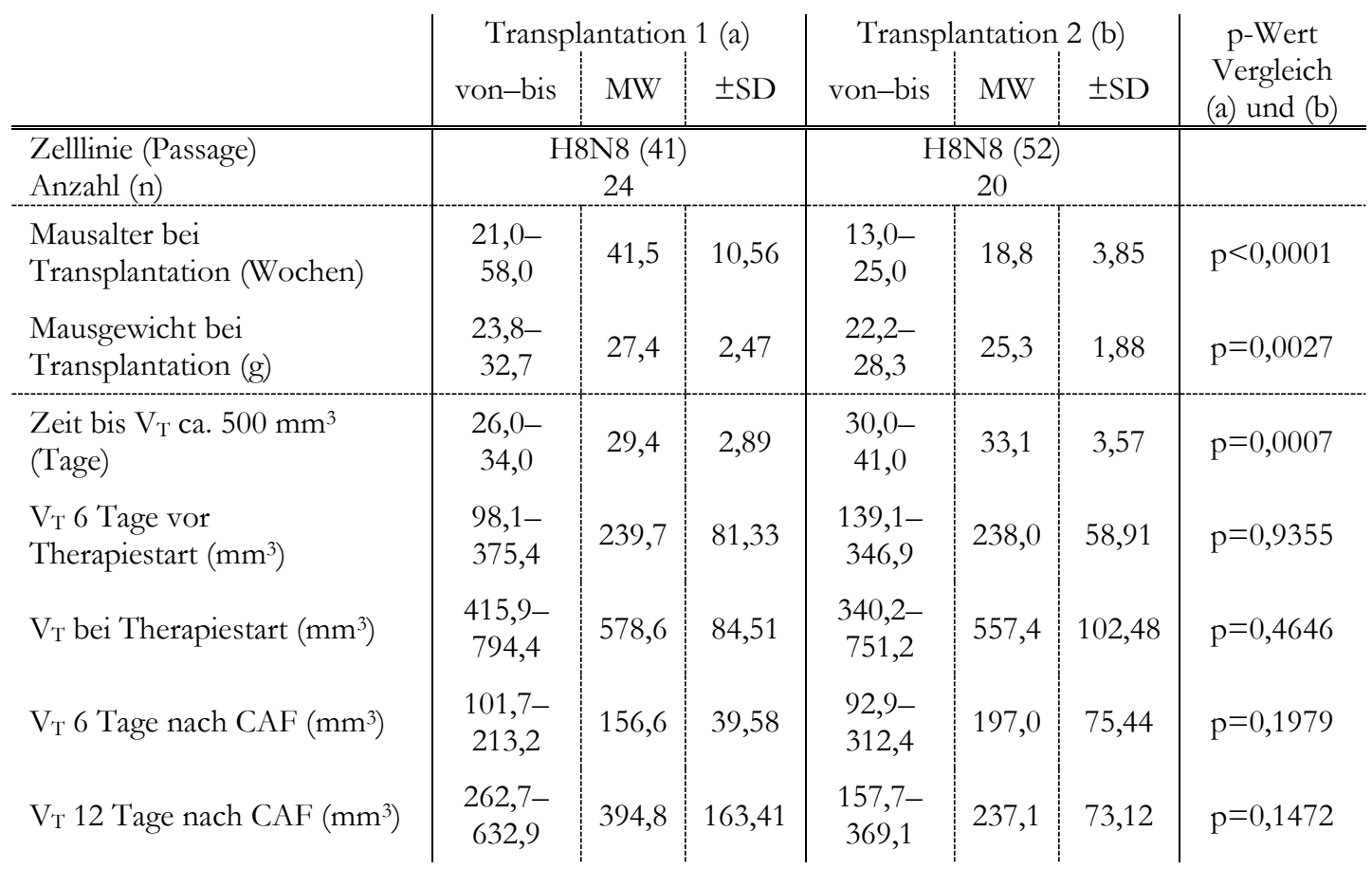

Die Auftragung der berechneten $\mathrm{V}_{\mathrm{T}}$ aus den mit der Schieblehre gemessenen Tumormaßen über die Zeit in Abbildung 7a zeigt, dass die Wachstumskinetiken der H8N8-Tumore in den 44 transplantierten Mäusen bis zum Therapiestart vergleichbar waren und dass die Tumore innerhalb von 14,3 Tagen $( \pm 3,87$ Tage $)$ ein $V_{T}$ von $568,0 \mathrm{~mm}^{3}\left( \pm 92,60 \mathrm{~mm}^{3}\right)$ erreichten. Die 22 mit CAF therapierten Tumore befanden sich nach Therapiestart 6,7 Tage ( $\pm 1,35$ Tage) in Remission und das $V_{T}$ wurde auf $148,7 \mathrm{~mm}^{3}\left( \pm 47,22 \mathrm{~mm}^{3}\right)$ reduziert. An die Remissionsphase schloss sich die Progression der Residualtumore an, die nach 6,5 Tagen ( $\pm 1,86$ Tage) ein $V_{T}$ von 404,6 $\mathrm{mm}^{3}\left( \pm 255,45 \mathrm{~mm}^{3}\right)$ (Abbildung 7a) erreichten.

Zur weiteren Beurteilung der H8N8-Wachstumskinetik wurden die $\mathrm{V}_{\mathrm{T}}$ der jeweiligen Gruppe und Transplantation auf das mittlere $\mathrm{V}_{\mathrm{T}}$ aller Tumore der Transplantation $1\left(578,6 \mathrm{~mm}^{3}\right)$ bzw. Transplantation $2\left(557,4 \mathrm{~mm}^{3}\right)$ bei Therapiestart (Tag 0) normiert, gemittelt und in Abbildung $7 \mathrm{~b}$ gegen die Zeit aufgetragen. Die horizontale gestrichelte Linie beim Wert 1 markiert das mittlere $\mathrm{V}_{\mathrm{T}}$ aller Tumore der Transplantation 1 bzw. Transplantation 2 bei Therapiestart (Abbildung 7b). Die CAF-Therapie reduzierte das $\mathrm{V}_{\mathrm{T}}$ der Gruppe CAF - Remission innerhalb von sechs Tagen nach Applikation temporär durchschnittlich um 72,9 \% ( $\pm 8,40 \%)$. Das $V_{T}$ der Tumore der Gruppe CAF - Progression 
reduzierte sich nach CAF-Applikation um durchschnittlich 73,5 \% ( $\pm 8,50 \%)$ innerhalb von im Mittel 7,5 Tagen ( $\pm 1,37$ Tage). Diese Residualtumore begannen anschließend wieder zu wachsen und erreichten im Mittel 14,1 Tage ( $\pm 1,38$ Tage) nach CAF-Applikation durchschnittlich 71,4 \% ( $\pm 44,3 \%)$ ihres $\mathrm{V}_{\mathrm{T}}$ bei Therapiestart (Abbildung $\left.7 \mathrm{~b}\right)$.

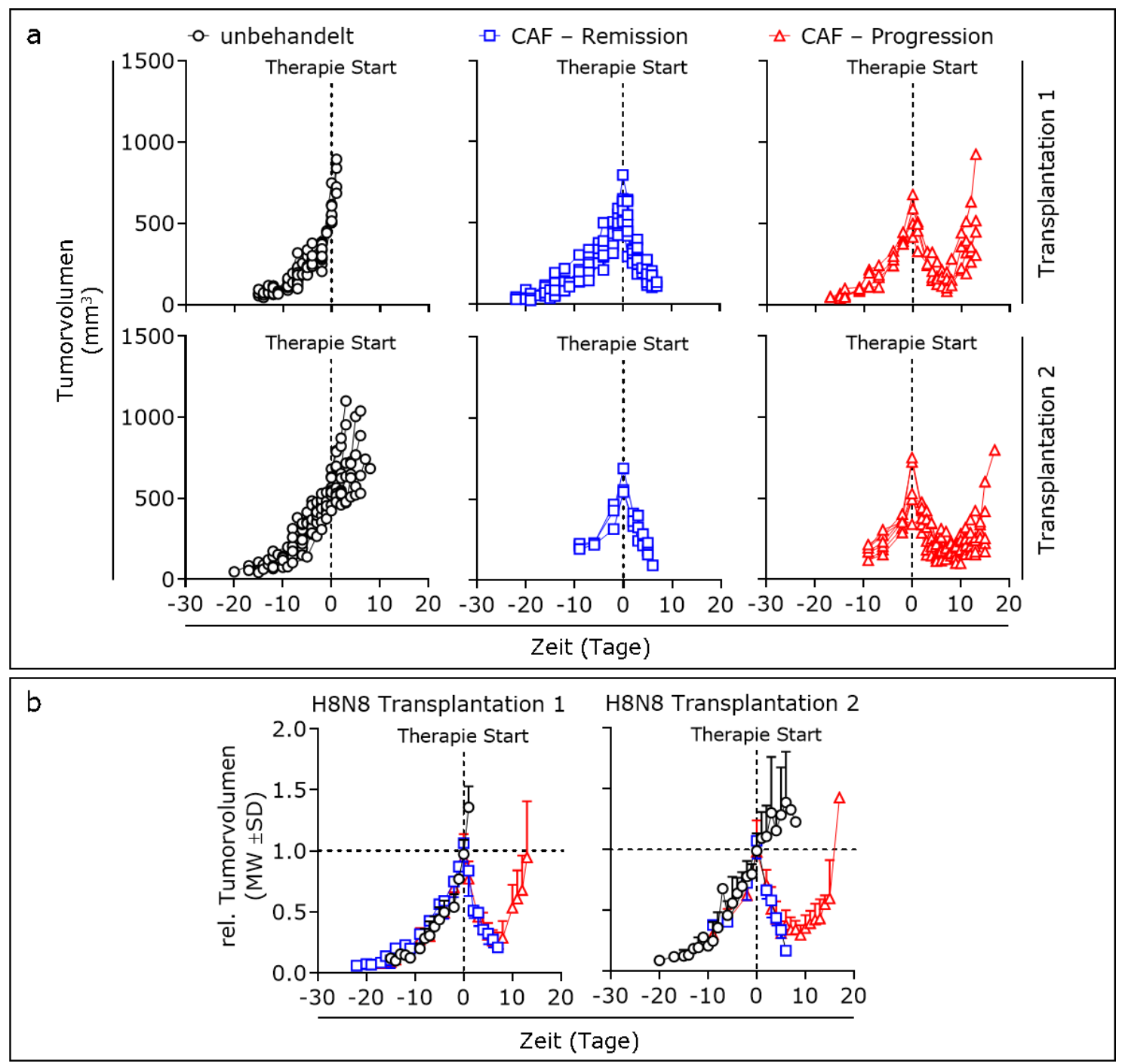

Abbildung 7: H8N8-Wachstumskinetiken von den zwei durchgeführten Transplantationen

Dargestellt sind Wachstumskinetiken unbehandelter Tumore (Transplantation 1: $\mathrm{n}=12$ / Transplantation 2: $\mathrm{n}=10$ ), CAF therapierter Tumore in Remission (Transplantation 1: $\mathrm{n}=8 /$ Transplantation 2: $\mathrm{n}=3$ ) und von therapierten Tumoren in Progression (Transplantation 1: $n=4$ / Transplantation 2: $n=7$ ). Der Tag 0 auf der $x-$ Achse markiert den Zeitpunkt, an dem die Tumore das $\mathrm{V}_{\mathrm{T}}$ von ca. $500 \mathrm{~mm}^{3}$ erreichten und CAF in den entsprechenden Gruppen appliziert wurde. a: Dargestellt sind die absoluten Werte aller Tumore der Transplantation 1 und 2. b: Zusehen sind die mittleren relativen Wachstumskinetiken der zwei Transplantationen. Die $V_{T}$ der Transplantationen wurden auf den MW der $V_{\mathrm{T}}$ aller Tumore der jeweiligen Transplantation bei Therapiestart (Tag 0) normiert (gestrichelte horizontale Linie) und anschließend gemittelt. a und b: Tumore wurden in situ an der noch lebenden Maus vermessen. 


\subsubsection{Einordnung der Wachstumskinetiken nach RECIST-Kriterien}

Durch Anwendung der RECIST-Kriterien (Eisenhauer et al. 2009) wurden die $\mathrm{V}_{\mathrm{T}^{-}}$-Veränderungen aller Tumore über die Zeit analysiert und die Wachstumskinetiken der Tumore nach CAF-Therapie drei Phasen zugeordnet (Abbildung 8).

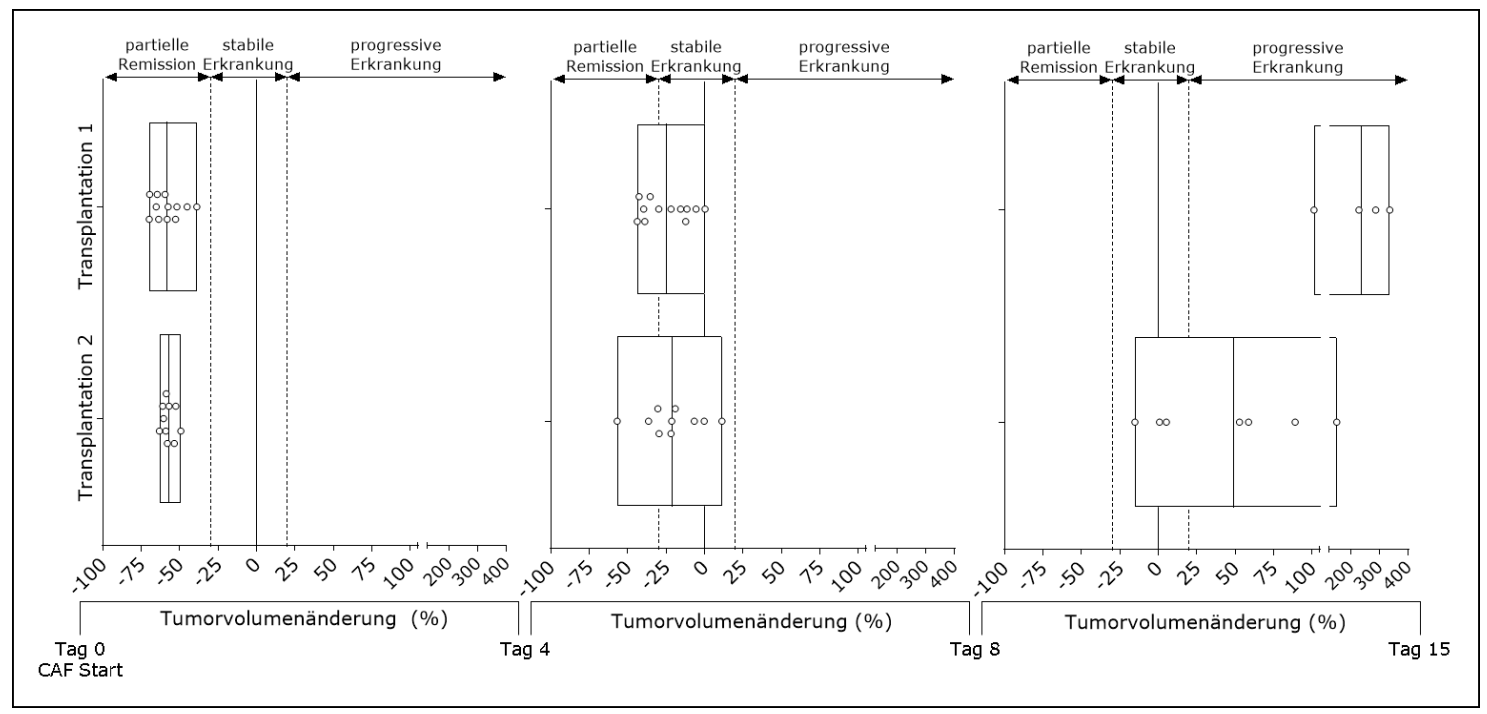

Abbildung 8: Drei Phasen der H8N8-Wachstumskinetik nach CAF-Therapie

Dargestellt sind die einzelnen prozentualen $\mathrm{V}_{\mathrm{T}}$-Veränderungen und die MW beider Transplantationen der CAF therapierten Tumore. Sie wurden nach den RECIST-Kriterien (Eisenhauer et al. 2009) zur Beurteilung von Behandlungserfolgen von soliden Krebserkrankungen, wie in der Klinik angewendet, in die Phasen partielle Remission, stabile Erkrankung und progressive Erkrankung eingeordnet. Aufgetragen sind die Veränderungen der $\mathrm{V}_{\mathrm{T}}$ zwischen Tag null und vier nach CAF-Applikation (Phase der partiellen Remission; Transplantation 1: $\mathrm{n}=12$ / Transplantation 2: $\mathrm{n}=10$ ), zwischen Tag vier und acht nach CAF-Applikation (Phase der stabilen Erkrankung; Transplantation 1: $n=11$ / Transplantation 2: $n=10$ ) und zwischen Tag acht und 15 nach CAFApplikation (Phase der progressiven Erkrankung; Transplantation 1: $\mathrm{n}=4$ / Transplantation 2: $\mathrm{n}=7$ ).

Die erste Phase ist die partielle Remission. Hier reduzierte die CAF-Therapie das $V_{\mathrm{T}}$ im Mittel um mindestens $30 \%$. Während der ersten vier Tage nach CAF-Applikation wiesen die H8N8-Tumore eine $\mathrm{V}_{\mathrm{T}}$-Reduzierung um durchschnittlich $-57,7 \%( \pm 7,46 \%)$ auf, was laut RECIST-Kriterien einer partiellen Remission entspricht (Tabelle 25). Der zweiten Phase wird laut RECIST-Kriterien die stabile Erkrankung zugeordnet. Die Tumore zeigten im Mittel weder progressives Wachstum noch befanden sie sich eindeutig in Remission. Die $\mathrm{V}_{\mathrm{T}^{-}}$Veränderung befand sich im Mittel zwischen -30\% $\mathrm{V}_{\mathrm{T}}$-Reduzierung und $+20 \% \mathrm{~V}_{\mathrm{T}}$-Zunahme. Zwischen dem vierten und achten Tag nach der CAFApplikation wiesen die H8N8-Tumore eine $\mathrm{V}_{\mathrm{T}}$-Reduzierung um durchschnittlich $-23,1 \%$ $( \pm 17,04 \%)$ auf (Tabelle 25). Zur dritten Phase nach der CAF-Applikation gehört die progressive Erkrankung. Während dieser Phase begannen oder zeigten die Residualtumore ein progressives Wiederwachstum im Mittel von mehr als $+20 \%$. Die wieder wachsenden Residualtumore nach CAF 
Therapie wiesen während dieser Zeit eine $\mathrm{V}_{\mathrm{T}}$ Zunahme von durchschnittlich 117,8 \% ( $\left.\pm 119,51 \%\right)$ auf (Tabelle 25).

Tabelle 25: Volumenveränderungen während der partiellen Remission, stabilen Erkrankung und progressiven Erkrankung nach CAF Therapie

Die hier mittels Schieblehre gemessenen und berechneten Werte beziehen sich auf die $\mathrm{V}_{\mathrm{T}}$-Änderungen der Tumore in situ in den noch lebenden Mäusen von zwei unabhängigen Transplantationen nach CAF Therapie. Die statistische Signifikanz (p-Wert) zum Vergleich von zwei Gruppen wurde mit dem ungepaarten Student-tTest ermittelt.

\begin{tabular}{|c|c|c|c|c|c|c|c|}
\hline \multirow[b]{2}{*}{ RECIST-Kriterien } & \multicolumn{3}{|c|}{ Transplantation 1 (a) } & \multicolumn{3}{|c|}{ Transplantation 2 (b) } & \multirow{2}{*}{$\begin{array}{l}\text { p-Wert } \\
\text { Vergleich } \\
\text { (a) und (b) }\end{array}$} \\
\hline & von-bis & MW & $\pm \mathrm{SD}$ & von-bis & MW & $\pm \mathrm{SD}$ & \\
\hline partielle Remission (\%) & $\begin{array}{c}-69,8 \\
\text { bis }-38,8\end{array}$ & $-58,0$ & 9,54 & $\begin{array}{c}-63,2 \\
\text { bis }-49,2\end{array}$ & $-57,2$ & 4,30 & $\mathrm{p}=0,8054$ \\
\hline stabile Erkrankung (\%) & $\begin{array}{c}-43,8 \text { bis } \\
0,3\end{array}$ & $-24,7$ & 15,54 & $\begin{array}{c}-56,9 \text { bis } \\
11,3\end{array}$ & $-21,1$ & 19,35 & $\mathrm{p}=0,6427$ \\
\hline progressive Erkrankung (\%) & $\begin{array}{c}101,2 \text { bis } \\
336,5\end{array}$ & 238,4 & 101,51 & $\begin{array}{c}-15,2 \text { bis } \\
151,4\end{array}$ & 48,9 & 58,53 & $\mathrm{p}=0,0250$ \\
\hline
\end{tabular}

Die Ergebnisse zeigen, dass die Wirkung der CAF-Therapie auf die H8N8-Tumore, trotz unterschiedlicher Zelllinienpassage, Mausalter und -gewichte zum Zeitpunkt der Transplantation sowie Dauer der initialen Tumorprogression bis zum $\mathrm{V}_{\mathrm{T}}$ von ca. $500 \mathrm{~mm}^{3}$, in beiden zu unterschiedlichen Zeitpunkten durchgeführten Transplantationen und Behandlungen vergleichbar waren. Die Wirkung der CAF-Therapie über die Zeit auf die H8N8-Tumore kann wie folgt zusammengefasst werden: Nach 6,7 Tagen ( $\pm 1,35$ Tage) in Remission und einer $V_{T}$-Reduzierung von durchschnittlich 73,2\% $( \pm 8,20 \%)$ waren die tumortragenden Mäuse vier bis acht Tage nach der CAF-Applikation laut den RECIST-Kriterien stabil erkrankt. Daraus entwickelte sich erneut eine progressive Erkrankung, deutlich an wieder wachsenden Residualtumoren, die zwischen Tag acht und 15 nach CAF-Applikation an Volumen zunahmen. Die CAF-Therapie ist also nicht vollständig und nur temporär in der Lage, das $V_{\mathrm{T}}$ von H8N8-Tumoren zu reduzieren. Die RECIST-Kriterien verdeutlichen, dass die Wirkung der CAF-Therapie von Tag eins bis acht auf die H8N8-Tumore in beiden Transplantationen vergleichbar stark war. Die $\mathrm{V}_{\mathrm{T}^{-}}$-Veränderungen, nach begonnenem Wiederwachstum von Tag acht bis 15, zeigen unterschiedliche $\mathrm{V}_{\mathrm{T}}$-Zunahmen beim Vergleich der beiden Transplantationen. Die Unterschiede waren bei der Analyse der aufgetragenen relativen mittleren $V_{T}$ nicht aufgefallen, vermutlich aufgrund der sehr ähnlich verlaufenden Wachstumskinetiken. 


\subsection{Einfluss von CAF auf den Allgemeinzustand der Mäuse}

Die Behandlung mit Chemotherapeutika führt oft zu starken Nebenwirkungen, die bei Patientinnen oft mit einem Verlust an Lebensqualität einhergeht. Um zu ermitteln, welchen Einfluss die CAFTherapie auf den Allgemeinzustand der Mäuse hatte, wurde dieser durch Orientierung an den Body Condition Score (BCS) nach Ullman-Cullere et al. mit einem Punktesystem bewertet (Ullman-Culleré und Foltz 1999), bei dem der Wert eins einem guten und der Wert fünf einem sehr schlechten Allgemeinzustand entspricht. Da die Gewichtsveränderungen der Mäuse wichtige Kriterien zur Bewertung der Nebenwirkungen sind, wurden sie von der Transplantation bis zur Sektion aufgezeichnet.

\subsubsection{CAF therapierte Mäuse zeigen schlechten Allgemeinzustände}

Die Bewertung der Allgemeinzustände der unbehandelten sowie der CAF therapierten Mäuse sind in der Abbildung 9a dargestellt. Die unbehandelten Mäuse wurden während des Tumorwachstums mit einem BCS von 1,7 $( \pm 0,83)$ bewertet, der vergleichbar mit einem BCS einer nicht tumortragenden Maus ist. Dagegen zeigten Mäuse unter CAF-Therapie und mit einem Tumor in Remission einen drastisch schlechteren Allgemeinzustand, deutlich an einem BCS von 4,3 $( \pm 0,65)$. Therapierte Mäuse mit einem Tumor in Progression hatten mit einem BCS von 4,0 $( \pm 0,89)$ eine vergleichbar schlechte körperliche Verfassung.

Die beobachtete Verschlechterung des Allgemeinzustandes nach der CAF-Therapie ging einher mit der Reduzierung der Mausgewichte über die Zeit (Abbildung 9b). Mäuse nach CAF-Therapie, zum Zeitpunkt der Tumorremission wiesen sechs Tage nach CAF-Applikation, am Tag der Sektion, ein Gewichtsverlust von durchschnittlich 24,1 \% ( $\pm 1,56 \%)$ auf. Mäuse die schon vor Tag sechs, also vor dem geplanten Versuchsende, ein Gewichtsverlust von $20 \%$ aufwiesen, wurden getötet und seziert. Mäuse mit Tumoren in Progression nach CAF-Therapie wiesen 14 Tage nach Applikation eine Gewichtsreduktion von durchschnittlich 21,7\% ( $\pm 6,39 \%)$ auf. Mäuse die schon vor dem geplanten Versuchsende der Gruppe CAF - Progression ein Gewichtsverlust von $20 \%$ aufwiesen, wurden getötet und seziert. In dieser Gruppe trat, obwohl das Mausgewicht mit andauernder progressiver Erkrankung nach CAF-Therapie wieder anstieg, von 21,7 \% ( $\pm 6,39 \%)$ am Tag 14 auf 16,0 \% ( $\pm 9,00 \%)$ am Tag 16, auffällig häufig ein Ileus auf, der bei der Sektion nachweisbar war (Daten nicht gezeigt). 
Wegen der Verschlechterung der Allgemeinzustände und schnell fallenden Mausgewichten bei einigen CAF therapierten Tieren, mit einem Gewichtsverlust von mehr als $20 \%$, wurden diese Tiere früher als geplant seziert. So konnte bei diesen Mäusen nicht der ganze Prozess des progressiven Wiederwachstums der Residualtumore nach CAF-Therapie beurteilt werden. Diese Ergebnisse zeigen außerdem, dass die Progression der unbehandelten H8N8-Tumore den Allgemeinzustand nicht sichtbar beeinflussen und dass das Tumorwachstum keine messbare Gewichtsveränderung bei den Mäusen bewirkte.

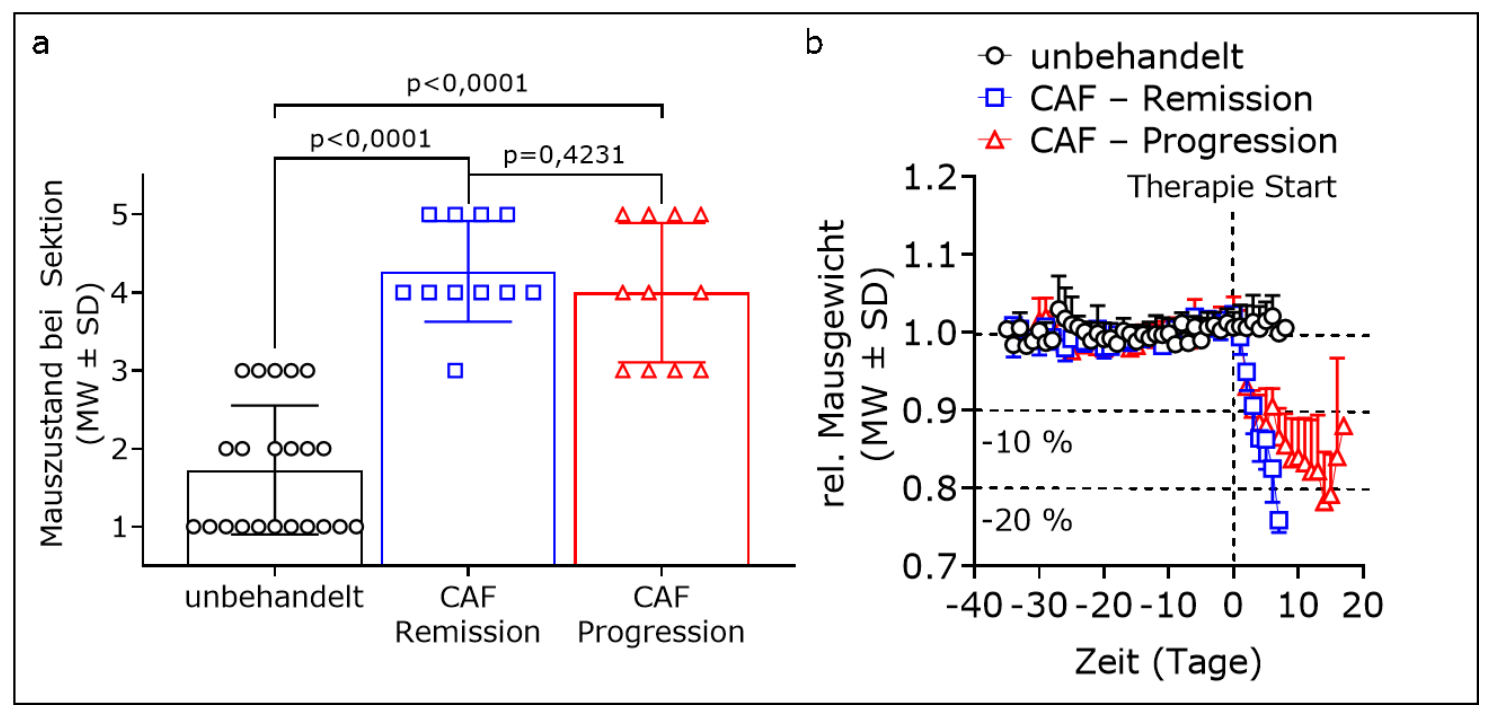

Abbildung 9: Einfluss der CAF-Therapie auf Allgemeinzustand und Mausgewicht

a: Dargestellt sind die Allgemeinzustände der Mäuse mit unbehandelten $(\mathrm{n}=22)$ und CAF therapierten Tumoren (CAF - Remission: $n=11$ und CAF - Progression: $n=11$ ) am Tag der Sektion. Die Mäuse wurden mit dem BCS-Score von 1 (gut) bis 5 (sehr schlecht) bewertet. b: Zusehen sind die mittleren relativen Mausgewichtsveränderungen über die Zeit der in a untersuchten Mäuse. Die Mausgewichte wurden auf den MW der Mausgewichte aller Mäuse bei Therapiestart (Tag 0) normiert (oberste gestrichelte horizontale Linie) und anschließend gemittelt. In dieser Art wurden die mittleren relativen Mausgewichte berechnet. Der Tag 0 markiert den Zeitpunkt der CAF-Applikation und damit den Zeitpunkt eines $V_{\mathrm{T}}$ von ca. $500 \mathrm{~mm}^{3}$. Die Markierungen für $-10 \%$ bzw. $-20 \%$ Gewichtsverlust dienen als Orientierung und zur Bewertung der Allgemeinzustände nach der CAFTherapie.

\subsubsection{Bessere Therapieverträglichkeit bei gleicher Wirksamkeit durch Ver- ringerung der Konzentration von Cyclophosphamid}

Da die CAF-Therapie von den Mäusen, wie in Abbildung 9 dargestellt, schlecht vertragen wurde und es bei einigen Mäusen zu einem Darmverschluss kam, sollte untersucht werden, wie sich eine Verringerung der Konzentration von Cyclophosphamid auf 40 mg/kg KG, bei unveränderter Konzentrationen von Doxorubicin und 5-Fluouracil, auf den Allgemeinzustand auswirkt und welchen Ein- 
fluss dies auf das $\mathrm{V}_{\mathrm{T}}$ hat (Abbildung 11). Cyclophosphamid wurde in einer reduzierten Dosis eingesetzt, weil u.a. Durchfall und Verstopfung als bekannte Nebenwirkungen beschrieben wurden (McQuade et al. 2016; Hayashi et al. 2017). Nach orthotoper Transplantation von 1x106 H8N8-Tumorzellen in WAP-T-NP8-Mäuse, wurden unbehandelte Tiere $(\mathrm{n}=9)$ bei einem $\mathrm{V}_{\mathrm{T}}$ von ca. $500 \mathrm{~mm}^{3}$ seziert. Die Gruppe $\mathrm{C}^{40} \mathrm{AF}(\mathrm{n}=21)$ beinhaltet Tiere, die spätestens bei einem $\mathrm{V}_{\mathrm{T}}$ von ca. $500 \mathrm{~mm}^{3}$ oder aber wegen einem Mausgewichtsverlust, von maximal $20 \%$, nach der C ${ }^{40} \mathrm{AF}-$ Applikation seziert wurden (Abbildung 10).

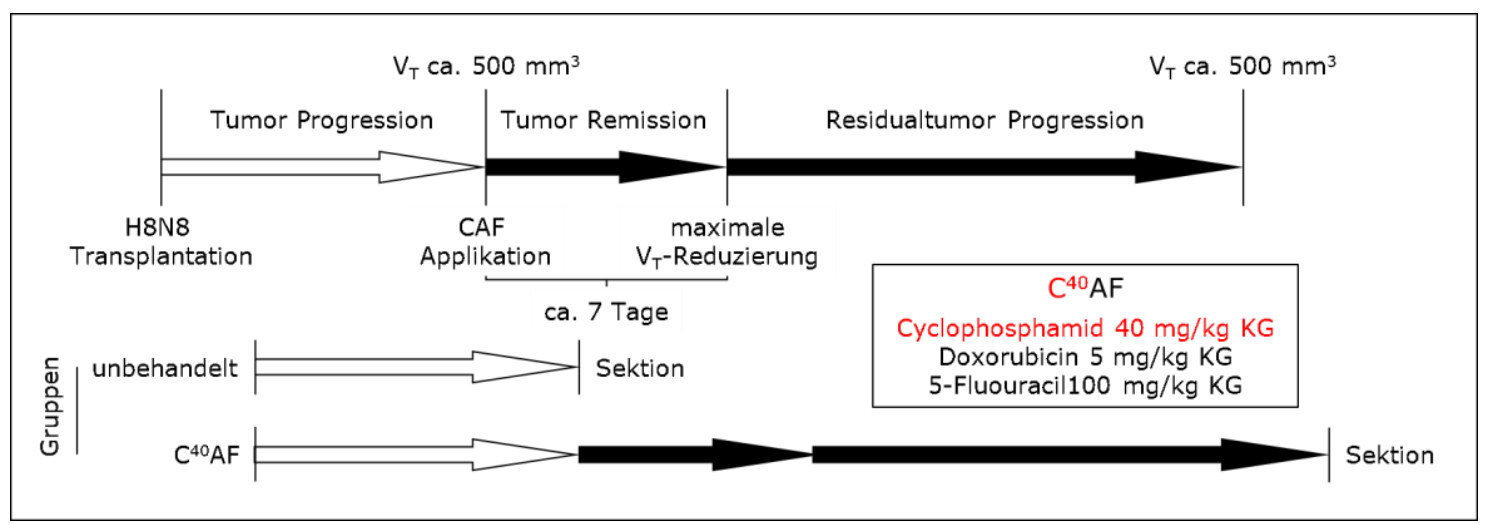

Abbildung 10: C ${ }^{40} \mathrm{AF}-$ bzw. CAF-Behandlungsschema von H8N8 tumortragenden Mäusen

Behandlungsschema und Gruppeneinteilung der weiblichen nicht induzierten transgenen heterozygotenWAPT-NP8-Mäuse zur Untersuchung der Therapieverträglichkeit der $\mathrm{C}^{40} \mathrm{AF}-\mathrm{Chemotherapie} \mathrm{und} \mathrm{Auswirkungen}$ auf das Wachstum der H8N8-Tumore nach orthotoper Transplantation im Vergleich zur CAF-Therapie. Die Konzentrationen der $\mathrm{C}^{40} \mathrm{AF}-$ Komponenten sind mit angegeben.

Der Vergleich der relativen Mausgewichte über die Zeit zeigt, dass die C ${ }^{40}$ AF-Therapie sehr viel besser von den Mäusen vertragen wurde. Die Mausgewichte der $\mathrm{C}^{40} \mathrm{AF}$ therapierten Mäuse waren im Vergleich zu denen der unbehandelten Mäuse nach der $\mathrm{C}^{40} \mathrm{AF}$-Applikation nur kurze Zeit und nur um ca. $10 \%$ reduziert (Abbildung 11a). Zur Bewertung der Wirkung von $\mathrm{C}^{40} \mathrm{AF}$ auf das Wachstum wurden die relativen $\mathrm{V}_{\mathrm{T}}$ der $\mathrm{CAF}$ und der $\mathrm{C}^{40} \mathrm{AF}$ therapierten Tumore miteinander verglichen (Abbildung 11b). Die Wirkung der $\mathrm{C}^{40} \mathrm{AF}$ - und CAF-Therapie auf das $\mathrm{V}_{\mathrm{T}}$ ist identisch und wird deutlich an den vergleichbaren Wachstumskinetiken in den unterschiedlichen Gruppen. Bei gleicher Wirksamkeit verloren die $\mathrm{C}^{40} \mathrm{AF}$ therapierten Mäuse weniger Gewicht (Abbildung 11c) und entwickelten keine erkennbaren Illeen (Daten nicht gezeigt), verglichen mit den Mäusen die nach dem CAF-Protokoll behandelt wurden. 


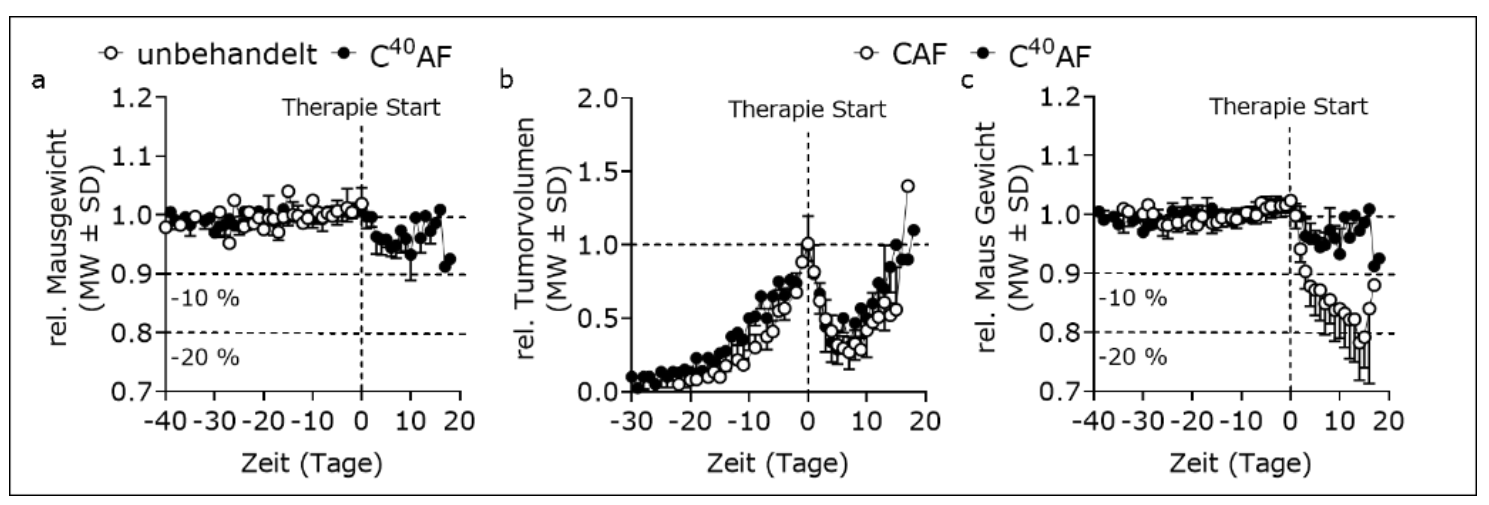

Abbildung 11: Verträglichkeit und Wirkung der CAF-Therapie im Vergleich zu dem C40AF-Behandlungsprotokoll

a: Zusehen sind die mittleren relativen Mausgewichtsveränderungen über die Zeit von unbehandelten $(n=9)$ und $\mathrm{C}^{40} \mathrm{AF}$ therapierten Tumoren $(\mathrm{n}=21)$. b: Dargestellt sind die mittleren relativen Wachstumskinetiken von CAF $(n=22)$ und $C^{40} A F$ therapierten Tumoren $(n=21)$. Die mittleren relativen $V_{T}$ wurden auf den MW der $V_{T}$ aller Tumore bei Therapiestart (Tag 0) normiert (gestrichelte horizontale Linie). Die Tumore wurden in situ und in lebenden Mäusen vermessen. c: Zusehen sind die mittleren relativen Mausgewichtsveränderungen über die Zeit von CAF $(n=22)$ und $C^{40} A F$ therapierten Tumoren $(n=21)$. a und $\mathbf{c}$ : Die mittleren relativen Mausgewichte wurden auf den MW der Mausgewichte aller Mäuse bei Therapiestart (Tag 0) normiert (oberste gestrichelte horizontale Linie). Der Tag 0 markiert den Zeitpunkt der CAF-Applikation und damit den Zeitpunkt eines $V_{\mathrm{T}}$ von ca. $500 \mathrm{~mm}^{3}$. Die Markierungen für -10\% bzw. -20\% Gewichtsverlust dienen als Orientierung und zur Bewertung der Allgemeinzustände nach CAF- bzw. C ${ }^{40} \mathrm{AF}-$ Therapie.

\subsection{Auswirkungen der CAF-Therapie auf den Tumorphänotyp}

Wie die Ergebnisse in Abschnitt 5.1.1 zeigen, bewirkt die CAF-Therapie nur eine temporäre Reduzierung der $\mathrm{V}_{\mathrm{T}}$. Es ist bekannt, dass einige Patientinnen mit Mammakarzinomen von vornherein nicht auf die verwendete Chemotherapie ansprechen, man spricht von de novo Therapieresistenz und andere Mammakarzinome im Verlauf der Therapie Resistenzen entwickeln und der Tumor das Wiederwachstum initiiert (erworbene Resistenz). Beide Formen der Resistenz sind mit einer schlechten Prognose, einer aggressiveren Tumorprogression und einer erschwerten Behandlung assoziiert (Ahmad 2013). Im nächsten Abschnitt wurde i) mittels durchflusszytometrischen Analysen geklärt, wie sich die Zusammensetzung der Tumore nach CAF-Therapie von unbehandelten Tumoren unterscheidet, ii) mittels histochemischen und IHC-Färbungen untersucht, wie sich Tumormorphologie und Proteinsynthese unter der CAF-Therapie veränderten und iii) mit Hilfe der mRNA-Sequenzierung analysiert, welche molekularbiologischen genregulatorischen Prozesse durch die CAF-Therapie initiiert werden. In Abbildung 12 sind repräsentative makroskopische Aufnahmen der unbehandelten und CAF therapierten Tumore dargestellt. Tumore aller Gruppen waren im gleichen Maß mit Blutgefäßen versorgt (schwarze Pfeile) und physiologisches Mammagewebe ist in der näheren Umgebung erkennbar (schwarze Pfeilspitzen) (Abbildung 12a-c). 


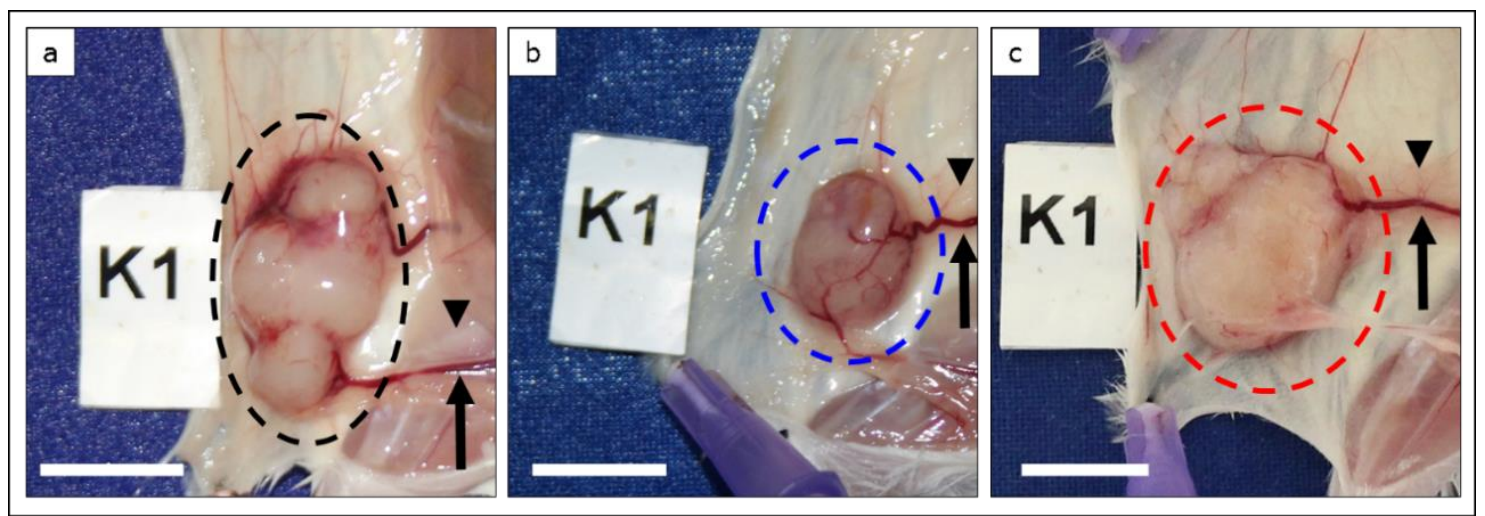

Abbildung 12: Makroskopische Darstellung repräsentativer H8N8-Tumore der einzelnen Gruppen

Abgebildet sind zu unterschiedlichen Zeitpunkten sezierte Mammakarzinome post mortem, nach orthotoper Transplantation von $1 \times 10^{6}$ H8N8-Zellen in WAP-T-NP8-Mäuse. a: Unbehandelter Tumor 28 Tage nach Transplantation mit einem $\mathrm{V}_{\mathrm{T}}$ von $700,6 \mathrm{~mm}^{3}$. b: CAF-behandelter Tumor in Remission 40 Tage nach Transplantation und 6 Tag nach CAF-Applikation mit einem $\mathrm{V}_{\mathrm{T}}$ von $168,7 \mathrm{~mm}^{3}$. c: Progressiv wachsender Tumor nach CAF-Therapie und Wiederwachstum 42 Tage nach Transplantation und 13 Tage nach CAF-Applikation mit einem $\mathrm{V}_{\mathrm{T}}$ von $656,6 \mathrm{~mm}^{3}$. In a-c deutet jeweils der schwarze Pfeil auf Blutgefäße und die schwarze Pfeilspitze auf physiologisches Mammagewebe. Der Balken entspricht $1 \mathrm{~cm}$. $\mathrm{V}_{\mathrm{T}}$ : Tumorvolumen nach der Sektion und Tumor ex vivo.

\subsubsection{Veränderte Zusammensetzung und Histopathologie von Tumoren nach CAF-Therapie}

Durch Kombination mehrerer AK gegen zelltypspezifische Antigene sowie durch verschiedene $G a-$ ting-Strategien wurde die Anzahl von Epithelzellen, Endothelzellen, tumorinfiltrierenden Leukozyten (TIL), Fibroblasten und Erythrozyten in den Tumoren mittels FACS-Analysen quantitativ bestimmt, um so den Einfluss der CAF-Therapie auf die Zusammensetzung der Zellen in den H8N8Tumoren zu untersuchen (Abbildung 13a). Aus jeder Gruppe wurde Gewebe von vier Tumoren dissoziiert (Tabelle 26), die daraus isolierten Zellen mit den Fluorochrom-konjugierten Antikörpern Epcam-PE, Cd31-PE-Vio770, Cd90.2-APC, Ter119-FITC und Cd45-VioBlue gefärbt und anschlieBend, ohne vorangehende Anreicherung eines bestimmten Zelltyps, durchflusszytometrisch mittels FACS analysiert (Abbildung 13). 
Tabelle 26: Angaben zu CAF-Applikation und $\mathrm{V}_{\mathrm{T}}$ (ex vivo) der mittels FACS analysierten Tumore

\begin{tabular}{|c|c|c|c|c|}
\hline Gruppe & Tumor & $\begin{array}{c}\text { Tage nach } \\
\text { Transplantation }\end{array}$ & $\begin{array}{c}\text { Tage nach } \\
\text { CAF-Applikation }\end{array}$ & $\begin{array}{c}\mathrm{V}_{\mathrm{T}}-\text { Tumor } \\
\text { ex vivo }\left(\mathrm{mm}^{3}\right) \\
\end{array}$ \\
\hline \multirow{4}{*}{ unbehandelt } & 6163 & 28 & & 671,3 \\
\hline & 6164 & 28 & & 700,6 \\
\hline & 6165 & 28 & & 758,3 \\
\hline & 6166 & 28 & & 863,5 \\
\hline \multirow{4}{*}{$\begin{array}{c}\text { CAF } \\
\text { Remission }\end{array}$} & 6171 & 40 & 6 & 139,7 \\
\hline & 6172 & 40 & 6 & 196,3 \\
\hline & 6173 & 40 & 6 & 198,0 \\
\hline & 6174 & 40 & 6 & 148,5 \\
\hline \multirow{4}{*}{$\begin{array}{c}\text { CAF } \\
\text { Progression }\end{array}$} & 6228 & 42 & 13 & 275,4 \\
\hline & 6229 & 42 & 13 & 656,6 \\
\hline & 6230 & 42 & 13 & 400,0 \\
\hline & 6231 & 42 & 13 & 506,5 \\
\hline
\end{tabular}

Die FACS-Messungen zeigen (Abbildung 13b), dass sich unbehandelte Tumore aus den folgenden Zellen zu verschiedenen prozentualen Anteilen zusammensetzten: 43,7 \% ( $\pm 2,78 \%)$ Epcam ${ }^{+} \mathrm{Cd} 45-$ Epithelzellen; 1,2\% ( $\pm 0,43 \%) \quad \mathrm{Cd} 31{ }^{+} \mathrm{Cd} 45$-Endothelzellen $29,5 \%( \pm 2,27 \%) \quad \mathrm{Cd} 45{ }^{+} \mathrm{Cd} 31$-TIL; 0,7\% ( $\pm 0,09 \%) \quad C d 90.2^{+} \mathrm{Cd} 45$-Fibroblasten und 4,1\% ( $\left.\pm 1,62 \%\right)$ Ter119+Cd45-Erythrozyten. Nach CAF-Therapie bei Tumoren in Remission reduzierte sich vor allem der Anteil vitaler Epcam ${ }^{+} \mathrm{Cd} 45-$-Epithelzellen auf 13,3\% ( $\left.\pm 3,38 \%\right)$. Im Verlauf der CAF-Therapie bei Wiederwachstum der Tumore, der Gruppe CAF - Progression, stieg der Anteil vitaler Epcam ${ }^{+} \mathrm{Cd} 45$-Epithelzellen auf 24,7\% ( $\pm 1,60 \%$ ). In Tumoren der Gruppe CAF - Remission waren die Cd45+Cd31-TIL mit $15,8 \%( \pm 1,89 \%)$ signifikant weniger, verglichen mit einem Anteil von 40,2\% $( \pm 3,75 \%)$ in den Tumore der Gruppe CAF - Progression. 


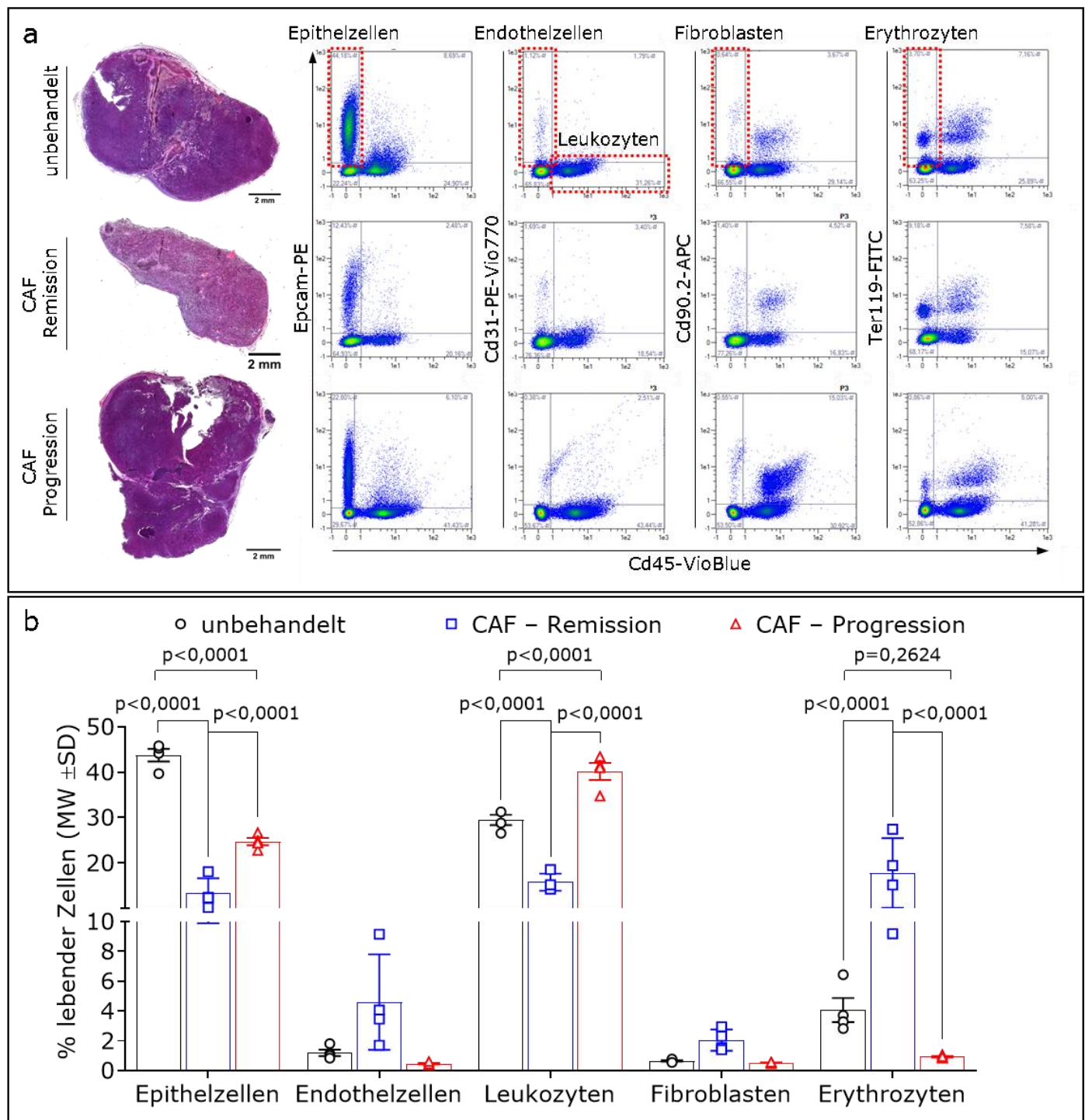

Abbildung 13: Zusammensetzung der H8N8-Tumore aus unterschiedlichen Zellpopulationen

a: Abgebildet sind durchflusszytometrisch analysierte repäsentative Tumore folgender Gruppen: ein unbehandelter Tumor 34 Tage nach Transplantation mit einem $V_{T}=810,7 \mathrm{~mm}^{3}$, ein Tumor in Remission 34 Tage nach Transplantation und fünf Tage nach CAF-Applikation mit einem $\mathrm{V}_{\mathrm{T}}=251,0 \mathrm{~mm}^{3}$ sowie ein Tumore in Progression 46 Tage nach Transplantation und 17 Tage nach CAF-Applikation mit einem $\mathrm{V}_{\mathrm{T}}=806,8 \mathrm{~mm}^{3}$. Weiter sind FACS-Färbungen dissoziierter Einzel-Zellsuspensionen mit Epcam-PE, Cd31-PE-Vio770, Cd90.2-APC, Ter119-FITC und Cd45-VioBlue AK dargestellt. b: Zusehen sind die Anteile verschiedener vitaler Zelltypen in den Einzel-Zellsuspensionen der untersuchten Gruppen (je n=4). Vorher wurden Zelldebris und PI-gefärbte tote Zellen aus der Gesamtpopulation eliminiert. Die rot gepunkteten Kästen in a markieren die Populationen, welche in $\mathbf{b}$ den aufgetragenen Zelltypen entsprechen: Epithelzellen: Epcam ${ }^{+} \mathrm{Cd} 45^{-}, \mathrm{En}^{-}$ dothelzellen: $\mathrm{Cd} 31^{+} \mathrm{Cd} 45^{-}$, Leukozyten: $\mathrm{Cd} 31-\mathrm{Cd} 45^{+}$, Fibroblasten: $\mathrm{Cd} 90.2^{+} \mathrm{Cd} 45^{-}$und Erythrozyten: Ter119+Cd45- a: Mosaikaufnahme 50x Vergrößerung, Balken $2 \mathrm{~mm}$. $\mathrm{V}_{\mathrm{T}}$ : Tumorvolumen nach der Sektion und Tumor ex vivo. Tumordissoziation und anschließende FACS-Analysen wurden zusammen mit D. Agorku (Miltenyi Biotec $\mathrm{GmbH}$, Bergisch Gladbach) durchgeführt.

Um die Wirkung der CAF-Therapie auf die Morphologie zu analysieren, wurden Paraffinschnitte der sezierten Tumore aus den verschiedenen Gruppen mit chemischen Färbemethoden (HE und MTS) gefärbt und mikroskopisch begutachtet. Da unbehandelte Tumore unterschiedlich differenzierte Gewebeanteile aufwiesen, wurden eher differenzierte Randbereiche, mit teilweise nodulär angeordneten Tumorzellen (Pfeil in Abbildung 14) und undifferenzierte Bereiche im Tumorzentrum (Abbildung 
15) getrennt voneinander betrachtet. Weiter wurden die Ergebnisse der FACS-Analysen, die zeigen, dass CAF die Zusammensetzung der Tumore verändert, durch IHC-Färbungen mit AK gegen das H8N8-Tumorzellen-markierende T-Ag, den Proliferationsmarker Pcna (proliferating cell nuclear antigen) und den TIL-Marker Cd45 untersucht.

Die chemischen und IHC-Färbungen zeigen (Abbildung 14 und Abbildung 15), dass in Tumoren in Remission viele verschiedene Zelltypen zu finden sind und Tumore der Gruppe CAF - Progression wie auch unbehandelte Tumore vorwiegend aus H8N8-Tumorzellen bestehen. Dies wird auch deutlich an der positiven Färbung der Tumorzellen nach Inkubation der Tumorschnitte mit dem H8N8spezifischen T-Ag-AK. Dieser markiert spezifisch das T-Ag im Zellkern von H8N8-Tumorzellen auf Proteinebene, wenn das SV40-Transgen exprimiert wird. Mit abnehmender Differenzierung der Tumore wurde mittels T-Ag-Färbung gezeigt, dass die SV40-Transgenexpression inaktiviert wird, zusehen an den vermehrt ungefärbten Tumorzellen in undifferenzierten Bereichen (Abbildung 15) und den überwiegend T-Ag-positiven Kernfärbungen der H8N8-Tumorzellen in Bereichen mit vorhandener Differenzierung (Abbildung 14). Zudem waren die Zellkerne der H8N8-Tumorzellen in den unbehandelten Tumoren intensiv für den Proliferationsmarker Pcna positiv, was ein Hinweis auf eine intakte DNA-Synthese und aktive Zellteilung ist (Abbildung 14 und Abbildung 15). In CAF therapierten Tumoren in Remission waren zwar weniger Tumorzellen in den remittierten Tumoren vorhanden und wiesen oft einen vergrößerten Nukleus auf, verglichen mit den Nuklei von unbehandelten und Residualtumorzellen nach Wiederwachstum (Abbildung 14und Abbildung 15). In Remission setzten sich die CAF therapierten Tumore aus verschiedenen, nicht mit dem T-Ag-AK gefärbten Zellen zusammen, die annähernd alle eine aktive DNA-Synthese und aktive Zellteilung aufwiesen, deutlich an der positiven Pcna-Kernfärbung (Abbildung 14 und Abbildung 15). Dagegen bestanden Tumore der Gruppe CAF - Progression nach CAF-Therapie vorwiegend aus mit dem T-Ag-AK markierten Tumorzellen, welche eine intensive Pcna-Färbung aufwiesen. Diese Tumore besaßen über den ganzen histologischen Schnitt verteilt größere Bereiche mit differenzierten, nodulär angeordneten Tumorzellen (Pfeile in Abbildung 14). In den Zwischenräumen der nodulär angeordneten Tumorzellen fanden sich Zellen, die überwiegend T-Ag negativ und nur vereinzelt im Zellkern Pcna positiv waren (Abbildung 14). Undifferenzierte Bereiche der wieder gewachsenen Tumore aus der Gruppe CAF - Progression waren häufig von T-Ag-negativen kleinkernigen Zellen mit einer hohen 
Syntheseaktivität infiltriert, zu sehen an der positiven Pcna-Kernfärbung (Abbildung 15). Um zu prüfen, ob i) diese kleinkernigen Zellen im Tumor TIL sind, ii) wie stark H8N8-Tumore von TIL infiltriert werden und ii) ob die CAF-Therapie eine Veränderung der TIL-Anteile in den Tumoren verursacht, wurden die Tumorschnitte mittels IHC auf den Cd45-AK hin untersucht. Unbehandelte Tumore waren nicht von TIL infiltriert, deutlich an ungefärbten Zellen im Tumorzentrum nach Färbung mit dem Cd45-AK. Vereinzelt konnten Cd45-positive Zellen in der Tumorperipherie und in Randbereichen der Tumorschnitte außerhalb des Tumors lokalisiert werden. In den remittierten Tumoren der Gruppe CAF - Remission zeigten sich vermehrt Cd45 positiv gefärbte Zellen. Obwohl Tumore nach Wiederwachstum (Gruppe CAF - Progression) sehr viele identische runde kleinkernige Zellen aufwiesen, war nur ein kleiner Teil dieser Zellen Cd45 positiv gefärbt (Abbildung 14 und Abbildung 15).

Mit dem MTS-Färbeprotokoll wurden in den Tumorschnitten Kollagene der EZM blau gefärbt. Vorwiegend in differenzierten Randbereichen der unbehandelten Tumore fanden sich Areale, die durch die MTS-Färbung blau gefärbtes Kollagen anzeigten(Abbildung 14), wohingegen in undifferenzierten Bereichen des Tumorzentrums kaum Färbungen zu beobachten waren (Abbildung 15). Dieses Färbeergebnis war vergleichbar mit den Tumoren der Gruppe CAF - Progression, mit Ausnahme der differenzierten Bereiche wo Tumorzellen noduläre Strukturen bildeten, die gering blau angefärbt waren und auf eine leichte Kollagenablagerung hindeutet. Tumore in Remission wiesen einen größeren Anteil an blau gefärbtem faserigem Kollagen auf (Pfeile in Abbildung 14).

Die Quantifizierung (Abschnitt 4.3.5.1) von Kollagenanteilen der mittels MTS-gefärbten Tumorschnitten (Abbildung 14 und Abbildung 15) erfolgte durch bildanalytische Methoden in ImageJ (Abbildung 16a). Die repräsentativen Tumore (Abbildung 16b) und der dazugehörige prozentuale Kollagenanteil entspricht ungefähr dem MW der jeweiligen Gruppe, welche im Diagramm in Abbildung 16c veranschaulicht sind. H8N8-Tumore in Remission, nach einer CAF-Therapie, bilden vermutlich vermehrt Kollagen, da unbehandelte Tumore vor der CAF-Therapie mit 0,6 \% ( $\pm 0,30 \%)$ fast keinen Kollagenanteil aufwiesen, die Tumore der Gruppe CAF - Remission aber ein Anteil von durchschnittlich 5,0\% ( $\pm 3,78 \%$ ). Die Anteilszunahme in der Gruppe CAF - Remission betrug im Vergleich zu unbehandelten Tumoren einer Vermehrung um das 8,3-fache. Der Kollagenanteil der 
Gruppe CAF - Progression war im Vergleich zu den Tumoren der Gruppe CAF - Remission signi-

fikant verringert und verglichen mit unbehandelten Tumoren nicht signifikant, um nur 0,7 \% erhöht.

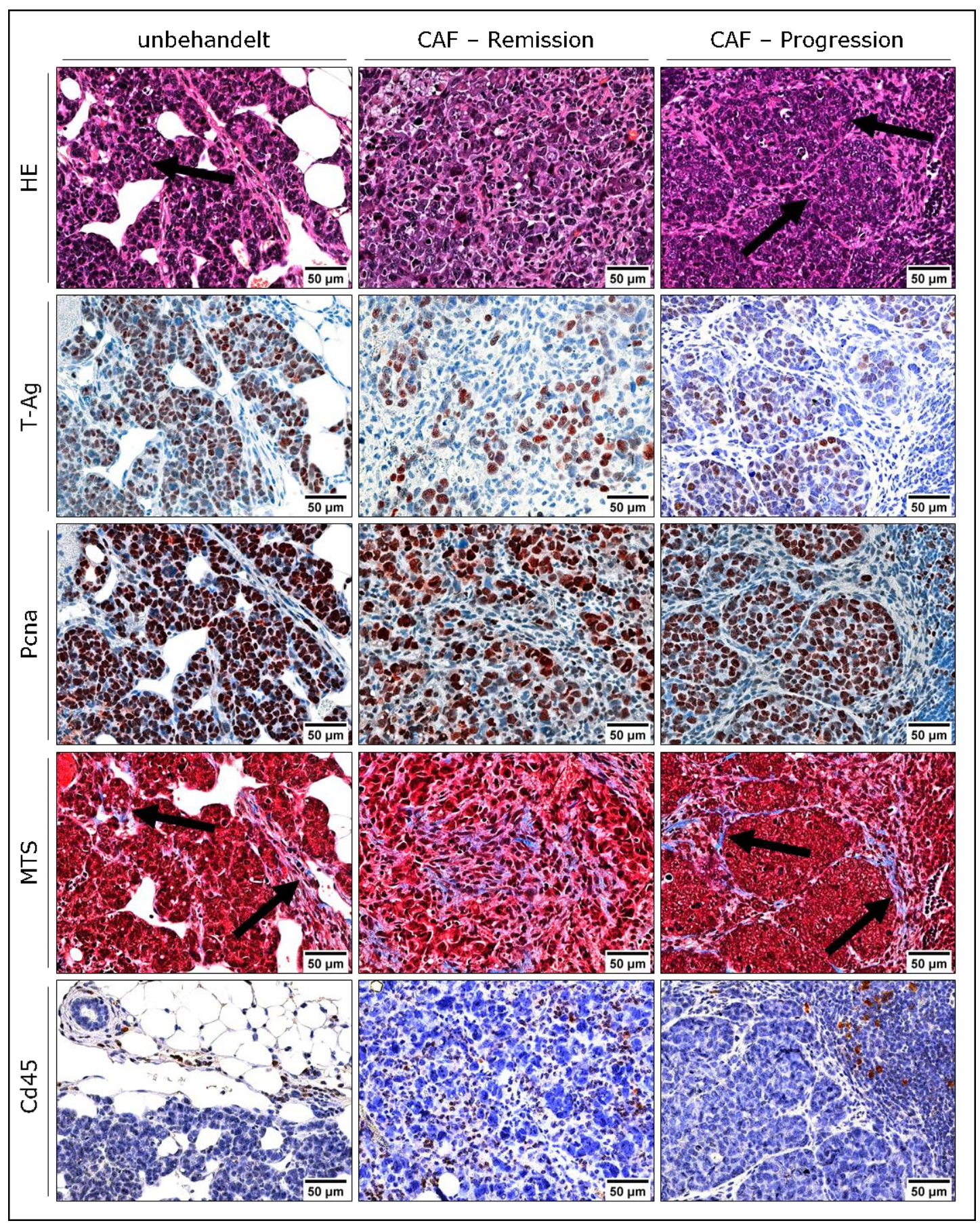

Abbildung 14: Darstellung der Zellzusammensetzung von Tumoren nach CAF-Therapie mittels chemischen und IHC-Färbemethoden in differenzierten Bereichen der Tumore

Dargestellt sind repräsentative histologische (HE und MTS) und IHC-Färbungen (AK gegen T-Ag, Pcna und $\mathrm{Cd} 45)$ in differenzierten Bereichen von Paraffinschnitten eines unbehandelten Tumors $\left(\mathrm{V}_{\mathrm{T}}=810,7 \mathrm{~mm}^{3} ; 34\right.$ Tage nach Transplantation), eines Tumors in Remission nach CAF-Therapie $\left(\mathrm{V}_{\mathrm{T}}=251,0 \mathrm{~mm}^{3}\right.$; 34 Tage nach Transplantation und fünf Tage nach CAF-Applikation) und eines Tumors in Progression nach CAF-Therapie $\left(\mathrm{V}_{\mathrm{T}}=806,8 \mathrm{~mm}^{3}\right.$; 46 Tage nach Transplantation und 17 Tage nach CAF-Applikation). Die Pfeile in den HEFärbungen markieren die nodulär angeordneten Tumorzellen und die Pfeile in den MTS-Färbungen markieren Kollagenablagerungen in der angrenzenden EZM. Die mikroskopischen Bilder der Färbungen je Gruppe gehören jeweils zum selben Tumor. Detailaufnahme 400x Vergrößerung, Balken $50 \mu \mathrm{m}$. $\mathrm{V}_{\mathrm{T}}$ : Tumorvolumen nach der Sektion und Tumor ex vivo. 


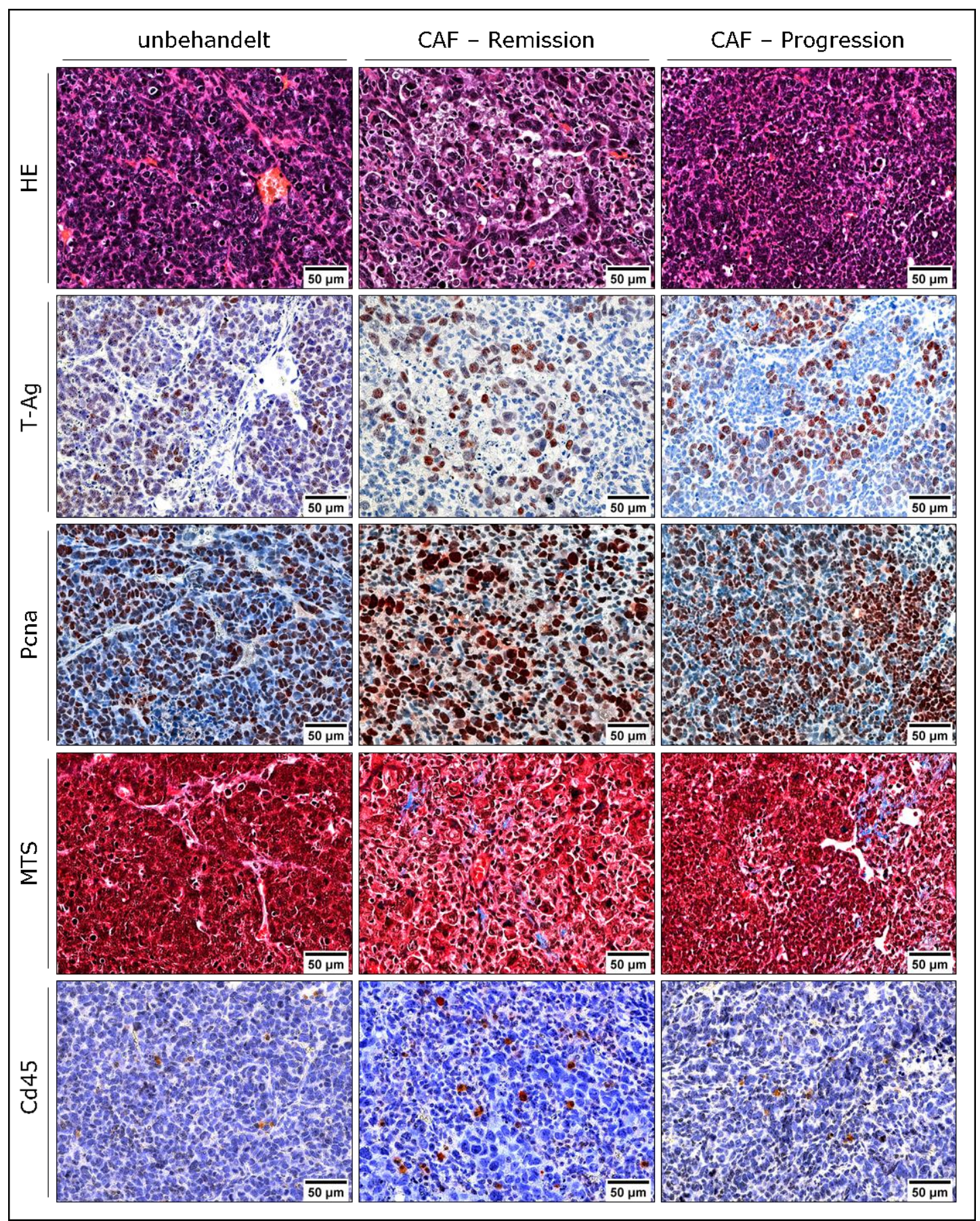

Abbildung 15: Darstellung der Zellzusammensetzung von Tumoren nach CAF-Therapie mittels chemischen und IHC-Färbemethoden in undifferenzierten Bereichen der Tumore

Dargestellt sind repräsentative histologische (HE und MTS) und IHC-Färbungen(AK gegen T-Ag, Pcna und Cd45) in undifferenzierten Bereichen von Paraffinschnitten eines unbehandelten Tumors $\left(V_{T}=810,7 \mathrm{~mm}^{3} ; 34\right.$ Tage nach Transplantation), eines Tumors in Remission nach CAF-Therapie $\left(V_{T}=251,0 \mathrm{~mm}^{3} ; 34\right.$ Tage nach Transplantation und fünf Tage nach CAF-Applikation) und eines Tumors in Progression nach CAF-Therapie $\left(V_{\mathrm{T}}=806,8 \mathrm{~mm}^{3} ; 46\right.$ Tage nach Transplantation und 17 Tage nach CAF-Applikation). Die mikroskopischen Bilder der Färbungen je Gruppe gehören jeweils zum selben Tumor. Detailaufnahme 400x Vergrößerung, Balken $50 \mu \mathrm{m} . \mathrm{V}_{\mathrm{T}}$ : Tumorvolumen nach der Sektion und Tumor ex vivo. 


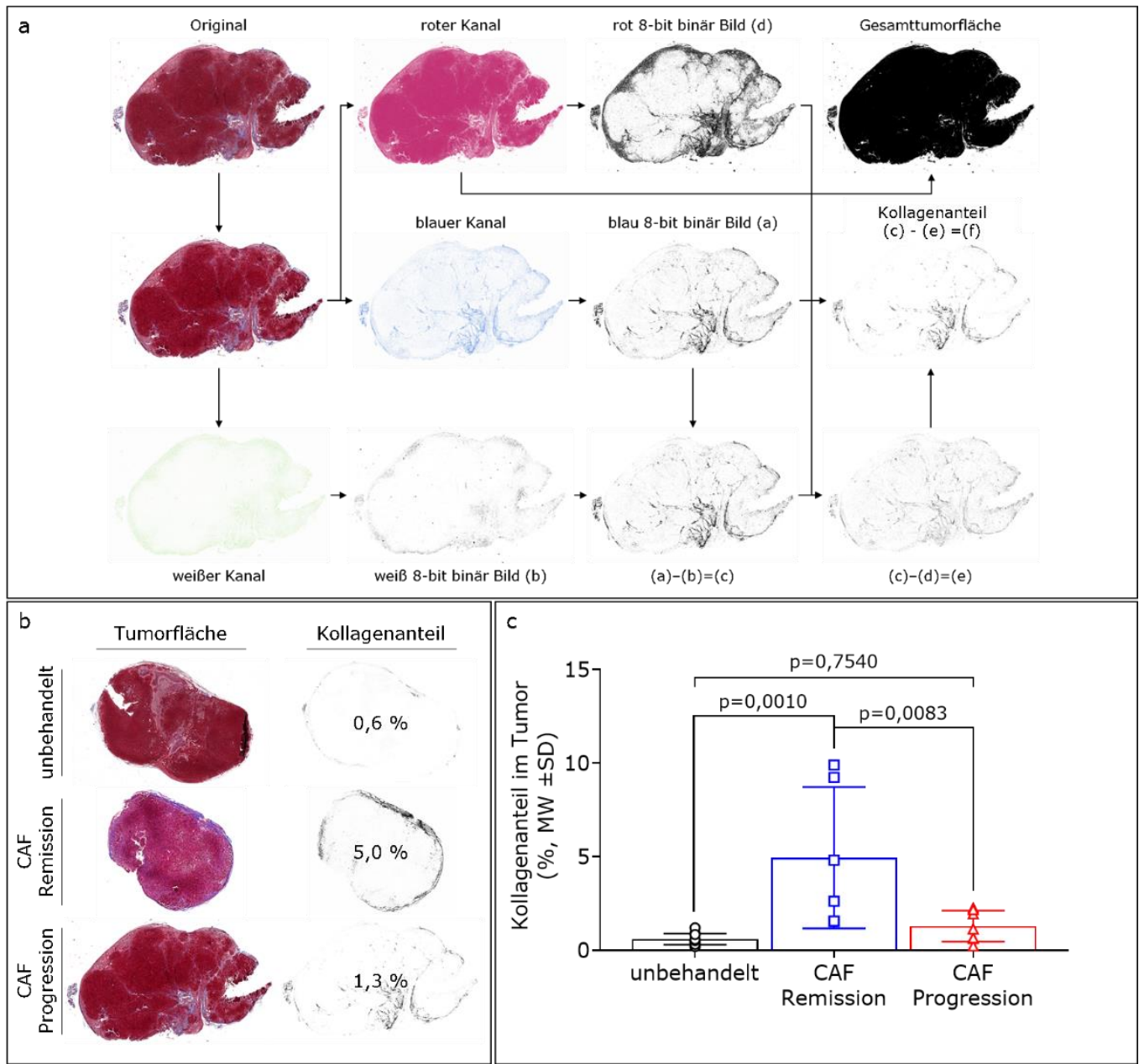

Abbildung 16: Bildanalytische Quantifizierung der Kollagenanteile nach MTS-Färbung

a: Abbildung der Arbeitsschritte in ImageJ zur Analyse und Berechnung der Kollagenanteile im Tumor. Als Grundlage dient die MTS-Färbung. In die Analyse einbezogen wurden nur die spezifisch blau gefärbten Kollagenbereiche. b: Repräsentative Abbildung der MTS-Färbung (Tumorfläche) und der analysierten Kollagenfärbung des binären 8-bit Bildes (Kollagenanteil). Repräsentativ dargestellt ist jeweils ein Tumor jeder Gruppe: unbehandelter Tumor $\left(V_{\mathrm{T}}=810,7 \mathrm{~mm}^{3} ; 34\right.$ Tage nach Transplantation), CAF therapierter Tumor in Remission $\left(V_{\mathrm{T}}=126,6 \mathrm{~mm}^{3}\right.$; 36 Tage nach Transplantation und 7 Tage nach CAF Applikation) und CAF therapierter Tumor in Progression $\left(\mathrm{V}_{\mathrm{T}}=307,3 \mathrm{~mm}^{3}\right.$; 44 Tage nach Transplantation und 15 Tage nach CAF Applikation). c: Das Dotplot-Diagramm stellt die Ergebnisse der MTS-Färbung als prozentualen Anteil der Kollagenanteile im Tumor dar. Die Kollagenanteile wurden berechnet durch die folgende Formel: binärer Kollagenanteil-Gesamttumorfläche $=\%$-Kollagenanteil im Tumor. $\mathrm{V}_{\mathrm{T}}$ : Tumorvolumen nach der Sektion und Tumor ex vivo. Gruppen: unbehandelt $n=10, \mathrm{CAF}-$ Remission $n=6$ und CAF - Progression $n=7$.

Zusammengefasst zeigen diese Ergebnisse, dass die durch CAF verursachte temporäre Remission des Tumors mit einer Umstrukturierung und Änderung des Tumorphänotypen einhergeht. Tumore in Remission wiesen weniger T-Ag-positive H8N8-Tumorzellen und mehr T-Ag ungefärbte Nichttumorzellen auf, so u.a. Cd45 ${ }^{+}$TIL. Sie zeigten außerdem keine vorhandene strukturelle Ordnung und die bildanalytische Quantifizierung der Kollagenanteile nach MTS-Färbung deutet an, dass während der Remission vermehrt Kollagen gebildet und in der EZM abgelagert wird. Tumore nach Wiederwachstum aus der Gruppe CAF - Progression glichen von ihrer Zusammensetzung und Struktur unbehandelten Tumoren, bis auf einer vermehrten Anzahl von Cd45+ TIL. 


\subsubsection{CAF induziert EMT während der Remission}

Die vorangegangenen Resultate führten zur Hypothese, dass in CAF therapierten Tumoren EMTProzesse stattfinden. Epithelial-mesenchymale Transition ist ein wichtiger Mechanismus für Tumorzellen, um auf eine Chemotherapie zu reagieren und Umstrukturierungen zu initiieren. Dieser Mechanismus ist zum einen in der Lage statische in mobile Zellen umzuwandeln und zum anderen Tumorzellen mit Resistenzeigenschaften auszustatten (Smith und Bhowmick 2016). Immunhistochemische Färbungen an Tumorschnitten mit AK, die gegen EMT-assozierte Markerproteine (E-Cadherin, Vimentin, alpha-smooth muscle actin [ $\alpha$-Sma] und Tenascin-C) gerichtet sind, sollten klären, inwieweit EMT in CAF therapierten H8N8-Tumoren stattfindet.

Die AK-Färbung gegen das Adhäsionsprotein E-Cadherin, einem epithelialen Marker, zeigte in der IHC-Untersuchung unbehandelter Tumore eine schwache Membranfärbung der Tumorzellen, bis auf wenige Tumorzellen, die eine intensivere Membranfärbung durch den E-Cadherin AK aufwiesen. Dagegen waren CAF-therapierte Tumorzellen sowohl intensiver im Plasma als auch in der Membran für E-Cadherin gefärbt (Abbildung 17). Nach Inkubation der Tumorschnitte mit dem AK gegen das Intermediärfilament Vimentin, einem mesenchymalen Marker, waren die meisten Zellen in den Tumoren der Gruppe CAF - Remission intensiv zytoplasmatisch positiv gefärbt (Abbildung 17).In Tumoren der Gruppe CAF - Progression waren, im Vergleich mit unbehandelten Tumoren, mehr Zellen mit dem Vimentin-AK positiv gefärbt aber verglichen mit den Tumoren der Gruppe CAF Remission deutlich weniger (Abbildung 17). Da eine Zuordnung der einzelnen Zellen in bestimmte Zelltypen so nicht möglich war, da neben mesenchymalen Tumorzellen auch Stromazellen wie Fibroblasten oder Endothelzellen Vimentin als Teil ihres Zytoskeletts aufweisen, wurden weitere IHCFärbungen mit AK gegen weitere EMT-assoziierte Markerproteine durchgeführt: i) Alpha-Sma, ein Mikrofilamentprotein, das einen Hinweis auf Myofibroblasten und auf aktivierte tumorassoziierte Fibroblasten (TAF) liefert, welche sich u.a. durch EMT vermehrt aus konventionellen Fibroblasten differenzieren (Sasaki et al. 2018) und ii) Tenascin-C, das von Myofibroblasten im aktivierten Status vermehrt gebildet wird und kaum in der physiologischen Mamma vorkommt (Kalluri und Zeisberg 2006). Tumore der Gruppen CAF - Remission und CAF - Progression hatten mehr $\alpha$-Sma positive Zellen im Tumorzentrum, verglichen mit sehr vereinzelt $\alpha$-Sma positiven Zellen am Tumorrand, dort 
wo vermehrt Gefäße zu erkennen waren (Abbildung 17). Tenascin-C, ein in der EZM u.a. von TAF produziertes Glykoprotein, wurde stark vermehrt in der EZM von Tumoren der Gruppe CAF Remission und auch vereinzelt in Bereichen von Stromastraßen in Tumoren der Gruppe CAF Progression lokalisiert. Unbehandelte Tumor hingegen wiesen nur am Tumorrand eine geringe Tenascin-C-Färbung auf (Abbildung 17).

Um nachfolgende molekularbiologische und durchflusszytometrische Analysen zelltypspezifisch an unbehandelten Tumorzellen und an Tumorzellen der Tumore der Gruppen CAF - Remission und CAF - Progression durchzuführen, wurden Nichttumorzellen depletiert und die H8N8-Tumorzellen angereichert. Mit Hilfe der magnetischen Zellseparation wurden Zellen nach AK-Bindung, aufgrund der am AK gebundenen magnetischen Partikel, mittels Säulen, in denen ein magnetisches Feld erzeugt wurde, zurückgehalten oder im Fall keiner AK-Bindung im Durchfluss aufgefangen. Dafür wurden über eine MACS-basierte Depletion die Nichttumorzellen wie Leukozyten, Endothelzellen, Fibroblasten und Erythrozyten aus der Einzel-Zellsuspension mittels magnetischer Separation depletiert, um zu erreichen, dass sich im Durchfluss die H8N8 Tumorzellen anreichern, was mittels FACSAnalysen durch Färbung der Tumorzellfraktion mit Epcam-PE und Cd45-VioBlue nachgewiesen wurde (Abbildung 18a). Die in Tabelle 26 aufgelisteten Tumore wurden dissoziiert und für nachfolgende Versuche Tumorzellen durchflusszytometrisch angereichert, analysiert und wahlweise isoliert. Nachfolgende Untersuchungen konnten so an Tumorzellen durchgeführt werden, ohne aufgrund von Verunreinigungen von anderen Zelltypen mit großen Verfälschungen der Ergebnisse rechnen zu müssen. Die Tumorzellfraktion der Tumore in Remission nach CAF wies einen Anteil von 18,6 \% $( \pm 0,94 \%)$ Epcam $^{+}$-Tumorzellen auf, der sich dann in Tumoren der Gruppe CAF - Progression wieder auf $51,6 \%( \pm 4,81 \%)$, verglichen mit 71,8\% ( $\pm 1,52 \%)$ Epcam ${ }^{+}$-Zellen in unbehandelten Tumoren, erhöht.

Die hier gemachten Beobachtungen, i) die Reduktion der Epcam+-Tumorzellen während der Remission nach CAF-Therapie und ii) der Anstieg der Epcam+-Tumorzellen nach beginnender Progression der Residualtumore (Abbildung 18b), deutet darauf hin, da Epcam und E-Cadherin epitheliale EMTMarker sind, dass aktive EMT-Prozesse als Folge der CAF-Therapie in H8N8-Tumoren stattfinden. 


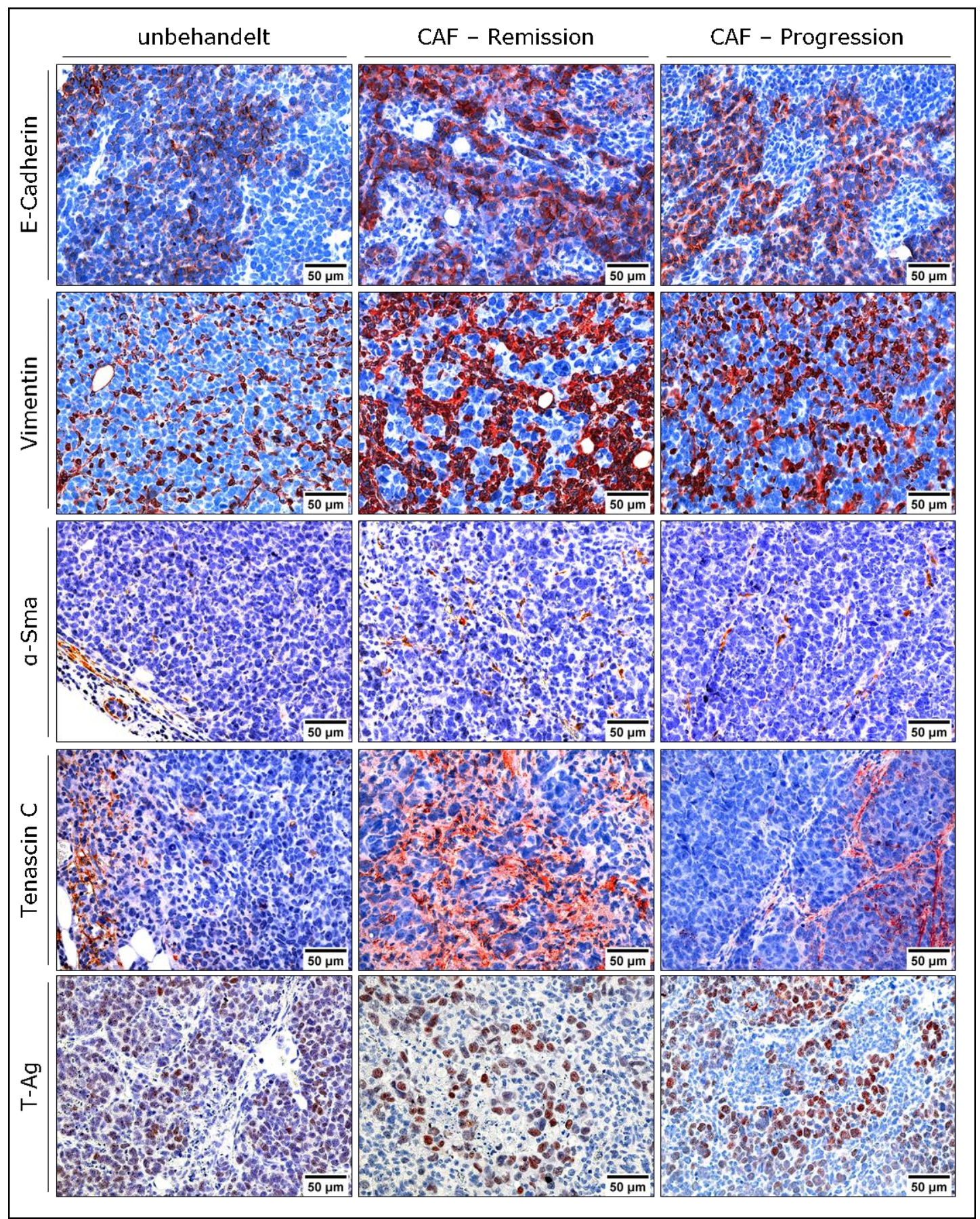

Abbildung 17: Durch CAF induziert Synthese EMT-assozierter Markerproteine

Dargestellt sind repräsentative IHC Färbungen (AK gegen E-Cadherin, Vimentin, $\alpha$-Sma, Tenascin-C und T$\mathrm{Ag})$ von Tumorschnitten mit undifferenzierten Bereichen eines unbehandelten Tumors $\left(\mathrm{V}_{\mathrm{T}}=810,7 \mathrm{~mm}^{3} ; 34\right.$ Tage nach Transplantation), eines Tumors in Remission nach CAF Therapie $\left(V_{T}=251,0 \mathrm{~mm}^{3} ; 34\right.$ Tage nach Transplantation und fünf Tage nach CAF Applikation) und eines progressivem Residualtumors nach CAF und Wiederwachstum $\left(V_{\mathrm{T}}=806,8 \mathrm{~mm}^{3} ; 46\right.$ Tage nach Transplantation und 17 Tage nach CAF Applikation). Die Abbildungen der verschiedenen Färbungen je Gruppe wurden von Tumorschnitten des gleichen Tumors angefertigt. Detailaufnahme 400x Vergrößerung, Balken $50 \mu \mathrm{m}$. V $\mathrm{V}_{\mathrm{T}}$ : Tumorvolumen nach der Sektion und Tumor ex vivo. 


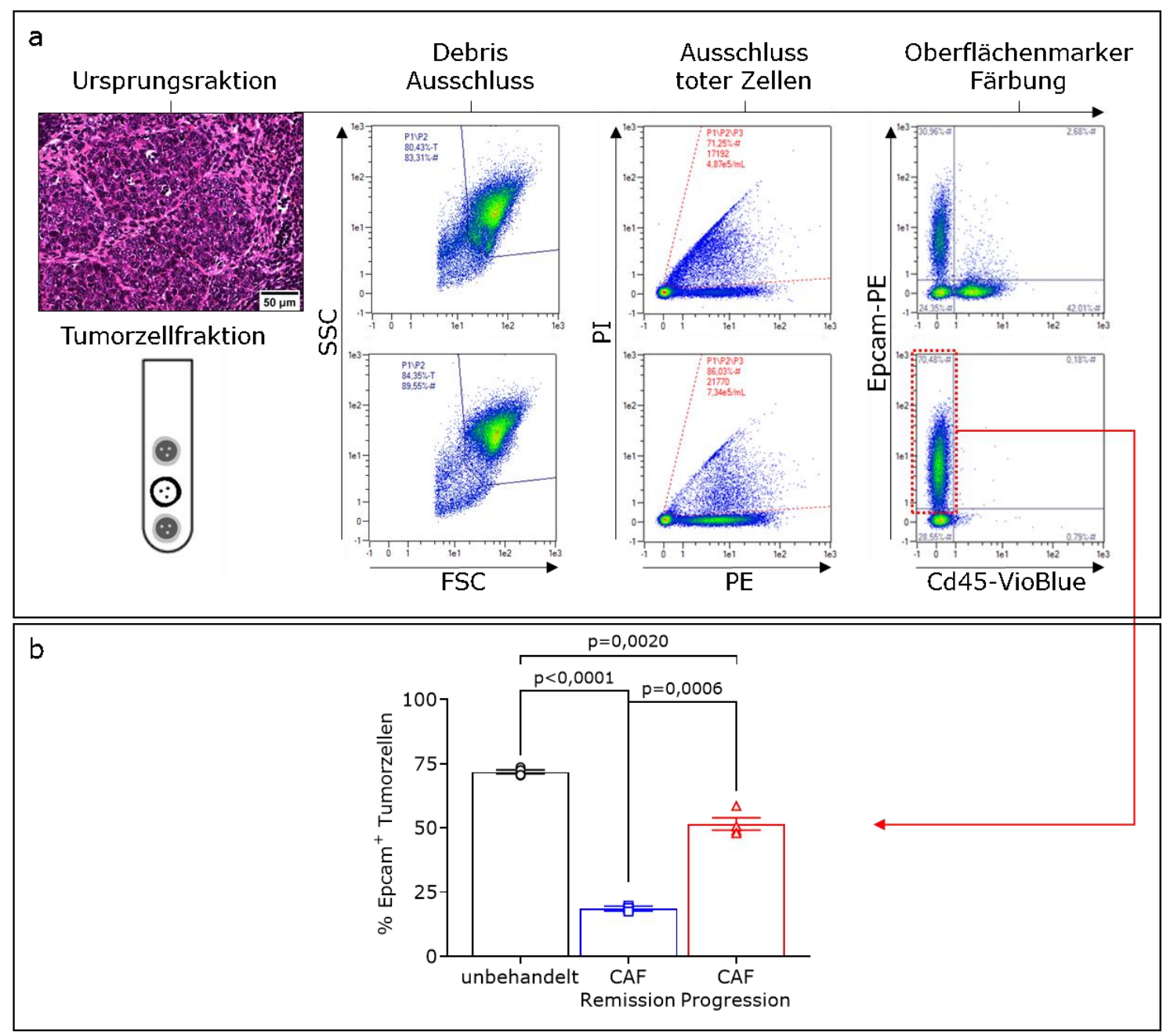

Abbildung 18: Magnetische Seperation und Epcam FACS-Färbung der angereicherten Tumorzellen

In a sind Cd45-VioBlue und Epcam-PE Färbungen der dissoziierten Einzel-Zellsuspensionen vor und nach Anreicherung exemplarisch dargestellt. Dem Cd45-VioBlue/Epcam-PE Gating vorangestellt waren der Ausschluss von Zelldebris und PI-gefärbter toter Zellen. b: Das Balkendiagramm zeigt die prozentualen Populationsgrößen von Epcam ${ }^{+}$Tumorzellen von unbehandelten $(n=4)$ und CAF therapierten Tumoren $(\mathrm{CAF}-\mathrm{Re}-$ mission n=4, CAF - Progression n=4). Tumordissoziation und anschließende FACS-Analysen wurden zusammen mit D. Agorku (Miltenyi Biotec GmbH, Bergisch Gladbach) durchgeführt.

Von den durch magnetische Separation angereicherten Tumorzellen aus den Tumoren aus Tabelle 26 wurden $1 \times 10^{6}$ Zellen isoliert und kryokonserviert, um anschließend mittels mRNA-Sequenzierung und Genexpressionsanalysen die Frage zu beantworten, welche EMT-Markergene wie und in welchem Maß nach CAF reguliert sind (Abbildung 19a). Die Ergebnisse und die Qualität der mRNASequenzierung sind in Abbildung 19b und Abbildung 19c dargestellt. Die Hauptkomponentenanalyse in Abbildung 19b dient der vereinfachten Darstellung großer Datensätze und verdeutlich anhand der Varianzstreuung, dass die Ergebnisse der Genexpressionsanalyse und die damit verbundenen durch CAF verursachten Veränderungen in den Gruppen konsistent sind. Die distanzbasierte Clusteranalyse in Abbildung 19c, die der Analyse dient, wie stark sich zwei Datensätze/Gruppen ähneln, zeigt, 
dass die Genexpressionsprofile der Tumorzellen innerhalb der Gruppe, diejenigen die gleich behandelt wurden, die genomischen Ähnlichkeiten aufwiesen. Weiter wird deutlich, dass die Tumorzellen aus Tumoren der Gruppe CAF - Progression den unbehandelten Tumorzellen im Genexpressionsprofil ähnlicher waren als den Tumorzellen aus Tumoren der Gruppe CAF - Remission. Die in Abbildung 19d dargestellten relativen Genexpressionen der Tumorzellen der Gruppen CAF - Remission und CAF - Progression wurden auf die unbehandelten Tumorzellen normiert und sind als $\log 2 \mathrm{FC}$ angegeben. Die Genexpression des epithelialen Markers E-Cadherin war in den Tumorzellen in Remission um das Doppelte erhöht, verglichen mit unbehandelten Tumorzellen und den Tumorzellen der Tumore der Gruppe CAF - Progression. Weiter waren mesenchymale Markergene wie Fibronektin-1 und Vimentin in Tumorzellen der Tumore in Remission hochreguliert. Vimentin blieb auch bei Wiederwachstum der Tumore in den Tumorzellen der Gruppe CAF - Progression stärker exprimiert als unbehandelte Tumorzellen. Transkriptionsfaktoren wie u.a. Snai1, Snai2 und Twist1, die einen mesenchymalen Phänotypen fördern, waren in den Tumorzellen der Gruppe CAF - Progression stärker hochreguliert als in Tumorzellen der remittierten Tumore der Gruppe CAF - Remission. Dafür waren Transkriptionsfaktoren, die den epithelialen Phänotyp fördern, stärker in Tumorzellen der Tumore in Remission heruntereguliert. Nähere Details zu den erläuterten und dargestellten mRNA-Sequenzdaten können der Tabelle 33 und Tabelle 34 im Anhang entnommen werden.

Neben den ausgewählten Genen in Abbildung 19d zeigen auch die Enrichment-Plots in Abbildung 20a die Hochregulierung der meisten Gene des EMT-Hallmark-Gensets. Diese Gensammlung beinhaltet 200 Gene, die in Zusammenhang mit EMT beschrieben wurden. Das EMT-Hallmark-Genset ist Teil der Cancer-Hallmark-Genset-Sammlung der Molecular Signature Database (MSigDB) in der 50 Gensets, die für biologischen Abläufe, Prozesse und Vorgänge in Tumorzellen definiert wurden, enthalten sind (Subramanian et al. 2005; Liberzon et al. 2015). Gene, die bis zum ersten Wendepunkt zur Steigung des Enrichment-Score beitragen, lassen sich mittels LEA aller 50 Gensets der CancerHallmark-Genset-Sammlung vergleichen. Gene, die besonders häufig in verschiedenen Gensets Teil der Leading-Edge sind, spielen demnach bei den Prozessen, in diesem Fall EMT, eine wichtige Rolle. Die LEA zeigt(Abbildung 20b), dass in Tumorzellen der beiden CAF-therapierten Gruppen (CAF Remission und CAF - Progression), verglichen mit Tumorzellen aus unbehandelten Tumoren, das Zytokin Il6 in zehn von 50 Gensets Teil der Leading-Edge war. 
Damit nimmt Il6 anscheinend eine Schlüsselfunktion in Tumorzellen der CAF therapierten Tumoren ein. Da bekannt ist, dass sich $\mathrm{Il6}$ und Nf-кb gegenseitig stimulieren und so via dem Tnf- $\alpha$-Signalweg Chemotherapieresistenzen vermitteln (Dethlefsen et al. 2013), wurde im nächsten Schritt untersucht, welche Wirkung die CAF-Therapie auf den Tnf- $\alpha$-Signalweg hat. Dazu wurde eine weitere GSEAAnalyse zur Untersuchung der Genaktivität relevanter Tnf- $\alpha$-Signaltransduktionsgene durchgeführt, gefolgt von der Analyse der Genexpression von Nfkb-induzierten Zielgenen in der sequenzierten Tumorzell-mRNA der CAF therapierten Tumore.

Die Ergebnisse der durchgeführten GSEA-Analysen sind in Abbildung 21a dargestellt und zeigen, dass die CAF-Therapie den Tnf- $\alpha$-Signalweg sowohl in der akuten Phasen während der Remission in Tumorzellen der Gruppe CAF - Remission als auch in Tumorzellen nach Wiederwachstum der Gruppe CAF - Progression stimuliert und wichtige Gene dieses Signalwegs hochreguliert. In Abbildung 21b sind die Genexpressionen wichtiger antiapoptotischer Gene, wie Bcl1 (Cyclin-D1), Bcl2 (B cell leukemia/lymphoma 2), Bclxl (BCL2-like 1) und Mcl1 (myeloid cell leukemia sequence 1), von isolierter und sequenzierter Tumorzell-mRNA abgebildet und sie zeigen, dass in den Tumorzellen der beiden CAF therapierten Tumoren (CAF - Remission und CAF - Progression ) die Genexpressionen antiapoptotischer Gene hochreguliert waren. Da über den Tnf- $\alpha$-Signalweg auch zahlreiche inflammatorischen Zytokine ausgeschüttet werden, wurden u.a. die Tnf- $\alpha$-Zielgene Interleukin-10 (II1), -11 (II11) und -23 (II23), welche eine immunmodulatorische Wirkung besitzen, auf eine veränderte Genexpression hin untersucht. Die Ergebnisse zeigen eine Hochregulierung der drei untersuchten Interleukine in den Tumorzellen der Tumor nach CAF-Therapie, insbesondere der Tumorzellen der Tumore der Gruppe CAF - Remission. Nähere Details zu den erläuterten und dargestellten mRNA Sequenzdaten können der Tabelle 35 und Tabelle 36 im Anhang entnommen werden. 


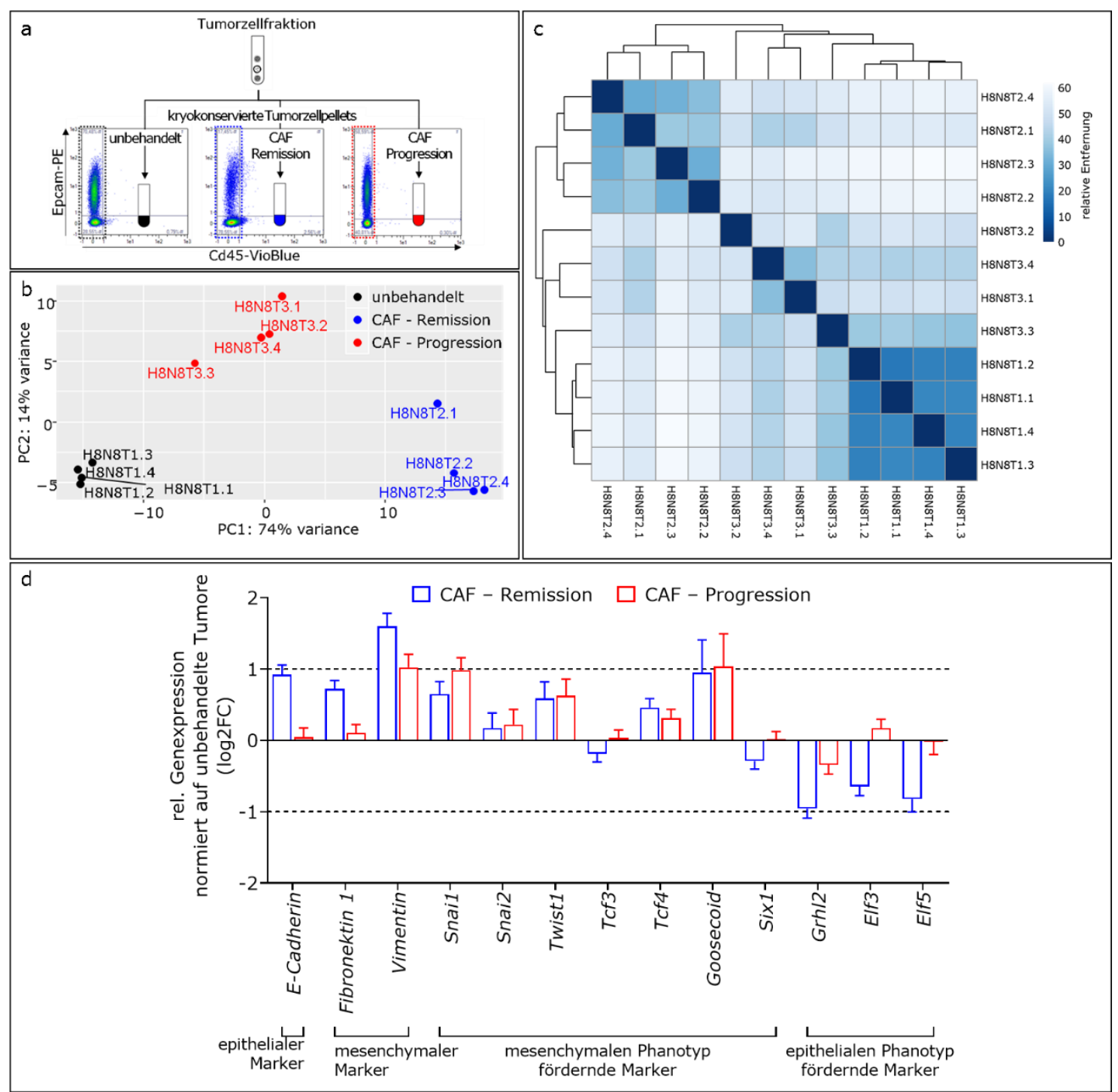

Abbildung 19: Ergebnis der Sequenzierung der isolierten Tumorzell-mRNA und Analyse von EMTMarkergenen sowie EMT-TF

a: Schematische Darstellung der verwendeten kryokonservierten Tumorzellpellets zur mRNA-Sequenzierung. Die Kryokonservierung fand nach durchflusszytometrischen Färbungen der angereicherten Tumorzellen und anschließender Isolierung statt. b: Hauptkomponentenanalyse zur vereinfachten Darstellung großer Datensätze anhand der Varianzstreuung nach mRNA-Sequenzierung der unbehandelten und CAF therapierten Tumore. c: Distanzbasierte Clusteranalyse zur Analyse, wie stark sich zwei Datensätze/Gruppen ähneln, hier dargestellt der Vergleich der unbehandelten und behandelten Gruppen in Form einer Heatmap. d: Relative Genexpression epithelialer und mesenchymaler EMT-Markergene sowie wichtiger EMT-TF der CAF behandelten Tumore in Remission ( $n=4)$ und Progression $(n=4)$ normiert gegen die Genexpressionswerte der unbehandelten Tumore $(\mathrm{n}=4)$. Die Isolierung der RNA, Herstellung der mRNA-Bibliothek und Analyse der Daten erfolgte in Kollaboration mit Dr. Florian Wegwitz (AG Wegwitz, Universitätsmedizin Göttingen). 


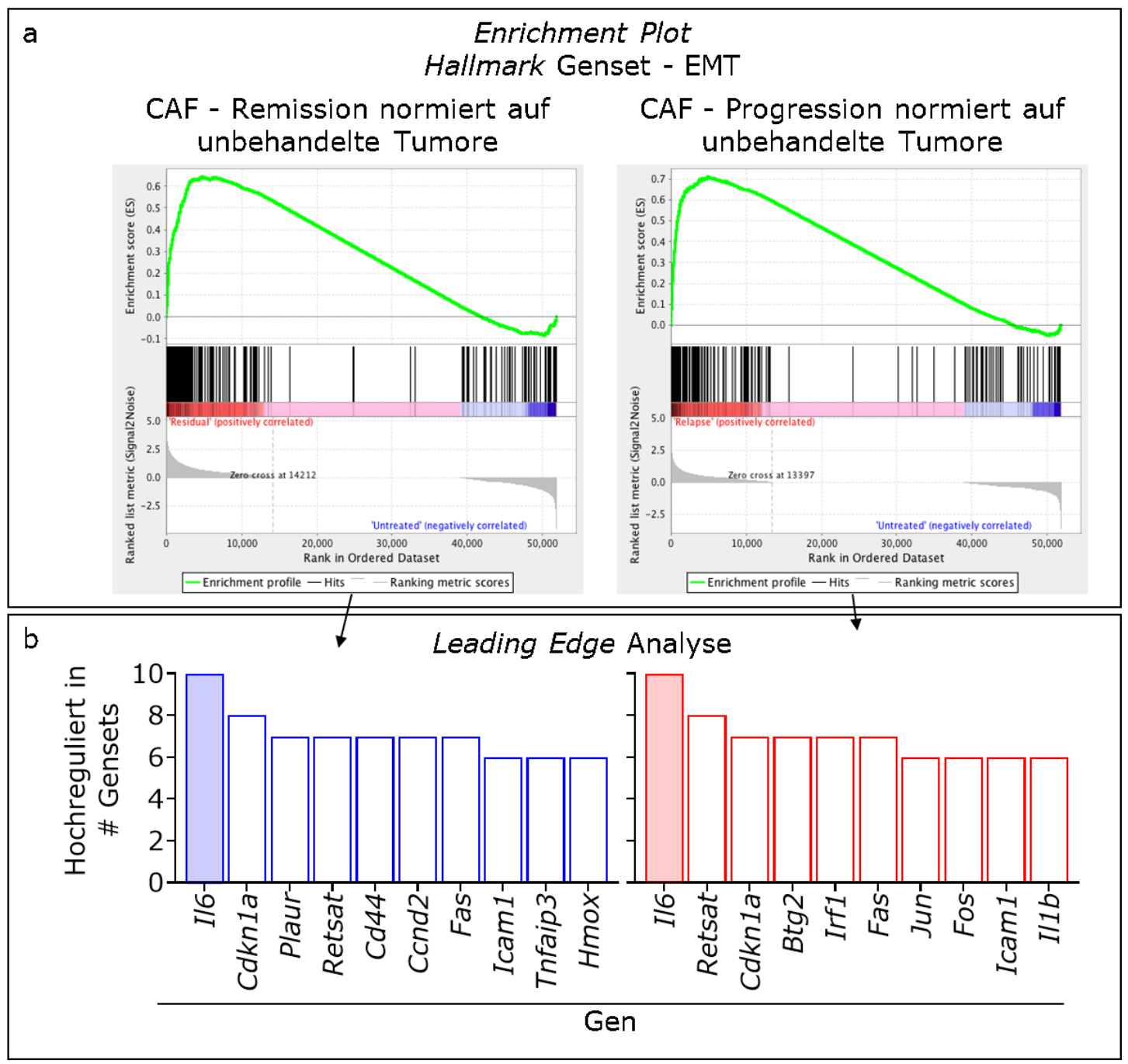

Abbildung 20: GSEA- und LEA-Analysen der sequenzierten Tumorzell-mRNA von H8N8-Tumoren

a: Im Diagramm sind die Enrichment-Plots der GSEA-Analysen der sequenzierten mRNA aus den Tumorzellen der einzelnen Gruppen jeweils relativ zu den Ergebnissen der Sequenzierung der unbehandelten Tumorzellen, in Bezug auf 200 Gene die als EMT-spezifische Gene definiert sind, dargestellt. b: Die LEA gibt an, wie oft ein Gen in der Leading-Edge, der zu vergleichenden Gruppen aus a, vorkommt, aus dem Vergleich der 50 analysierten Gensammlungen der Cancer-Hallmark-Genset-Sammlung. Die Isolierung der RNA, Herstellung der mRNA-Bibliothek und Analyse der Daten erfolgte in Kollaboration mit Dr. Florian Wegwitz (AG Wegwitz, Universitätsmedizin Göttingen). 


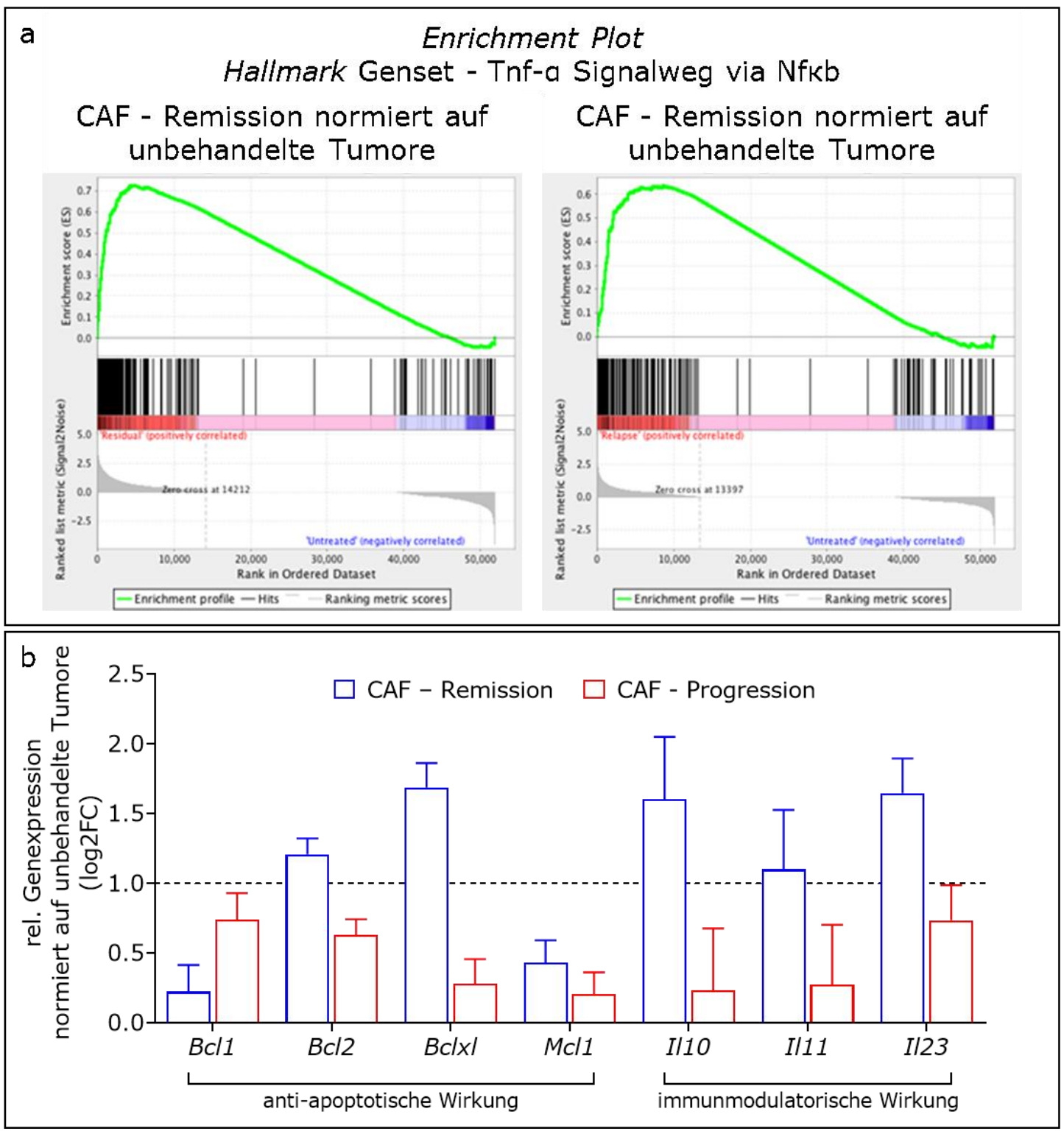

Abbildung 21: GSEA-Analyse vom Tnf- $\alpha$-Signalweg und Genexpression assoziierter Gene in H8N8Tumorzellen nach CAF-Therapie

a: Im Diagramm sind die Enrichment-Plots der GSEA-Analyse der Gruppen CAF - Remission und CAF Progression jeweils relativ zu den unbehandelten Tumoren, in Bezug auf 200 Gene die von Nf-кb als Antwort auf Tnf- $\alpha$ reguliert werden, dargestellt. b: Abgebildet ist die relative Genexpression von Zielgenen, die von Nf-kb als Antwort auf Tnf- $\alpha$ reguliert werden, der CAF behandelten Tumore in Remission ( $\mathrm{n}=4$ ) und Progression $(n=4)$ normiert gegen die Genexpressionswerte der unbehandelten Tumore $(n=4)$. Die Isolierung der RNA, Herstellung der mRNA-Bibliothek und Analyse der Daten erfolgte in Kollaboration mit Dr. Florian Wegwitz (AG Wegwitz, Universitätsmedizin Göttingen). 


\subsubsection{Tumorzellen in Remission haben Stammzellcharakter}

Interleukin-6 stimuliert in Tumorzellen den Tnf- $\alpha$-Signalweg. Umgekehrt stimuliert der Tnf- $\alpha$-Signalweg durch Nf-kb-Signaltransduktion, einem wichtigen Signalvermittler in der Tnf- $\alpha$-Signalkaskade, die Hochregulierung der Il6-Expression, wodurch eine positive Rückkopplung entsteht (Dethlefsen et al. 2013). So zeigen die GSEA-Analysen von Tumorzellen aus Tumoren der Gruppen CAF - Remission und CAF - Progression, normiert zu den Tumorzellen unbehandelter Tumore, einen aktivierten Il6-Jak1-Stat3-Signalweg, verdeutlicht durch die Hochregulierung wichtiger assoziierter Gene der Il6-Jak1-Stat3-Signalkaskade nach CAF Therapie (Abbildung 22a)

Zum Nachweis, dass die CAF-Therapie die Il6-Sekretion stimuliert und dadurch die Il6-Jak1-Stat3Signalkaskade induziert wird, wurden unbehandelte Tumore und CAF therapierte Tumore mit einen gegen Il6 gerichteten AK IHC gefärbt. Mittels IHC-Färbungen wurde das vermehrte Vorkommen von 116 in der EZM im remittierten Tumor, verglichen mit unbehandelten Tumoren und Tumoren der Gruppe CAF - Progression, nachgewiesen. In unbehandelten Tumore und Tumoren der Gruppe CAF - Progression war Il6 vermehrt im Zytoplasma von Tumorzellen in den Randbereichen der Tumore und sehr leicht vereinzelt in der EZM lokalisiert (Abbildung 22b).

Die 116 Genexpression von CAF therapierten Tumorzellen war besonders während der Tumorremission hochreguliert (Abbildung 22c). Die Tumorzellen der Tumore der Gruppe CAF - Remission wiesen außerdem eine erhöhte Genexpression der für die Il6-Signaltransduktion benötigten Rezeptoren Il6r und Gp130 auf. Dahingegen war die Genexpression der Tumorzellen der Tumore der Gruppe CAF - Progression auf das Level der Tumorzellen der unbehandelten Tumore reduziert. Die Signaltransduktion nach I16-Bindung an den löslichen Rezeptor Il6r, den Transmembranrezeptor Gp130 oder den heterodimeren Transmembranrezeptor Gp130/Il6r erfolgt durch eine Signalkaskade über die Jak1- und Stat3-Gene, die beide in Tumorzellen der Tumore der Gruppe CAF Remission hochreguliert waren. Bis auf das Socs3-Gen, welches die Il6-Jak1-Stat3-Signaltransduktion hemmt, waren die anderen dargestellten Gene in den Tumorzellen der Tumore der Gruppe CAF Progression schwächer hochreguliert (Abbildung 22c). Nähere Details zu den erläuterten und dargestellten mRNA-Sequenzdaten können der Tabelle 37 und Tabelle 38 im Anhang entnommen werden. 


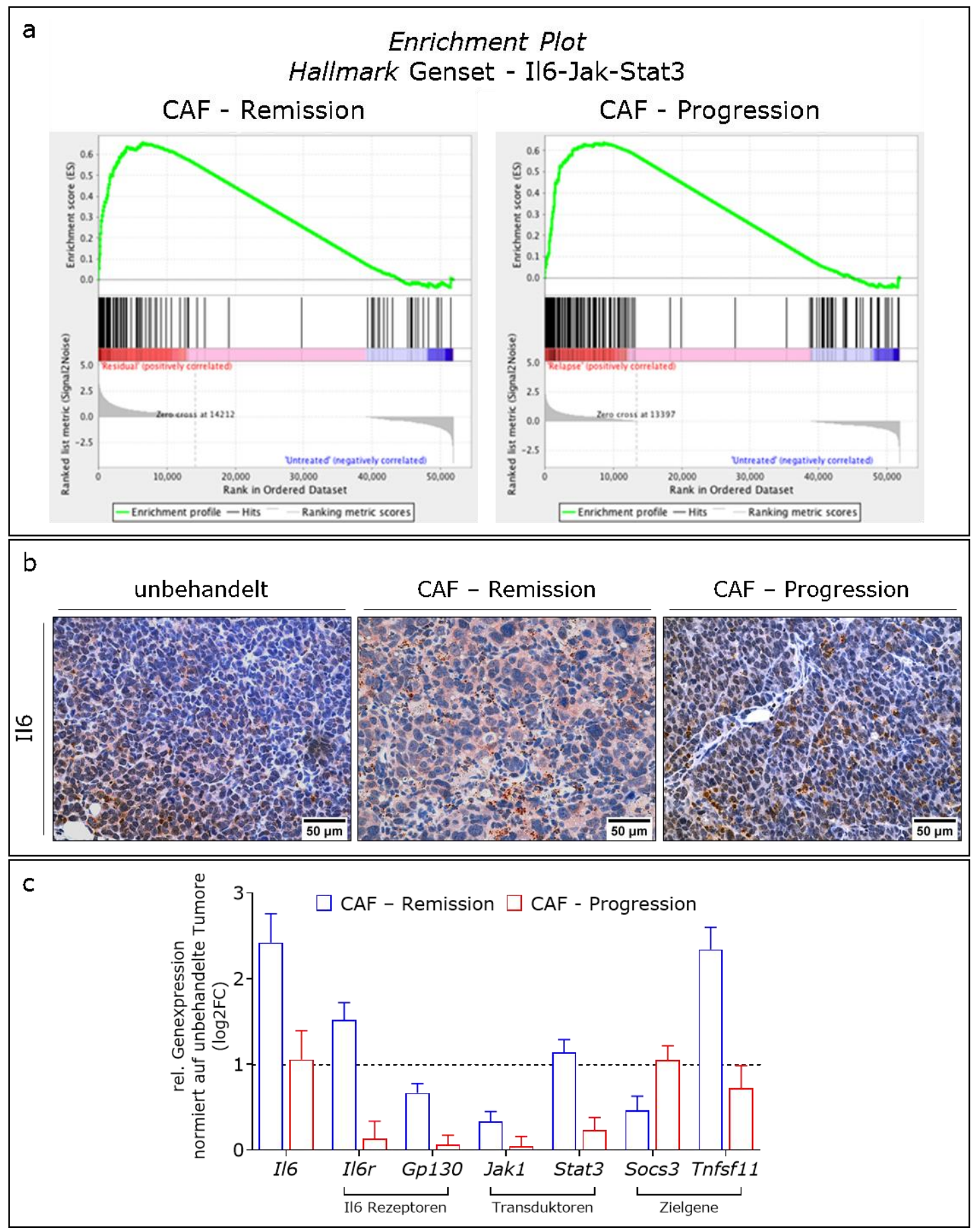

Abbildung 22: GSEA-Analyse vom I16-Jak1-Stat3-Signalweg und Genexpression assoziierter Proteine und Gene in isolierter Tumorzell-mRNA nach CAF Therapie

a: Im Diagramm sind die Enrichment-Plots der GSEA-Analyse der Tumorzellen aus den Gruppen CAF Remission und CAF - Progression jeweils relativ zu den Ergebnissen der unbehandelten Tumore, in Bezug auf 87 Gene, die durch 116 über Stat3 hochreguliert werden, dargestellt. b: Immunhistochemische Il6 Färbungen repräsentativ dargestellt durch einen unbehandelten Tumor $\left(\mathrm{V}_{\mathrm{T}}=810,7 \mathrm{~mm}^{3}\right.$; 34 Tage nach Transplantation), einen Tumor in Remission nach CAF Therapie $\left(V_{\mathrm{T}}=151,3 \mathrm{~mm}^{3}\right.$; 36 Tage nach Transplantation und sechs Tage nach CAF Applikation) und durch einen Tumor der Gruppe CAF - Progression $\left(V_{T}=806,8 \mathrm{~mm}^{3} ; 46\right.$ Tage nach Transplantation und 17 Tage nach CAF Applikation). Detailaufnahme 400x Vergrößerung, Balken $50 \mu \mathrm{m}$. $\mathrm{V}_{\mathrm{T}}$ : Tumorvolumen nach der Sektion und Tumor ex vivo c: Abgebildet ist die relative Genexpression wichtiger Gene des Il6-Jak1-Stat3-Signalwegs in Tumorzellen von CAF therapierten Tumoren in Remission $(n=4)$ und Progression $(n=4)$ normiert gegen die Genexpressionswerte der Tumorzellen unbehandelter Tumore $(n=4)$. Die Isolierung der RNA, Herstellung der mRNA-Bibliothek und Analyse der Daten erfolgte in Kollaboration mit Dr. Florian Wegwitz (AG Wegwitz, Universitätsmedizin Göttingen). 
In remittierten Tumoren war die Sekretion von Il6 in die EZM erhöht und der I16-Jak1-Stat3-Signalweg aktiv. Iliopoulos et al. postulierte 2011, dass möglicherweise Il6 die Differenzierung von CSC aus Nichttumorstammzellen initiiert und damit die Resistenzentwicklung und das Wiederwachstum der Residualtumore fördert (Iliopoulos et al. 2011). Im Folgenden wurden deshalb Tumorzellen mit durchflusszytometrischen FACS-Analysen auf das Vorkommen der Oberflächenmoleküle Cd95, Cd104, Cd107a, Cd146, Cd201 und Sca1, die mit einem Resistenz- und Stammzell-Phänotyp assoziiert sind, charakterisiert (Abbildung 23). Für die FACS-Analyse wurden durch negative Depletion angereicherte Tumorzellen der Tumore aus Tabelle 26 verwendet; mit Ausnahme des Tumors 6171, da hier nicht genügend Tumorzellen erzielt wurden.

Abbildung 23a zeigt, dass die Anreicherung der Tumorzellen erfolgreich war und dass sich die folgenden prozentualen Anteile mit einer hohen Wahrscheinlichkeit auf sortierte, bisher unmarkierte LCR-Tumorzellen beziehen. Tumore der Gruppe CAF - Remission verloren dreiviertel ihrer Cd24+Tumorzellen und die Cd44+-Tumorzellen, in dieser Gruppe, wiesen um die Hälfte mehr Zellen auf als unbehandelte Tumore. Der Anteil der Cd24+-Tumorzellen war in Tumoren der Gruppe CAF Progression erhöht, verglichen mit Tumoren der Gruppe CAF - Remission. Im Gegenzug sank der Anteil an $\mathrm{Cd} 44^{+}$-Tumorzellen im wieder gewachsenen Tumor der Gruppe CAF - Progression auf einen mit den unbehandelten Tumoren vergleichbaren Anteil. Tumorzellen der Tumore der Gruppe CAF - Remission waren, im Vergleich zu Tumorzellen unbehandelter Tumore charakterisiert durch i) einen deutlichen Anstieg an $\mathrm{Cd} 95^{+}-$Tumorzellen, von $23,2 \%( \pm 2,22 \%)$ in unbehandelten Tumoren auf $66,9 \%( \pm 3,41 \%)$ bei Tumoren der Gruppe CAF - Remission sowie auch an Cd201+-Tumorzellen, von $23,7 \%( \pm 7,63 \%)$ auf 65,3\% ( $\pm 4,17 \%)$; ii) einen moderaten Anstieg der Anteile Cd146 ${ }^{+}$ Tumorzellen, von $28,4 \%( \pm 2,16 \%)$ auf $35,5 \%( \pm 6,27 \%)$ sowie der Sca ${ }^{+}-$Tumorzellen, von 36,8 $\%( \pm 1,81 \%)$ auf $57,8 \%( \pm 3,95 \%)$. Die Anteile Cd104+- und Cd107a+-Tumorzellen waren hingegen in Tumoren der Gruppe CAF - Remission verringert. Die Tumorzellen der Tumore der Gruppe CAF - Progression waren, verglichen mit den Anteilen der Tumorzellen unbehandelter Tumore, in vergleichbaren Mengen einfachpositiv mit den AK-gegen die Marker Cd95, Cd107a, Cd201 oder Sca1 gefärbt. Der Anteil Cd104+- und Cd146+-Tumorzellen entsprach während des Wiederwachstums der Tumore der Gruppe CAF - Progression ungefähr den Anteilen an Cd104+- bzw. Cd146+-Tumorzellen der Tumore der Gruppe CAF - Remission. 


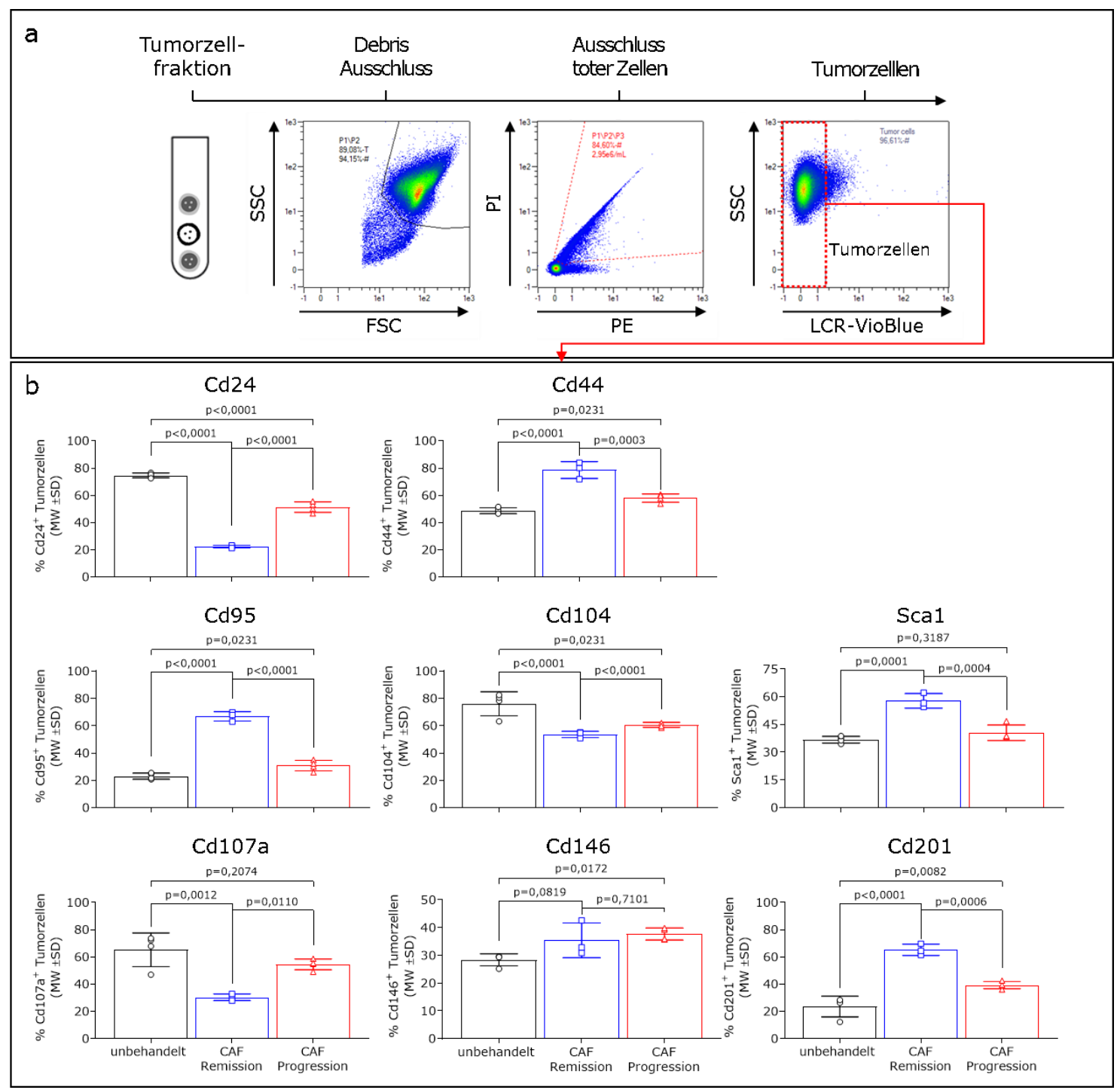

Abbildung 23: FACS-Analysen von Tumorzellen nach Färbung mit AK die mit einem Resistenz- und CSC-Phänotyp assoziiert sind

a: Schematische Darstellung der FACS-Analysen nach Anreicherung von Tumorzellen durch magnetische Separation. Den AK-Färbungen war der Ausschluss von Zelldebris und PI-gefärbter toter Zellen vorangestellt. Analysiert wurden Tumorzellen von vier unbehandelten Tumoren, drei Tumoren der Gruppe CAF - Remission und vier Tumore der Gruppe CAF - Progression. b: Die FACS-Analysen wurden mit den folgenden AK angefertigt: Cd24-FITC, Cd44-APC-Vio770, Cd95-PE-Vio770, Cd104-APC, Cd107a-APC, Cd146-PE, Cd201APC und Sca1-PE-Vio770. Dargestellt sind die Ergebnisse der FACS-Analysen, die die Tumorzellen auf Oberflächenmoleküle hin charakterisierten, die mit Resistenz und CSC-Eigenschaften assoziiert sind und die nach CAF-Therapie in veränderten Anteilen auf der Zelloberfläche präsentiert werden. Tumordissoziation und anschließende FACS-Analysen wurden zusammen mit D. Agorku (Miltenyi Biotec GmbH, Bergisch Gladbach) durchgeführt.

Die Ergebnisse der FACS-Analysen aus Abbildung 23 wurden durch IHC-Färbungen an Paraffinschnitten der Tumore der einzelnen Gruppen mit AK gegen die Oberflächenmoleküle Cd44 und Cd24 validiert. Die Färbeergebnisse in Abbildung 24 zeigen, dass sowohl unbehandelte als auch Tumore nach Wiederwachstum der Gruppe CAF - Progression eine große Anzahl Tumorzellen mit einer eindeutigen Cd44-Membranfärbung aufwiesen. Tumorzellen der Tumore in Remission waren 
fast ausschließlich für $\mathrm{Cd} 44$ positiv. Zellen der Randbereiche unbehandelter Tumore waren fast komplett Cd24 positiv und in Richtung Tumorzentrum mit zunehmend undifferenzierten Arealen wurden vermehrt ungefärbte Zellen beobachtet. Tumore der Gruppe CAF - Progression zeigten ein vergleichbares Ergebnis mit einer teilweise intensiveren Membranfärbung. Die Zellen der remittierten Tumore der Gruppe CAF - Remission waren schwächer mit dem Cd24-AK gefärbt, vorwiegend zytoplasmatisch und mehr Zellen blieben ungefärbt.

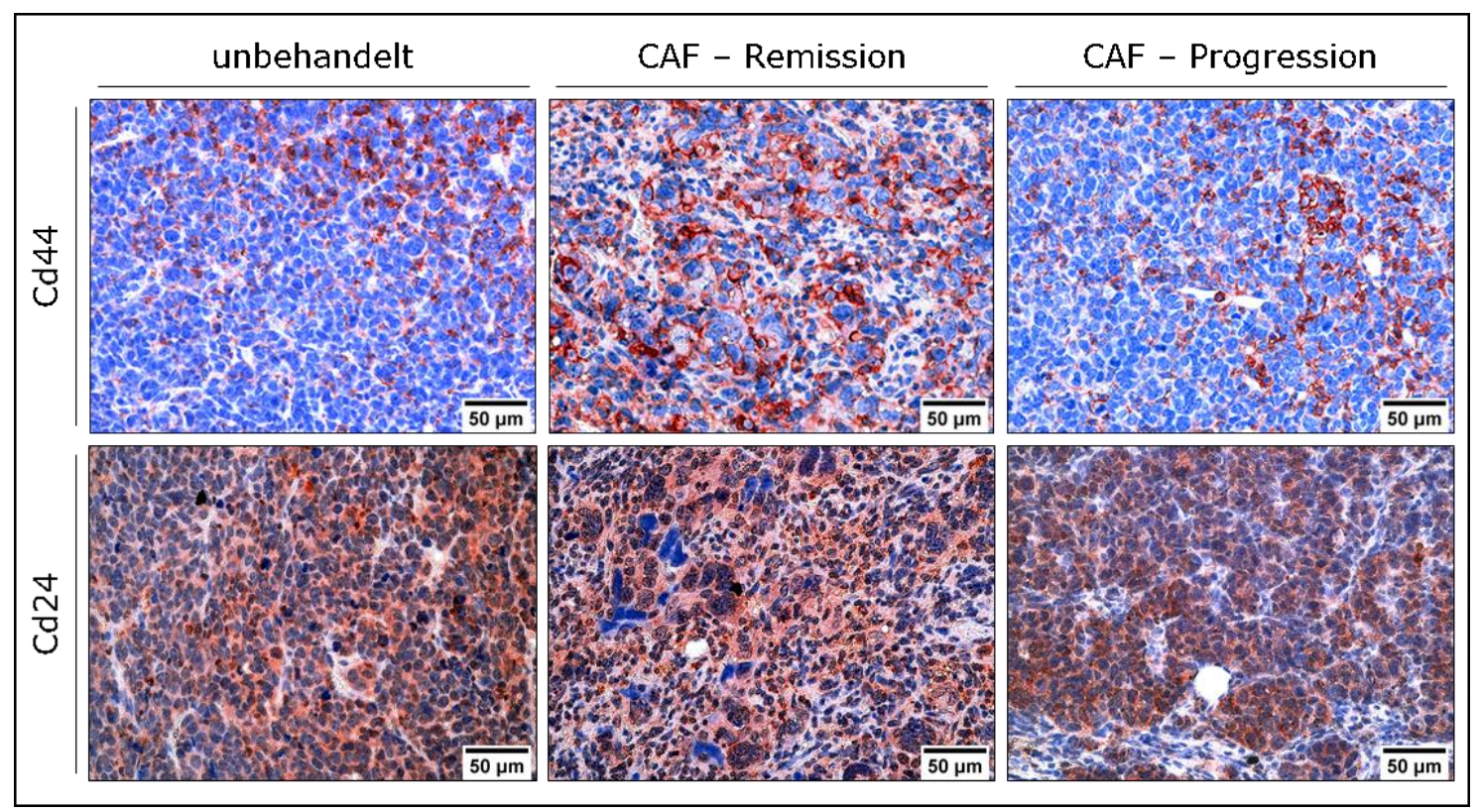

Abbildung 24: Verstärkte Cd44- und verminderte Cd24-Expression in remittierten Tumoren nach CAF-Therapie

Abgebildet sind IHC gefärbte repräsentative Tumorschnitte mit AK gegen Cd44 und Cd24, von einem unbehandelten Tumor $\left(\mathrm{Cd} 44: \mathrm{V}_{\mathrm{T}}=810,7 \mathrm{~mm}^{3} ; 34\right.$ Tage nach Transplantation; $\mathrm{Cd} 24: \mathrm{V}_{\mathrm{T}}=768,6 \mathrm{~mm}^{3} ; 28$ Tage nach Transplantation), zwei remittierten Tumoren der Gruppe CAF - Remission (Cd44: $\mathrm{V}_{\mathrm{T}}=251,0 \mathrm{~mm}^{3} ; 34$ Tage nach Transplantation und fünf Tage nach CAF-Applikation; $\mathrm{Cd} 24: \mathrm{V}_{\mathrm{T}}=126,6 \mathrm{~mm}^{3} ; 36$ Tage nach Transplantation und sechs Tage nach CAF-Applikation) sowie von einem Tumor der Gruppe CAF - Progression (Cd44 und Cd24: $\mathrm{V}_{\mathrm{T}}=806,8 \mathrm{~mm}^{3}$; 46 Tage nach Transplantation und 17 Tage nach CAF-Applikation). Detailaufnahme 400x Vergrößerung, Balken $50 \mu \mathrm{m}$. $\mathrm{V}_{\mathrm{T}}$ : Tumorvolumen nach der Sektion und Tumor ex vivo.

Abbildung 25 zeigt die Ergebnisse der FACS-Analysen spezifisch für die Cd44+Cd24-Tumorzellen, die mit der Fähigkeit zur Selbsterneuerung und gesteigerter Chemotherapieresistenz assoziiert werden (Al-Hajj et al. 2004; Shibue und Weinberg 2017) und das Vorkommen von resistenzenvermittelnden Oberflächenmolekülen wie Cd95, Cd104, Cd107a, Cd146, Cd201 und Sca1 auf der Zelloberfläche der $\mathrm{Cd} 44{ }^{+} \mathrm{Cd} 24-$ Tumorzellen von unbehandelten und CAF-therapierten Tumoren..

Die Hypothese, dass in CAF-therapierten Tumoren während der Remission der Anteil Cd44+Cd24--

Tumorzellen zunimmt (Abbildung 25a) und umgekehrt der Anteil Cd24+-Tumorzellen abnimmt (Ab-

bildung 25c) konnte so bestätigt werden. Im Verlauf der Progression der Residualtumore gleichen 
sich die prozentualen Anteile dem Niveau von unbehandelten Tumoren an. Weiter zeigen die Analysen, dass $\mathrm{CAF}$-therapierte $\mathrm{Cd} 44{ }^{+} \mathrm{Cd} 24$-Tumorzellen während der Remission signifikant häufiger als unbehandelte $\mathrm{Cd} 44{ }^{+} \mathrm{Cd} 24$-Tumorzellen und als $\mathrm{Cd} 44{ }^{+} \mathrm{Cd} 24$-Tumorzellen der Tumore der Gruppe CAF - Progression die Oberflächenmoleküle Cd95, Cd104, Cd107a, Cd146, Cd201 und Sca1 auf ihrer Zelloberfläche präsentierten (Abbildung 25b). Mit Ausnahme der $\mathrm{Cd} 24^{+} \mathrm{Cd} 95^{+}$und Cd24+Cd201+ Tumorzellen starben ein Großteil der Tumorzellen mit den Oberflächenmolekülsignaturen $\mathrm{Cd} 24^{+} \mathrm{Cd} 104^{+}, \mathrm{Cd} 24^{+} \mathrm{Cd} 107 \mathrm{a}^{+}, \mathrm{Cd} 24{ }^{+} \mathrm{Cd} 1466^{+}$und $\mathrm{Cd} 24{ }^{+} \mathrm{CdSca} 1{ }^{+}$nach $\mathrm{CAF}$ Applikaten während der Tumorremission, verdeutlicht an den reduzierten prozentualen Anteilen der Gruppe CAF - Remission. Im Verlauf des progressiven Wiederwachstums der Residualtumore waren, mit Ausnahme der $\mathrm{Cd} 24^{+} \mathrm{Cd} 95^{+}$und der $\mathrm{Cd} 24^{+} \mathrm{Cd} 201^{+}$Tumorzellen, die prozentualen Anteile der $\mathrm{Cd} 24^{+} \mathrm{Cd} 104^{+}, \mathrm{Cd} 24^{+} \mathrm{Cd} 107 \mathrm{a}^{+}, \mathrm{Cd} 24^{+} \mathrm{Cd} 1466^{+}$und $\mathrm{Cd} 24^{+} \mathrm{CdSca} 1{ }^{+}$Tumorzellen erhöht, verglichen mit den Anteilen der Gruppe CAF - Remission (Abbildung 25d).

Anhand der Oberflächenmolekülsignaturen wurde nachgewiesen, dass $\mathrm{Cd} 44{ }^{+} \mathrm{Cd} 24$-Tumorzellen im remittierten Tumor vermehrt resistenzenvermittelnde Oberflächenmoleküle auf ihrer Zelloberfläche präsentieren. Durch Analyse der isolierten und sequenzierten Tumorzell-mRNA bezüglich der Genexpression von CSC- und Pluripotenzmarkern wurde untersucht, ob die durchflusszytometrischen Ergebnisse auf der Ebene der Genexpression validiert werden können, um die CAF verursachte Selektion von resistenten $\mathrm{Cd} 44+\mathrm{Cd} 24-\mathrm{CSC}$ zu belegen. Dafür wurden die Genexpressionen der Tumorzell-mRNA der Tumore der Gruppe CAF-Remission und CAF - Progression gegen die Ergebnisse der sequenzierten Tumorzell-mRNA unbehandelter Tumore normiert.

Für Mammakarzinomzellen sind Integrin $\alpha-6$ (Itga6), aldehyde dehydrogenase family 1, subfamily A3 (Aldh1a3) und ATP binding cassette subfamily $G$ member 2 (Abcg2) wichtige mit CSC-Eigenschaften assoziierte Gene (Akrap et al. 2016). Verdeutlicht an den relativen Genexpressionen wird in der Abbildung 26 gezeigt, dass nach CAF Therapie sowohl im remittierten Tumor als auch im wieder gewachsenen progressiven Residualtumor diese Gene, mit Ausnahme von Itga6, verglichen mit den relativen Genexpressionen der unbehandelten Tumoren um einen $\log 2 \mathrm{FC}$ von eins bis zwei erhöht waren. Da bekannt ist, dass Mammakarzinom-CSC aufgrund ihrer tumorigenen Fähigkeiten erhöhte Genexpression von Genen besitzen, die mit Pluripotenz assoziiert sind, wurde diese im Weiteren analysiert. Die Tumorzell-mRNA Sequenzierungen ergaben, dass CAF therapierte Tumorzellen in 
Remission eine mehr als verdoppelte relative Genexpression der Pluripotenzmarker Nanog homeobox (Nanog) und SRY (sex determining region Y)-box 2 (Sox2) aufwiesen und alleinig der log2FC des Sox2 Gens von Residualtumorzellen im Verlauf der Progression der Tumore der Gruppe CAF Progression abnimmt (Abbildung 26).

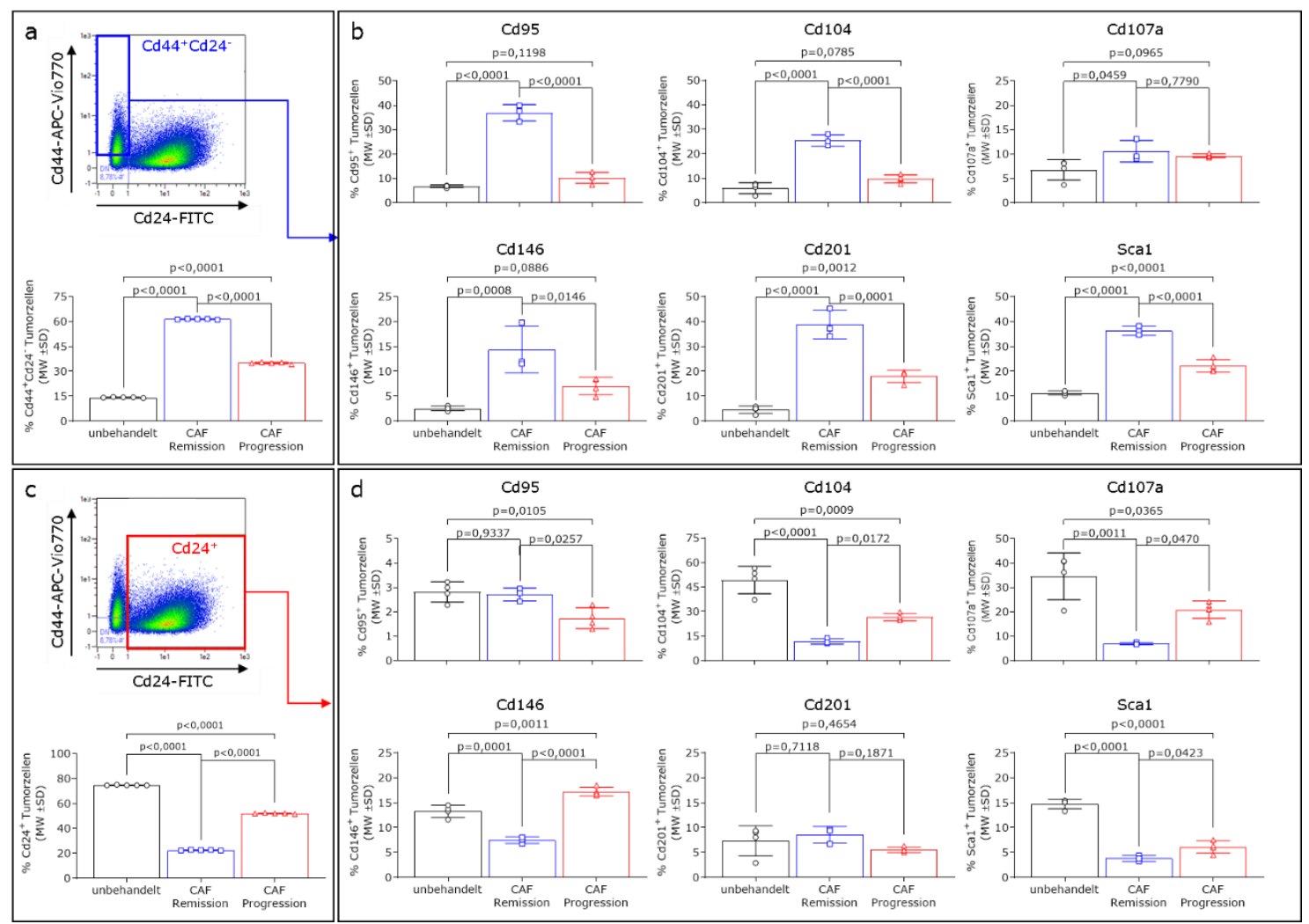

Abbildung 25: Vermehrte Anzahl Cd44+Cd24--Tumorzellen im remittierten Tumor nach CAF sind assoziert mit der Expression von Resistenz- und Stammzellmarkern

a und c: Darstellung der FACS-Analysen isolierter H8N8 Tumorzellen nach magnetischer Separation. Der Cd44 und Cd24 AK-Färbungen war der Ausschluss von Zelldebris, PI-gefärbter toter Zellen und LCR- Tumorzellen vorangestellt. Analysiert wurden LCR- Tumorzellen von vier unbehandelten Tumoren, drei Tumoren nach CAF in Remission und vier Residualtumoren in Progression. Im Diagramm sind die Unterschiede der Populationsgrößen der $\mathrm{Cd} 44^{+} \mathrm{Cd} 24^{-}$bzw. der $\mathrm{Cd} 24^{+}$Tumorzellen nach CAF Therapie dargestellt. b und d: Im blauen bzw. roten Kasten sind die Populationen markiert, auf die sich die folgenden Färbungen mit den hier genannten konjugierten AK beziehen: Cd95-PE-Vio770, Cd104-APC, Cd107a-APC, Cd146-PE, Cd201-APC und Sca1-PE-Vio770. Tumordissoziation und anschließende FACS-Analysen wurden zusammen mit D. Agorku (Miltenyi Biotec GmbH, Bergisch Gladbach) durchgeführt.

Betrachtet man die Ergebnisse des Abschnitts 5.3, zeigt sich für CAF therapierte Tumore in Remission bzw. für Residualtumore in Progression das folgende Bild. Durchflusszytometrische Analysen zeigen, dass die CAF Chemotherapie i) eine Zunahme der $\mathrm{Cd} 44{ }^{+} \mathrm{Cd} 24$ - Tumorzellen in remittierten Tumoren verursacht. Diese Population exprimiert während der Remission vermehrt Oberflächenmarker, die mit Stammzell- und Resistenzeigenschaften assoziiert sind und im Verlauf der Residual- 
tumorprogression wieder einen geringeren Anteil an der Gesamttumorzellzahl ausmacht. Histopathologische Beobachtungen ergaben, dass ii) nach CAF eine Umstrukturierung der Mammakarzinome während der Remission in Verbindung mit Kollagenbildung initiiert wird. Diese Umstrukturierung kehrt sich im Verlauf der Progression der Residualtumore wieder um, bis zu einer dem unbehandelten Tumor ähnelnden Histopathologie. Die mittels mRNA Sequenzierung erarbeiteten molekularbiologischen Daten lieferten den Nachweis, dass iii) nach CAF während der Remission EMT Prozesse ablaufen. Außerdem sind als Reaktion auf CAF anti-apoptotische Mechanismen zur Resistenzausbildung mittels Tnf- $\alpha$ - und Il6-Jak1-Stat3- Signaltransduktion aktiviert. Dies sind eventuell die verantwortlichen stimulierenden Signalwege für eine durch 116 vermittelte Zunahme der $\mathrm{Cd} 44{ }^{+} \mathrm{Cd} 24-$ Tumorzellpopulation.

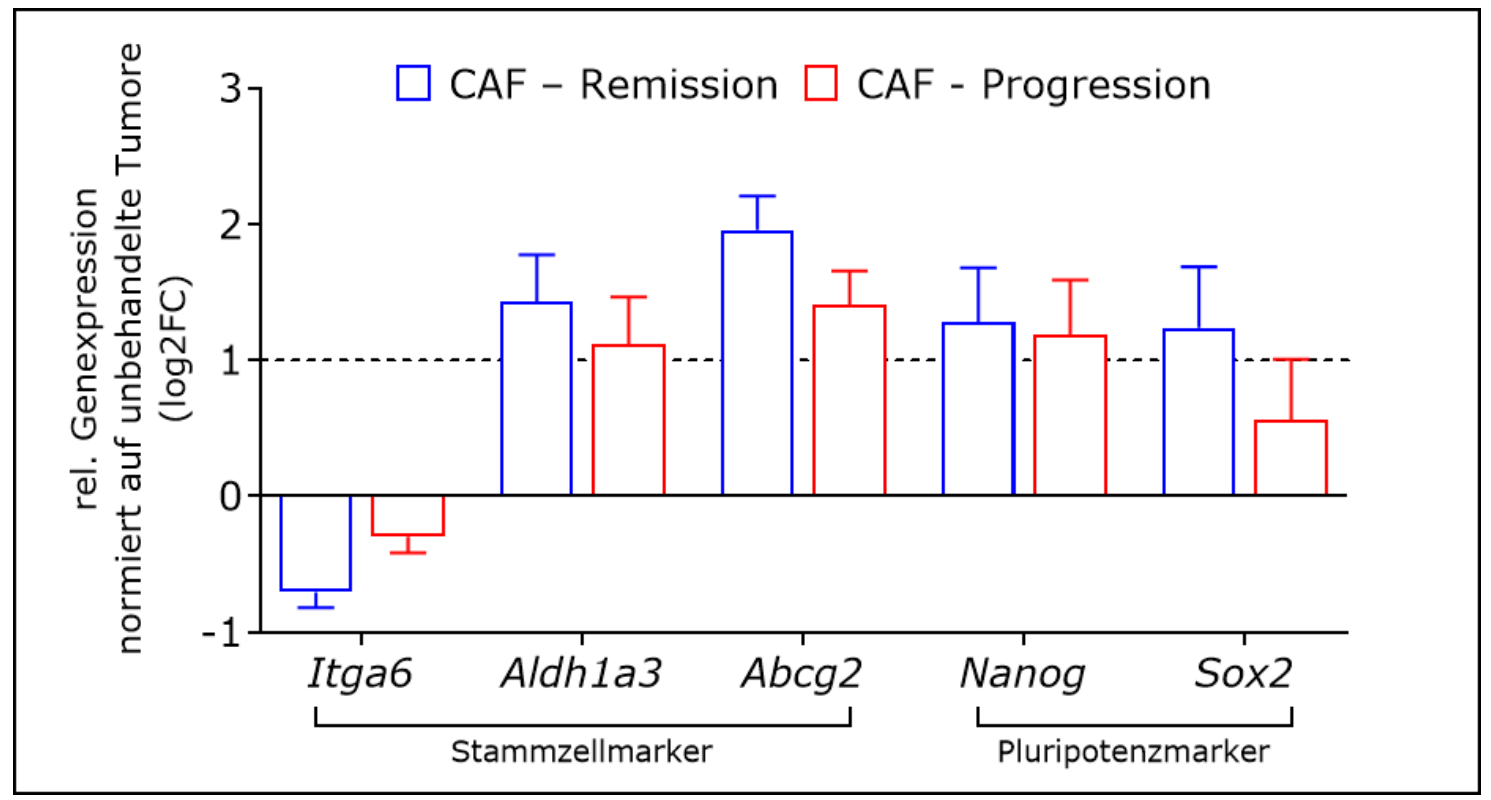

Abbildung 26: Relative Expression von Genen, die mit CSC-Eigenschaften und Pluripotenz assoziert sind, in H8N8-Tumorzellen nach CAF-Therapie

Relative Genexpression von Genen, die mit CSC-Eigenschaften und Pluripotenz assoziiert sind nach Tumorzell-mRNA Sequenzierung von CAF therapierten Tumoren in Remission $(n=4)$ und Progression $(n=4)$ normiert gegen die Genexpressionswerte der unbehandelten Tumore $(n=4)$. Die Isolierung der RNA, Herstellung der mRNA Bibliothek und Analyse der Daten erfolgte in Kollaboration mit Dr. Florian Wegwitz (AG Wegwitz, Universitätsmedizin Göttingen). 


\subsection{Einfluss von CAF auf bereits CAF therapierte Tumore}

Nach Anwendung der CAF-Therapie reichern sich $\mathrm{Cd} 44{ }^{+} \mathrm{Cd} 24-$-Tumorzellen mit einem EMT-typischen Genexpressionsprofil, Resistenz- und CSC-Eigenschaften im Tumor an. Da diskutiert wird, ob mit Chemotherapie behandelte überlebende Residualtumorzellen bei erneuter Therapie einen Überlebensvorteil erfahren (Kotiyal und Bhattacharya 2014; Felipe Lima et al. 2016), wurde untersucht, ob H8N8T2-Tumorzellen die aus Tumoren der Gruppe CAF - Remission isoliert wurden, nach Kultivieren und Retransplantieren in WAP-T-Mäuse bei erneuter CAF-Therapie mit einer gesteigerten Resistenz auf die CAF-Therapie reagieren. Die Ergebnisse der H8N8T2-Tumorzellen wurden mit den Ergebnissen der mittransplantierten zuvor unbehandelten H8N8T1-Tumorzellen und den zuvor CAF therapierten H8N8T3-Tumorzellen aus Tumoren der Gruppe CAF - Progression verglichen. Die H8N8T1- und H8N8T3-Tumorzellen wiesen in FACS-Analysen einen kleineren Anteil $\mathrm{Cd} 44{ }^{+} \mathrm{Cd} 24-$-Tumorzellen, verglichen mit dem Anteil Cd44+Cd24-Tumorzellen in Tumoren der Gruppe CAF - Remission, auf.

\subsubsection{Isolierte Tumorzellen behalten in vitro H8N8 Eigenschaften}

Aufgrund der starken Nebenwirkungen der CAF-Therapie war es nicht möglich, nach Wiederwachstum der Residualtumore, die Mäuse mit einem zweiten CAF-Zyklus zu therapieren. Deshalb wurden Tumorzellen aus Tumoren der Gruppen i) unbehandelt, ii) CAF - Remission und iii) CAF - Progression durch magnetische Separation isoliert, anschließend kultiviert und in WAP-T-NP8-Mäuse retransplantiert. Für die folgenden Auswertungen wurden die verschiedene H8N8-Tumorzelllinien in Tabelle 1 wie folgt zusammengefasst: T1.1, T1.2 und T1.4 Zellen aus unbehandelten Tumoren als H8N8T1-Gruppe, die T2.2 und T2.3 Zellen aus Tumoren der Gruppe CAF - Remission als H8N8T2-Gruppe sowie die T3.2, T3.3 und T3.4 Zellen aus Tumoren der Gruppe CAF - Progression als H8N8T3-Gruppe.

Die FACS-Ergebnisse in Abbildung 27a verdeutlichen nochmal, dass der Anteil Epcam+-Tumorzellen in den Tumoren der Gruppe CAF - Remission, verglichen mit den Anteilen in unbehandelten Tumoren und Tumoren der Gruppe CAF - Progression, am kleinsten war. Ein kleiner Anteil Epcam $^{+}$-Tumorzellen korreliert nach Kultivierung, bei einer frühen Passage kurz nach dem Isolieren, 
mit einem spindelförmig länglichen Phänotyp, der an mesenchymale Zellen erinnert. Tumorzellen mit einem großen Anteil Epcam ${ }^{+}$Tumorzellen wachsen für Epithelzellen typisch in einer Kopfsteinpflaster-artigen Morphologie. Die Phasenkontrastaufnahmen (Abbildung 27b) der kultivierten Tumorzellen der zuvor unbehandelten H8N8T1-Tumorzellen zeigen in Kultur vermehrt eine Kopfsteinpflaster-artige Morphologie (Pfeil in Abbildung 27b), welche bei kultivierten H8N8T2-Tumorzellen nicht zusehen und bei H8N8T3-Tumorzellen ansatzweise zu erahnen war (Pfeil in Abbildung 27b). In den Aufnahmen der kultivierten H8N8T2- und H8N8T3-Tumorzellen aus Tumoren der Gruppe CAF - Remission bzw. CAF - Progression sind ausschließlich (H8N8T2) bzw. mit wenigen Ausnahmen (H8N8T3) spindelförmige Zellen zu sehen, die einen mesenchymalen Phänotyp andeuten.

Abbildung 28 zeigt, dass auch nach CAF-Therapie sowie nach Isolation und Kultivierung der Tumorzellen, die für H8N8-Tumorzellen spezifischen Eigenschaften bei den verschiedenen H8N8 Varianten nach mehrwöchiger Kultivierung erkennbar waren. So zeigen alle drei H8N8T-Varianten die für H8N8-Tumorzellen spezifische T-Ag-Kernfärbung. In Abbildung 27b war keine epitheliale Kopfsteinpflaster-artige Morphologie bei kultivierten Tumorzellen einer früher Passage der H8N8T2-Tumorzellen erkennbar. Nach mehrwöchiger Kultivierung und mehrmaligen passagieren glichen sich die Morphologien der drei H8N8T-Varianten an, deutlich an den immunzytochemischen Fluoreszenzfärbungen in Abbildung 28. Tumorzellen, die mit Fluorophor-gekoppelten sAK gefärbt wurden, zeigen dass die verschiedenen H8N8T-Varianten vergleichbar sowohl den epithelialen als auch den mesenchymalen Phänotyp ausbildeten. 


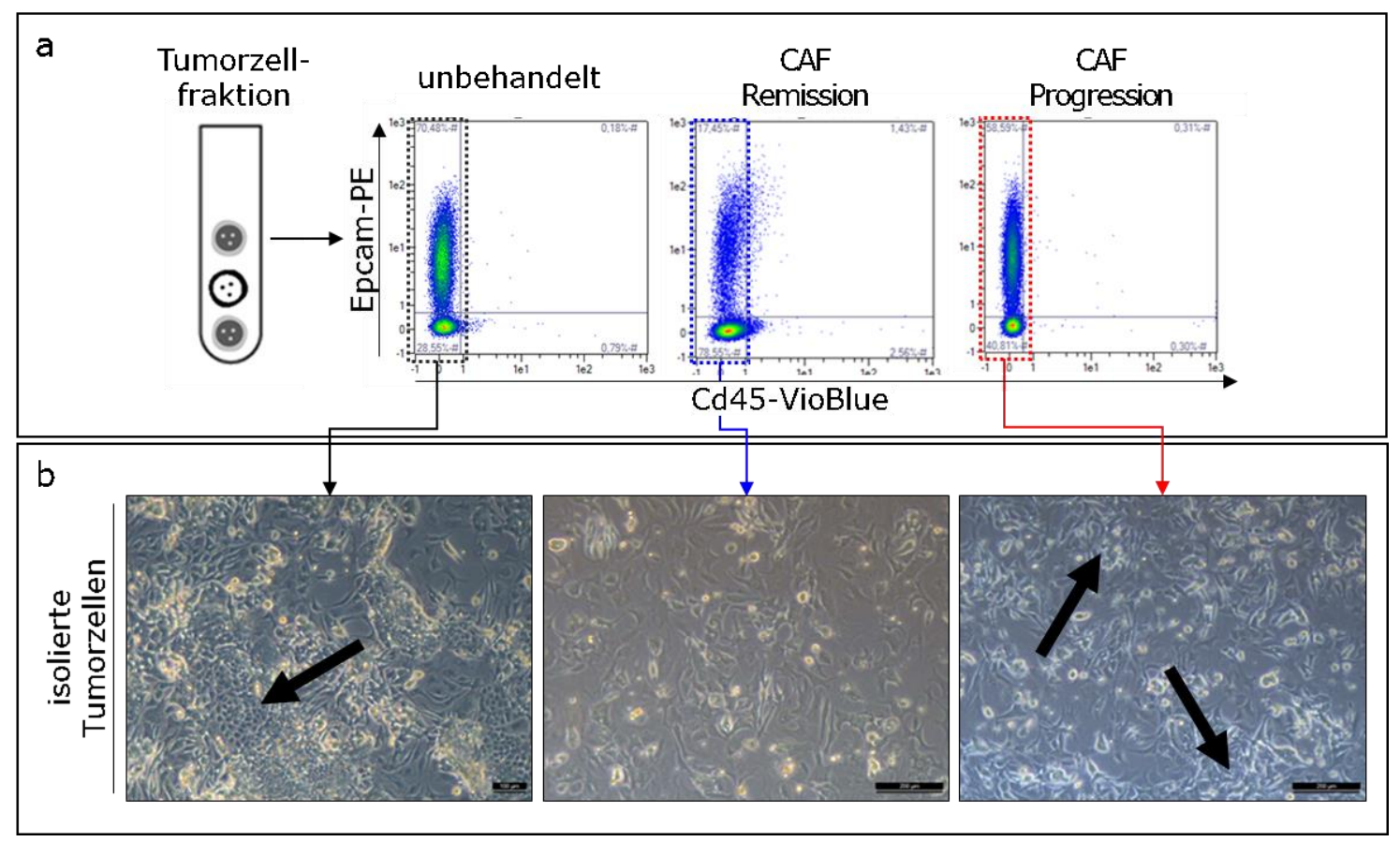

Abbildung 27: Kultivierung von unbehandelten und CAF therapierten Tumorzellen kurz nach Isolierung

a: Schematische Darstellung repräsentativer Cd45-VioBlue- und Epcam-PE-Färbungen der dissoziierten Einzel-Zellsuspension nach Anreicherung der unbehandelten und CAF therapierten Tumorzellen durch magnetische Separation. Dem Cd45-VioBlue/Epcam-PE-Gating vorangestellt waren der Ausschluss Zelldebris, PIgefärbter toter Zellen und LCR-Tumorzellen. In $\mathbf{b}$ sind beispielhafte Phasenkontrastaufnahmen der angereicherten und anschließend isolierten Tumorzellen von unbehandelten und CAF therapierten Tumoren in einer frühen Passage, kurz nach der Isolierung, in Kultur abgebildet. Phasenkontrastaufnahmen (100x Vergrößerung), Tumordissoziation und anschließende FACS-Analysen sowie Tumorzellisolierung wurden zusammen mit D. Agorku (Miltenyi Biotec GmbH, Bergisch Gladbach) durchgeführt.

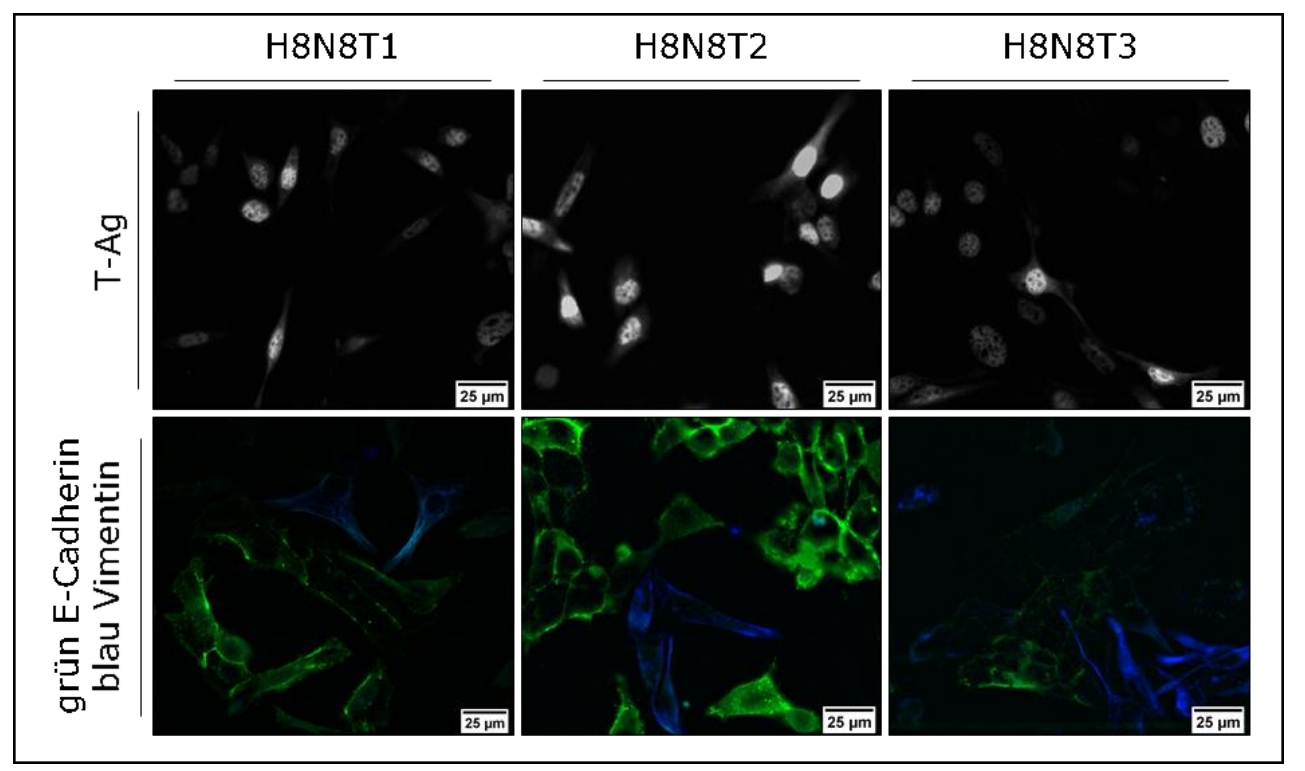

Abbildung 28: Expression von T-Ag, E-Cadherin und Vimentin nach CAF-Therapie in vitro

Hier sind repräsentative immunzytochemische Fluoreszenzfärbungen mit pAK gegen T-Ag sowie Doppelfärbungen mit pAK gegen E-Cadherin (grün) und Vimentin (blau) in Kombination mit unterschiedlich fluoreszenzmarkierten sAK abgebildet, von i) kultivierten isolierten zuvor in vivo unbehandelten H8N8T1Tumorzellen, ii) von zuvor in vivo CAF therapierten H8N8T2-Tumorzellen aus Tumoren der Gruppe CAF Remission sowie iii) von zuvor in vivo CAF therapierten H8N8T3-Tumorzellen aus Tumoren der Gruppe CAF - Progression, in einer späten Passage. Detailaufnahme 600x Vergrößerung, Balken $25 \mu \mathrm{m}$. 


\subsubsection{Erhöhte Resistenz bereits CAF therapierter retransplantierter Tumor- zellen nach erneuter CAF-Therapie in vivo}

Nach der erfolgreichen Überprüfung, dass die verschiedenen isolierten Tumorzellen weiterhin H8N8-Eigenschaften besaßen, wurden je 1x106 Zellen der T1.1-, T1.2-, T1.4-, T2.2-, T2.3-, T3.2-, T3.3- und T3.4-Tumorzelllinien orthotop in die rechte Mamma des vierten Mammapaars von syngenen WAP-T-NP8-Mäusen transplantiert. Dieser Versuch diente der Untersuchung, ob bereits CAF therapierte Tumorzellen bei erneuter CAF-Therapie einen Überlebensvorteil haben bzw. ob H8N8Tumorzellvarianten mit einem höheren Anteil an $\mathrm{Cd} 44{ }^{+} \mathrm{Cd} 24-$-Tumorzellen, wie die H8N8T2.2- oder die H8N8T2.3-Tumorzelllinie, bei erneuter CAF-Therapie resistenter sind. Die transplantierten Tiere wurden in die folgenden Gruppeneingeteilt und nach dem in Abbildung 29 gezeigtem Schema behandelt.

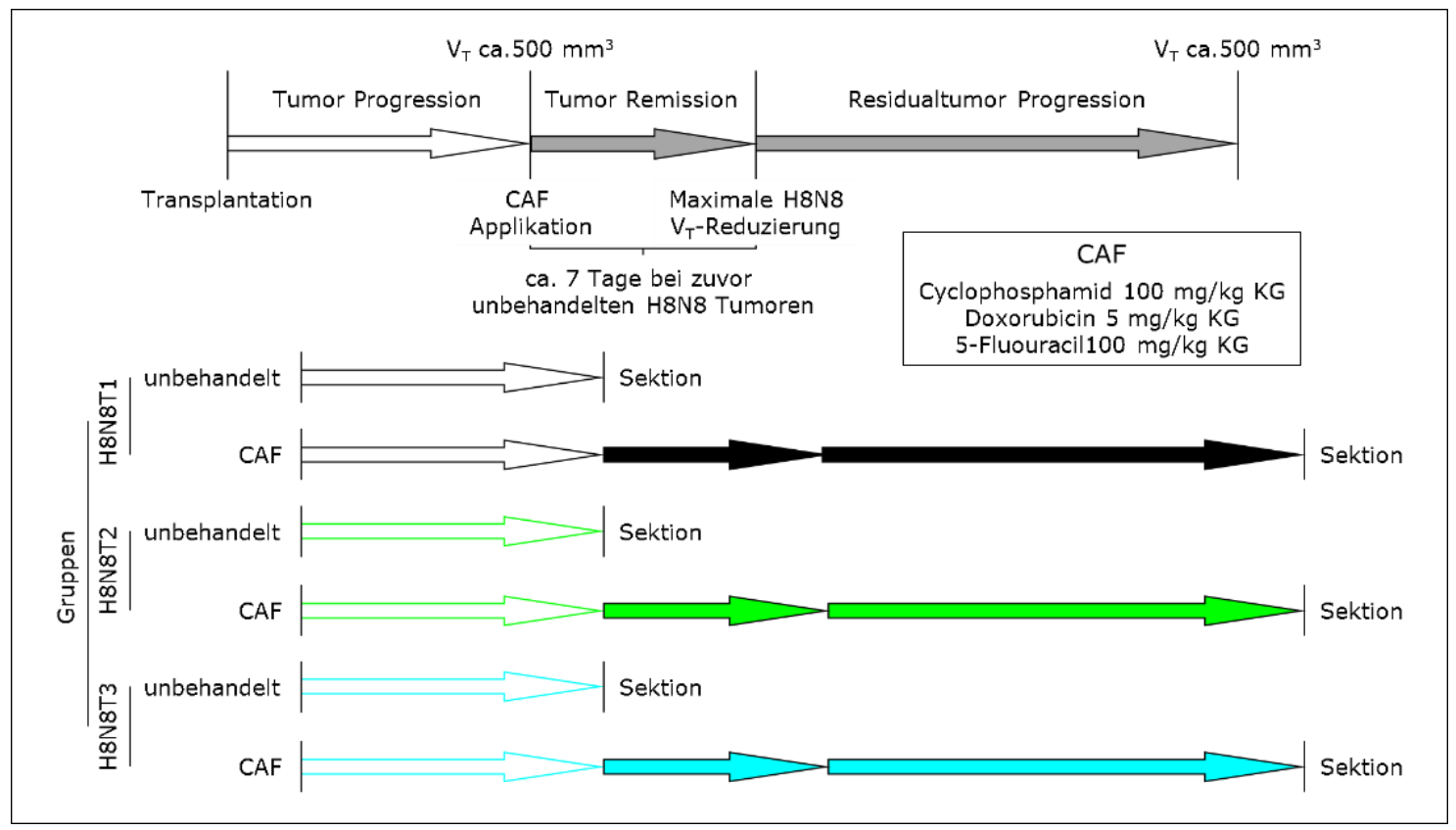

Abbildung 29: CAF-Behandlungsschema von H8N8T1, T2 und T3 tumortragenden Mäusen

Behandlungsschema und Gruppeneinteilung der weiblichen nicht induzierten transgenen heterozygotenWAPT-NP8-Mäuse zur Untersuchung der Wirkung der CAF-Therapie auf zuvor aus Tumoren isolierten unbehandelten H8N8T1 und bereits einmalig in vivo CAF therapierten H8N8T2 und H8N8T3 Tumorzellen. Weiter ist die Konzentration der jeweiligen CAF-Komponente angegeben.

Tabelle 27 und Abbildung 30 zeigen die Ergebnisse der Wirkung der CAF-Therapie, nach Retransplantation zuvor unbehandelter und CAF therapierter Tumorzellen, auf das Tumorwachstum mittels Bestimmung des $\mathrm{V}_{\text {T. }}$ Nach dem die Tumore aus transplantierten H8N8T2- undH8N8T3-Tumorzel- 
len erstmals ein bestimmbares $V_{\mathrm{T}}$ erreichten und vermessen wurden, war ihr Tumorwachstum schneller als das von Tumoren aus H8N8T1-Tumorzellen. Nach CAF-Applikation wiesen die H8N8T2 und H8N8T3-Tumorzellen eine gesteigerte Resistenz auf, weniger Tumorzellen wurden eliminiert, wodurch das $\mathrm{V}_{\mathrm{T}}$ der H8N8T2- und H8N8T3-Tumore, verglichen mit H8N8T1-Tumoren, weniger an $\mathrm{V}_{\mathrm{T}}$ verloren.

Die Ergebnisse zeigen, dass die Tumore, die sich aus zuvor CAF therapierten retransplantierten H8N8T2- und H8N8T3-Tumorzellen entwickelten, trotz vergleichbaren Mausalter und -gewichten zum Zeitpunkt der Transplantation, eine im Vergleich zu H8N8T1-Tumorzellen schnellere initiale Wachstumskinetik bis zum $\mathrm{V}_{\mathrm{T}}$ von ca. $500 \mathrm{~mm}^{3}$ aufwiesen, deutlich an einem größeren $\mathrm{V}_{\mathrm{T}}$ sechs Tage vor CAF-Applikation. $\mathrm{Zu}$ diesem Zeitpunkt hatten die H8N8T2-Tumore bereits ein $\mathrm{V}_{\mathrm{T}}$ von $395,8 \mathrm{~mm}^{3}\left( \pm 54,50 \mathrm{~mm}^{3}\right)$, die H8N8T3-Tumore bereits ein VT von $309,1 \mathrm{~mm}^{3}\left( \pm 99,01 \mathrm{~mm}^{3}\right) \mathrm{im}$ Vergleich zu den unbehandelten H8N8T1-Tumore mit einem signifikant kleineren $V_{T}$ von $246,7 \mathrm{~mm}^{3}\left( \pm 78,14 \mathrm{~mm}^{3}\right)$.

Zur Beurteilung der Wirkung der CAF-Therapie auf das Tumorwachstum sind die $\mathrm{V}_{\mathrm{T}}$ sechs und 12 Tage nach der CAF-Applikation in Tabelle 27 angegeben. Das $V_{\mathrm{T}}$ war sechs Tage nach der CAFTherapie bei Tumoren aus zuvor unbehandelten H8N8T1-Tumorzellen auf $175,4 \mathrm{~mm}^{3}$ $\left( \pm 54,62 \mathrm{~mm}^{3}\right)$, bei Tumoren aus zuvor CAF therapierten remittierten H8N8T2-Tumorzellen auf $369,0 \mathrm{~mm}^{3}\left( \pm 89,48 \mathrm{~mm}^{3}\right)$ bzw. bei H8N8T3 nach Progression auf $395,0 \mathrm{~mm}^{3}\left( \pm 164,59 \mathrm{~mm}^{3}\right)$ reduziert. Das $\mathrm{V}_{\mathrm{T}}$ war 12 Tage nach der CAF-Therapie bei Tumoren aus H8N8T1-Tumorzellen noch auf $305,6 \mathrm{~mm}^{3}\left( \pm 345,11 \mathrm{~mm}^{3}\right)$, bei Tumoren aus H8N8T2-Tumorzellen auf 400,4 $\mathrm{mm}^{3}\left( \pm 109,14 \mathrm{~mm}^{3}\right)$ und bei Tumoren aus H8N8T3-Tumotzellen auf 446,0 $\mathrm{mm}^{3}\left( \pm 236,62 \mathrm{~mm}^{3}\right)$ verkleinert. Die CAFTherapie war gegen Tumore aus zuvor CAF therapierten H8N8T2- und H8N8T3-Tumorzellen, die erneut therapiert wurden, verglichen mit der CAF-Wirkung auf unbehandelte H8N8T1-Tumore, sechs Tage nach CAF-Applikation signifikant weniger wirksam ergo zeigten Tumore aus H8N8T2und H8N8T3-Tumorzellen eine gesteigerte CAF-Resistenz. 
Tabelle 27 Vergleich verschiedener Parameter nach Retransplantation von H8N8T1-, T2- und T3Tumorzellen nach CAF-Therapie

Die hier mittels Schieblehre gemessenen und berechneten Werte beziehen sich auf das $\mathrm{V}_{\mathrm{T}}$ der Tumore in situ in den noch lebenden Mäusen nach Retransplantation von H8N8T1-, H8N8T2- und H8N8T3-Tumorzellen. Die statistische Signifikanz (p-Wert) zum Vergleich von zwei Gruppen wurde mit dem ungepaarten Student-tTest ermittelt.

\begin{tabular}{|c|c|c|c|c|c|c|c|c|c|c|}
\hline & \multicolumn{3}{|c|}{ H8N8T1 } & \multicolumn{3}{|c|}{ H8N8T2 } & \multicolumn{3}{|c|}{ H8N8T3 } & \multirow{3}{*}{$\begin{array}{c}\text { p-Wert } \\
\text { Vergleich } \\
\text { (a)H8N8T2/T1 } \\
\text { (b)H8N8T3/T1 }\end{array}$} \\
\hline & $\begin{array}{c}\text { von- } \\
\text { bis }\end{array}$ & MW & $\pm \mathrm{SD}$ & $\begin{array}{c}\text { von- } \\
\text { bis }\end{array}$ & MW & $\pm \mathrm{SD}$ & $\begin{array}{c}\text { von- } \\
\text { bis }\end{array}$ & MW & $\pm \mathrm{SD}$ & \\
\hline $\begin{array}{l}\text { Zelllinie (Passage) } \\
\text { Anzahl (n) }\end{array}$ & \multicolumn{3}{|c|}{$\begin{array}{c}\text { H8N8T1.1 (25) } \\
\text { H8N8T1.2 (13) } \\
\text { H8N8T1.4 (25) } \\
16\end{array}$} & \multicolumn{3}{|c|}{$\begin{array}{c}\text { H8N8T2.2 (29) } \\
\text { H8N8T2.3 (29) } \\
11\end{array}$} & \multicolumn{3}{|c|}{$\begin{array}{c}\text { H8N8T3.2 (25) } \\
\text { H8N8T3.3 (13) } \\
\text { H8N8T3.4 (25) } \\
15\end{array}$} & \\
\hline $\begin{array}{l}\text { Mausalter bei } \\
\text { Transplantation } \\
\text { (Wochen) }\end{array}$ & $\begin{array}{l}9,0- \\
35,0\end{array}$ & 20,3 & 7,63 & $\begin{array}{c}11,0- \\
35,0\end{array}$ & 20,4 & 8,70 & $\begin{array}{l}9,0- \\
32,0\end{array}$ & 18,6 & 7,49 & $\begin{array}{l}\text { a) } p=0,9697 \\
\text { b) } p=0,4821\end{array}$ \\
\hline $\begin{array}{l}\text { Mausgewicht bei } \\
\text { Transplantation (g) }\end{array}$ & $\begin{array}{l}19,8- \\
28,6\end{array}$ & 23,8 & 2,55 & $\begin{array}{l}19,9- \\
32,2\end{array}$ & 23,5 & 3,26 & $\begin{array}{l}19,5- \\
27,4\end{array}$ & 23,4 & 2,13 & $\begin{array}{l}\text { a) } p=0,8470 \\
\text { b) } p=0,6210\end{array}$ \\
\hline $\begin{array}{l}\text { Zeit bis } V_{\mathrm{T}} \text { ca. } 500 \mathrm{~mm}^{3} \\
\text { (Tage) }\end{array}$ & $\begin{array}{c}15,0- \\
28,0\end{array}$ & 18,1 & 3,30 & $\begin{array}{c}14,0- \\
19,0\end{array}$ & 18,2 & 1,40 & $\begin{array}{c}20,0- \\
43,0\end{array}$ & 22,8 & 6,05 & $\begin{array}{l}\text { a) } p=0,3111 \\
\text { b) } p=0,0140\end{array}$ \\
\hline $\begin{array}{l}\mathrm{V}_{\mathrm{T}} 6 \text { Tage vor } \\
\text { Therapiestart }\left(\mathrm{mm}^{3}\right)\end{array}$ & $\begin{array}{l}137,6- \\
380,5\end{array}$ & 246,7 & 78,14 & $\begin{array}{c}309,5- \\
477,6\end{array}$ & 395,8 & 54,50 & $\begin{array}{l}89,1- \\
476,6\end{array}$ & 309,1 & 99,01 & $\begin{array}{l}\text { a) } p<0,0001 \\
\text { b) } p=0,0631\end{array}$ \\
\hline $\begin{array}{l}V_{\mathrm{T}} \text { bei Therapiestart } \\
\left(\mathrm{mm}^{3}\right)\end{array}$ & $\begin{array}{c}502,7- \\
659,1\end{array}$ & 582,6 & 49,19 & $\begin{array}{l}500,9- \\
717,6\end{array}$ & 612,0 & 81,63 & $\begin{array}{l}370,3- \\
866,7\end{array}$ & 590,1 & 114,85 & $\begin{array}{l}\text { a) } p=0,3029 \\
\text { b) } p=0,5764\end{array}$ \\
\hline $\begin{array}{l}\mathrm{V}_{\mathrm{T}} 6 \text { Tage nach CAF } \\
\left(\mathrm{mm}^{3}\right)\end{array}$ & $\begin{array}{l}119,5- \\
306,4\end{array}$ & 175,4 & 54,62 & $\begin{array}{c}255,3- \\
490,6\end{array}$ & 368,0 & 89,48 & $\begin{array}{c}221,0- \\
674,9\end{array}$ & 395,0 & 164,59 & $\begin{array}{l}\text { a) } p=0,0018 \\
\text { b) } p=0,0065\end{array}$ \\
\hline $\begin{array}{l}\text { VT } 12 \text { Tage nach CAF } \\
\left(\mathrm{mm}^{3}\right)\end{array}$ & $\begin{array}{l}68,9- \\
994,8\end{array}$ & 305,6 & 345,11 & $\begin{array}{c}268,8- \\
575,5\end{array}$ & 400,4 & 109,14 & $\begin{array}{c}157,6- \\
879,9\end{array}$ & 446,0 & 236,62 & $\begin{array}{l}\text { a) } p=0,5449 \\
\text { b) } p=0,4152\end{array}$ \\
\hline
\end{tabular}

Zur weiteren Beurteilung der Tumorwachstumskinetiken wurden die $\mathrm{V}_{\mathrm{T}}$ auf das mittlere $\mathrm{V}_{\mathrm{T}}$ aller Tumore der H8N8T1- (582,6 mm³), H8N8T2- (612,0 mm3) bzw. H8N8T3-Zelllinie (590,1 mm³) bei Therapiestart (Tag 0) normiert, gemittelt und in Abbildung 30b gegen die Zeit aufgetragen. Die horizontale gestrichelte Linie beim Wert 1 markiert das mittlere $\mathrm{V}_{\mathrm{T}}$ aller Tumore der jeweiligen retransplantierten Zelllinie bei Therapiestart (Abbildung 30b). Das linke X-Y-Diagramm in Abbildung 30b zeigt, dass die Wachstumskinetiken der Tumore der H8N8T1-, H8N8T2- und H8N8T3-Zelllinien ohne Behandlung vergleichbar sind. Tumore aus den retransplantierten zuvor bereits einmalig CAF therapierten Tumorzelllinien H8N8T2 und H8N8T3, welche einen höheren Anteil an $\mathrm{Cd}_{4} 4^{+} \mathrm{Cd} 24-$ Tumorzellen aufwiesen, zeigten nach erneuter CAF Therapie, verglichen mit Tumoren aus retransplantierten zuvor unbehandelten H8N8T1 Tumorzellen. Das $V_{\mathrm{T}}$ der Tumore aus H8N8T1-Tumorzellen reduzierte sich nach CAF-Applikation um 68,6\% ( $\pm 13,38 \%)$ innerhalb der ersten sieben Tage nach CAF-Applikation. Tumore aus H8N8T2-Tumorzellen, also diejenigen aus remittierten CAF therapierten Tumoren, waren nach sieben Tagen nur um 42,7\% ( $\pm 21,22 \%)$ und Tumore aus 
H8N8T3 Tumorzellen, die aus wieder wachsenden Residualtumoren isoliert wurden, um 26,3\% $( \pm 31,69 \%)$ in ihrem Volumen verkleinert.

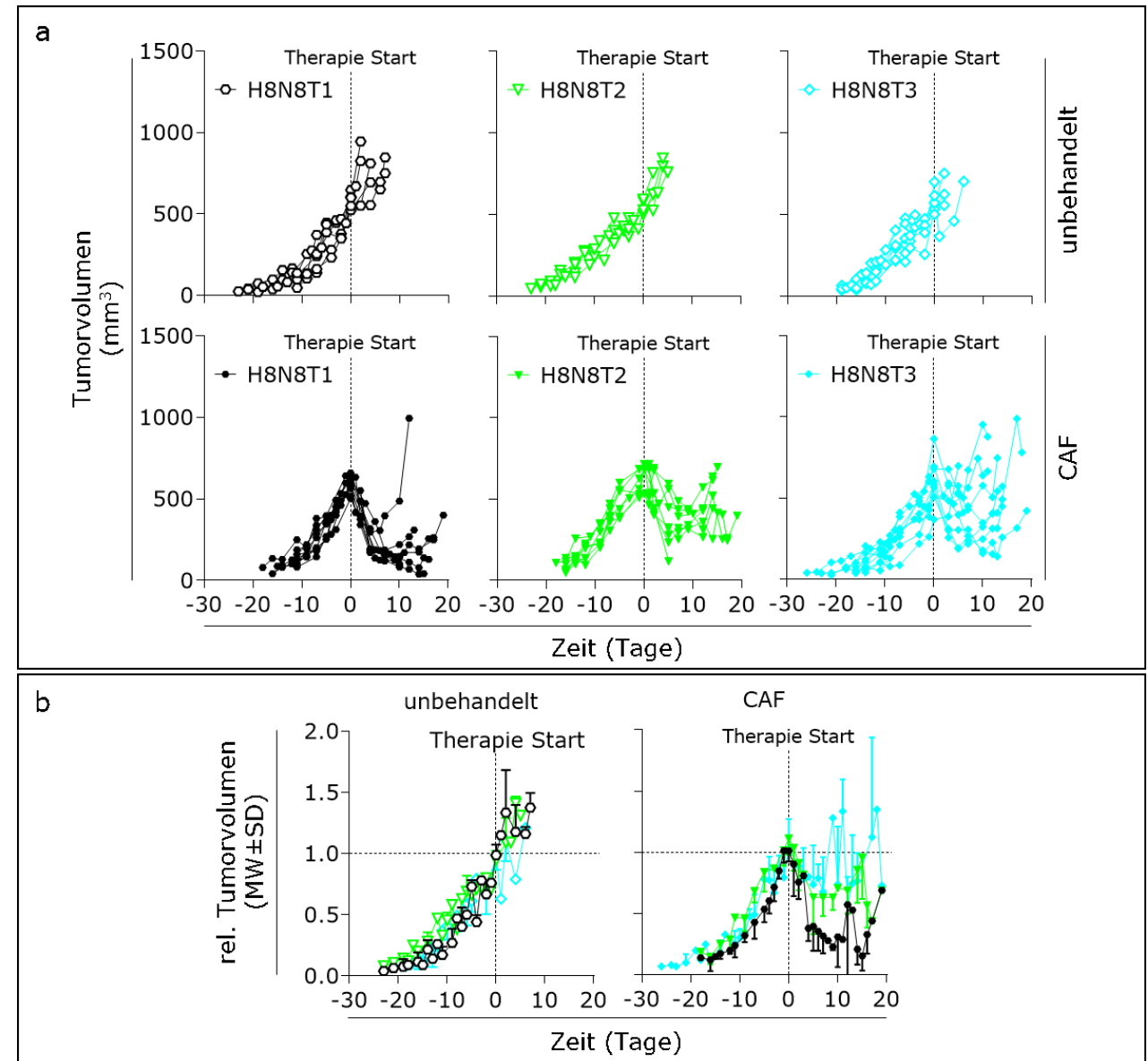

Abbildung 30: Wachstumskinetiken der Tumore aus den retransplantierten H8N8T1-, T2- und T3Tumorzellen

Dargestellt sind Wachstumskinetiken von Tumoren aus zuvor unbehandelten H8N8T1 Tumorzellen (unbehandelt $n=6 / C A F n=10$ ), von Tumoren aus zuvor CAF remittierten H8N8T2 Tumorzellen (unbehandelt $\mathrm{n}=4$ / CAF $\mathrm{n}=7$ ) und von Tumoren aus zuvor CAF therapierten H8N8T3 Residualtumorzellen in Progression (unbehandelt $\mathrm{n}=6$ / CAF $\mathrm{n}=9$ ). Der Tag 0 auf der $\mathrm{x}$-Achse markiert den Zeitpunkt, an dem die Tumore das $\mathrm{V}_{\mathrm{T}}$ von ca. $500 \mathrm{~mm}^{3}$ erreichten und CAF in den entsprechenden Gruppen appliziert wurde. a: Dargestellt sind die absoluten Werte aller Tumore. b: Zusehen sind die mittleren relativen Wachstumskinetiken. Die $V_{\mathrm{T}}$ der Transplantationen wurden auf den MW der $\mathrm{V}_{\mathrm{T}}$ aller Tumore der jeweiligen Zelllinien bei Therapiestart (Tag 0) normiert (gestrichelte horizontale Linie) und anschließend gemittelt. $\mathrm{V}_{\mathrm{T}}$ : Tumorvolumen. $\mathbf{a}$ und $\mathbf{b}$ : Tumore wurden in situ an der noch lebenden Maus vermessen. 


\subsubsection{Isolierte, bereits CAF therapierte Tumorzellen besitzen gesteigerte CAF Resistenz in vitro}

Die Transplantationsversuche ergaben, dass CAF therapierte Tumorzellen nach Retransplantation und erneuter CAF-Therapie in vivo weniger effektiv durch CAF eliminiert wurden, verglichen mit einmalig behandelten Tumoren. Die Resistenzfähigkeiten der einmal und zweimal therapierten Tumorzellen wurden in vitro mittels Impedanzmessungen für Toxizitätsanalysen weiter validiert. Die Impedanzmessung beruht auf der Aufzeichnung sich verändernder Wechselstromwiderstände bei unterschiedlichen Zelldichten. Der gemessene Widerstand ergo die Impedanz wird größer, wenn der jeweilige Zelltyp durch Proliferation einen dichteren Zell-Monolayer mit mehr Adhäsionsverbindungen ausbildet.

Zur Bestimmung der Impedanz unter CAF Therapie wurde die Impedanz von unbehandelten H8N8, T1.1-, T1.2- und T1.4-, von zuvor CAF therapierten T2.2-, T2.3- sowie T3.2- und T3.3-Tumorzellen (Tabelle 1) nach Kultivierung und Behandlung mit verschiedenen CAF-Konzentrationen in transparenten NSP96-Multiwellsensorplatten gemessen. Als positive Kontrollen wurden Zellen mit $2 \%$ Tween behandelt und als negative Kontrollen dienten unbehandelte Zellen in DMEM. Die Zellen wurden mit den folgenden CAF-Konzentrationen behandelt: letale Dosis (LD) 25, LD50, LD75 und LD100. Die LD-Werte wurden im Voraus mittels MTT-Viabilitätsmessungen der Zellen anhand der parentalen H8N8-Mammakarzinom-Zelllinie ermittelt (Daten nicht gezeigt). Die verwendeten Konzentrationen der jeweiligen CAF-Komponente sind in Tabelle 28 aufgelistet:

Tabelle 28: Verwendete CAF-Konzentrationen für Impedanzmessungen am CardioExcyte96

\begin{tabular}{l|ccc} 
& Cyclophosphamid & Doxorubicin & 5-Fluouracil \\
\hline \hline LD25 & $0,0259 \mu \mathrm{g} / \mathrm{ml}$ & $0,0013 \mu \mathrm{g} / \mathrm{ml}$ & $0,0259 \mu \mathrm{g} / \mathrm{ml}$ \\
LD50 & $0,1895 \mu \mathrm{g} / \mathrm{ml}$ & $0,0095 \mu \mathrm{g} / \mathrm{ml}$ & $0,1895 \mu \mathrm{g} / \mathrm{ml}$ \\
$\mathrm{LD} 75$ & $1,3890 \mu \mathrm{g} / \mathrm{ml}$ & $0,0690 \mu \mathrm{g} / \mathrm{ml}$ & $1,3890 \mu \mathrm{g} / \mathrm{ml}$ \\
LD100 & $20,000 \mu \mathrm{g} / \mathrm{ml}$ & $1,0000 \mu \mathrm{g} / \mathrm{ml}$ & $20,000 \mu \mathrm{g} / \mathrm{ml}$
\end{tabular}

Auf transparenten NSP96-Multiwellsensorplatten wurden zwei Zellinien gleichzeitig analysiert und jede Konzentration bzw. Kontrolle mit je acht Replikaten verwendet. Die Zellen wurden hier mit einer Konzentration von 50000 Zellen/200 $\mu$ l/Well (250 000 Zellen/ml) ausgesät. Daraus ergab sich der folgende in Tabelle 29 dargestellte Plattenbelegungsplan: 
Tabelle 29: Plattenbelegungsplan der Impedanzmessungen am CardioExcyte96

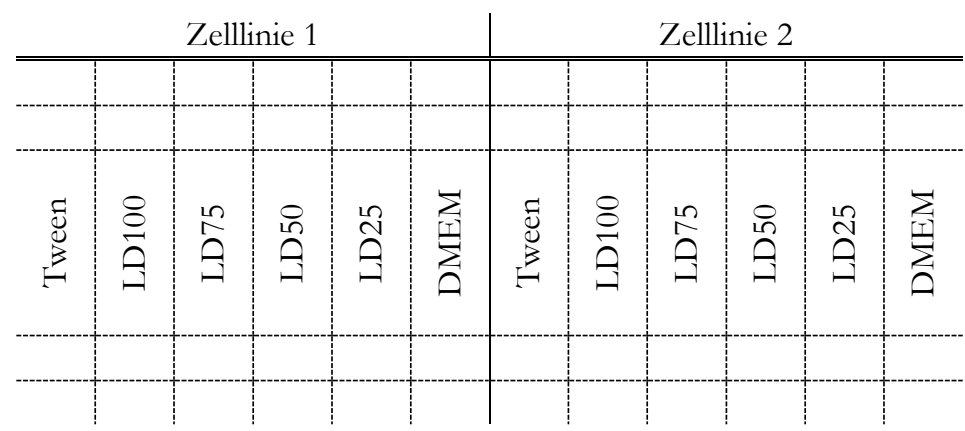

Abbildung 31 zeigt, dass H8N8T2-Tumorzellen, die zuvor in vivo mit CAF therapiert und aus einem remittierten Tumor isoliert wurden, resistenter bei erneuter in vitro CAF-Therapie waren. So zeigten H8N8T2-Tumorzellen nach einer Therapie mit der LD50 CAF-Konzentration, höhere und schneller ansteigende Impedanzkurven (Abbildung 31), was einhergeht mit einem vermehrten Tumorzellwachstum, bei einer Konzentration wo die anderen Tumorzelllinien starben bzw. ihr Wachstum gehemmt wurde. Die H8N8T3-Tumorzellene hingegen zeigten in den in vitro Untersuchungen, verglichen mit H8N8 und H8N8T1 keine erhöhte CAF-Resistenz, im Gegenteil, die H8N8T3-Tumorzellen reagierten in vitro eher sensitiver auf eine erneute CAF-Therapie.

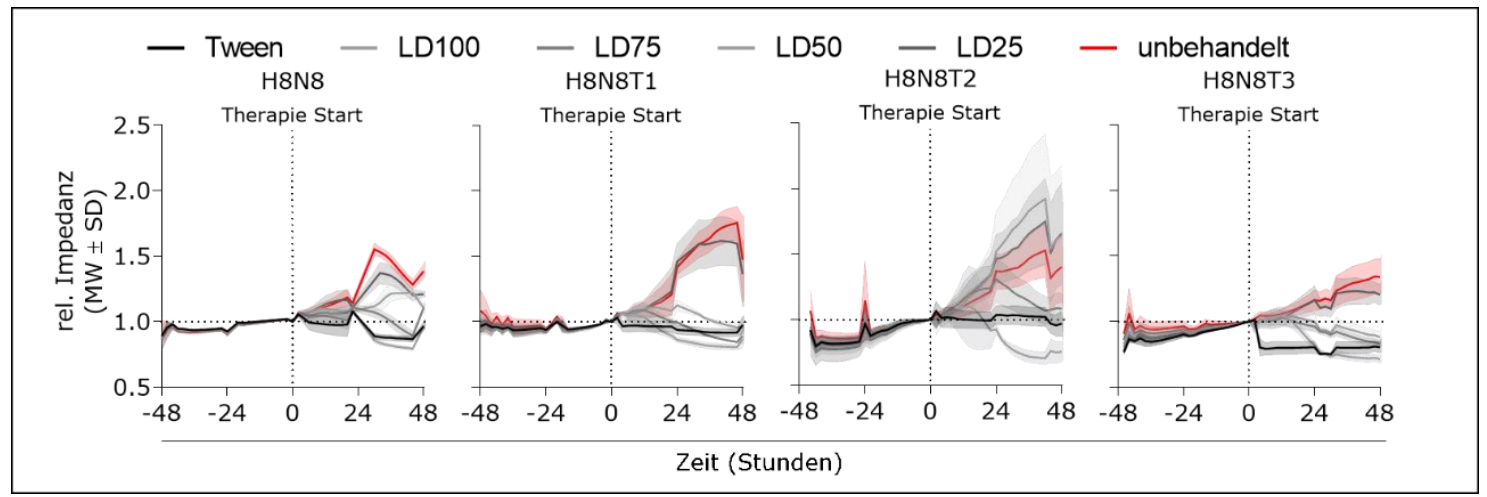

Abbildung 31: Nachweis der gesteigerten CAF-Resistenz in H8N8T2-Tumorzellen nach CAFTherapie in vitro

a: Darstellung der Ergebnisse nach Impedanzmessung am CE96 von H8N8-, H8N8T1-, H8N8T2- und H8N8T3-Tumorzellen. Nach initialem Zellwachstum über $48 \mathrm{~h}$ wurden die Zellen mit CAF in verschiedenen Konzentration (LD25, LD50, LD75 und LD100; siehe Tabelle 31) für $48 \mathrm{~h}$ behandelt. Die vertikale gestrichelte Linie markiert den CAF-Therapiestart. Die horizontale gestrichelte Linie markiert die Grundimpedanz und wurde berechnet aus der Normierung der gemessenen Werte auf den MW der gemessenen Werte vor Therapiestart. Das Messintervall betrug $5 \mathrm{~s}$ alle $1 \mathrm{~h}$. Als positive Kontrollen wurden Zellen mit $2 \%$ Tween behandelt und als negative Kontrollen dienten unbehandelte Zellen in DMEM.

Die im Abschnitt 5.4 dargelegten Resultate bestätigen sowohl mit in vitro als auch mit in vivo Experimenten, dass H8N8T2 Tumorzellen isoliert aus CAF therapierten Tumoren in Remission, welche höhere Anteile $\mathrm{Cd} 44{ }^{+} \mathrm{Cd} 24$ - Tumorzellen hatten, bei erneuter CAF Therapie einen Überlebensvorteil 
besaßen und eine gesteigerte Resistenz gegenüber Chemotherapie aufwiesen. Dies wurde für H8N8T3 Tumorzellen nur nach Retransplantation und erneuter CAF Therapie in vivo nachgewiesen.

\subsection{Kombinationstherapie aus CAF und Siltuximab}

Die Ergebnisse zeigen, dass die CAF-Therapie während der Remission i) zur Ausschüttung und Stimulierung von Il6 durch den Tnf- $\alpha$ und den Il6-Jak1-Stat3-Signalweg sowie ii) zur Anreicherung von $\mathrm{Cd}_{4}{ }^{+} \mathrm{Cd} 24-$-Tumorzellen in CAF therapierten Tumoren in Remission führt. Ob es einen Zusammenhang zwischen der verstärkten Sekretion von $\mathrm{Il} 6$ und der Anreicherung von $\mathrm{Cd} 44{ }^{+} \mathrm{Cd} 24-\mathrm{Tu}-$ morzellen gibt, so wie es Iliopoulos et al. beschrieb(Iliopoulos et al. 2011), wurde durch die Anwendung einer Kombinationstherapie aus CAF und dem Il6-Inhibitor Siltuximab im syngenen WAP-TMammakarzinom-Mausmodell untersucht. Das Behandlungsschema mit der Gruppeneinteilung ist in Abbildung 32 schematisiert dargestellt.

Nach orthotoper Transplantation der H8N8-Tumorzellen wurden zehn Tiere bei einem VT von ca. $500 \mathrm{~mm}^{3}$ mit $10 \mathrm{mg} / \mathrm{kg}$ KG Siltuximab in PBS, alle drei Tage über eine Zeitraum von maximal $30 \mathrm{Ta}-$ gen, intraperitoneal behandelt; je zehn Tiere einmalig nur mit CAF (100 mg/kg KG Cyclophosphamid, $5 \mathrm{mg} / \mathrm{kg} \mathrm{KG}$ Doxorubicin und $100 \mathrm{mg} / \mathrm{kg} \mathrm{KG} \mathrm{5-Fluouracil)} \mathrm{bzw.} \mathrm{einmalig} \mathrm{mit} \mathrm{CAF}$ (100 mg/kg KG Cyclophosphamid, 5 mg/kg KG Doxorubicin und 100 mg/kg KG 5-Fluouracil) in Kombination mit $10 \mathrm{mg} / \mathrm{kg}$ KG Siltuximab in PBS, alle drei Tage und die erste Gabe einen Tag vor der CAF-Applikation. Zehn unbehandelte Tiere dienten als Kontrolle. Die Tumore wurden spätestens bei einem maximalen $V_{\mathrm{T}}$ von ca. $1000 \mathrm{~mm}^{3}$ oder aber wegen einem Mausgewichtsverlust, von maximal $20 \%$, früher nach der CAF-Applikation seziert. 


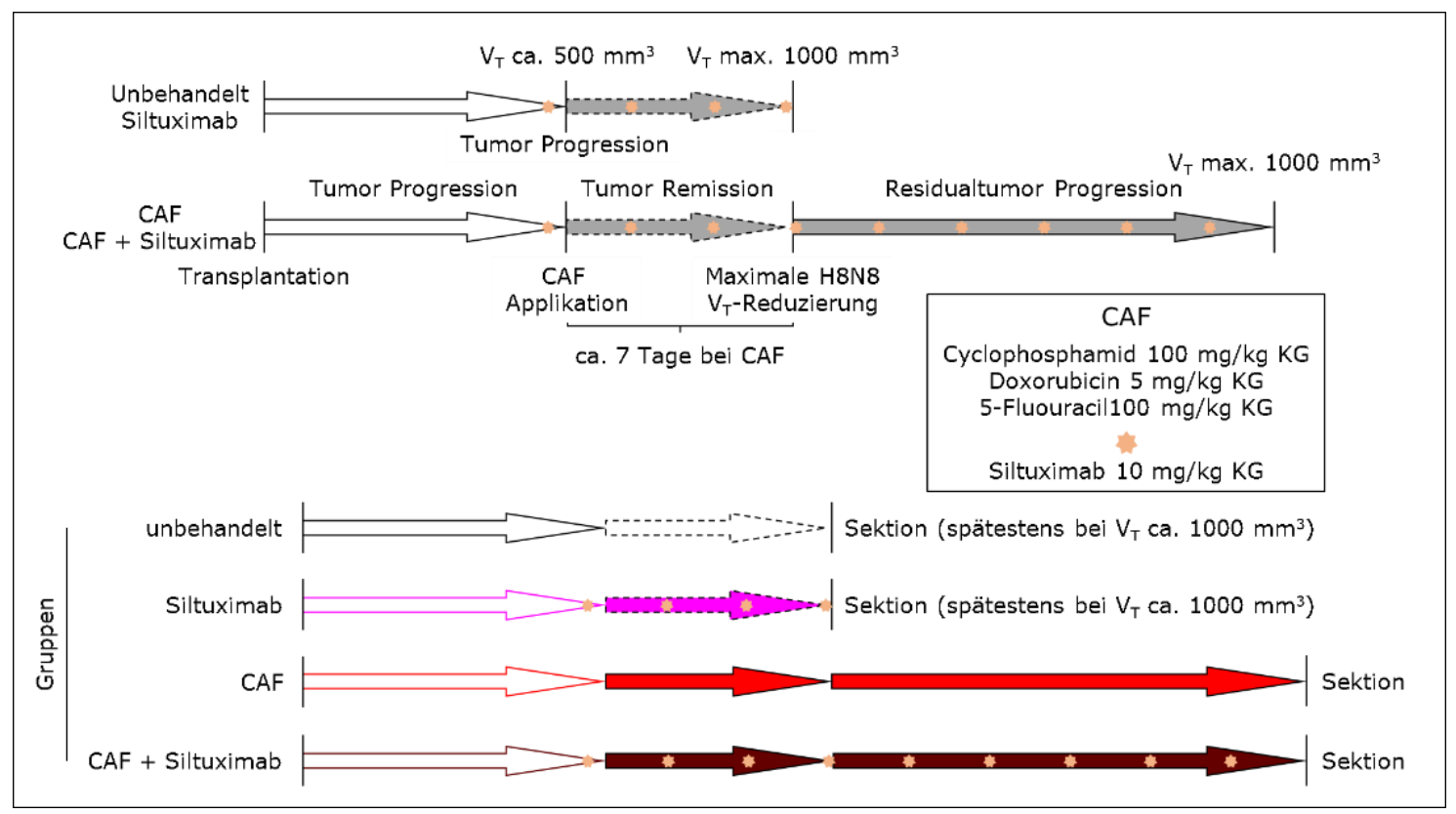

Abbildung 32: Behandlungsschema von H8N8 tumortragenden Mäusen zum Vergleich der CAF/STherapie mit der CAF-Therapie

Behandlungsschema und Gruppeneinteilung der weiblichen nicht induzierten transgenen heterozygotenWAPT-NP8-Mäuse zur Untersuchung der Wirkung der CAF- Chemotherapie in Kombination mit dem Il6-Inhibitor Siltuximab auf H8N8-Tumore nach orthotoper Transplantation. Weiter sind die Konzentrationen der jeweiligen Therapiekomponenten angegeben.

\subsubsection{Gleiche Wirkung der CAF/S-Therapie und der CAF-Therapie auf die H8N8-Wachstumskinetik}

Zur Beurteilung der Wirkung der CAF/S-Therapie sind die $\mathrm{V}_{\mathrm{T}}$ der einzelnen Gruppen sechs, 12 und 15 Tage nach Therapiestart in Tabelle 30 angegeben. Über die gesamte Beobachtungszeit war kein Unterschied der Wachstumskinetiken der unbehandelten und allein mit Siltuximab therapierten Tumore erkennbar (Tabelle 30 und Abbildung 33). Das $V_{T}$ war sechs Tage nach Therapiestart bei CAF therapierten Tumoren auf $179,7 \mathrm{~mm}^{3}\left( \pm 63,90 \mathrm{~mm}^{3}\right)$ und bei Tumoren nach CAF/S-Therapie auf $151,2 \mathrm{~mm}^{3}\left( \pm 54,28 \mathrm{~mm}^{3}\right)$ reduziert, somit ist die Wirksamkeit der CAF-Therapie und der CAF/STherapie auf das $V_{T}$ vergleichbar. Das $V_{T}$ war 12 Tage nach der CAF-Therapie noch auf 187,6 $\mathrm{mm}^{3}$ $\left( \pm 72,28 \mathrm{~mm}^{3}\right)$ und bei der CAF/S-Therapie noch auf $188,6 \mathrm{~mm}^{3}\left( \pm 83,54 \mathrm{~mm}^{3}\right)$ reduziert und die Wirksamkeit der Therapien auf das $\mathrm{V}_{\mathrm{T}}$ nahezu identisch. Auch 15 Tage nach Therapiestart war, bei einem $V_{\mathrm{T}}$ von $337,2 \mathrm{~mm}^{3}\left( \pm 174,72 \mathrm{~mm}^{3}\right)$ bei CAF therapierten bzw. $283,7 \mathrm{~mm}^{3}\left( \pm 169,79 \mathrm{~mm}^{3}\right)$ bei CAF/S therapierten, kein signifikanter Unterschied der Wirksamkeit der Therapien auf das $V_{\mathrm{T}}$ erkennbar. 
Zur weiteren Beurteilung wurden die $\mathrm{V}_{\mathrm{T}}$ auf das mittlere $\mathrm{V}_{\mathrm{T}}$ aller Tumore der jeweiligen Gruppe, unbehandelt $\left(590,3 \mathrm{~mm}^{3}\right)$, Siltuximab $\left(528,2 \mathrm{~mm}^{3}\right), \mathrm{CAF}\left(564,7 \mathrm{~mm}^{3}\right)$ und CAF/S $\left(622,6 \mathrm{~mm}^{3}\right)$ bei Therapiestart (Tag 0) normiert, gemittelt und in Abbildung 33b gegen die Zeit aufgetragen. Die horizontale gestrichelte Linie beim Wert 1 markiert das mittlere $\mathrm{V}_{\mathrm{T}}$ aller Tumore der jeweiligen Gruppe bei Therapiestart (Abbildung 33b). Das obere X-Y Diagramm in Abbildung 33b zeigt, dass unbehandelte und mit Siltuximab behandelte Tumore ein vergleichbares Wachstum zeigten. Das $\mathrm{V}_{\mathrm{T}}$ der Tumore der CAF therapierten Tumore reduzierte sich innerhalb der ersten sechs Tage nach Applikation um 68,2 \% ( $\pm 9,94 \%)$ und Tumore nach CAF/S-Therapie um 71,7\% ( $\pm 11,13 \%)$. Nach der Remission begannen die Residualtumore beider Gruppen erneut zu wachsen und erreichten nach 12 bzw. 15 Tagen ein nicht signifikant abweichendes $\mathrm{V}_{\mathrm{T}}$.

Mäuse, deren Tumore mit CAF therapiert wurden, zeigten in diesem Versuchsansatz einen sehr schlechten Allgemeinzustand (Abbildung 34a) und eine Reduzierung des Mausgewichts nach Therapiestart um ca. $20 \%$ (Abbildung 34b). Bei der CAF/S-Therapie hingegen wurde eine leichte aber signifikante Verbesserung des Allgemeinzustandes (Abbildung 34a) und eine weniger starke Mausgewichtsreduzierung (Abbildung 34b) beobachtet. 
Tabelle 30: Vergleich verschiedener Parameter von H8N8-Tumoren nach CAF- und CAF/S-Therapie

Die hier mittels Schieblehre gemessenen und berechneten Werte beziehen sich auf das $V_{T}$ der Tumore in situ in den noch lebenden Mäusen von unbehandelten und therapierten H8N8-Tumoren. Die statistische Signifikanz (p-Wert) zum Vergleich von zwei Gruppen wurde mit dem ungepaarten Student-t-Test ermittelt.

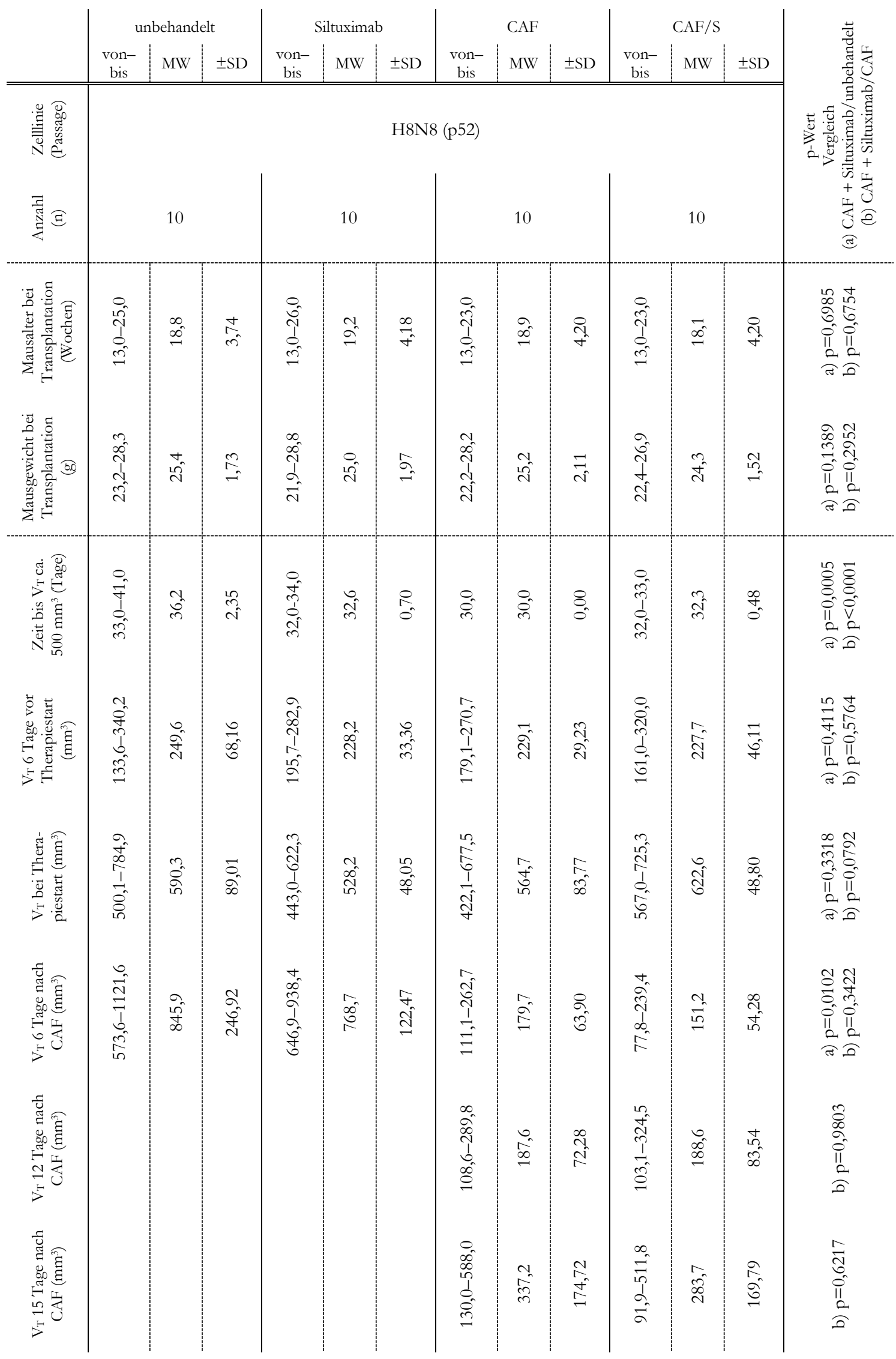




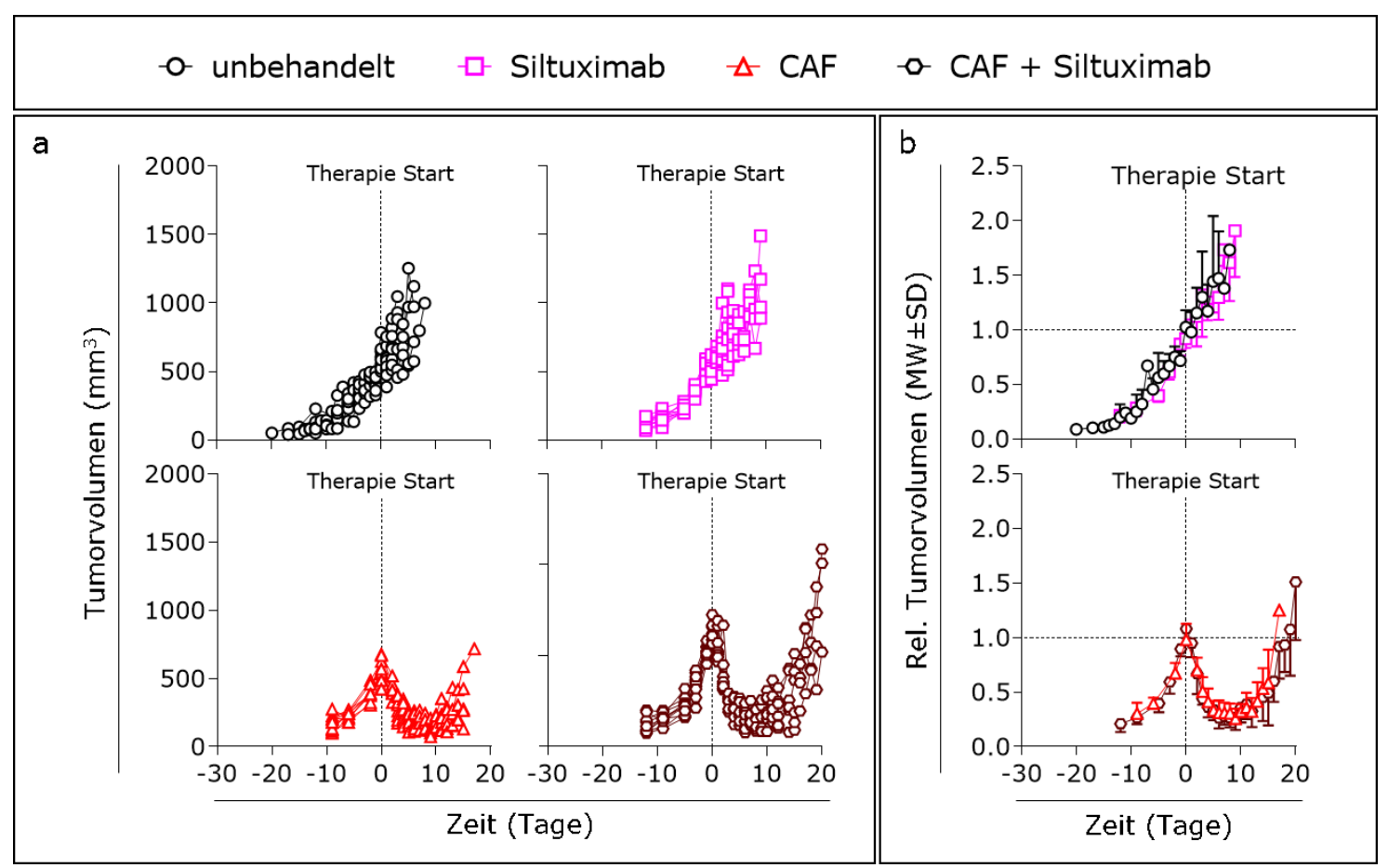

Abbildung 33: Wachstumskinetiken von H8N8-Tumoren nach CAF- und CAF/S-Therapie

Dargestellt sind H8N8-Wachstumskinetiken unbehandelter $(n=10)$, Siltuximab therapierter $(n=10)$, CAF therapierte $(n=10)$ und CAF/S therapierte Tumore $(n=10)$. Der Tag 0 auf der $\mathrm{x}$-Achse markiert den Zeitpunkt, an dem die Tumore das $\mathrm{V}_{\mathrm{T}}$ von ca. $500 \mathrm{~mm}^{3}$ erreichten und die Therapie appliziert wurde. a: Dargestellt sind die absoluten Werte aller Tumore. b: Zusehen sind die mittleren relativen Wachstumskinetiken. Die $V_{\mathrm{T}}$ der Transplantationen wurden auf den MW der $\mathrm{V}_{\mathrm{T}}$ aller Tumore der jeweiligen Gruppe bei Therapiestart (Tag 0) normiert (gestrichelte horizontale Linie) und anschließend gemittelt. $\mathbf{a}$ und $\mathbf{b}$ : Tumore wurden in situ an der noch lebenden Maus vermessen.

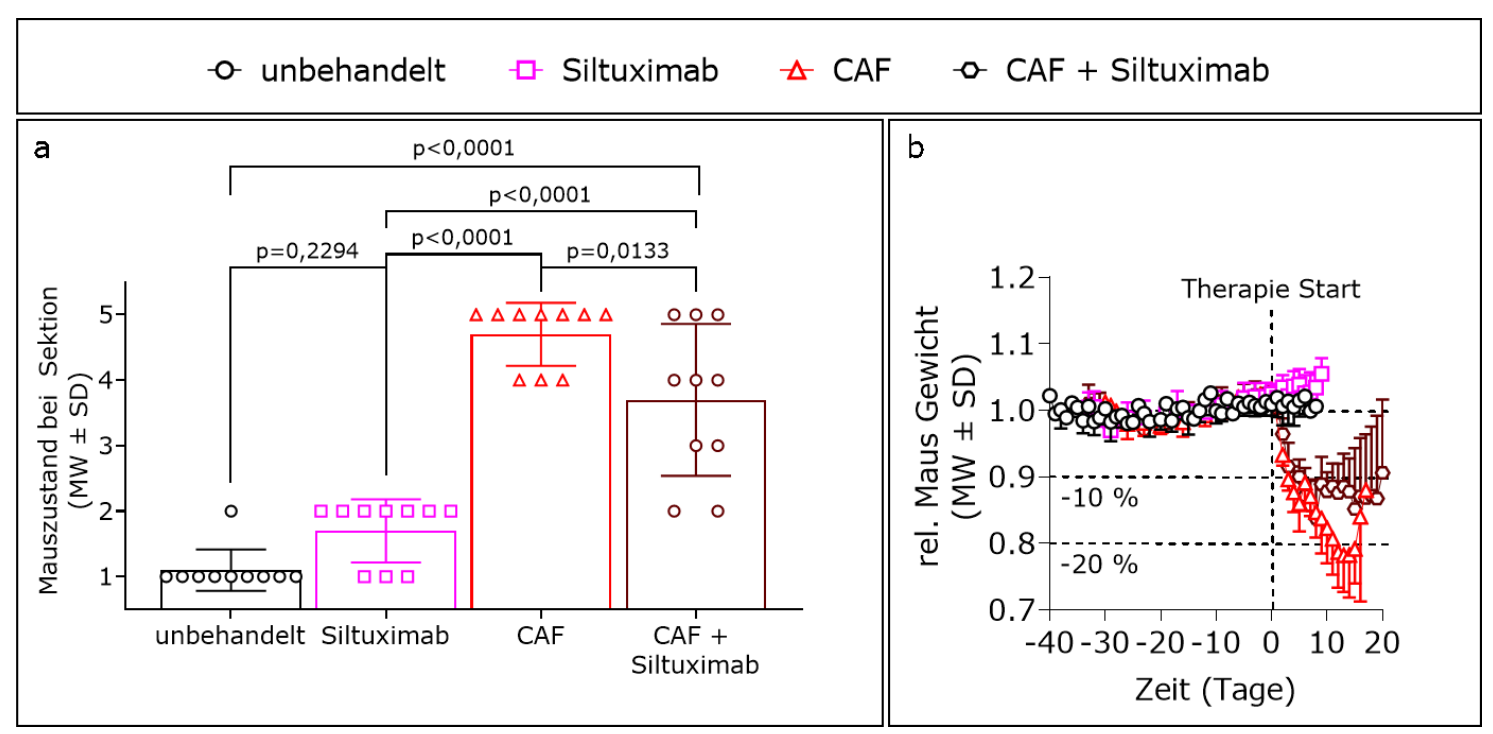

Abbildung 34: Einfluss von Siltuximab bei CAF-Therapie auf Allgemeinzustand und Mausgewicht

a: Dargestellt sind die Allgemeinzustände der Mäuse mit unbehandelten $(n=10)$, Siltuximab therapierten $(n=10), C A F$ therapierten $(n=10)$ und CAF/S therapierten $(n=10)$ Tumoren. Die Mäuse wurden mit dem BCSScore von 1 (gut) bis 5 (sehr schlecht) bewertet b: Zusehen sind die mittleren relativen Mausgewichtsveränderungen über die Zeit der unter a aufgelisteten Tumoren. Die Mausgewichte wurden auf den MW der Mausgewichte aller Mäuse bei Therapiestart (Tag 0) normiert (oberste gestrichelte horizontale Linie) und anschließend gemittelt. In dieser Art wurden die mittleren relativen Mausgewichte berechnet. Der Tag 0 markiert den Zeitpunkt der Therapieapplikation und damit den Zeitpunkt eines Tumorvolumens von ca. $500 \mathrm{~mm}^{3}$. Die Markierungen für $-10 \%$ bzw. $-20 \%$ Gewichtsverlust dient als Orientierung und zur Bewertung der Allgemeinzustände nach den Therapien. 


\subsubsection{Schnellere Tumorvolumenreduzierung nach CAF/S-Therapie}

Hier wurde untersucht, ob unter der Anwendung der RECIST-Kriterien ein Unterschied zwischen der Wirksamkeit der CAF-Therapie und der CAF/S-Therapie deutlich wird (Abbildung 35). In der Phase der partiellen Tumorremission wurde ein signifikanter Unterschied $(p=0,0309)$ der Tumorvolumenreduzierung bei CAF/S therapierten Tumoren sichtbar, verglichen mit CAF therapierten Tumoren der Transplantationsversuche aus Abschnitt 5.1. Beim Vergleich der Gruppe CAF/S mit CAF therapierten Tumoren aus dieser Transplantation wurde eine schnellere, aber nicht signifikante $(p=0,0661)$ Reduzierung des $V_{T}$ ermittelt. Die CAF therapierten Tumore wiesen eine Tumorvolumenreduzierung von $-58,5 \%( \pm 6,24 \%)$ und die CAF/S therapierten von $-65,3 \%( \pm 8,40 \%)$ auf (Abbildung 35 und Tabelle 31). Die mit CAF und CAF/S behandelten Tumore zeigten, im Verlauf von der stabilen Erkrankung hin zur progressiven Erkrankung, vergleichbare durchschnittliche $\mathrm{V}_{\mathrm{T}^{-}}$ Veränderungen (Abbildung 35 und Tabelle 31).

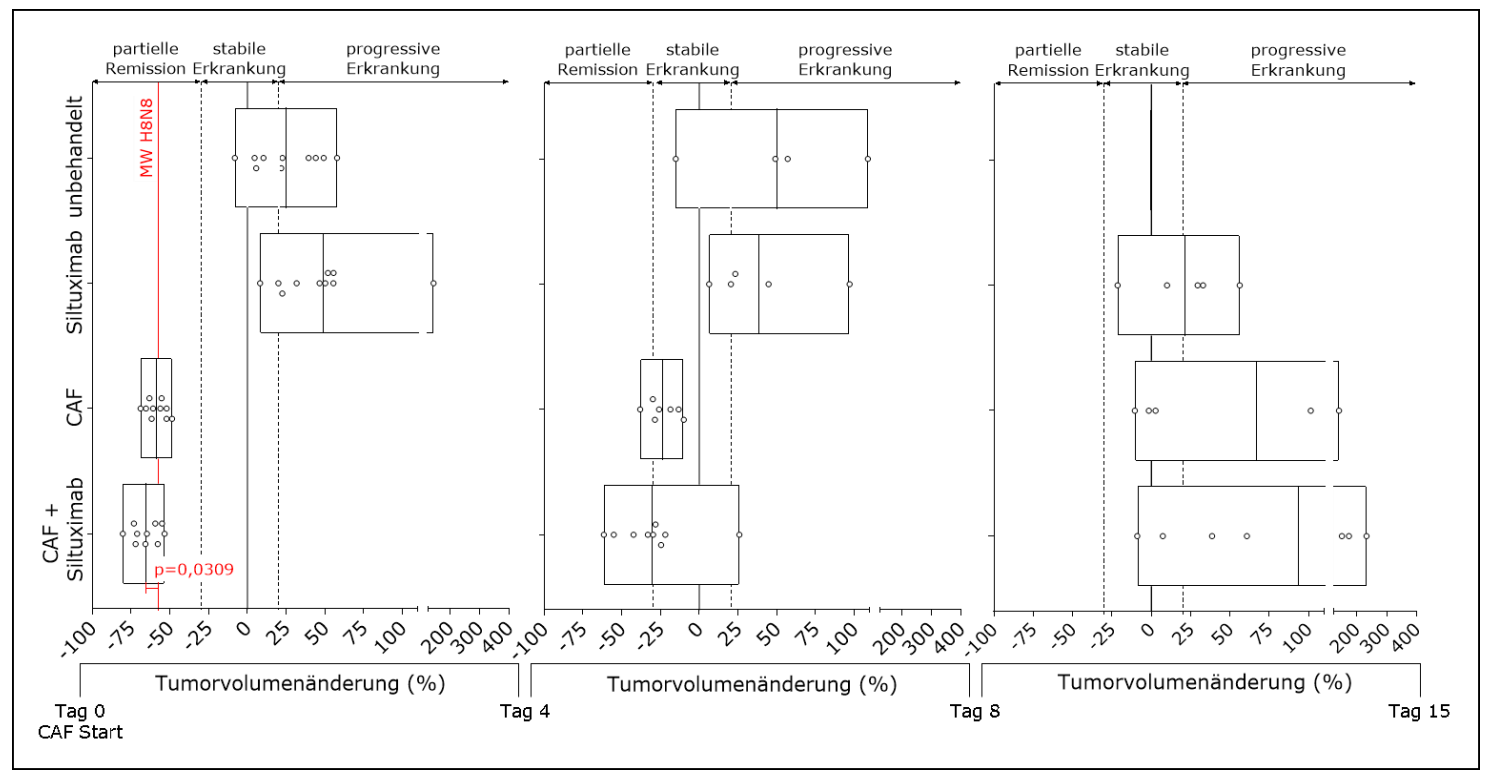

Abbildung 35: Drei Phasen der H8N8-Wachstumskinetik nach CAF- und CAF/S-Therapie

Dargestellt sind die prozentualen $\mathrm{V}_{\mathrm{T}}$-Veränderungen und die MW der Volumina von unbehandelten, mit Siltuximab, CAF oder CAF/S behandelten Tumoren. Sie wurden nach den RECIST-Kriterien (Eisenhauer et al. 2009) in die Phasen i) partielle Remission, ii) stabile Erkrankung und iii) progressive Erkrankung eingeordnet. Aufgetragen sind die Veränderungen der $\mathrm{V}_{\mathrm{T}}$ zwischen Tag null und vier nach CAF Applikation (Phase der partiellen Remission; alle Gruppen $\mathrm{n}=10$ ), zwischen Tag vier und acht nach CAF-Applikation (Phase der stabilen Erkrankung; unbehandelt $n=4$, Siltuximab $n=5, C A F n=7$ und $C A F / S n=9)$ und zwischen Tag acht und 15 nach CAF-Applikation (Phase der progressiven Erkrankung; unbehandelt $n=1$, Siltuximab $n=5$, CAF $n=7$ und $\mathrm{CAF} / \mathrm{S} \mathrm{n}=7)$. 
Tabelle 31: Volumenveränderungen während der partiellen Remission, stabilen Erkrankung und progressiven Erkrankung nach CAF- und CAF/S-Therapie

Die hier mittels Schieblehre gemessenen und berechneten Werte beziehen sich auf die $\mathrm{V}_{\mathrm{T}}$ - ̈̈nderungen der Tumore in situ in den noch lebenden Mäusen nach CAF- und CAF/S-Therapie. Die statistische Signifikanz (pWert) zum Vergleich von zwei Gruppen wurde mit dem ungepaarten Student-t-Test ermittelt. (a) Vergleich der Gruppen CAF/S und unbehandelt zur Berechnung der p-Werte. (b) Vergleich der Gruppen CAF/S und CAF zur Berechnung der p-Werte.

\begin{tabular}{|c|c|c|c|c|c|c|c|c|c|c|c|c|c|}
\hline \multirow[b]{2}{*}{$\begin{array}{l}\text { RECIST- } \\
\text { Kriterien }\end{array}$} & \multicolumn{3}{|c|}{ unbehandelt } & \multicolumn{3}{|c|}{ Siltuximab } & \multicolumn{3}{|c|}{ CAF } & \multicolumn{3}{|c|}{$\mathrm{CAF} / \mathrm{S}$} & \multirow{2}{*}{ 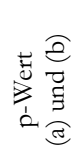 } \\
\hline & $\begin{array}{l}\text { von- } \\
\text { bis }\end{array}$ & MW & $\pm \mathrm{SD}$ & $\begin{array}{l}\text { von- } \\
\text { bis }\end{array}$ & MW & $\pm \mathrm{SD}$ & $\begin{array}{l}\text { von- } \\
\text { bis }\end{array}$ & MW & $\pm \mathrm{SD}$ & $\begin{array}{l}\text { von- } \\
\text { bis }\end{array}$ & MW & $\pm \mathrm{SD}$ & \\
\hline 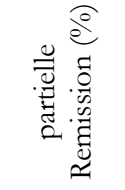 & $\begin{array}{l}\infty \\
\hat{n} \\
n \\
0 \\
0 \\
\overrightarrow{0} \\
\overbrace{1}\end{array}$ & 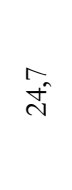 & $\stackrel{n}{\infty}$ & $\begin{array}{l}\stackrel{a}{j} \\
\vec{J} \\
.00 \\
\overrightarrow{0} \\
\vec{\infty}\end{array}$ & 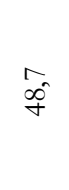 & $\begin{array}{l}\text { I } \\
\text { in }\end{array}$ & $\begin{array}{l}0 \\
0 \\
1 \\
1 \\
0 \\
0 \\
0 \\
0 \\
0 \\
1\end{array}$ & $\begin{array}{l}10 \\
\infty \\
10 \\
10\end{array}$ & $\begin{array}{l}\text { ते } \\
\text { b }\end{array}$ & 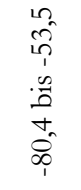 & $\begin{array}{l}m^{2} \\
\overbrace{1}^{2}\end{array}$ & $\begin{array}{l}q \\
+\infty \\
\infty\end{array}$ & $\begin{array}{ll}\vec{\delta} & \overline{0} \\
0 & 0 \\
0 & 0 \\
v & 11 \\
0 & 0 \\
\Theta & \hat{e}\end{array}$ \\
\hline 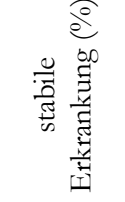 & 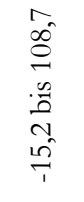 & $\vec{g}$ & $\begin{array}{l}\tilde{\sigma} \\
\dot{f}\end{array}$ & 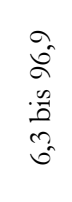 & $\begin{array}{l}m \\
\infty^{n} \\
n^{2}\end{array}$ & $\begin{array}{l}\hat{n} \\
\hat{n}\end{array}$ & $\begin{array}{l}0 \\
0 \\
0 \\
1 \\
0 \\
0 \\
0 \\
\infty \\
0 \\
0\end{array}$ & $\tilde{\vartheta}_{\hat{\imath}}^{\tilde{\vartheta}^{2}}$ & $\begin{array}{l}\stackrel{+}{N} \\
\text { a }\end{array}$ & 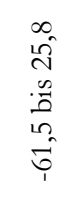 & $\overrightarrow{\hat{n}}$ & in & 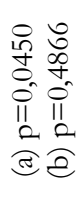 \\
\hline 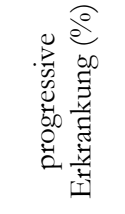 & $\stackrel{0}{0}$ & O & $\mathbb{8}_{0}$ & 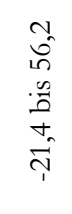 & 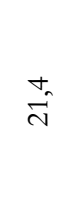 & ลิ & $\begin{array}{l}0 \\
\vec{J} \\
\pm \\
0 \\
\frac{0}{2} \\
n \\
0 \\
\frac{1}{1}\end{array}$ & $\begin{array}{l}0 \\
\hat{0}\end{array}$ & 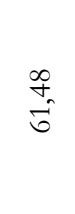 & 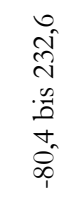 & $\stackrel{0}{\approx}$ & $\begin{array}{l}\underset{f}{c} \\
i \infty \\
\infty\end{array}$ & $\begin{array}{l}\tilde{m} \\
\stackrel{3}{n} \\
0 \\
0 \\
0 \\
0\end{array}$ \\
\hline
\end{tabular}

\subsubsection{Weniger Cd44+-Tumorzellen nach CAF/S-Therapie}

Der Il6-Inhibitor Siltuximab bindet das extrazelluläre Il6 und hemmt so die Signaltransduktion des Tnf- $\alpha$ - und Il6-Jak1-Stat3-Signalweg. Im Folgenden wurden die in Tabelle 32 aufgelisteten Tumore untersucht, um zu klären, ob die Hemmung von Il6 die Anteile an Cd44+Cd24--Tumorzellen verändert und welchen Einfluss die CAF/S-Therapie auf die Präsentation von Oberflächenmolekülen, die wichtig für die Aktivierung des Tnf- $\alpha$ - bzw. Il6-Jak1-Stat3-Signalweg sind, hat.

Abbildung 36a zeigt, dass in CAF/S therapierten Tumoren nach Wiederwachstum der Anteil Cd44+_ Tumorzellen erniedrigt war, verglichen mit CAF therapierten Tumoren nach Wiederwachstum. Die Anzahl an $\mathrm{Cd} 24^{+}$-Tumorzellen war in allen Tumoren über die Gruppen hinweg vergleichbar. Obwohl eine Reduzierung der Cd44+'Tumorzellen in Tumoren nach CAF/S-Therapie per FACS nachgewiesen wurde, war der Anteil der $\mathrm{Cd} 44{ }^{+} \mathrm{Cd} 24-$-Tumorzellen bei CAF und CAF/S therapierten Tumoren nach Wiederwachstum nicht signifikant verändert, deutlich an den Cd24-Cd44-Doppelfärbungen der 
FACS-Analysen in Abbildung 36a. Im Gegenteil, die Ergebnisse zeigen einen kleinen nicht signifikanten Zuwachs an Cd44+Cd24- Tumorzellen in Residualtumoren nach Kombinationstherapie.

Tabelle 32: Angaben zu Therapieapplikation und $\mathrm{V}_{\mathrm{T}}$ (ex vivo) der mittels FACS analysierten Tumore

\begin{tabular}{|c|c|c|c|c|}
\hline Gruppe & Tumor & $\begin{array}{c}\text { Tage nach } \\
\text { Transplantation } \\
\end{array}$ & $\begin{array}{c}\text { Tage nach } \\
\text { Therapiestart }\end{array}$ & $\begin{array}{r}\mathrm{V}_{\mathrm{T}}-\text { Tumor } \\
\text { ex vivo }\left(\mathrm{mm}^{3}\right) \\
\end{array}$ \\
\hline \multirow{4}{*}{ unbehandelt } & 6831 & 42 & & 812,9 \\
\hline & 6832 & 42 & & 1232,0 \\
\hline & 6833 & 42 & & 936,4 \\
\hline & 6834 & 42 & & 1092,7 \\
\hline \multirow{4}{*}{ Siltuximab } & 6827 & 42 & 9 & 1021,1 \\
\hline & 6828 & 42 & 9 & 1254,8 \\
\hline & 6829 & 42 & 9 & 1230,6 \\
\hline & 6830 & 42 & 9 & 1224,2 \\
\hline \multirow{3}{*}{ CAF } & 6842 & 45 & 15 & 450,5 \\
\hline & 6843 & 45 & 15 & 388,8 \\
\hline & 6844 & 45 & 15 & 307,3 \\
\hline \multirow{3}{*}{$\mathrm{CAF} / \mathrm{S}$} & 6860 & 53 & 20 & 476,2 \\
\hline & 6861 & 53 & 20 & 1012,9 \\
\hline & 6862 & 53 & 20 & 947,1 \\
\hline
\end{tabular}

Als Reaktion auf die Il6-Hemmung nahm die Anzahl an Tumorzellen, die den Il6-Rezeptor (Cd126) exprimieren nach CAF/S-Therapie signifikant von 11,7\% ( $\pm 1,71 \%)$ auf $8,7 \%( \pm 1,5 \%)$ ab, verglichen mit unbehandelten und Siltuximab therapierten Tumoren waren sie weiterhin stark vermehrt vorhanden (Abbildung 36b). Unter $5 \%$ der Tumorzellen unbehandelter und Siltuximab therapierter Tumore exprimieren den Tumor Necrosis Factor Receptor-2 (Cd120b). Nach CAF bzw. CAF/STherapie stieg der Anteil CD120b+-Tumorzellen auf 14,3\% ( $\pm 3,88 \%$ ) bzw. auf 15,4 \% ( $\pm 1,94 \%)$ an (Abbildung 36b). Den Ifn $\gamma \mathrm{r}-\beta$ präsentierten nach CAF-Therapie $0,7 \%( \pm 0,20 \%)$ der Tumorzellen, bei CAF/S-Therapie wurde dieser Rezeptor mit einem Anteil von 2,1\% ( $\pm 0,7 \%)$ Ifn $\gamma \mathrm{r}-\beta^{+}{ }_{-}$ Tumorzellen signifikant häufiger auf der Zelloberfläche von Tumorzellen gebildet (Abbildung 36b). 

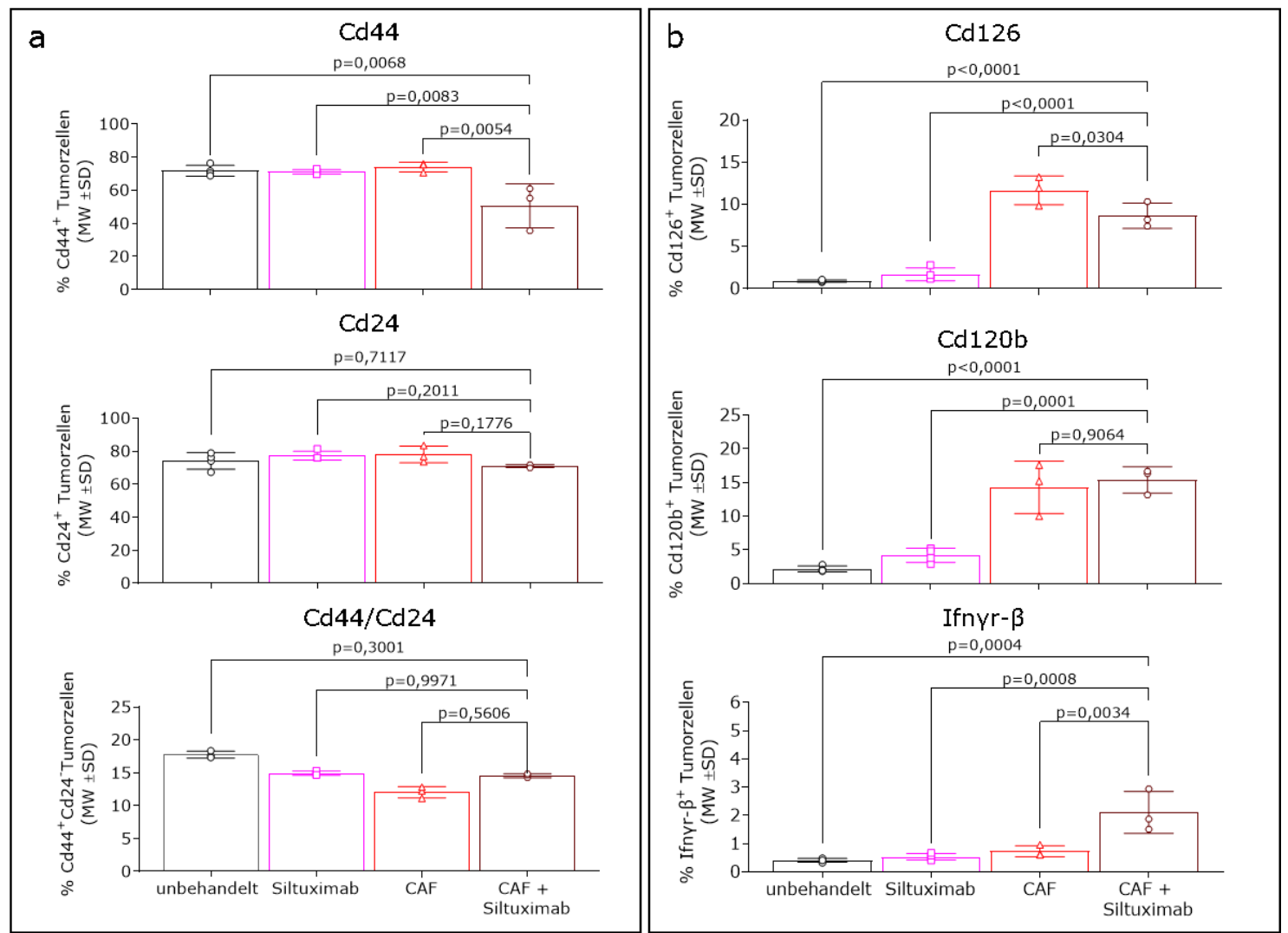

Abbildung 36: Weniger Cd44+-Tumorzellen und veränderte Rezeptorexpression nach CAF/STherapie in FACS-Analysen

Darstellung der FACS-Analysen isolierter H8N8-Tumorzellen nach magnetischer Separation. Den AK-Färbungen war der Ausschluss von Zelldebris, PI-gefärbter toter Zellen und LCR--Tumorzellen vorangestellt. Analysiert wurden Tumorzellen von je vier unbehandelten und Siltuximab behandelten Tumoren und je drei $\mathrm{CAF}$ bzw. CAF/S behandelten Tumoren. In a sind Diagramme unterschiedlicher Populationsgrößen nach Cd44-VioBlue-, Cd24-APC-Vio770- und Cd44-VioBlue-, Cd24-APC-Vio770-AK-Färbung- und in $\mathbf{b}$ nach

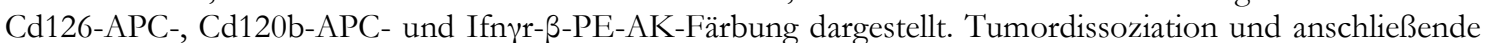
FACS-Analysen wurden zusammen mit D. Agorku (Miltenyi Biotec GmbH, Bergisch Gladbach) durchgeführt.

Die Ergebnisse aus Abbildung 36 wurden durch-IHC Färbungen von Tumorschnitten von unbehandelten, Siltuximab therapierten, CAF therapierten und CAF/S therapierten Tumoren mit AK gegen die Oberflächenmoleküle Cd44 und Cd24 validiert. Die Färbeergebnisse in Abbildung 37 zeigen, dass sowohl der Anteil an Cd44 gefärbten Zellen als auch die Intensitäten der Färbungen in allen Gruppen vergleichbar waren. Nach IHC-Färbung der Tumorschnitte mit dem Cd24-AK war bei unbehandelten Tumoren nahezu jede Zelle im Randbereich gefärbt aber mit abnehmender Differenzierung in Richtung Tumorzentrum wurden vermehrt ungefärbte Zellen registriert. Die Färbung der Siltuximab therapierten Tumorschnitte mit dem Cd24-AK verdeutlicht, dass diese Tumore die geringste Anzahl an Cd24-positiven Zellen aufwiesen. Die Zellen in den Tumoren die mit der CAF/S-Therapie behandelt wurden, zeigten eine schwächere Färbung mit dem Cd24-AK, verglichen mit denen in CAF 
therapierten Tumoren. Die Ergebnisse beider Gruppen machen deutlich, dass überwiegend Tumorzellen gefärbt und stromareiche Zwischenräume, welche noduläre Tumorzellbereiche voneinander trennten, ungefärbt waren (Abbildung 37).

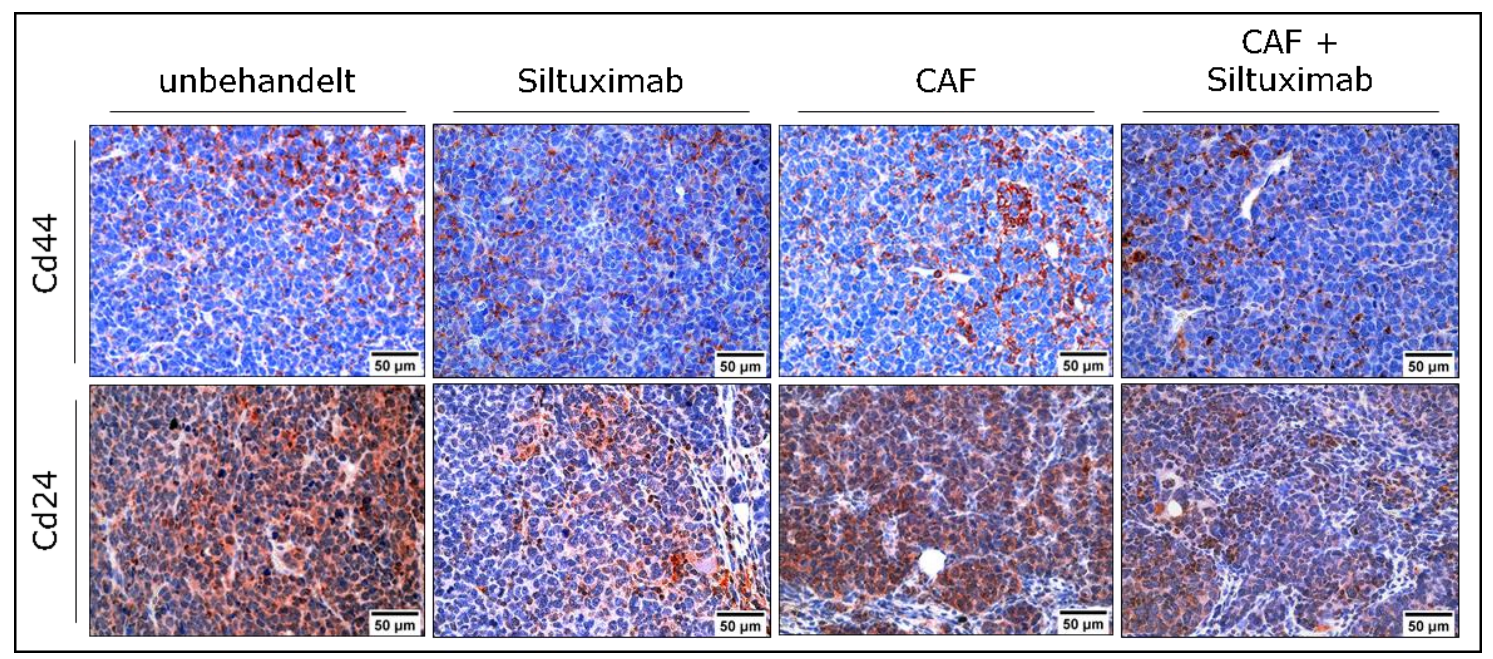

Abbildung 37: Veränderte Cd44- und Cd24-Expression in Tumoren nach CAF/S-Therapie

Abgebildet sind IHC gefärbte repräsentative Tumorschnitte mit AK gegen Cd44 und Cd24, von einem unbehandelten Tumor (Cd44: $\mathrm{V}_{\mathrm{T}}=810,7 \mathrm{~mm}^{3} ; 34$ Tage nach Transplantation; $\mathrm{Cd} 24: \mathrm{V}_{\mathrm{T}}=768,6 \mathrm{~mm}^{3} ; 28$ Tage nach Transplantation), einem Siltuximab therapierten Tumor $\left(\mathrm{Cd} 44: \mathrm{V}_{\mathrm{T}}=984,4 \mathrm{~mm}^{3} ; 37\right.$ Tage nach Transplantation und vier Tage nach Therapiestart; $\mathrm{Cd} 24: \mathrm{V}_{\mathrm{T}}=1254,8 \mathrm{~mm}^{3} ; 42$ Tage nach Transplantation und neun Tage nach Therapiestart), einem CAF therapierten Tumor (Cd44 und Cd24: $\mathrm{V}_{\mathrm{T}}=806,8 \mathrm{~mm}^{3} ; 46$ Tage nach Transplantation und 17 Tage nach Therapiestart) sowie von einem CAF/S therapierten Tumor $\left(\mathrm{Cd} 44: \mathrm{V}_{\mathrm{T}}=947,1 \mathrm{~mm}^{3}\right.$; 53 Tage nach Transplantation und 20 Tage nach Therapiestart; $\mathrm{Cd} 24: \mathrm{V}_{\mathrm{T}}=1012,9 \mathrm{~mm}^{3}$; 53 Tage nach Transplantation und 20 Tage nach Therapiestart). Detailaufnahme 400x Vergrößerung, Balken $50 \mu \mathrm{m}$. VT: Tumorvolumen gemessen nach der Sektion mit Tumor ex vivo.

Die Ergebnisse des Abschnitts 5.5 zeigen, dass die Kombination der CAF-Therapie zusammen mit dem Il6-Inhibitor Siltuximab die Anzahl Cd44+Cd24-Tumorzellen im Verlauf der Progression des wieder wachsenden Tumors nicht vermindern kann. Jedoch wurde eine Reduzierung der Cd44+-Tumorzellen nach CAF/S-Therapie mittels FACS- und IHC-Färbungen nachgewiesen. Weiter zeigen die Ergebnisse, dass bei CAF/S-Therapie das Ifn $\gamma$ r- $\beta$-Oberflächenmolekül signifikant häufiger auf Tumorzellen und der Il6-Rezeptor signifikant weniger auf Tumorzellen exprimiert wurde. Zusammengefasst war die Wirkung der CAF/S-Therapie auf die Wachstumskinetik der H8N8-Tumore während der ersten vier Tage nach Applikation geringfügig effektiver, verglichen mit der CAF Therapie. Die Mäuse unter CAF/S-Therapie zeigten aber einen besseren Allgemeinzustand, weil niedrigeren BCS-Score sowie weniger Mausgewichtsverlust im Vergleich zu den Mäusen der CAF-Therapie. 


\section{Diskussion}

\subsection{Wie wirkt sich die CAF-Therapie auf die Wachstumskinetik und den H8N8-Tumorphänotyp aus?}

Die orthotope Transplantation von H8N8-Mammakarzinomzellen in WAP-T-Mäuse führt zu Tumoren mit reproduzierbaren Wachstumskinetiken, wie in dieser Arbeit durch zwei zeitlich unabhängige Transplantationen gezeigt wurde. Nach Transplantation der H8N8-Tumorzellen entwickeln sich innerhalb von ca. 14,3 Tage $( \pm 3,87$ Tage $)$ Tumore mit einem ungefähren $V_{T}$ von $500,0 \mathrm{~mm}^{3}$. Dies ermöglich es, den Beginn der CAF-Therapie, mit einer für alle Mäuse vergleichbaren Ausgangssituation, bei einem zu diesem Zeitpunkt vergleichbaren $V_{T}$, zu gewährleisten und die Wirksamkeit von CAF-Therapien verschiedener Transplantationen vergleichend zu untersuchen. Die vorliegenden Wachstumskinetiken von zwei Transplantationen zeigen, das CAF das $V_{\mathrm{T}}$ temporär für 6,7 Tage $( \pm 1,35$ Tage $)$ um $73,2 \%( \pm 8,20 \%)$ reduziert, bevor die Tumore 14,1 Tage $( \pm 1,38$ Tage $)$ nach der CAF-Applikation wieder ein $V_{\mathrm{T}}$ von durchschnittlich $71,4 \%( \pm 44,3 \%)$ ihres $V_{\mathrm{T}}$ bei Therapiestart erreichen. Im Verlauf der CAF-Therapie treten die Tumore nach Remission in eine Phase ein, die nach den RECIST-Kriterien als stabile Erkrankung definiert wird (Eisenhauer et al. 2009), nachgefolgt von dem progressiven Wiederwachstum der Residualtumore. Der Vergleich der $\mathrm{V}_{\mathrm{T}^{-}}$-Veränderungen mittels RECIST-Kriterien deckte unterschiedlich große $\mathrm{V}_{\mathrm{T}}$-Zunahmen im Zeitraum der progressiven Erkrankung zwischen Tag acht und 15 nach der CAF-Applikation auf, die möglicherweise auf die individuelle Tumorzusammensetzung und Resistenzeigenschaften der therapierten H8N8Tumorzellen zurückzuführen ist und für einen sehr heterogenen Residualtumor spricht.

Die hier verwendete CAF-Therapie ist verglichen mit den Ergebnissen der Studie von Jannasch et al., weniger wirksam auf das H8N8-Tumorwachstum in der WAP-T-NP8-Mauslinie. Sie konnten zeigen, dass Tumore aus G2-Tumorzellen, einer ebenfalls aus dem WAP-T-Mausmodell isolierten murinen Tumorzellinie mit Eigenschaften luminaler und basaler Mammakarzinome (Krepulat et al. 2005; Heinlein et al. 2008; Wegwitz et al. 2010), in Reaktion auf die CAF-Therapie ihr $\mathrm{V}_{\mathrm{T}}$ zwischen Tag sieben und neun deutlich stärker bis auf ein sehr kleines $V_{T}$ von $0,02-0,05$ mm3 (ca. 99,9\%) reduzierten. Im Vergleich vermindert die CAF-Therapie das $\mathrm{V}_{\mathrm{T}}$ der H8N8-Tumoren nur um 73,5 \%. 
Des Weiteren unterscheiden sich die G2-Tumore und H8N8-Tumore noch wie folgt: i) H8N8-Tumore brauchen länger, um ein $V_{T}$ von $500 \mathrm{~mm}^{3}$ zu erreichen. ii) G2-Tumore erreichen erst 31 Tage und H8N8 Tumore bereits 14 Tage nach Therapiestart wieder das Ausgangs- $V_{\mathrm{T}}$ von $500 \mathrm{~mm}^{3} \mathrm{zu}$ Beginn der CAF-Therapie (Jannasch et al. 2015). Die unterschiedliche CAF-Wirkung, in den beiden Studien, kann u.a. zurückgeführt werden auf die unterschiedlichen initialen Tumorwachstumsgeschwindigkeiten bis zum $\mathrm{V}_{\mathrm{T}}$ von $500 \mathrm{~mm}^{3}$ von 22 Tagen bei G2-Zellen (Jannasch et al. 2015; Maenz et al. 2015) und von ca. 31 Tagen bei H8N8-Zellen. Da Chemotherapeutika stark proliferierende Tumorzellen effektiver eliminieren, dass $\mathrm{V}_{\mathrm{T}}$ stärker reduziert wird und weniger vitale Residualtumorzellen im G2-Tumor nach CAF-Therapie verbleiben, benötigen die resistenten Residualtumorzellen mehr Zeit, um das Wiederwachstum zu initiieren.

Die CAF-Therapie wird von den Mäusen schlecht vertragen und verursacht Nebenwirkungen, wie einen reduzierten Allgemeinzustand und starke Gewichtsverluste. Eine Anpassung des Behandlungsprotokolls hin zu einer verringerten Cyclophosphamidkonzentration, nach dem $\mathrm{C}^{40} \mathrm{AF}-\mathrm{Schema}$ (40 mg/kg KG anstatt 100 mg/kg KG), war für den Allgemeinzustand und das Gewicht der Mäuse vorteilhaft bei gleicher Wirksamkeit, verglichen mit der CAF-Therapie. Die Metastudie der EBCTCG-Kollaborationsgruppe zum Vergleich adjuvanter Chemotherapien beim Mammakarzinom im Frühstadium zeigt, dass eine Behandlung mit einer Kombinationschemotherapie bestehend aus drei Komponenten, wie CAF, das Tumorvolumen $\left(\mathrm{V}_{\mathrm{T}}\right)$ um 15-20\% mehr reduziert als vergleichbare Chemotherapien bestehend aus zwei Komponenten. In dieser Studie konnte gezeigt werden, dass die Wahrscheinlichkeit während der ersten vier Jahre an einem Rezidiv zu erkranken bei Anwendung einer auf Anthrazyklin basierenden Chemotherapie (z.B. CAF) um $31 \%$ reduziert ist, verglichen mit unbehandelten Tumoren. Nach vier Jahren war die Gesamtmortalität bei behandelten Patientinnen nur noch um $8 \%$ reduziert, verglichen mit unbehandelten Patientinnen (Early Breast Cancer Trialists' Collaborative Group (EBCTCG) 2012).

Jannasch et al. verwendeten in einer anderen Studie zur Bestimmung des $\mathrm{V}_{\mathrm{T}}$ die flatpanel-basierte Computertomographie (fpVCT), wodurch auch die Blutgefäßbildung im Tumor dargestellt wurde. Die Vermessung der Tumore mit dem fpVCT ist sehr viel aufwendiger und invasiver, da die Mäuse einer Strahlendosis von 40 \pm 5 mGY ausgesetzt, narkotisiert und ein Kontrastmittel verabreicht werden muss, weshalb Jannasch et al. nur sechs Messungen pro Maus im Zeitraum von max. 182 Tagen 
durchführten (Jannasch et al. 2009) Diese invasive Methode bedeutet für die Maus zudem Stress und dessen Auswirkung auf das $\mathrm{V}_{\mathrm{T}}$ ist ungewiss. Für die hier bearbeitete Fragestellung erzielte die engmaschige nicht invasive Vermessung der H8N8-Tumore durch zwei unabhängige Personen mittels Schieblehre ausreichend genaue Messwerte, um die Tumorvolumenveränderungen durch die CAFTherapie über die Zeit in der lebenden Maus zu erfassen.

Die unbehandelten Tumore setzten sich vor der CAF-Therapie zum Großteil aus H8N8-Tumorzellen zusammen. Vereinzelt am Tumorrand werden $\alpha$-SMA positive Zellen lokalisiert und eine positive Tenascin-C-Färbung in der EZM in der Nähe dieser Zellen. Die durch $\alpha$-SMA markierten Zellen in Verbindung mit mehr Tenascin-C in den unbehandelten Tumoren deuten an, dass dies Überbleibsel der Myoepithelzellschicht sein könnten, die in der physiologischen Mamma zwischen der Basallamina und den eigentlich sekretproduzierenden glandulär-luminalen Mammaepithelzellen, zur kontraktilen Unterstützung der Sekretabgabe, lokalisiert ist. Die CAF-Therapie verändert die Tumorzusammensetzung und damit den Phänotyp der H8N8-Tumore. Dies zeigt sich besonders stark während der Tumorremission. Der remittierte Tumor ist charakterisiert durch eine dezimierte Anzahl an T-Agpositiven H8N8-Tumorzellen mit auffällig vergrößerten Nuklei sowie das Auftreten einer Vielzahl T-Ag-negativer Zelltypen. Unter ihnen sind vor allem im Tumorzentrum auch vermehrt CD45+-TIL, verglichen mit unbehandelten Tumoren, zu finden. Der vergrößerte Nukleus einer CAF-therapierten Tumorzelle kann auf gesteigerte DNA-Synthese- und Transkriptionsraten aber auch auf aktive Zellteilung hinweisen, deutlich an der intensiven Pcna-Färbung der Nuklei von Tumorzellen. Andererseits können auch DNA-Vernetzungen und eine gestörte Zellteilung aufgrund der zytotoxischen Wirkungen der verschiedenen CAF-Komponenten die Vergrößerung der Nuklei verursachen. Der Phänotyp des remittierten Tumors geht außerdem im Vergleich zu unbehandelten Tumoren mit einer verstärkten Kollagenbildung, einem vermehrten Auftreten $\alpha$-Sma-positiver Zellen, flankiert mit einem erhöhten Tenascin-C-Vorkommen und der Expression von EMT-TF und -Markerproteinen einher. Alpha-SMA positive Zellen in Verbindung mit einer gesteigerten Tenascin-C Färbung könnte ein Hinweis auf eine Vermehrung von tumorassoziierten Fibroblasten sein (Shiga et al. 2015), die u.a. fähig sind Kollagen zu synthetisieren und in die EZM zu sekretieren, was die gesteigerte Kollagenablagerung in den Tumoren der Gruppe CAF - Remission erklären könnte. Die Bildung und Ablagerung von Kollagen trägt zur Versteifung der EZM bei, was zur Folge hat, dass Chemotherapien 
durch die veränderte Mikroumgebung und räumliche Abgrenzung schwieriger in Kontakt mit Tumorzellen treten. Rossow et al. konnten zeigen, dass die Chemotherapieresistenz durch die Zunahme an Kollagen im Tumor gesteigert wird (Rossow et al. 2018). Die CAF-Therapie führt damit zu charakteristischen Eigenschaften, welche auch bei unbehandelten Tumorentitäten mit einer schlechten Überlebensrate und einer schnellen erneuten Tumorprogression nach Therapie assoziiert sind (Conklin et al. 2011; Oskarsson et al. 2011; Bae et al. 2013; Robertson 2016). Der Phänotyp der wieder gewachsenen Tumore der Gruppe CAF - Progression, die in etwa wieder das $V_{T}$ von $500 \mathrm{~mm}^{3}$ von unbehandelten Tumoren zum Zeitpunkt der Sektion erreicht haben, ist mit dem Phänotyp unbehandelter Tumore vergleichbar. Dies zeigt die Plastizität der H8N8-Tumorzellen, die fähig sind nach einem fast kompletten Verlust des Phänotyps der unbehandelten Tumore nach Tumorremission, wieder einen Phänotyp nach Wiederwachstum in den Tumoren der Gruppe CFA - Progression zu generieren der dem unbehandelter Tumore ähnelt.

Die Verwendung des immunkompetenten transgenen WAP-T-Mausmodells ermöglicht es, die Wirkung der CAF-Therapie auf Zellen des Immunsystems zu untersuchen. Wir konnten durchflusszytometrisch nachweisen, dass die Anzahl an TIL in CAF therapierten Tumoren nach Wiederwachstum, verglichen mit unbehandelten Tumoren und remittierten Tumoren am Größten ist. Histochemisch und mittels IHC-Färbungen fanden sich in den Residualtumoren zwar vermehrt kleinkernige homogene Zellen, die nach ihrer Morphologie her eingewanderte Immunzellen hätten sein können, aber nur ein verhältnismäßig kleiner Anteil war durch den Cd45-AK positiv gefärbt. Unter Einbezug der Ergebnisse der Durchflusszytometrie, zur Bestimmung der TIL-Anzahl im Tumor, zeigt sich, dass Cd45+-TIL vermehrt in Tumoren der Gruppe CAF - Progression nach Wiederwachstum einwandern. Jeder TIL-Subtyp hat nach seinen individuellen spezifischen Eigenschaften antagonistisch tumorfördernde bzw. tumorhemmende Funktionen (Lança und Silva-Santos 2012; Nagarajan und McArdle 2018), weshalb der TIL-Subtyp detailliert bestimmt werden muss, um mittels der TIL-Anzahl und der genauen Charakterisierung der TIL-Subtypen im Mammakarzinom, eine prognostische Vorhersage machen zu können.

Mehrere Studien beschreiben, dass beim TNBC und ERBB2+-Mammakarzinom eine erhöhte TILKonzentration mit einer effektiveren Wirksamkeit der neoadjuvanten Chemotherapie und einer besseren Überlebenszeit der Patientinnen assoziiert sind. Für luminale ERBB2-Mammakarzinome 
wurde hingegen das Gegenteilige beobachtet (Asano et al. 2018; Denkert et al. 2018). Die FACSAnalysen dieser Studie ergaben, dass die CAF-Therapie den Anteil Cd45+-TIL in remittierten H8N8Tumoren verringert, im Vergleich zu unbehandelten Tumoren. Die Beobachtung, dass die CAFTherapie die Anzahl Cd45+-TIL dezimiert, kann ein Grund für das schnelle Wiederwachstum der H8N8-Tumore sein, denn laut mehreren Studien besteht eine höhere Wahrscheinlichkeit eines Wiederwachstums von Mammakarzinomen, wenn nur eine kleine Anzahl an TIL im Tumor vorhanden ist (Dieci et al. 2015; Asano et al. 2018). Die hier vorliegenden FACS-Analysen zeigen, dass Residualtumore nach CAF und Wiederwachstum die meisten TIL, verglichen mit den anderen Gruppen aufweisen und bekräftigen die Ergebnisse von Dieci et al., dass neoadjuvante Therapien die Anzahl CD45+-TIL im Mammakarzinom erhöhen (Dieci et al. 2015).

\subsection{Welche Gene, Signalwege und Oberflächenmarker sind für die remittierten H8N8-Tumorzellen charakteristisch und befähigen sie nach CAF-Therapie zum Wiederwachstum?}

In dieser Arbeit sind die Tumore, die nach CAF-Therapie in Remission bzw. nach Wiederwachstum in Progression sind, gekennzeichnet durch eine größere Anzahl Tumorzellen, die für den mesenchymalen Phänotyp spezifisch Vimentin exprimieren, was auf eine CAF-Therapie-vermittelte EMT hinweist. Weiter verzeichnen diese CAF-therapierten Tumore eine Dezimierung der epithelialen Epcam ${ }^{+}$-Tumorzellen sowie eine hochregulierte Genexpression von EMT-TF und ein GSEA-Profil, das die Aktivität von EMT nach CAF während der Tumorremission bestätigt. Der Einfluss der CAFTherapie führt durch EMT zur Umwandlung des epithelialen Phänotyps in unbehandelten Tumoren, zu einem mesenchymalen Phänotyp in remittierten Tumoren. Im Verlauf des Wiederwachstums der Residualtumore nach CAF-Therapie, werden i) mesenchymale Markergene vermindert exprimiert, im Gegenzug sind ii) Gene, die den epithelialen Phänotyp fördern hochreguliert, ii) weniger Tumorzellen Vimentin positiv gefärbt und iv) ein größerer Anteil Tumorzellen präsentieren das für den epithelialen Phänotyp spezifische Oberflächenmolekül Epcam. Beim Vergleich der Phänotypen unbehandelter Tumore und CAF-therapierter Tumore nach Wiederwachstum, weisen wieder gewachsene Tumore mehr mesenchymale Eigenschaften, wie eine positive Vimentin-Färbung und verstärkte Expression 
von EMT-TF auf. H8N8-Tumore induzieren demnach, als Reaktion auf die CAF-Therapie, zu Beginn der Remission EMT-Prozesse. Wie mehrere andere Studien beschreiben, ist das Durchlaufen der EMT in Chemotherapie behandelten Tumorzellen assoziiert mit einer gesteigerten Invasivität, einer verbesserten Resistenz und einem Zugewinn an tumorigenen Fähigkeiten (Kurrey et al. 2009; Nieto et al. 2016; Shibue und Weinberg 2017; Li et al. 2018). So ist es sehr wahrscheinlich, dass die hier gezeigten CAF induzierten Resistenzen der H8N8-Tumore durch EMT induziert werden und zum Wiederwachstum der Tumore beitragen.

Wir konnten zeigen, dass die EMT-TF Gene Snai1, Snai2 und Twist1 verstärkt in den Tumorzellen nach CAF-Therapie exprimiert werden. Es ist bekannt, dass die EMT über verschiedene EMT-TF gesteuert wird (Puisieux et al. 2014; Chen et al. 2017) und zahlreiche Prozesse der Tumorprogression, -dissemination und -resistenz vermittelt werden. Studien zeigen, dass die veränderte Expression von EMT-TF die Fähigkeit von Tumorzellen zur Resistenz beeinflusst. Die gesteigerte Synthese der EMT-TF Snai1 und Snai2 kann in CAF-therapierten H8N8-Tumorzellen auf verschiedene Weise zu einer verstärkten Resistenz als Antwort auf die CAF-Therapie führen, u.a. durch Hemmung von Apoptose (Kurrey et al. 2009), Runterregulierung des Er- $\alpha$ (Vesuna et al. 2012) und Hochregulierung des proto-Onkogens Akt2 (Thymoma Viral proto-Oncogene-2) (Cheng et al. 2007). Li et al. konnten in vitro mittels TWIST1-Knockdown das Multidrug Resistance Protein-1 (MDR1) hemmen und dadurch die Empfindlichkeit von humanen HepG2-Leberkarzinomzellen gegenüber einer Kombinationschemotherapie bestehend aus 5-Fluouracil, Cisplatin und Doxorubicin steigern. Diese Zellen besaßen vor dem TWIST1-Knockdown erhöhte Mengen des TWIST1 Proteins, vergleichbar zu unseren Beobachtungen in H8N8-Tumoren nach CAF-Therapie und nach dem Wiederwachstum der Tumore der Gruppe CAF - Progression, die auch hochregulierte TWIST1-Genexpression nach CAF-Therapie zeigten und resistenter waren. Der TWIST1-Knockdown in der Studie von Li et al. war negativ mit der Expression des MDR1-Gens und positiv mit der Synthese von E-Cadherin korreliert. Die Autoren beobachteten nach dem Knockdown außerdem eine verminderte migratorische Aktivität und einen unterdrückten mesenchymalen Phänotyp, was Sie zur der Aussage führte, dass TWIST1 ein potenzieller Angriffspunkt für neuartige therapeutische Strategien sein kann (Li et al. 2018). Es darf jedoch nicht übersehen werden, was eine weitere Konsequenz bei einer Hemmung oder kompletten Unterdrückung der TWIST1-Aktivität sein könnte: So wäre es möglich, dass bereits 
disseminierte zirkulierende Tumorzellen veranlasst werden, andere Gewebe zu invadieren, sich dort mittels MET durch Aktivierung epithelialer Marker anzusiedeln und dadurch das Wachstum von Metastasen zu erhöhen. Da H8N8-Tumore als ein Mammakarzinom-Mausmodell beschrieben ist, das mit einer Rate von 20 \% metastasiert (Maenz et al. 2015), könnte ein TWIST1-Knockdown kombiniert mit der CAF-Therapie, die nachweislich EMT induziert, die Metastasierungsrate erhöhen.

Die hier erzielten Ergebnisse zeigen in der IHC mit dem E-Cadherin-AK eine intensive Membranfärbung und eine annähernd verdoppelte Genexpression von E-Cadherin in Tumorzellen remittierter Tumore. Durchflusszytometrische Analysen ergaben, dass in remittierten Tumoren ca. 18,6\% der vitalen Tumorzellen Epcam ${ }^{+}$sind. Diese Zellen könnten nach der CAF-Therapie weiterhin E-Cadherin exprimieren und damit für die positive E-Cadherin-AK-Färbung verantwortlich sein. Es gibt Hinweise darauf, dass eine verstärkte Expression und Membraneinlagerung von E-Cadherin, mit einer gesteigerten Chemotherapieresistenz assoziiert ist, da adhärente Tumorzellen als dichter Verband eine räumliche Barriere bilden und den Chemotherapeutika der Zugang zu den Tumorzellen erschwert und das Eindringen in die Zellen vermindert ist (Green et al. 2004). Solche Ergebnisse wurden bisher nach Wachstum der humanen HAT-29-Kolonkarzinomzellen als Tumorspheroide im in vitro 3D-Modell beobachtet, was dem in vivo Zustand zwar näherkommt als Monolayer-Kulturen, jedoch steht die in vivo Analyse noch aus (Chao et al. 2010; Chao et al. 2012). Eine andere in vitro Studie zeigt, dass Mammakarzinomzellen nach E-Cadherin-Knockdown und Co-Kultur mit Leberepithelzellen nach sechs Tagen erneut E-Cadherin exprimierten und mit erhöhter Resistenz, durch Hochregulierung des MAP-Kinase- und des PI3K/AKT-Signalwegs assoziiert waren (Chao et al. 2010; Chao et al. 2012). Hieraus lassen sich folgende Hypothesen zur Resistenzentwicklung im Mammakarzinom als Reaktion auf die CAF-Therapie aufstellen: i) Zum einen die Hypothese des EMT-vermittelten Resistenzzugewinns von Tumorzellen mit einem mesenchymaleren Intermediärphänotyp und ii) zum anderen die Hypothese, dass die abschirmende Wirkung, der durch das Adhäsionsmolekül E-Cadherin geschaffenen Barriere, die Tumorzellen räumlich von der CAF-Therapie abschirmen.

Nach CAF-Applikation ist der Tnf- $\alpha$-Signalweg, via der vermittelnden Funktion von Nf-кb, sowohl im remittierten wie auch im progressiv wachsenden H8N8-Tumor aktiviert, verbunden mit der Expression antiapoptotischer Gene. So sind insbesondere $B c l 2$ und $B c l x l$ in remittierten Tumore um 
das doppelte hochreguliert und tragen dadurch zum Verstärken der CAF-Therapieresistenz bei. Baritaki et al. reduzierten die Resistenzfähigkeit von Prostata-Adenokarzinomzellen und Melanomzellen durch Inhibieren des Proteosoms mittels dem Proteosominhibitor NPI-0052, wodurch die Proteinsynthese von Snail und Nf-kb verringert wurde (Baritaki et al. 2009). Daneben ist auch der Il6-Jak1Stat3-Signalweg im remittierten Tumor, im Vergleich zu Tumoren der Gruppe CAF - Progression, als Antwort auf die CAF-Therapie, aktiviert. Für metastasierende PC3-Prostatakarzinome beschrieb Gao et al., dass eine siRNA (small interfering RNA) verursachte Reduzierung der Stat3-Expression, die Expression von antiapoptotischen Genen wie $B c 11, B c l 2$ und $M y c$ mindert und damit vermutlich eine Schwächung der Il6-Jak1-Stat3-Signaltransduktion hervorruft (Gao et al. 2005).

Die Daten der sequenzierten Tumorzell-mRNA weisen in CAF-remittierten Tumoren eine verstärkte I16-Genexpression auf, verbunden mit einer gesteigerten Expression des Rank-Liganden-Gens Tnfsf11. Es gibt zahlreiche Studien, die den Tnf- $\alpha$ - (Acharyya et al. 2012; Zeligs et al. 2016; Zhang et al. 2018) und den Il6-Jak1-Stat3-Signalweg (Hartman et al. 2013; Lee et al. 2014; Banerjee und Resat 2016) als wichtige Steuerelemente von Tumorzellen für die Entwicklung von Resistenzmechanismen beschreiben.Tnfsf11kann nach Bindung an den Rank-Rezeptor die Osteoklastenreifung fördern und damit zur Knochenmetastasenbildung beitragen (Infante et al. 2019). Aufgrund einer Metastasierungsrate der H8N8-Tumore von 20 \% (Maenz et al. 2015), könnte durch die CAF-Therapie kombiniert mit der Tnfsf11-vermittelten Osteoklastenreifung in H8N8-tumortragenden Mäusen das Metastasierungspotential erhöht sein. Dies könnte mittels einer spezifischen PCR gegen die mutierte Form des Tp53 (mutp53), welches nur im Genom der H8N8 Zellen und nicht bei den WAP-T-NP8 Mäusen integriert ist (Krepulat et al. 2005; Heinlein et al. 2008; Lenfert et al. 2015), im syngenen WAPT-Mausmodell untersucht werden und von großem Interesse sein.

Immunhistochemische Il6-Färbungen lassen eine gesteigerte Sekretion aufgrund erhöhter extrazellulärer Vorkommen des Il6-Proteins nach CAF im remittierten Tumor vermuten. In Verbindung mit der GSEA-Analyse, wodurch die Aktivität des Il6-Jak1-Stat3-Signalwegs in CAF therapierten Tumorzellen belegt wird, führt die CAF-Therapie im Tumor zu einer verstärkten Il6-Expression und Sekretion in die EZM. In vitro Studien bestätigen dieses Ergebnis, dass der Il6-Jak1-Stat3-Signalweg zur Phosphorylierung von Stat3, um Resistenzmechanismen zu initiieren, hauptsächlich über eine auto- bzw. parakrine Produktion und Sekretion von Il6 aktiviert wird (Berishaj et al. 2007; Lieblein 
et al. 2008). Die Bestimmung der Il6-Konzentrationen nach CAF-Therapie kann mittels Il6-ELISA ermittelt werden und würde der Überprüfung des beschriebenen Ergebnisses dienen und eine Quantifizierung ermöglichen zu welchem Zeitpunkt nach CAF-Applikation die Il6-Konzentration im Tumor das Maximum erreicht. Hartman et al. waren in vivo in der Lage nachzuweisen, dass nach einer autokrinen Il6-Signaltransduktion-induzierten Resistenz, eine siRNA-verursachte Inhibition von $I l 6$ und Interleukin-8 (II8) zu einer Reduzierung der Paclitaxel-Resistenz und Erhöhung antiapoptotischer Mechanismen führt, wohingegen ein alleiniger Il6-Knockdown nicht dazu befähigt war (Hartman et al. 2013). Das Ergebnis dieser Studie, zusammen mit dem Zeitpunkt der maximalen Il6-Konzentration im Tumor nach CAF-Applikation, könnte ein Ansatzpunkt für eine neues Behandlungsprotokoll zur Vermeidung von Residualtumorzellen sein.

Die Ergebnisse der FACS-Analysen zeigen, dass die CAF-Therapie bei Tumoren in Remission eine Steigerung der Anzahl Cd44+Cd24--Tumorzellen um ca. $45 \%$ hervorruft, wohingegen Tumore nach progressiven Wiederwachstum weniger dieser Zellen beinhalten. Verschiedene Studien zeigen, dass die in dieser Arbeit eingesetzte CAF-Therapie sehr effizient nCSC eliminiert aber wirkungslos gegen CSC vom TNBC ist, wodurch diese TNBC innerhalb von vier bis sechs Wochen nach Therapiestart mit dem Wiederwachstum beginnen (Naujokat und Laufer 2013; Ahmed et al. 2017; Wang et al. 2017b). Da die Resistenzentwicklung nach Chemotherapie eng mit EMT und dem vermehrten Vorkommen von potenziellen Cd44+Cd24--CSC korreliert (Thiery et al. 2009; Singh und Settleman 2010; Kotiyal und Bhattacharya 2014; Felipe Lima et al. 2016; Vijay et al. 2019; Zhang et al. 2019), ist die Schlussfolgerung, dass die CAF-Therapie die $\mathrm{Cd} 44{ }^{+} \mathrm{Cd} 24$-Tumorzellen aufgrund ihrer Stammzellund Resistenzeigenschaften selektioniert. Deshalb machen diese Tumorzellen ca. 60 \% der Tumorzellen im remittierten H8N8-Tumor aus und könnten so Ausgangszelle für das progressive Wiederwachstum der Residualtumore sein. Die Studie von Iliopoulos et.al zeigt, für humane Zelllinien und isolierte Mammakarzinomzellen, dass Il6 die Differenzierung von nCSC zu Cd44+Cd24--CSC fördert, die Bildung von Mammosphären in vitro stimuliert und eine Il6-Hemmung die Konvertierung hin zu CSC blockiert (Iliopoulos et al. 2011).

Die Charakterisierung der Mammakarzinom-CSC in den Tumoren der Gruppen CAF - Remission und CAF - Progression allein mit der Oberflächenmolekül-Signatur $\mathrm{Cd} 44{ }^{+} \mathrm{Cd} 24$ - ist nicht ausreichend und benötigt weiterer Validierung durch Mammakarzinom CSC-Markergene wie Integrin- $\alpha-6$ 
(Itga6) (Cariati et al. 2008), Delta/Notch-like EGF Repeat Containing (Dner) (Pece et al. 2010), Aldehyde Dehydrogenase Family-1, subfamily-A3 (Aldh1a3) (Ginestier et al. 2007; Marcato et al. 2011; Shao et al. 2014) oder ATP-Binding-Cassette Subfamily-G member-2 (Abcg2) (Doyle et al. 1998) sowie durch. Pluripotenzmarker wie POU Domain, Class 5, Transcription Factor-1 (Pou5f1), Nanog Homeobox (Nanog) und SRY (Sex Determining Region-Y)-box-2 (Sox2) (Ben-Porath et al. 2008; Prud'homme 2012), um zu gewährleisten, dass die selektierten $\mathrm{Cd} 44+\mathrm{Cd} 24$-Tumorzellen der Tumore der Gruppe CAF - Remission tatsächlich CSC-Eigenschaften besitzen, befähigt sind Tumorentwicklung zu initiieren und mit Resistenzen gegen Chemotherapien ausgestattet sind (Akrap et al. 2016). Die sequenzierte Tumorzell-mRNA von remittierten Tumorzellen, die zu einem ca. 60 \%igen Anteil aus $\mathrm{Cd} 44{ }^{+} \mathrm{Cd} 24-$-Tumorzellen bestanden, zeigen, mit Ausnahme für das Itga6- und Dner-Gen, das CAF die Expression von Aldh1a3, Abcg2, Pou5f1, Nanog und Sox2 verdoppelt bis vervierfacht. Das führt zu der Annahme, dass Tumore nach CAF-Therapie vermehrt aus $\mathrm{Cd} 44+\mathrm{Cd} 24$--Tumorzellen mit erhöhten tumorfördernden CSC- und Pluripotenzeigenschaften bestehen und die CAF-Therapie diese Tumorzellen wegen ihrer Resistenzfähigkeit nicht eliminiert. Dies trifft für $\mathrm{Cd} 44{ }^{+} \mathrm{Cd} 24-\mathrm{Tu}-$ morzellen aus einem wieder gewachsenen Tumor nach CAF-Therapie nur bedingt zu, da die Genexpression der erwähnten CSC- und Pluripotenz-Markergene nicht in dem Maß wie in remittierten Tumoren erhöht war.

Mittels FACS-Analysen wurde in dieser Studie gezeigt, dass Tumore in Remission mit $\mathrm{Cd} 44{ }^{+} \mathrm{Cd} 24$ Tumorzellen nach CAF-Therapie vermehrt die Oberflächenmoleküle Cd95, Cd104, Cd107a, Cd146, Cd201 und Sca1 auf der Zelloberfläche präsentieren. Die sortierten Cd24+-Tumorzellen, die ebenfalls einen dieser Oberflächenmoleküle präsentieren, sterben größtenteils durch die CAF-Therapie. Tumorzellen erhalten keine Resistenz allein durch die Expression eines resistenzvermittelnden Oberflächenmoleküls, sondern sie benötigen eine Kombination aus mehreren Proteinen, die dabei verschiedene Aufgaben übernehmen. Ceppi et al. haben die Funktion von Cd95 in TNBC-Zelllinien in vivo und in vitro untersucht und fanden heraus, dass der Anstieg der Anteile des Cd95-Oberflächenmoleküls auf der Zelloberfläche, so wie es auch für CAF therapierte $\mathrm{Cd} 44{ }^{+} \mathrm{Cd} 24$-Tumorzellen zu trifft, mit einer sinkenden Apoptoseempfindlichkeit und einem steigenden CSC-Charakter, vermittelt durch EMT, assoziiert ist. Demnach könnte der hoch signifikante Anstieg der $\mathrm{Cd} 44{ }^{+} \mathrm{Cd} 24-\mathrm{Cd} 95^{+-}$ 
Tumorzellen nach CAF-Therapie in den Tumoren der Gruppe CAF - Remission, den H8N8-Tumorzellsubtyp identifizieren, der einen großen Teil der resistenten Tumorzellen ausmacht und diese, vermittelt durch EMT, das Wiederwachstum initiieren können. Das könnte erklären, warum die H8N8T2-Tumorzellen, die aus einem CAF-therapierten remittierten Tumor isoliert wurden, nach Retransplantation und erneuter CAF-Applikation die größte Resistenz und die geringste $\mathrm{V}_{\mathrm{T}}$-Reduzierung zeigten, weil sie den größten Anteil $\mathrm{Cd} 44{ }^{+} \mathrm{Cd} 24-\mathrm{Cd} 95^{+-}$Tumorzellen beinhalteten. Jedoch waren die CSC, welche vermehrt Cd95 auf der Zelloberfläche präsentierten, mit einer höhere DICE-Empfindlichkeit ausgestattet. Die Abkürzung DICE steht für Death Induced by Cd95R/L Elimination und wurde erstmals bei Tumorzellen beobachtet, denen zuvor Cd95 oder dessen Ligand entfernt wurde. Wenn DICE initiiert wird, dann führt das zum Zelluntergang durch Zellschwellung und Bildung reaktiver Sauerstoffspezies, gefolgt von DNA-Schädigungen sowie Aktivierung von Caspase 2 und entspricht einer nekrotischen Form des Zelltodes (Ceppi et al. 2014).

Beim Übergang vom epithelialen zum mesenchymalen Phänotyp wurden mittlerweile Intermediärphänotypen als Übergangsformen während der EMT beschrieben (Nieto et al. 2016; Shibue und Weinberg 2017), die mit einer gesteigerten Resistenz, Invasivität und tumorigenen Aktivität assoziiert sind. In der Publikation von Kröger et al. wurden humane TNBC-ähnliche HMLER-Tumorzellen mit der Oberflächenmolekül-Signatur $\mathrm{CD} 44^{+} \mathrm{CD} 104^{+}$als Intermediärphänotyp (EM) definiert. Kröger et al. zeigt in der Publikation, dass $\mathrm{CD} 44^{+} \mathrm{CD} 104^{+}-$Tumorzellen ihre Plastizität einbüßten, in dem EM-Status blockiert aber mit eine erhöhten tumorigenen Aktivität und CSC-Eigenschaften ausgestattet waren (Kröger et al. 2019). Unsere Ergebnisse der FACS-Analysen bestätigen zwar die Vermehrung von $\mathrm{Cd} 44^{+} \mathrm{Cd} 24-\mathrm{Cd} 104^{+}-$Tumorzellen, befürworten aber nicht die Beobachtungen von Kröger et al., dass Tumorzellen dieses Phänotyps an Plastizität einbüßen, weil der Anteil $\mathrm{Cd} 44{ }^{+} \mathrm{Cd} 24-$ Cd104+-Tumorzellen im Tumor nach Wiederwachstum stark dezimiert war und eine doch vorhanden Plastizität der $\mathrm{Cd} 44^{+} \mathrm{Cd} 24-\mathrm{Cd} 104^{+}-$Tumorzellen vermutet werden kann, da die Tumorzellen im Verlauf des Wiederwachstums die Oberflächenmolekül-Signatur anscheinend verändert.

Das Vorhandensein von CD107a (Wang et al. 2017a) und CD146 (Zeng et al. 2012) auf der Zelloberfläche von Mammakarzinomzellen aus humanen Mammakarzinomgewebe ist für beide Marker mit einer schlechten Prognose beschrieben. Speziell CD146+-Tumorzellen sind charakterisiert als 
Tumorzellen, die den epithelialen Phänotyp unterdrücken, einen schlecht differenzierten TNBC-ähneln, einen mesenchymalen Phänotyp entsprechen, Invasivität fördern und mit CSC-Eigenschaften assoziiert sind (Zeng et al. 2012). Lu et al. charakterisierten die Eigenschaften von humanen CD $44^{+} \mathrm{CD} 24-\mathrm{Cd} 201^{+}-\mathrm{CSC}$ und im Gegensatz zu den Eigenschaften der oben beschriebenen CD146 ${ }^{+}$-Tumorzellen, die gesteigerte migratorische Eigenschaften aufwiesen, zeigen $\mathrm{CD} 44{ }^{+} \mathrm{CD} 24-$ Cd201+_CSC schlechte migratorische Fähigkeiten und geringe Proliferationsraten, waren dafür aber mit einer stark erhöhten Resistenz gegen den epigenetischen Inhibitor Vorinostat ausgestattet (Lu und Labhasetwar 2013). Grange et al. untersuchten die tumorigene Fähigkeiten von Sca1+-Tumorzellen in transgenen BALB-neuT-Mäusen und es zeigte sich, dass neben der tumorigenen Fähigkeit von Sca1+-Tumorzellen, nach der Isolierung und Kultivierung der Sca1+-Tumorzellen als Tumorspheroide, diese eine Doxorubicinresistenz besaßen (Grange et al. 2008). Die drei zuvor genannten Studien (Grange et al. 2008; Zeng et al. 2012; Lu und Labhasetwar 2013) beschreiben Oberflächenmolekülsignaturen von Tumorzellen, welche auf der Zelloberfläche von H8N8-Tumoren nach CAFTherapie und Tumorremission vermehrt präsentiert werden, ob die $\mathrm{CD} 44^{+} \mathrm{CD} 24-\mathrm{Cd} 201^{+}$, CD $44^{+} \mathrm{CD} 24-\mathrm{Cd} 201^{+}-$bzw. CD $44^{+} \mathrm{CD} 24-\mathrm{Sca} 1^{+}-$Tumorzellsubtypen aber auch die beschrieben Eigenschaften haben, muss nach Isolierung des jeweiligen Subtyps und Retransplantation in vivo validiert werden.

Auch wenn diese Studien unterstreichen, dass die untersuchten Oberflächenmarker Resistenzen und CSC-Eigenschaften bei $\mathrm{CD} 44^{+} \mathrm{CD} 24-$-Tumorzellen vermitteln und in Kombination mit den hier vorgestellten Ergebnissen vermutlich nach CAF in einer höheren Anzahl im Tumor vorkommen und eventuell den Hauptbestandteil ausmachen und Ursache für das Wiederwachstum der Residualtumore sind, gibt es einzelne Studien die gegenteiliges zeigen. Eine Studie mit 50 MammakarzinomGewebeproben nach neoadjuvanter Epirubicin/Cyclophosphamid-Therapie zeigt mittels Immunfluoreszenz-Doppelfärbungen, dass der Anteil an $\mathrm{CD} 44{ }^{+} \mathrm{CD} 24-$-Tumorzellen auf $2 \%$ reduziert war. Die Wiederholung der Untersuchung mit 16 weiteren Mammakarzinom-Gewebeproben nach adjuvanter Therapie mit vier Zyklen Doxorubicin/Pemetrexed, gefolgt von vier Zyklen Docetaxel oder mit vier Zyklen Doxorubicin/Cyclophosphamid, gefolgt von vier Zyklen Docetaxel zeigte, dass der Anteil $\mathrm{Cd} 44{ }^{+} \mathrm{Cd} 24$-Tumorzellen erneut reduziert war und diesmal sogar auf 1,1\% (Aulmann et al. 2010). Auch wenn diese Publikation nur an einer geringen Probenzahl vorgenommen wurde zeigt 
sie, wie wichtig die genaue Definition und Charakterisierung der Mammakarzinom-CSC ist, um Rückschlüsse auf das Resistenzpotenzial der Tumore zu schließen.

Die orthotope Retransplantation der isolierten und kultivierten H8N8T1-, H8N8T2- und H8N8T3Tumorzelllinien in WAP-T-NP8-Mäuse zeigt, dass ein Zusammenhang zwischen der Resistenzfähigkeit und dem Anteil an $\mathrm{Cd} 44{ }^{+} \mathrm{Cd} 24-$-Tumorzellen im Tumor bei der Behandlung mit der CAF-Therapie besteht. H8N8T2-Tumorzellen aus einem remittierten Tumor der Gruppe CAF - Remission und H8N8T3-Tumorzellen aus einem wieder gewachsenen Tumor der Gruppe CAF - Progression waren sechs Tage nach erneuter CAF-Applikation signifikant resistenter gegenüber der CAF-Therapie, deutlich an einer geringeren Tumorvolumenreduzierung nach CAF-Applikation. Außerdem besaßen sowohl die H8N8T2- als auch die H8N8T3-Tumorzellinien einen höheren Anteil Cd44 ${ }^{+} \mathrm{Cd} 24$ -Tumorzellen. Zur nachgewiesenen CAF-Resistenz der bereits CAF-therapierten Tumore gegenüber einem weiteren CAF-Zyklus trägt außerdem das Präsentieren der Oberflächenmoleküle Cd95, CD104, Cd107a, Cd146, Cd201 und Sca1 bei, da diese allesamt auf ihre Art und Weise Resistenzen fördern und von Tumoren der Gruppe CAF - Remission nach CAF-Therapie präsentiert wurden. Es muss jedoch berücksichtig werden, dass dieses Ergebnis durch Retransplantation von Tumorzellen keines bestimmten Subtyps erarbeitet wurde. Die Isolation und anschließende Retransplantation von Tumorzellen mit den Oberflächenmolekülsignaturen $\mathrm{Cd} 44^{+} \mathrm{Cd} 24-\mathrm{Cd} 95^{+}, \mathrm{Cd} 44^{+} \mathrm{Cd} 24-\mathrm{CD} 104^{+}$, Cd44 ${ }^{+} \mathrm{Cd} 24-\mathrm{Cd} 107 \mathrm{a}^{+}, \mathrm{Cd} 44^{+} \mathrm{Cd} 24-\mathrm{Cd} 146^{+}, \mathrm{Cd} 44^{+} \mathrm{Cd} 24-\mathrm{Cd} 201^{+}$oder $\mathrm{Cd} 44^{+} \mathrm{Cd} 24-\mathrm{Sca} 1^{+}$könnte nach CAF-Applikation den Ursprung der gesteigerten Resistenz genauer untersuchen und den Tumorzellsubtyp mit dem größten Resistenzpotential identifizieren.

\subsection{Wie wirkt sich die Hemmung von Interleukin-6 in Verbin- dung mit der CAF-Therapie auf Wachstumskinetik, Ober- flächenmarker und CAF-Resistenz der Tumorzellen aus?}

Die vergleichende Analyse der Wirkung der CAF/S-Kombinationstherapie mit der CAF-Therapie zeigt, dass i) die CAF/S-Therapie das $\mathrm{V}_{\mathrm{T}}$ während der ersten vier Tage schneller reduziert als die CAF-Therapie alleine, ii) beide Therapien eine vergleichbare maximale $\mathrm{V}_{\mathrm{T}}$-Reduzierung bewirken und iii) dass die CAF/S-Therapie nicht in der Lage war, das Wiederwachstum der Residualtumore über 
einen längeren Zeitraum als die CAF-Therapie zu verzögern. Die alleinige Gabe von Siltuximab hat keine Wirkung auf das Tumorwachstum; die Wachstumskinetik der Tumore in dieser Gruppe war vergleichbar mit unbehandelten Tumoren.

Die Ergebnisse sind vergleichbar mit denen von Casneuf et al., die die Wirkung von Siltuximab im Vergleich zu Fulvestrant, einem sogenannten Selective Estrogen Receptor Degrader (SERD), der effektiv Estrogenrezeptoren degradiert und von der Kombination aus Siltuximab/Fulvestrant im ER- $\alpha$-positiven Mammakarzinom-Xenograft-Mausmodell untersuchten. Sie fanden, dass die Kombinationstherapie zu keiner Verbesserung des Therapieergebnisses, verglichen mit der alleinigen Fulvestranttherapie führte. Weiter zeigen sie, im Gegensatz zu den eigenen Ergebnissen dass die Behandlung mit Siltuximab allein bereits das $V_{T}$ von ER- $\alpha$-positiven Mammakarzinomen effektiv reduzierte (Casneuf et al. 2016). Dieses Ergebnis konnten wir so in unserem murinen syngenen WAP-TMausmodell, welches dem humanen TNBC ähnlich ist, nicht beobachten, da die Tumore nach Siltuximabtherapie vergleichbar zu den Kontrollen weiterwuchsen. Die stärkere Wirkung von Siltuximab auf ER- $\alpha$-positive Mammakarzinome im Vergleich zu TNBC-ähnlichen Tumore kann teilweise dadurch erklärt werden, dass HR-positive Mammakarzinomzellen intrinsisch bereits höhere IL6Konzentrationen synthetisieren und für ihr Wachstum auf IL6-Signaltransduktion über den IL6JAK1-STAT3 Signalweg angewiesen sind. Dementsprechend reagieren die Tumorzellen bei Hemmung von IL6 empfindlicher und werden so effektiver eliminiert (Fontanini et al. 1999; Chavey et al. 2007; Masjedi et al. 2018).

Die IL6-induzierte Signaltransduktion wird über zwei Wege stimuliert: i) Bei der klassischen Signaltransduktion bindet IL6 an den IL6R (CD126) und überträgt das Signal nach Komplexbildung mit dem GP130-Rezeptor durch Phosphorylierung von JAK1 in die Zelle, wodurch eine antiinflammatorische Antwort ausgelöst wird. ii) Bei der trans-vermittelten Signaltransduktion ist es für die Empfängerzelle ausreichend ausschließlich den GP130-Rezeptor auf der Oberfläche zu präsentieren, da die Signalübertragung nach Bindung des nichtmembranständigen gelösten IL6-IL6R-Komplex an den GP130-Rezeptor aktiviert wird, was eine proinflammatorische Antwort auslöst. Der IL6R wird durch die proteolytische Aktivität der Disintegrin und Metalloproteinase 10 oder 17 (ADAM10/17) von der Zellmembran gelöst und kann in der EZM durch IL6-IL6R-Rezeptorbindung einen Kom- 
plex bilden. Laut Chiu et al. ist die Expression von $I L 6 R$ in HR-negativen, verglichen mit HR-positiven humanen Mammakarzinom-Zellen höher (Chiu et al. 1996). Unsere Untersuchungen in einem dem humanen TNBC-ähnelnden murinen Tumormodell zeigen, dass durch die CAF-Therapie die II6r-Genexpression im remittierten Tumor deutlich ansteigt und der Il6r auf der Zelloberfläche nach Wiederwachstum des Residualtumors stark vermehrt präsentiert wird. Für Tumore nach progressivem Wiederwachstum, die mit der CAF/S-Therapie behandelt wurden, zeigen wir, dass die Tumorzellen, im Vergleich zu Tumorzellen nach CAF-Therapie, signifikant weniger Il6r auf der Oberfläche präsentieren. Aus diesen Beobachtungen ergeben sich zwei Hypothesen: i) Durch die Kombinationstherapie wird weniger Il6r exprimiert und auf der Oberfläche präsentiert und/oder ii) durch die Kombinationstherapie wird der Il6r vermehrt durch Adam10 oder Adam17 von der Zellmembran gelöst, wirkt durch Komplexbildung mit Il6 in der EZM antagonistisch zur Il6-Hemmung des Siltuximabs und aktiviert nach Bindung an den GP130-Rezeptor verstärkt proinflammatorische Prozesse. Diese Hypothesen sind in weiterführenden Versuchen noch zu validieren und könnten mittels Co-Färbungen mit AK-gekoppelten Fluorophoren untersucht werden.

In der Casneuf et al. Studie wurden die Mäuse mit einer Siltuximabkonzentration von $20 \mathrm{mg} / \mathrm{kg} \mathrm{KG}$ zweimal wöchentlich und in dieser Arbeit mit einer Konzentration von 10 mg/kg KG dreimal wöchentlich behandelt (Casneuf et al. 2016). Eine Wiederholung der hier vorgestellten Transplantationsversuche mit einem modifizierten Behandlungsprotokoll und einer erhöhten Siltuximabkonzentration könnte erstrebenswert sein, da die Ergebnisse während der ersten vier Tage nach Applikation der CAF/S-Therapie eine schnellere $\mathrm{V}_{\mathrm{T}}$-Reduzierung, verglichen mit den nur CAF-therapierten Tumoren, zeigen und die Wirkung eventuell durch eine effektivere Il6-Hemmung verstärkt werden kann. Eine gesteigerte Siltuximabkonzentration könnte für den Allgemeinzustand der Mäuse vertretbar sein, da die hier Siltuximab-therapierten Mäuse die Therapie gut vertrugen und einige Studien bereits die Toxizität von Siltuximab bei humanen Erkrankungen untersuchten und für nicht bedenklich einstuften(Hudes et al. 2013; Kurzrock et al. 2013; Markham und Patel 2014).

Durch Il-6-Hemmung wurde der Anteil an Tumorzellen mit dem Oberflächenmolekül Cd44 reduziert, jedoch trifft das nicht für den Anteil $\mathrm{Cd} 44{ }^{+} \mathrm{Cd} 24-$-Tumorzellen zu, dieser ist bei CAF-therapierten und CAF/S-therapierten Tumoren nach Remission und Wiederwachstum in den FACS-Analysen vergleichbar. Demnach hat die Hemmung von Il-6 in unserem syngenen WAP-T-Mammakarzinom- 
Mausmodell mit den hier verwendeten Konzentrationen keinen Einfluss auf die Anzahl Cd44 ${ }^{+} \mathrm{Cd} 24$

-Tumorzellen im wieder gewachsenen Tumor nach Kombinationstherapie. Da aber in den CAFtherapierten remittierten Tumoren, wenn das $\mathrm{V}_{\mathrm{T}}$ maximal reduziert ist, das progressive Wiederwachstum noch nicht gestartet hat und zu diesem Zeitpunkt der größte prozentuale Anteil $\mathrm{Cd} 44^{+} \mathrm{Cd} 24-$ Tumorzellen im Tumor gemessen wurde, soll in einem zukünftigen Transplantationsversuch eine zeitliche Kinetik aufgenommen werden, um zu untersuchen, wie sich die Anteile $\mathrm{Cd} 44{ }^{+} \mathrm{Cd} 24-\mathrm{Tu}-$ morzellen zu verschiedenen Zeitpunkten (1 Tag, 3 Tag, 6 Tage, 9 Tage, 12 Tage und 15 Tage) nach der CAF- bzw. CAF/S-Therapie verändern und sich eventuell in den untersuchten Gruppen unterscheiden.

Der Anteil an Cd44+-Tumorzellen, ohne Betrachtung des Cd24-Oberflächenmoleküls, ist beim Vergleich der CAF-Therapie mit der Kombinationstherapie signifikant verringert. Phuc et al. regulierten die CD44Genexpression mittels siRNA in isolierten humanen $\mathrm{CD} 44{ }^{+} \mathrm{CD} 24-$-Tumorzellen runter und zeigen, dass $\mathrm{CD}_{4}{ }^{+}{ }_{\text {Knockdown }} \mathrm{CD} 24-$-Tumorzellen im Vergleich zu den normalen $\mathrm{CD} 44^{+} \mathrm{CD} 24-$ Tumorzellen empfindlicher auf eine Doxorubicintherapie reagieren und vermehrt durch Apoptose eliminiert werden. Die Autoren schlussfolgern, dass $\mathrm{CD}_{4} 4^{+}{ }_{\text {Knockdown }} \mathrm{CD} 24-$-Tumorzellen eine gesteigerte Doxorubicinresistenz durch die verringerte Aktivität der ABC-Transporter, welche in normalen CD $44{ }^{+} \mathrm{CD} 24-$ Tumorzellen das Doxorubicin aktiv aus der Tumorzelle ausschleusen, hervorruft (Van Phuc et al. 2011). Dabei verallgemeinern die Autoren mit der Aussage, dass der CD44-Knockdown CSC empfindlicher gegen Chemotherapeutika, durch schwächen der Resistenzmechanismen macht, wobei dies nur nach Doxorubicingabe untersucht wurde. Für andere Chemotherapeutika, deren Wirkungen durch CSC über andere Mechanismen neutralisiert werden, haben die Autoren nicht gezeigt oder diskutiert, ob in CSC durch CD44-Knockdown Resistenzen geschwächt sind.

\subsection{Fazit und Ausblick}

Die Untersuchungen zur Resistenzentwicklung von H8N8-Tumorzellen im syngenen orthotopen WAP-T-Mammakarzinom-Mausmodell zeigen, dass die CAF-Therapie H8N8-Tumore verkleinert aber nicht vollständig reduzieren kann und so nur temporär auf das Tumorwachstum wirksam ist. Dies geht mit einer Umstrukturierung und Änderung des Tumorphänotypen einher, da remittierte 
Tumore zum überwiegenden Anteil aus mit Resistenz- und CSC-Eigenschaften ausgestatteten Cd44 ${ }^{+} \mathrm{Cd} 24-$ Tumorzellen bestehen. Dies erklärt, warum die CAF-therapierten Tumore nach kurzer Zeit wiederwachsen und nach Retransplantation, von remittierten Tumorzellen, bei erneuter CAFTherapie, durch einen CAF-verursachten Resistenzzugewinn selektioniert werden und Tumore unempfindlicher auf CAF reagieren. Die CAF-Therapie beeinflusst die Genexpression der Tumorzellen dahingegen, dass antiapoptotische und mit Pluripotenz-, Stammzell- und Resistenz-assoziierte Gene hochreguliert und EMT-vermittelnde Signalwege wie der Tnf- $\alpha$ - und der Il6-Jak1-Stat3-Signalweg initiiert werden und damit zur Entwicklung von Resistenzen nach CAF-Therapie beitragen. Eine Kombination der CAF-Therapie mit dem Il6-Inhibitor Siltuximab verursacht nach Wiederwachstum in den Tumoren eine Reduzierung der $\mathrm{Cd}_{4} 4^{+}$-Tumorzellen. Die therapeutische Wirkung auf die Wachstumskinetik und die Anteile $\mathrm{Cd} 44{ }^{+} \mathrm{Cd} 24$-Tumorzellen in den Tumoren nach Wiederwachstum ist vergleichbar zu CAF-therapierten Tumoren. Nach CAF/S-Therapie wird das VT in den ersten vier Tagen nach Therapiestart signifikant schneller reduziert. Warum sich die Wachstumskinetik der CAF/S-therapierten Tumore im Anschluss wieder der Wachstumskinetik CAF-therapierter Tumore angleicht, muss in zukünftigen Versuchen untersuch werden.

Aus den hier vorliegenden Ergebnissen ergeben sich neue Fragestellungen, die durch künftige Experimente zu beantworten wären. Da Tumore nach CAF-Therapie und Widerwachstum vermehrt durch CD45+-TIL infiltriert werden, wäre die individuelle Charakterisierung CD45+-TIL anhand von Oberflächenmolekülen mittels FACS-Analysen zur genauen Beschreibung des Tumorimmunstatus vor und nach der CAF-Therapie aus therapeutischer Sicht erstrebenswert. Mit diesem Wissen könnten Therapien entwickelt werden, die die eliminierenden Fähigkeiten einiger CD45 ${ }^{+}$-TIL stimulieren oder es können CD45+-TIL reprimiert werden, die für die Tumore vorteilhafte Eigenschaften besitzen und dadurch deren Resistenz oder Progression steigern.

Die Beobachtung, dass remittierte H8N8-Tumore nach CAF-Therapie vermehrt aus $\mathrm{Cd} 444^{+} \mathrm{Cd} 24-$ Tumorzellen bestehen, die eine Vielzahl an Resistenz- und CSC-vermittelnden Oberflächenmolekülen präsentieren sowie mit Pluripotenz- und CSC-Eigenschaften-assoziierte Gene verstärkt exprimieren, sollten $\mathrm{Cd} 44{ }^{+} \mathrm{Cd} 24-$ Tumorzellsubtypen in den remittierten Tumoren identifiziert werden. Um den $\mathrm{Cd} 44{ }^{+} \mathrm{Cd} 24-$-Tumorzellsubtyp mit der höchsten tumorigenen und resistenzvermittelnden Fähig- 
keit zu identifizieren, sollten diese Zellen mittels der MACS-Technologie angereichert sowie anschlieBend isoliert werden und nach Retransplantation in WAP-T-Mäuse, verbunden mit der Behandlung des jeweiligen individuellen $\mathrm{Cd} 44+\mathrm{Cd} 24$--Tumorzellsubtyps mit der CAF-Therapie, auf ihre Resistenzfähigkeiten untersucht werden., Diese Information wird in Zukunft helfen passende Therapieansätze für die Behandlung von therapieresistenten TNBC zu entwickeln.

Da der Effekt der Kombination der CAF-Therapie mit Siltuximab keinen Vorteil in der Wirksamkeit zur Hemmung des Tumorwachstum ergab, sollte die Il6-Hemmung auf einzelne Tumorzellsubtypen weiter untersucht werden. Um genau den Einfluss des I16-Jak1-Stat3-Signalwegs auf den Anteil Cd44+Cd24--Tumorzellen und die Entstehung von Resistenzen zu entschlüsseln, sollten mittels molekularbiologischen Methoden ein Il6-, Il6r- oder gp130-Knockdown oder die Hemmung der Jak1bzw. Stat3-Signaltransduktion verursacht werden, um genau den Einfluss des Il6-Jak1-Stat3-Signalwegs auf den Anteil Cd44+Cd24--Tumorzellen und die Entstehung von Resistenzen zu entschlüsseln. Das Auftreten von EMT-Prozessen und die Aktivierung der Tnf- $\alpha$ - und Il6-Jak1-Stat3-Signaltransduktion sind Faktoren, die erklären, wie die CAF-Therapie eine Mikroumgebung schafft, welche die Entwicklung von Resistenzen durch Anreicherung der $\mathrm{Cd} 44+\mathrm{Cd} 24-$-Tumorzellen im Tumor unterstützen. Da H8N8-Tumore nach der CAF-Therapie stark vermehrt von Immunzellen infiltriert werden und die Charakterisierung dieser Immunzellen von großer therapeutischer Relevanz ist, könnte das WAP-T-Mausmodell geeignet sein, die Rolle des Immunsystems bei der Entwicklung von Resistenzen zu untersuchen. 


\section{$7 \quad$ Zusammenfassung}

Bei Mammakarzinom-Patientinnen ist normalerweise nicht der Primärtumor selbst die Todesursache, sondern eher die Entstehung eines lokoregionalen oder Fernrezidivs. Trotz einer scheinbar vollständigen Tumorresektion ist die Kombination mit einer adjuvanten und/oder neoadjuvanten Strahlenbzw. Chemotherapie oft nicht fähig alle Tumorzellen zu eliminieren, da einzelne Tumorzellen Resistenzfähigkeiten erlangen/besitzen und Ausgangspunkt für die Bildung eines lokoregionalen oder eines Fernrezidivs sind. Ziel dieser Arbeit war es, i) die Wirkung der Cyclophosphamid-, Doxorubicinund 5-Fluouracil-(CAF-) Therapie im WAP-T-Mammakarzinom-Mausmodell auf die Tumorwachstumskinetik und den -phänotyp zu untersuchen; ii) die Charakterisierung der Tumorzellen, die nach der CAF-Therapie den Großteil der remittierten Tumore ausmacht; iii) die Beschreibung von resistenzvermittelnden Signalwegen, die durch die CAF-Therapie initiiert werden; iv) die Untersuchung der Wirkung einer zu der CAF-Therapie zusätzlichen Hemmung von Interleukin-6 (I16) mit Siltuximab (CAF/S-Therapie) bezüglich Wachstumskinetik, Resistenz und Tumorzellphänotyp.

Hierfür wurden H8N8-Tumore mit der CAF- bzw. mit der CAF/S-Therapie im immunkompetenten syngenen WAP-T-Mausmodell, nach orthotoper Transplantation muriner H8N8-Mammakarzinomzellen, behandelt. Um die Wirkung der CAF- bzw. die Wirkung der CAF/S-Therapie, untersuchen zu können, wurde tumortragenden Mäusen bei einem Tumorvolumen $\left(V_{T}\right)$ von ca. $500 \mathrm{~mm}^{3}$ die jeweilige Therapie appliziert. Unbehandelte Tiere wurden bei einem max. $\mathrm{V}_{\mathrm{T}}$ von $1000 \mathrm{~mm}^{3}$ seziert, Tiere der Gruppe CAF - Remission spätestens sechs Tage nach Therapiestart und die Gruppen CAF - Progression und CAF/S-Therapie beinhalteten Tiere, die spätestens bei einem $V_{T}$ von ca. $1000 \mathrm{~mm}^{3}$ nach Wiederwachstum, seziert wurden. Kontrolltiere der CAF/S-Therapie wurden nur mit Siltuximab behandelt und bei einem max. $\mathrm{V}_{\mathrm{T}}$ von $1000 \mathrm{~mm}^{3}$ seziert. Weiter wurden Tumorzellen aus unbehandelten und CAF-therapierten Tumoren (CAF - Remission/CAF - Progression) durch magnetische Separation isoliert, die Tumorzellen kultiviert sowie retransplantiert und bei einem $V_{T}$ von ca. $500 \mathrm{~mm}^{3}$ mit CAF therapiert. Unbehandelte Tiere wurden bei einem maximalen $\mathrm{V}_{\mathrm{T}}$ von $1000 \mathrm{~mm}^{3}$ und CAF-therapierte spätestens bei einem Tumorvolumen nach Wiederwachstum von ca. $1000 \mathrm{~mm}^{3}$ seziert. 
Die Bestimmung der $\mathrm{V}_{\mathrm{T}}$ der CAF-therapierten Tumore über die Zeit zeigt, dass die CAF-Therapie das $\mathrm{V}_{\mathrm{T}}$ von H8N8-Tumoren nicht vollständig und nur temporär verringert. Anhand histochemischer (HE/MTS) und IHC-Färbungen (T-Ag, Pcna, Cd24, Cd44, Cd45, E-Cadherin, Vimentin, $\alpha$-Sma und Tenascin-C) wurde nachgewiesen, dass CAF EMT-Prozesse initiiert, verbunden mit der Veränderung von einem eher epithelialen Tumorphänotyp in unbehandelten, hin zu einem mesenchymaleren Tumorphänotyp in der Gruppe CAF - Progression. Tumore der Gruppe CAF - Remission wiesen die größten strukturellen Veränderungen auf. wie eine verstärkte Kollagenbildung, eine Verringerung an epithelialen Zellen und ein starker Zugewinn an mesenchymalen Zellen, sowie das vermehrte Vorkommen von $\mathrm{Cd} 44+\mathrm{Cd} 24-$ Tumorzellen. FACS-Analysen bestätigten die Anreicherung von Cd44+Cd24--Tumorzellen in Tumoren der Gruppe CAF - Remission und zeigten weiter, dass diese Tumorzellen vermehrt Oberflächenmoleküle wie Cd95, Cd104, Cd107a, Cd120b, Cd126, Cd146, Cd201 und Sca1 präsentieren, die mit Resistenz- und CSC-Eigenschaften in Verbindung gebracht werden. Die CAF-Therapie führt außerdem dazu, dass Signalwege wie der Tnf- $\alpha$ und der Il6-Jak1Stat 3 besonders in Tumoren der Gruppe CAF - Remission aktiv sind, sowie antiapoptotische und mit Pluripotenz-, Stammzell- und Resistenz-assoziierte Gene hochreguliert sind, verdeutlicht an Genexpressionsprofilen von Tumorzellen nach mRNA-Sequenzierung und GSEA-Analysen. Retransplantation von CAF-therapierten Tumorzellen aus einem Tumor der Gruppe CAF - Remission wies bei erneuter CAF-Therapie eine gesteigerte Resistenz auf. Die Wirkung der CAF/S-Therapie im WAP-T-Mausmodell unterscheidet sich nicht von der Wirkung der CAF-Therapie, was an den vergleichbaren Wachstumskinetiken deutlich wird. Lediglich eine schnellere Tumorvolumenreduzierung nach CAF/S-Therapie, verglichen mit der CAF-Therapie wurde während der ersten vier Tage nach Therapiestart beobachtet. Wieder gewachsene CAF/S-therapierte Tumore hatten, verglichen mit den CAF-therapierten Tumoren einen geringeren Anteil Cd44+-Tumorzellen, jedoch war keine Veränderung der Anteile der $\mathrm{Cd} 44{ }^{+} \mathrm{Cd} 24-$-Tumorzellen von $\mathrm{CAF} / \mathrm{S}$-therapierten Tumoren erkennbar. Zusammenfassend zeigen die Ergebnisse der vorliegenden Arbeit, wie wichtig die präklinische Evaluierung der Wirkung von Mammakarzinomtherapien, nicht nur im Hinblick auf das Tumorwachstum, sondern auch auf die Differenzierung von Tumorzellsubtypen ist, da einige, wie hier die $\mathrm{Cd} 44+\mathrm{Cd} 24-$ Tumorzellen, durch den therapiebedingten Selektionsdruck begünstigt werden, das Wiederwachstum befördern und bei erneuter Therapie mit gesteigerter Resistenz antworten. Das 
Auftreten von EMT-Prozessen und die Aktivierung der Tnf- $\alpha$ - und Il6-Jak1-Stat3-Signaltransduktion sind Faktoren, die erklären, wie die CAF-Therapie eine Mikroumgebung schafft, welche die Entwicklung von Resistenzen im Tumor unterstützen. Da H8N8-Tumore nach der CAF-Therapie stark vermehrt von Immunzellen infiltriert werden und die Charakterisierung dieser Immunzellen von großer therapeutischer Relevanz ist, könnte das WAP-T-Mausmodell geeignet sein, die Rolle des Immunsystems bei der Entwicklung von Resistenzen zu untersuchen. Deshalb ist die Evaluation von Therapien unter Einbezug von immunmodulatorischen Mechanismen für zukünftige therapeutische Ansätze zur Bekämpfung von Resistenzen im Mammakarzinom von großer Bedeutung. 


\section{Literaturverzeichnis}

Acharyya S, Oskarsson T, Vanharanta S, Malladi S, Kim J, Morris PG, Manova-Todorova K, Leversha M, Hogg N, Seshan VE, et al. (2012): A CXCL1 Paracrine Network Links Cancer Chemoresistance and Metastasis. Cell 150, 165-178

Afgan E, Baker D, Batut B, van den Beek M, Bouvier D, Čech M, Chilton J, Clements D, Coraor N, Grüning BA, et al. (2018): The Galaxy platform for accessible, reproducible and collaborative biomedical analyses: 2018 update. Nucleic Acids Res 46, W537-W544

Ahmad A (2013): Pathways to Breast Cancer Recurrence. ISRN Oncol 2013

Ahmed M, Chaudhari K, Babaei-Jadidi R, Dekker LV, Nateri AS (2017): Concise Review: Emerging Drugs Targeting Epithelial Cancer Stem-Like Cells. STEM CELLS $\underline{35}$, 839-850

Akhurst RJ, Derynck R (2001): TGF-beta signaling in cancer--a double-edged sword. Trends Cell Biol $\underline{11}$, S44-51

Akrap N, Andersson D, Bom E, Gregersson P, Ståhlberg A, Landberg G (2016): Identification of Distinct Breast Cancer Stem Cell Populations Based on Single-Cell Analyses of Functionally Enriched Stem and Progenitor Pools. Stem Cell Rep $\underline{6}, 121-136$

Al Saleh S, Al Mulla F, Luqmani YA (2011): Estrogen receptor silencing induces epithelial to mesenchymal transition in human breast cancer cells. PloS One $\underline{6}$, e20610

Al-Hajj M, Becker MW, Wicha M, Weissman I, Clarke MF (2004): Therapeutic implications of cancer stem cells. Curr Opin Genet Dev 14, 43-47

Aras S, Zaidi MR (2017): TAMeless traitors: macrophages in cancer progression and metastasis. Br J Cancer $\underline{117}, 1583-1591$

Asano Y, Kashiwagi S, Goto W, Takada K, Takahashi K, Hatano T, Takashima T, Tomita S, Motomura H, Ohsawa M, et al. (2018): Prediction of Treatment Response to Neoadjuvant Chemotherapy in Breast Cancer by Subtype Using Tumor-infiltrating Lymphocytes. Anticancer Res $\underline{38}, 2311-2321$

Aulmann S, Waldburger N, Penzel R, Andrulis M, Schirmacher P, Sinn HP (2010): Reduction of CD44(+)/CD24(-) breast cancer cells by conventional cytotoxic chemotherapy. Hum Pathol $\underline{41}$, 574-581

Bae YK, Kim A, Kim MK, Choi JE, Kang SH, Lee SJ (2013): Fibronectin expression in carcinoma cells correlates with tumor aggressiveness and poor clinical outcome in patients with invasive breast cancer. Hum Pathol 44, 2028-2037

Banerjee K, Resat H (2016): Constitutive activation of STAT3 in breast cancer cells: A review: Constitutive STAT3 activation in breast cancer. Int J Cancer 138, 2570-2578

Baritaki S, Yeung K, Palladino M, Berenson J, Bonavida B (2009): Pivotal Roles of Snail Inhibition and RKIP Induction by the Proteasome Inhibitor NPI-0052 in Tumor Cell Chemoimmunosensitization. Cancer Res $\underline{69}$, 8376-8385

Bartek J, Bartkova J, Lukas J (1997): The retinoblastoma protein pathway in cell cycle control and cancer. Exp Cell Res 237, 1-6

Becker S (2015): A historic and scientific review of breast cancer: The next global healthcare challenge. Int J Gynecol Obstet 131, S36-S39

Ben-Porath I, Thomson MW, Carey VJ, Ge R, Bell GW, Regev A, Weinberg RA (2008): An embryonic stem cell-like gene expression signature in poorly differentiated aggressive human tumors. Nat Genet $\underline{40}$, 499-507

Berishaj M, Gao SP, Ahmed S, Leslie K, Al-Ahmadie H, Gerald WL, Bornmann W, Bromberg JF (2007): Stat 3 is tyrosine-phosphorylated through the interleukin-6/glycoprotein 130/Janus kinase pathway in breast cancer. Breast Cancer Res 2 , R32

Blankenberg D, Gordon A, Von Kuster G, Coraor N, Taylor J, Nekrutenko A (2010): Manipulation of FASTQ data with Galaxy. Bioinformatics 26 6 , 1783-1785

Brabletz T, Kalluri R, Nieto MA, Weinberg RA (2018): EMT in cancer. Nat Rev Cancer 18, 128-134

Bray F, Ferlay J, Soerjomataram I, Siegel RL, Torre LA, Jemal A (2018): Global cancer statistics 2018: GLOBOCAN estimates of incidence and mortality worldwide for 36 cancers in 185 countries. CA Cancer $\mathrm{J}$ Clin $\underline{68}, 394-424$

Cardiff RD, Wellings SR (1999): The comparative pathology of human and mouse mammary glands. J Mammary Gland Biol Neoplasia 4, 105-122

Cariati M, Naderi A, Brown JP, Smalley MJ, Pinder SE, Caldas C, Purushotham AD (2008): Alpha-6 integrin is necessary for the tumourigenicity of a stem cell-like subpopulation within the MCF7 breast cancer cell line. Int J Cancer 122, 298-304

Casneuf T, Axel AE, King P, Alvarez JD, Werbeck JL, Verhulst T, Verstraeten K, Hall BM, Sasser AK (2016): Interleukin-6 is a potential therapeutic target in interleukin-6 dependent, estrogen receptor- $\alpha$ positive breast cancer. Breast Cancer Targets Ther $\underline{8}, 13-27$ 
Ceppi P, Hadji A, Kohlhapp FJ, Pattanayak A, Hau A, Liu X, Liu H, Murmann AE, Peter ME (2014): CD95 and CD95L promote and protect cancer stem cells. Nat Commun $\underline{5}, 5238$

Chang TK, Weber GF, Crespi CL, Waxman DJ (1993): Differential activation of cyclophosphamide and ifosphamide by cytochromes P-450 2B and 3A in human liver microsomes. Cancer Res $\underline{53}$, 5629_ 5637

Chao Y, Wu Q, Shepard C, Wells A (2012): Hepatocyte induced re-expression of E-cadherin in breast and prostate cancer cells increases chemoresistance. Clin Exp Metastasis 29, 39-50

Chao YL, Shepard CR, Wells A (2010): Breast carcinoma cells re-express E-cadherin during mesenchymal to epithelial reverting transition. Mol Cancer $\underline{9}, 179$

Chavey C, Bibeau F, Gourgou-Bourgade S, Burlinchon S, Boissière F, Laune D, Roques S, Lazennec G (2007): Oestrogen receptor negative breast cancers exhibit high cytokine content. Breast Cancer Res 9, R15

Chen T, You Y, Jiang H, Wang ZZ (2017): Epithelial-mesenchymal transition (EMT): A biological process in the development, stem cell differentiation and tumorigenesis. J Cell Physiol 232, 3261-3272

Cheng GZ, Chan J, Wang Q, Zhang W, Sun CD, Wang L-H (2007): Twist transcriptionally up-regulates AKT2 in breast cancer cells leading to increased migration, invasion, and resistance to paclitaxel. Cancer Res $\underline{67}, 1979-1987$

Chiu JJ, Sgagias MK, Cowan KH (1996): Interleukin 6 acts as a paracrine growth factor in human mammary carcinoma cell lines. Clin Cancer Res $\underline{2}$, 215-221

Conklin MW, Eickhoff JC, Riching KM, Pehlke CA, Eliceiri KW, Provenzano PP, Friedl A, Keely PJ (2011): Aligned collagen is a prognostic signature for survival in human breast carcinoma. Am J Pathol $\underline{178}$, 1221-1232

Corben AD (2013): Pathology of Invasive Breast Disease. Surg Clin North Am 무, 363-392

Craene BD, Berx G (2013): Regulatory networks defining EMT during cancer initiation and progression. Nat Rev Cancer 13, 97-110

Dall GV, Britt KL (2017): Estrogen Effects on the Mammary Gland in Early and Late Life and Breast Cancer Risk. Front Oncol 1

Darwin C (1860): On the Origin of Species by Means of Natural Selection, or the Preservation of Favoured Races in the Struggle for Life. Br Foreign Medico-Chir Rev 25, 367-404

De Palma M, Lewis CE (2013): Macrophage regulation of tumor responses to anticancer therapies. Cancer Cell $\underline{23}, 277-286$

Dean M (2009): ABC transporters, drug resistance, and cancer stem cells. J Mammary Gland Biol Neoplasia $\underline{14}, 3-9$

Denkert C, Liedtke C, Tutt A, von Minckwitz G (2017): Molecular alterations in triple-negative breast cancer-the road to new treatment strategies. The Lancet 389, 2430-2442

Denkert C, Minckwitz G von, Darb-Esfahani S, Lederer B, Heppner BI, Weber KE, Budczies J, Huober J, Klauschen F, Furlanetto J, et al. (2018): Tumour-infiltrating lymphocytes and prognosis in different subtypes of breast cancer: a pooled analysis of 3771 patients treated with neoadjuvant therapy. Lancet Oncol 19 , 40-50

Deppert W, Pates R (1979): Simian virus 40 specific proteins on surface of HeLa cells infected with adenovirus 2--SV40 hybrid virus Ad2+ND2. Nature 277, 322-324

Dethlefsen C, Højfeldt G, Hojman P (2013): The role of intratumoral and systemic IL-6 in breast cancer. Breast Cancer Res Treat 138, 657-664

Dieci MV, Criscitiello C, Goubar A, Viale G, Conte P, Guarneri V, Ficarra G, Mathieu MC, Delaloge S, Curigliano G, Andre F (2015): Prognostic value of tumor-infiltrating lymphocytes on residual disease after primary chemotherapy for triple-negative breast cancer: a retrospective multicenter study. Ann Oncol Off J Eur Soc Med Oncol 26, 1518

Dobin A, Davis CA, Schlesinger F, Drenkow J, Zaleski C, Jha S, Batut P, Chaisson M, Gingeras TR (2013): STAR: ultrafast universal RNA-seq aligner. Bioinformatics $\underline{29}, 15-21$

Doerr L, Thomas U, Guinot DR, Bot CT, Stoelzle-Feix S, Beckler M, George M, Fertig N (2015): New Easyto-Use Hybrid System for Extracellular Potential and Impedance Recordings. J Lab Autom 20, 175188

Doyle LA, Yang W, Abruzzo LV, Krogmann T, Gao Y, Rishi AK, Ross DD (1998): A multidrug resistance transporter from human MCF-7 breast cancer cells. Proc Natl Acad Sci U S A $\underline{95}, 15665-15670$

Early Breast Cancer Trialists' Collaborative Group (EBCTCG) (2012): Comparisons between different polychemotherapy regimens for early breast cancer: meta-analyses of long-term outcome among 100000 women in 123 randomised trials. The Lancet 379, 432-444

Eisenhauer EA, Therasse P, Bogaerts J, Schwartz LH, Sargent D, Ford R, Dancey J, Arbuck S, Gwyther S, Mooney M, et al. (2009): New response evaluation criteria in solid tumours: Revised RECIST guideline (version 1.1). Eur J Cancer 4ㄷ, 228-247

Elston CW, Ellis IO (1991): Pathological prognostic factors in breast cancer. I. The value of histological grade in breast cancer: experience from a large study with long-term follow-up. Histopathology 19, 403-410 
Felipe Lima J, Nofech-Mozes S, Bayani J, Bartlett JMS (2016): EMT in Breast Carcinoma-A Review. J Clin Med $\underline{5}$

Ferlay J, Colombet M, Soerjomataram I, Mathers C, Parkin DM, Piñeros M, Znaor A, Bray F (2019): Estimating the global cancer incidence and mortality in 2018: GLOBOCAN sources and methods. Int J Cancer 144, 1941-1953

Feuerhake F, Sigg W, Höfter EA, Dimpfl T, Welsch U (2000): Immunohistochemical analysis of Bcl-2 and Bax expression in relation to cell turnover and epithelial differentiation markers in the non-lactating human mammary gland epithelium. Cell Tissue Res 299, 47-58

Fontanini G, Campani D, Roncella M, Cecchetti D, Calvo S, Toniolo A, Basolo F (1999): Expression of interleukin 6 (IL-6) correlates with oestrogen receptor in human breast carcinoma. Br J Cancer $\underline{80}, 579$

Foulkes WD, Smith IE, Reis-Filho JS (2010): Triple-Negative Breast Cancer. N Engl J Med 363, 1938-1948

Gao L, Zhang L, Hu J, Li F, Shao Y, Zhao D, Kalvakolanu DV, Kopecko DJ, Zhao X, Xu D-Q (2005): Down-Regulation of Signal Transducer and Activator of Transcription 3 Expression Using VectorBased Small Interfering RNAs Suppresses Growth of Human Prostate Tumor In vivo. Clin Cancer Res 11, 6333-6341

Gerber B, Freund M, Reimer T (2010): Recurrent Breast Cancer. Dtsch Aerzteblatt Online

Gevensleben H: Genese des Mammakarzinoms in einem induzierbaren WAP-T-transgenen Mausmodell. Med. Diss. Hamburg. 2010

Gilbert LA, Hemann MT (2011): Chemotherapeutic resistance: surviving stressful situations. Cancer Res $\underline{71}$, 5062-5066

Ginestier C, Hur MH, Charafe-Jauffret E, Monville F, Dutcher J, Brown M, Jacquemier J, Viens P, Kleer CG, Liu S, et al. (2007): ALDH1 is a marker of normal and malignant human mammary stem cells and a predictor of poor clinical outcome. Cell Stem Cell $\underline{1}, 555-567$

Goecks J, Nekrutenko A, Taylor J, The Galaxy Team (2010): Galaxy: a comprehensive approach for supporting accessible, reproducible, and transparent computational research in the life sciences. Genome Biol 11, R86

Goetz F, Tzeng Y, Guhl E, Merker J, Graessmann M, Graessmann A (2001): The SV40 small t-antigen prevents mammary gland di $\square$ erentiation and induces breast cancer formation in transgenic mice; truncated large $\mathrm{T}$-antigen molecules harboring the intact p53 and pRb binding region do not have this e $\square$ ect. 8

Gonzalez DM, Medici D (2014): Signaling mechanisms of the epithelial-mesenchymal transition. Sci Signal $\underline{7}$, re8

Grange C, Lanzardo S, Cavallo F, Camussi G, Bussolati B (2008): SCA-1 Identifies the Tumor-Initiating Cells in Mammary Tumors of BALB-neuT Transgenic Mice. Neoplasia N Y N 10, 1433-1443

Green SK, Francia G, Isidoro C, Kerbel RS (2004): Antiadhesive antibodies targeting E-cadherin sensitize multicellular tumor spheroids to chemotherapy in vitro. Mol Cancer Ther $\underline{3}, 149-159$

Haensel D, Dai X (2018): Epithelial-to-mesenchymal transition in cutaneous wound healing: Where we are and where we are heading: EMT in Cutaneous Wound Healing. Dev Dyn 247, 473-480

Hanahan D, Weinberg RA (2000): The Hallmarks of Cancer. Cell $\underline{100}$, 57-70

Harmer M, Denoix P, Hamperl H (1968): Das TNM-System zur Klassifikation von Tumorkrankheiten. Klin Wochenschr $\underline{46}, 1181-1185$

Hartman ZC, Poage GM, Hollander P den, Tsimelzon A, Hill J, Panupinthu N, Zhang Y, Mazumdar A, Hilsenbeck SG, Mills GB, Brown PH (2013): Growth of Triple-Negative Breast Cancer Cells Relies upon Coordinate Autocrine Expression of the Proinflammatory Cytokines IL-6 and IL-8. Cancer Res $\underline{73}, 3470-3480$

Hay ED (1995): An Overview of Epithelio-Mesenchymal Transformation. Cells Tissues Organs 154, 8-20

Hayashi H, Suzuki A, Ohata K, Ishihara M, Kubota Y, Kobayashi R, Shibata Y, Nakamura H, Nakamura N, Kitagawa J, et al. (2017): Control of Constipation in Patients Receiving CHOP or CHOP-Like Chemotherapy Regimens for Non-Hodgkin's Lymphoma. Biol Pharm Bull 뜨, 698-702

Heinlein C, Krepulat F, Löhler J, Speidel D, Deppert W, Tolstonog GV (2008): Mutant p53R270H gain of function phenotype in a mouse model for oncogene-induced mammary carcinogenesis. Int J Cancer $\underline{122}, 1701-1709$

Honvo-Houéto E, Truchet S (2015): Indirect Immunofluorescence on Frozen Sections of Mouse Mammary Gland. J Vis Exp JoVE

Hudes G, Tagawa ST, Whang YE, Qi M, Qin X, Puchalski TA, Reddy M, Cornfeld M, Eisenberger M (2013): A phase 1 study of a chimeric monoclonal antibody against interleukin-6, siltuximab, combined with docetaxel in patients with metastatic castration-resistant prostate cancer. Invest New Drugs $\underline{31}$, 669676

Iliopoulos D, Hirsch HA, Wang G, Struhl K (2011): Inducible formation of breast cancer stem cells and their dynamic equilibrium with non-stem cancer cells via IL6 secretion. Proc Natl Acad Sci 108, 13971402 
Infante M, Fabi A, Cognetti F, Gorini S, Caprio M, Fabbri A (2019): RANKL/RANK/OPG system beyond bone remodeling: involvement in breast cancer and clinical perspectives. J Exp Clin Cancer Res $\underline{38}$, 12

Jannasch K, Dullin C, Heinlein C, Krepulat F, Wegwitz F, Deppert W, Alves F (2009): Detection of different tumor growth kinetics in single transgenic mice with oncogene-induced mammary carcinomas by flat-panel volume computed tomography. Int J Cancer 125, 62-70

Jannasch K, Wegwitz F, Lenfert E, Maenz C, Deppert W, Alves F (2015): Chemotherapy of WAP-T mouse mammary carcinomas aggravates tumor phenotype and enhances tumor cell dissemination: Phenotype changes in carcinoma after therapy. Int J Cancer 137, 25-36

Joshi H, Press MF: 22 - Molecular Oncology of Breast Cancer; in: The Breast (Fifth Edition); hrsg. v. Bland KI, Copeland EM, Klimberg VS, Gradishar WJ; Elsevier 2018, 282-307.e5

Kalluri R, Zeisberg M (2006): Fibroblasts in cancer. Nat Rev Cancer $\underline{6}$, 392-401

Kalluri R, Weinberg RA (2009): The basics of epithelial-mesenchymal transition. J Clin Invest 119, 1420_ 1428

Kang MH, Kang HN, Kim JL, Kim JS, Oh SC, Yoo YA (2009): Inhibition of PI3 kinase/Akt pathway is required for BMP2-induced EMT and invasion. Oncol Rep 22, 525-534

Kim SH, Kook MC, Shin YK, Park SH, Song HG (2004): Evaluation of antigen retrieval buffer systems. J Mol Histol $\underline{35}, 409-416$

Kotiyal S, Bhattacharya S (2014): Breast cancer stem cells, EMT and therapeutic targets. Biochem Biophys Res Commun $\underline{453}, 112-116$

Krepulat F, Löhler J, Heinlein C, Hermannstädter A, Tolstonog GV, Deppert W (2005): Epigenetic mechanisms affect mutant p53 transgene expression in WAP-mutp53 transgenic mice. Oncogene 24 , 4645-4659

Kröger C, Afeyan A, Mraz J, Eaton EN, Reinhardt F, Khodor YL, Thiru P, Bierie B, Ye X, Burge CB, Weinberg RA (2019): Acquisition of a hybrid E/M state is essential for tumorigenicity of basal breast cancer cells. Proc Natl Acad Sci $\underline{116}, 7353-7362$

Kurrey NK, Jalgaonkar SP, Joglekar AV, Ghanate AD, Chaskar PD, Doiphode RY, Bapat SA (2009): Snail and Slug Mediate Radioresistance and Chemoresistance by Antagonizing p53-Mediated Apoptosis and Acquiring a Stem-Like Phenotype in Ovarian Cancer Cells. Stem Cells 27, 2059-2068

Kurzrock R, Voorhees PM, Casper C, Furman RR, Fayad L, Lonial S, Borghaei H, Jagannath S, Sokol L, Usmani SZ, et al. (2013): A Phase I, Open-Label Study of Siltuximab, an Anti-IL-6 Monoclonal Antibody, in Patients with B-cell Non-Hodgkin Lymphoma, Multiple Myeloma, or Castleman Disease. Clin Cancer Res 19, 3659-3670

Lança T, Silva-Santos B (2012): The split nature of tumor-infiltrating leukocytes. Oncoimmunology 1 , 717 725

Lee H-J, Zhuang G, Cao Y, Du P, Kim H-J, Settleman J (2014): Drug Resistance via Feedback Activation of Stat3 in Oncogene-Addicted Cancer Cells. Cancer Cell 26, 207-221

Lenfert E, Maenz C, Heinlein C, Jannasch K, Schumacher U, Pantel K, Tolstonog GV, Deppert W, Wegwitz F (2015): Mutant p53 promotes epithelial-mesenchymal plasticity and enhances metastasis in mammary carcinomas of WAP-T mice. Int J Cancer 136, E521-E533

Li C-W, Xia W, Huo L, Lim S-O, Wu Y, Hsu JL, Chao C-H, Yamaguchi H, Yang N-K, Ding Q, et al. (2012): Epithelial-mesenchymal transition induced by TNF- $\alpha$ requires NF- $x \mathrm{~B}$-mediated transcriptional upregulation of Twist1. Cancer Res $\underline{72}$, 1290-1300

Li R, Li R, Wu C, Wu C, Liang H, Liang H, Zhao Y, Zhao Y, Lin C, Lin C, et al. (2018): Knockdown of TWIST enhances the cytotoxicity of chemotherapeutic drugs in doxorubicin-resistant HepG2 cells by suppressing MDR1 and EMT. Int J Oncol $\underline{53}, 1763-1773$

Liao Y, Smyth GK, Shi W (2014): featureCounts: an efficient general purpose program for assigning sequence reads to genomic features. Bioinformatics $\underline{30}, 923-930$

Liberzon A, Subramanian A, Pinchback R, Thorvaldsdóttir H, Tamayo P, Mesirov JP (2011): Molecular signatures database (MSigDB) 3.0. Bioinformatics $\underline{27}$, 1739-1740

Liberzon A, Birger C, Thorvaldsdóttir H, Ghandi M, Mesirov JP, Tamayo P (2015): The Molecular Signatures Database Hallmark Gene Set Collection. Cell Syst 1, 417-425

Lieblein JC, Ball S, Hutzen B, Sasser AK, Lin H-J, Huang TH, Hall BM, Lin J (2008): STAT3 can be activated through paracrine signaling in breast epithelial cells. BMC Cancer $\underline{8}, 302$

Lord SJ, Marinovich ML, Patterson JA, Wilcken N, Kiely BE, Gebski V, Crossing S, Roder DM, Gattellari M, Houssami N (2012): Incidence of metastatic breast cancer in an Australian population-based cohort of women with non-metastatic breast cancer at diagnosis. Med J Aust 196, 688-692

Love MI, Huber W, Anders S (2014): Moderated estimation of fold change and dispersion for RNA-seq data with DESeq2. Genome Biol 15, 550

Lu S, Labhasetwar V (2013): Drug Resistant Breast Cancer Cell Line Displays Cancer Stem Cell Phenotype and Responds Sensitively to Epigenetic Drug SAHA. Drug Deliv Transl Res $\underline{3}$, 183-194 
Maenz C, Lenfert E, Pantel K, Schumacher U, Deppert W, Wegwitz F (2015): Epithelial-mesenchymal plasticity is a decisive feature for the metastatic outgrowth of disseminated WAP-T mouse mammary carcinoma cells. BMC Cancer 15, 178

Mantovani A, Marchesi F, Malesci A, Laghi L, Allavena P (2017): Tumour-associated macrophages as treatment targets in oncology. Nat Rev Clin Oncol 14, 399-416

Marcato P, Dean CA, Pan D, Araslanova R, Gillis M, Joshi M, Helyer L, Pan L, Leidal A, Gujar S, et al. (2011): Aldehyde dehydrogenase activity of breast cancer stem cells is primarily due to isoform ALDH1A3 and its expression is predictive of metastasis. Stem Cells Dayt Ohio 29, $32-45$

Mariotto AB, Etzioni R, Hurlbert M, Penberthy L, Mayer M (2017): Estimation of the Number of Women Living with Metastatic Breast Cancer in the United States. Cancer Epidemiol Biomark Prev Publ Am Assoc Cancer Res Cosponsored Am Soc Prev Oncol 26, 809-815

Markham A, Patel T (2014): Siltuximab: First Global Approval. Drugs 74, 1147-1152

Masjedi A, Hashemi V, Hojjat-Farsangi M, Ghalamfarsa G, Azizi G, Yousefi M, Jadidi-Niaragh F (2018): The significant role of interleukin- 6 and its signaling pathway in the immunopathogenesis and treatment of breast cancer. Biomed Pharmacother $\underline{108}, 1415-1424$

McNally S, Stein T: Overview of Mammary Gland Development: A Comparison of Mouse and Human; in: Mammary Gland Development: Methods and Protocols; hrsg. v. Martin F, Stein T, Howlin J; Springer New York, New York, NY 2017, 1-17

McQuade RM, Stojanovska V, Abalo R, Bornstein JC, Nurgali K (2016): Chemotherapy-Induced Constipation and Diarrhea: Pathophysiology, Current and Emerging Treatments. Front Pharmacol 7

Medina D (1996): The mammary gland: a unique organ for the study of development and tumorigenesis. J Mammary Gland Biol Neoplasia 1, 5-19

Micalizzi DS, Ford HL (2009): Epithelial-mesenchymal transition in development and cancer. Future Oncol Lond Engl $\underline{5}, 1129-1143$

Middleton JD, Stover DG, Hai T (2018): Chemotherapy-Exacerbated Breast Cancer Metastasis: A Paradox Explainable by Dysregulated Adaptive-Response. Int J Mol Sci 19

Mørch LS, Skovlund CW, Hannaford PC, Iversen L, Fielding S, Lidegaard Ø (2017): Contemporary Hormonal Contraception and the Risk of Breast Cancer. http://dx.doi.org/101056/NEJMoa1700732

Morschhäuser J (2003): Resistenzen und Resistenzmechanismen: Wie „entkommen” Pilze der Therapie? Pharm Unserer Zeit 32, 124-129

Mullis KB, Faloona FA (1987): Specific synthesis of DNA in vitro via a polymerase-catalyzed chain reaction. Methods Enzymol 155, 335-350

Murawa P, Murawa D, Adamczyk B, Połom K (2014): Breast cancer: Actual methods of treatment and future trends. Rep Pract Oncol Radiother 19, 165-172

Nagarajan D, McArdle SEB (2018): Immune Landscape of Breast Cancers. Biomedicines $\underline{6}$

Nakasone ES, Askautrud HA, Kees T, Park J-H, Plaks V, Ewald AJ, Fein M, Rasch MG, Tan Y-X, Qiu J, et al. (2012): Imaging tumor-stroma interactions during chemotherapy reveals contributions of the microenvironment to resistance. Cancer Cell 21, 488-503

Naujokat C, Laufer S (2013): Targeting Cancer Stem Cells with Defined Compounds and Drugs. J Cancer Res Updat 2 , 36-67-67

Nieto MA, Huang RY-J, Jackson RA, Thiery JP (2016): EMT: 2016. Cell 166, 21-45

Oskarsson T, Acharyya S, Zhang XH-F, Vanharanta S, Tavazoie SF, Morris PG, Downey RJ, Manova-Todorova K, Brogi E, Massagué J (2011): Breast cancer cells produce tenascin C as a metastatic niche component to colonize the lungs. Nat Med 17, 867-874

Otto B, Gruner K, Heinlein C, Wegwitz F, Nollau P, Ylstra B, Pantel K, Schumacher U, Baumbusch LO, Martin-Subero JI, et al. (2013a): Low-grade and high-grade mammary carcinomas in WAP-T transgenic mice are independent entities distinguished by Met expression. Int J Cancer 132, 1300-1310

Otto B, Streichert T, Wegwitz F, Gevensleben H, Klätschke K, Wagener C, Deppert W, Tolstonog GV (2013b): Transcription factors link mouse WAP-T mammary tumors with human breast cancer. Int J Cancer 132, 1311-1322

Pece S, Tosoni D, Confalonieri S, Mazzarol G, Vecchi M, Ronzoni S, Bernard L, Viale G, Pelicci PG, Di Fiore PP (2010): Biological and molecular heterogeneity of breast cancers correlates with their cancer stem cell content. Cell $\underline{140}, 62-73$

Piccart-Gebhart MJ, Procter M, Leyland-Jones B, Goldhirsch A, Untch M, Smith I, Gianni L, Baselga J, Bell R, Jackisch C, et al. (2005): Trastuzumab after Adjuvant Chemotherapy in HER2-Positive Breast Cancer. N Engl J Med $\underline{353}, 1659-1672$

Pittius CW, Hennighausen L, Lee E, Westphal H, Nicols E, Vitale J, Gordon K (1988): A milk protein gene promoter directs the expression of human tissue plasminogen activator cDNA to the mammary gland in transgenic mice. Proc Natl Acad Sci U S A $\underline{85}, 5874-5878$

Polyak K, Weinberg RA (2009): Transitions between epithelial and mesenchymal states: acquisition of malignant and stem cell traits. Nat Rev Cancer $\underline{9}$, 265-273 
Pomp V, Leo C, Mauracher A, Korol D, Guo W, Varga Z (2015): Differential expression of epithelial-mesenchymal transition and stem cell markers in intrinsic subtypes of breast cancer. Breast Cancer Res Treat $154,45-55$

Potten CS, Loeffler M (1990): Stem cells: attributes, cycles, spirals, pitfalls and uncertainties. Lessons for and from the crypt. Dev Camb Engl 110, 1001-1020

Prat A, Perou CM (2011): Deconstructing the molecular portraits of breast cancer. Mol Oncol $\underline{5}, 5-23$

Prud'homme GJ (2012): Cancer stem cells and novel targets for antitumor strategies. Curr Pharm Des $\underline{18}$, 2838-2849

Puisieux A, Brabletz T, Caramel J (2014): Oncogenic roles of EMT-inducing transcription factors. Nat Cell Biol 16, 488-494

Quintavalle M, Elia L, Price JH, Heynen-Genel S, Courtneidge SA (2011): A cell-based high-content screening assay reveals activators and inhibitors of cancer cell invasion. Sci Signal $\underline{4}$, ra49

Ramel S, Sanchez C, Schimke M, Neshat K, Cross S, Raskind W, Reid B (1995): Inactivation of p53 and the Development of Tetraploidy in the Elastase-SV40 T Antigen Transgenic Mouse Pancreas. Pancreas $\underline{11}, 213-222$

Ren Y, Zhou X, Yang J-J, Liu X, Zhao X, Wang Q, Han L, Song X, Zhu Z, Tian W, et al. (2015): AC1MMYR2 impairs high dose paclitaxel-induced tumor metastasis by targeting miR-21/CDK5 axis. Cancer Lett 362, 174-182

Robertson C (2016): The extracellular matrix in breast cancer predicts prognosis through composition, splicing, and crosslinking. Exp Cell Res $\underline{343}, 73-81$

Rossow L, Veitl S, Vorlová S, Wax JK, Kuhn AE, Maltzahn V, Upcin B, Karl F, Hoffmann H, Gätzner S, et al. (2018): LOX-catalyzed collagen stabilization is a proximal cause for intrinsic resistance to chemotherapy. Oncogene $\underline{37}, 4921$

Rothhammer T, Poser I, Soncin F, Bataille F, Moser M, Bosserhoff A-K (2005): Bone morphogenic proteins are overexpressed in malignant melanoma and promote cell invasion and migration. Cancer Res $\underline{65}$, 448-456

Ruffell B, Coussens LM (2015): Macrophages and therapeutic resistance in cancer. Cancer Cell 27, 462-472

Samborski A: Untersuchung der Genexpression im porcinen Endometrium während der Präimplantationsphase mittels HOCHDURCHSATZ-RNA-Sequenzierung und DNA-Microarrays. 2013

Sarrió D, Rodriguez-Pinilla SM, Hardisson D, Cano A, Moreno-Bueno G, Palacios J (2008): Epithelial-mesenchymal transition in breast cancer relates to the basal-like phenotype. Cancer Res 68, 989-997

Sasaki K, Sugai T, Ishida K, Osakabe M, Amano H, Kimura H, Sakuraba M, Kashiwa K, Kobayashi S (2018): Analysis of cancer-associated fibroblasts and the epithelial-mesenchymal transition in cutaneous basal cell carcinoma, squamous cell carcinoma, and malignant melanoma. Hum Pathol $\underline{79}, 1-8$

Schindelin J, Arganda-Carreras I, Frise E, Kaynig V, Longair M, Pietzsch T, Preibisch S, Rueden C, Saalfeld S, Schmid B, et al. (2012): Fiji: an open-source platform for biological-image analysis. Nat Methods $\underline{9}, 676-682$

Schulze-Garg C, Löhler J, Gocht A, Deppert W (2000): A transgenic mouse model for the ductal carcinoma in situ (DCIS) of the mammary gland. Oncogene $\underline{19}, 1028-1037$

Schwartz LH, Litière S, de Vries E, Ford R, Gwyther S, Mandrekar S, Shankar L, Bogaerts J, Chen A, Dancey J, et al. (2016): RECIST 1.1 - Update and Clarification: From the RECIST Committee. Eur J Cancer Oxf Engl $1990 \underline{62}, 132-137$

Scimeca M, Antonacci C, Colombo D, Bonfiglio R, Buonomo OC, Bonanno E (2016): Emerging prognostic markers related to mesenchymal characteristics of poorly differentiated breast cancers. Tumour Biol J Int Soc Oncodevelopmental Biol Med 37, 5427-5435

Shao C, Sullivan JP, Girard L, Augustyn A, Yenerall P, Rodriguez J, Liu H, Behrens C, Shay JW, Wistuba II, Minna JD (2014): Essential role of aldehyde dehydrogenase 1A3 (ALDH1A3) for the maintenance of non-small cell lung cancer stem cells is associated with the STAT3 pathway. Clin Cancer Res Off J Am Assoc Cancer Res 20, 4154-4166

Sheng Q, Love TM, Schaffhausen B (2000): J Domain-Independent Regulation of the Rb Family by Polyomavirus Large T Antigen. J Virol 74, 5280-5290

Shi SR, Key ME, Kalra KL (1991): Antigen retrieval in formalin-fixed, paraffin-embedded tissues: an enhancement method for immunohistochemical staining based on microwave oven heating of tissue sections. J Histochem Cytochem Off J Histochem Soc 푸, 741-748

Shibue T, Weinberg RA (2017): EMT, CSCs, and drug resistance: the mechanistic link and clinical implications. Nat Rev Clin Oncol 14, 611-629

Shiga K, Hara M, Nagasaki T, Sato T, Takahashi H, Takeyama H (2015): Cancer-Associated Fibroblasts: Their Characteristics and Their Roles in Tumor Growth. Cancers 7, 2443-2458

Shook D, Keller R (2003): Mechanisms, mechanics and function of epithelial-mesenchymal transitions in early development. Mech Dev 120, 1351-1383

Sigurdsson V, Hilmarsdottir B, Sigmundsdottir H, Fridriksdottir AJR, Ringnér M, Villadsen R, Borg A, Agnarsson BA, Petersen OW, Magnusson MK, Gudjonsson T (2011): Endothelial induced EMT in breast epithelial cells with stem cell properties. PloS One $\underline{6}$, e23833 
Singh A, Settleman J (2010): EMT, cancer stem cells and drug resistance: an emerging axis of evil in the war on cancer. Oncogene 29, 4741-4751

Smith BN, Bhowmick NA (2016): Role of EMT in Metastasis and Therapy Resistance. J Clin Med $\underline{5}$

Subramanian A, Tamayo P, Mootha VK, Mukherjee S, Ebert BL, Gillette MA, Paulovich A, Pomeroy SL, Golub TR, Lander ES, Mesirov JP (2005): Gene set enrichment analysis: A knowledge-based approach for interpreting genome-wide expression profiles. Proc Natl Acad Sci 102, 15545-15550

Taube JH, Herschkowitz JI, Komurov K, Zhou AY, Gupta S, Yang J, Hartwell K, Onder TT, Gupta PB, Evans KW, et al. (2010): Core epithelial-to-mesenchymal transition interactome gene-expression signature is associated with claudin-low and metaplastic breast cancer subtypes. Proc Natl Acad Sci 107, 15449-15454

Therasse P, Arbuck SG, Eisenhauer EA, Wanders J, Kaplan RS, Rubinstein L, Verweij J, Van Glabbeke M, van Oosterom AT, Christian MC, Gwyther SG (2000): New Guidelines to Evaluate the Response to Treatment in Solid Tumors. JNCI J Natl Cancer Inst 92, 205-216

Thiery JP, Acloque H, Huang RYJ, Nieto MA (2009): Epithelial-mesenchymal transitions in development and disease. Cell $\underline{139}$, 871-890

Thomas SJ, Snowden JA, Zeidler MP, Danson SJ (2015): The role of JAK/STAT signalling in the pathogenesis, prognosis and treatment of solid tumours. Br J Cancer 113, 365-371

Tomayko MM, Reynolds CP (1989): Determination of subcutaneous tumor size in athymic (nude) mice. Cancer Chemother Pharmacol 24, 148-154

Ullman-Culleré MH, Foltz CJ (1999): Body condition scoring: a rapid and accurate method for assessing health status in mice. Lab Anim Sci 49, 319-323

Van Phuc P, Nhan PLC, Nhung TH, Tam NT, Hoang NM, Tue VG, Thuy DT, Ngoc PK (2011): Downregulation of CD44 reduces doxorubicin resistance of CD44+CD24- breast cancer cells. OncoTargets Ther $4,71-78$

Vesuna F, Lisok A, Kimble B, Domek J, Kato Y, van der Groep P, Artemov D, Kowalski J, Carraway H, van Diest P, Raman V (2012): Twist contributes to hormone resistance in breast cancer by downregulating estrogen receptor- $\alpha$. Oncogene $\underline{31}, 3223-3234$

Vijay GV, Zhao N, Den Hollander P, Toneff MJ, Joseph R, Pietila M, Taube JH, Sarkar TR, Ramirez-Pena E, Werden SJ, et al. (2019): GSK3 $\beta$ regulates epithelial-mesenchymal transition and cancer stem cell properties in triple-negative breast cancer. Breast Cancer Res 21, 37

Waks AG, Winer EP (2019): Breast Cancer Treatment: A Review. JAMA 321, 288-300

Wang AC, Su QB, Wu FX, Zhang XL, Liu PS (2009): Role of TLR4 for paclitaxel chemotherapy in human epithelial ovarian cancer cells. Eur J Clin Invest $\underline{39}$, 157-164

Wang Q, Yao J, Jin Q, Wang X, Zhu H, Huang F, Wang W, Qiang J, Ni Q (2017a): LAMP1 expression is associated with poor prognosis in breast cancer. Oncol Lett $\underline{14}, 4729-4735$

Wang X, Wang X, Gu J, Zhou M, He Z, Wang X, Ferrone S (2017b): Overexpression of miR-489 enhances efficacy of 5-fluorouracil-based treatment in breast cancer stem cells by targeting XIAP. Oncotarget 8, 113837-113846

Wegwitz F: Entdeckung, Charakterisierung und Modulation des Tumorstammzellsystems im WAP-T Mammakarzinom-Mausmodell. Med. Diss. Hamburg. 2011

Wegwitz F, Kluth M-A, Mänz C, Otto B, Gruner K, Heinlein C, Kühl M, Warnecke G, Schumacher U, Deppert W, Tolstonog GV (2010): Tumorigenic WAP-T Mouse Mammary Carcinoma Cells: A Model for a Self-Reproducing Homeostatic Cancer Cell System. PLOS ONE $\underline{5}$, e12103

White ND (2018): Hormonal Contraception and Breast Cancer Risk. Am J Lifestyle Med 12, 224-226

Xie L, Law BK, Chytil AM, Brown KA, Aakre ME, Moses HL (2004): Activation of the Erk Pathway Is Required for TGF- $\beta 1$-Induced EMT In Vitro. Neoplasia N Y N $\underline{6}, 603-610$

Zavadil J, Böttinger EP (2005): TGF-beta and epithelial-to-mesenchymal transitions. Oncogene 24, 5764 5774

Zeligs KP, Neuman MK, Annunziata CM (2016): Molecular Pathways: The Balance between Cancer and the Immune System Challenges the Therapeutic Specificity of Targeting Nuclear Factor- B Signaling for Cancer Treatment. Clin Cancer Res 22, 4302-4308

Zeng Q, Li W, Lu D, Wu Z, Duan H, Luo Y, Feng J, Yang D, Fu L, Yan X (2012): CD146, an epithelial-mesenchymal transition inducer, is associated with triple-negative breast cancer. Proc Natl Acad Sci $\underline{109}$, $1127-1132$

Zhang S, Zhang H, Ghia EM, Huang J, Wu L, Zhang J, Lam S, Lei Y, He J, Cui B, et al. (2019): Inhibition of chemotherapy resistant breast cancer stem cells by a ROR1 specific antibody. Proc Natl Acad Sci 116, 1370-1377

Zhang Z, Lin G, Yan Y, Li X, Hu Y, Wang J, Yin B, Wu Y, Li Z, Yang X-P (2018): Transmembrane TNFalpha promotes chemoresistance in breast cancer cells. Oncogene $\underline{37}, 3456$

Zheng X, Turkowski K, Mora J, Brüne B, Seeger W, Weigert A, Savai R (2017): Redirecting tumor-associated macrophages to become tumoricidal effectors as a novel strategy for cancer therapy. Oncotarget $\underline{8}$, 48436-48452 
Zhou S, Schuetz JD, Bunting KD, Colapietro AM, Sampath J, Morris JJ, Lagutina I, Grosveld GC, Osawa M, Nakauchi H, Sorrentino BP (2001): The ABC transporter Bcrp1/ABCG2 is expressed in a wide variety of stem cells and is a molecular determinant of the side-population phenotype. Nat Med $\underline{7}$, 1028-1034

\subsection{Internetseitenverzeichnis}

Andrews S. http://www.bioinformatics.babraham.ac.uk/projects/fastqc/; Zugriff am 29.04.2019 Ferlay J, Ervik M, Lam F, Colombet M, Mery L, Piñeros M, Znaor A, Soerjomataram I, Bray F. http://gco.iarc.fr/today/home; Zugriff am 15.04.2019

NCI Thesaurus. https://ncit.nci.nih.gov/ncitbrowser/ConceptReport.jsp?dictionary $=$ NCI $\% 20$ Thesaurus\&code=C9533; Zugriff am 17.04.2019 


\section{$9 \quad$ Anhang}

Tabelle 33: EMT-Marker-Sequenzdaten der Tumorzell-mRNA der Gruppe CAF - Remission normiert gegen Tumorzell-mRNA der unbehandelten Tumore

\begin{tabular}{lcccccc} 
Gen Name & Abkürzung & MNR & Log2FC & SEM & p-Wert & $\begin{array}{c}\text { adjusted } \\
\text { p-Wert }\end{array}$ \\
\hline \hline E-Cadherin & Cdh1 & 1229,3 & 0,92 & 0,131 & $2,04 \mathrm{E}-12$ & $6,17 \mathrm{E}-11$ \\
\hline Fibronektin-1 & Fn1 & 50684,0 & 0,72 & 0,118 & $1,07 \mathrm{E}-09$ & $2,10 \mathrm{E}-08$ \\
Vimentin & Vim & 11950,3 & 1,60 & 0,182 & $1,89 \mathrm{E}-18$ & $1,15 \mathrm{E}-16$ \\
\hline snail family zinc finger 1 & Snai1 & 2359,0 & 0,65 & 0,176 & 0,0003 & 0,0014 \\
snail family zinc finger 2 & Snai2 & 257,2 & 0,17 & 0,213 & 0,4218 & 0,6032 \\
$\begin{array}{l}\text { twist basic helix-loop-helix } \\
\text { transcription factor 1 }\end{array}$ & Twist1 & 1055,3 & 0,59 & 0,233 & 0,0120 & 0,0403 \\
transcription Factor 3 & Tcf3 & 1244,1 & $-0,19$ & 0,114 & 0,0976 & 0,2111 \\
transcription Factor 4 & Tcf4 & 1499,5 & 0,46 & 0,125 & 0,0002 & 0,0015 \\
$\begin{array}{l}\text { goosecoid homeobox } \\
\text { sine oculis-related homeo- } \\
\text { box 1 }\end{array}$ & Gsc & 4,3 & 0,95 & 0,457 & 0,0378 & 0,1018 \\
\hline $\begin{array}{l}\text { grainyhead like Transcrip- } \\
\text { tion Factor 2 }\end{array}$ & Six1 & 470,8 & $-0,29$ & 0,111 & 0,0091 & 0,0323 \\
$\begin{array}{l}\text { E74-like factor 3 } \\
\text { E74-like factor 5 }\end{array}$ & Grhl2 & 686,7 & $-0,96$ & 0,132 & $3,93 \mathrm{E}-13$ & $1,30 \mathrm{E}-11$ \\
& Elf3 & 780,9 & $-0,65$ & 0,128 & $4,27 \mathrm{E}-07$ & $5,17 \mathrm{E}-06$ \\
& Elf5 & 801,8 & $-0,82$ & 0,182 & $6,10 \mathrm{E}-06$ & $5,70 \mathrm{E}-05$
\end{tabular}

Tabelle 34: EMT-Marker-Sequenzdaten der Tumorzell-mRNA der Gruppe CAF - Progression normiert gegen Tumorzell-mRNA der unbehandelten Tumore

\begin{tabular}{lcccccc} 
Gen Name & Abkürzung & MNR & Log2FC & SEM & p-Wert & $\begin{array}{c}\text { adjusted } \\
\text { p-Wert }\end{array}$ \\
\hline \hline E-Cadherin & Cdh1 & 1229,3 & 0,04 & 0,132 & 0,7463 & 0,9067 \\
\hline Fibronektin-1 & Fn1 & 50684,0 & 0,11 & 0,118 & 0,3750 & 0,6772 \\
Vimentin & Vim & 11950,3 & 1,02 & 0,183 & $1,98 \mathrm{E}-08$ & $9,48 \mathrm{E}-07$ \\
\hline snail family zinc finger 1 & Snai1 & 2359,0 & 0,98 & 0,176 & $2,16 \mathrm{E}-08$ & $1,02 \mathrm{E}-06$ \\
snail family zinc finger 2 & Snai2 & 257,2 & 0,22 & 0,211 & 0,2939 & 0,6002 \\
twist basic helix-loop-helix & Twist1 & 1055,3 & 0,63 & 0,233 & 0,0072 & 0,0532 \\
transcription factor 1 & Tcf3 & 1244,1 & 0,03 & 0,113 & 0,7611 & 0,9134 \\
transcription Factor 3 & Tcf4 & 1499,5 & 0,31 & 0,125 & 0,0129 & 0,0820 \\
transcription Factor 4 & Gsc & 4,3 & 1,04 & 0,457 & 0,0232 & 0,1241 \\
goosecoid homeobox & Six1 & 470,8 & 0,02 & 0,109 & 0,8888 & 0,9625 \\
$\begin{array}{l}\text { sine oculis-related homeo- } \\
\text { box 1 }\end{array}$ & Grhl2 & 686,7 & $-0,34$ & 0,129 & 0,0077 & 0,0557 \\
\hline $\begin{array}{l}\text { grainyhead like Transcrip- } \\
\text { tion Factor 2 }\end{array}$ & Elf3 & 780,9 & 0,17 & 0,125 & 0,1667 & 0,4434 \\
$\begin{array}{l}\text { E74-like factor 3 } \\
\text { E74-like factor 5 }\end{array}$ & Elf5 & 801,8 & $-0,02$ & 0,180 & 0,9184 & 0,9747
\end{tabular}


Tabelle 35: Sequenzierdaten der Zielgene des Tnf- $\alpha$-Signalwegs der Tumorzell-mRNA der Gruppe CAF - Remission normiert gegen Tumorzell-mRNA der unbehandelten Tumore

\begin{tabular}{lcccccc} 
Gen Name & Abkürzung & MNR & Log2FC & SEM & p-Wert & $\begin{array}{c}\text { adjusted } \\
\text { p-Wert }\end{array}$ \\
\hline \hline Cyclin-D1 & Bcl1 & 312,7 & 0,22 & 0,191 & 0,2442 & 0,4151 \\
B cell leukemia/Iymphoma 2 & Bcl2 & 624,7 & 1,21 & 0,114 & $3,55 \mathrm{E}-26$ & $4,27 \mathrm{E}-24$ \\
BCL2-like 1 & BclXL & 188,5 & 0,25 & 0,194 & 0,1965 & 0,3556 \\
$\begin{array}{l}\text { myeloid cell leukemia se- } \\
\text { quence 1 }\end{array}$ & Mcl1 & 6757,7 & 0,43 & 0,158 & 0,0062 & 0,0234 \\
Interleukin-10 & IL10 & 3,6 & 1,60 & 0,449 & 0,0004 & 0,0022 \\
Interleukin-11 & IL11 & 11,4 & 1,10 & 0,427 & 0,0102 & 0,0354 \\
Interleukin-23 & IL23 & 88,1 & 1,65 & 0,249 & $3,65 \mathrm{E}-11$ & $9,21 \mathrm{E}-10$
\end{tabular}

Tabelle 36: Sequenzierdaten der Zielgene des Tnf- $\alpha$-Signalwegs der Tumorzell-mRNA der Gruppe CAF - Progression normiert gegen Tumorzell-mRNA der unbehandelten Tumore

\begin{tabular}{lcccccc} 
Gen Name & Abkürzung & MNR & Log2FC & SEM & p-Wert & $\begin{array}{c}\text { adjusted } \\
\text { p-Wert }\end{array}$ \\
\hline \hline Cyclin-D1 & $B c l 1$ & 312,7 & 0,74 & 0,188 & $8,48 \mathrm{E}-05$ & 0,0015 \\
B cell leukemia/Iymphoma 2 & $B c 12$ & 624,7 & 0,63 & 0,114 & $4,22 \mathrm{E}-08$ & $1,91 \mathrm{E}-06$ \\
$\begin{array}{l}\text { BCL2-like 1 } \\
\text { myeloid cell leukemia se- }\end{array}$ & BclXL & 188,5 & 0,04 & 0,193 & 0,8175 & 0,9346 \\
quence 1 & Mcl1 & 6757,7 & 0,20 & 0,158 & 0,1993 & 0,4912 \\
Interleukin-10 & IL10 & 3,6 & 0,23 & 0,444 & 0,6025 & 0,8331 \\
Interleukin-11 & IL11 & 11,4 & 0,27 & 0,431 & 0,5296 & 0,7898 \\
Interleukin-23 & IL23 & 88,1 & 0,73 & 0,252 & 0,004 & 0,031
\end{tabular}

Tabelle 37: Sequenzierdaten I16-Rezeptor und -Zielgene des I16-Jak1-Stat3-Signalwegs der TumorzellmRNA der Gruppe CAF - Remission normiert gegen Tumorzell-mRNA der unbehandelten Tumore

\begin{tabular}{lcccccc} 
Gen Name & Abkürzung & MNR & Log2FC & SEM & p-Wert & $\begin{array}{c}\text { adjusted } \\
\text { p-Wert }\end{array}$ \\
\hline \hline Interleukin-6 & Il6 & 1343,2 & 2,42 & 0,338 & $7,18 \mathrm{E}-13$ & $2,30 \mathrm{E}-11$ \\
Interleukin-6-Rezeptor & Il6r & 546,8 & 1,52 & 0,200 & $2,98 \mathrm{E}-14$ & $1,11 \mathrm{E}-12$ \\
$\begin{array}{l}\text { interleukin 6 signal transducer } \\
\text { Januskinase-1 }\end{array}$ & Gp130 & 4019,6 & 0,67 & 0,110 & $1,32 \mathrm{E}-09$ & $2,54 \mathrm{E}-08$ \\
$\begin{array}{l}\text { signal transducer and activa- } \\
\text { tor of transcription 3 }\end{array}$ & Jak1 & 3195,2 & 0,33 & 0,115 & 0.0037 & 0.0150 \\
$\begin{array}{l}\text { suppressor of cytokine signal- } \\
\text { ing 3 }\end{array}$ & Stat3 & 6398,9 & 1,14 & 0,146 & $6,45 \mathrm{E}-15$ & $2,61 \mathrm{E}-13$ \\
$\begin{array}{l}\text { TNF (ligand) superfamily, } \\
\text { member 11 }\end{array}$ & Tnfsf11 & 11257.7 & 0.46 & 0.169 & 0.0065 & 0.0242 \\
& 205.0 & 2.34 & 0.259 & $1.40 \mathrm{E}-19$ & $9.13 \mathrm{E}-18$
\end{tabular}


Tabelle 38: Sequenzierdaten I16-Rezeptor und -Zielgene des I16-Jak1-Stat3-Signalwegs der TumorzellmRNA der Gruppe CAF - Progression normiert gegen Tumorzell-mRNA der unbehandelten Tumore

\begin{tabular}{lcccccc} 
Gen Name & Abkürzung & MNR & Log2FC & SEM & p-Wert & $\begin{array}{c}\text { adjusted } \\
\text { p-Wert }\end{array}$ \\
\hline \hline Interleukin-6 & Il6 & 1343,2 & 1,05 & 0,338 & 0,0018 & 0,0181 \\
Interleukin-6-Rezeptor & Il6r & 546,8 & 0,13 & 0,201 & 0,5079 & 0,7754 \\
$\begin{array}{l}\text { interleukin 6 signal transducer } \\
\text { Januskinase-1 }\end{array}$ & Gp130 & 4019,6 & 0,06 & 0,110 & 0,5806 & 0,8207 \\
$\begin{array}{l}\text { signal transducer and activa- } \\
\text { tor of transcription 3 }\end{array}$ & Jak1 & 3195,2 & 0,04 & 0,115 & 0.7050 & 0.8887 \\
$\begin{array}{l}\text { suppressor of cytokine signal- } \\
\text { ing 3 }\end{array}$ & Socs3 & 11257.7 & 1.05 & 0.169 & $5.29 \mathrm{E}-10$ & $3.53 \mathrm{E}-08$ \\
$\begin{array}{l}\text { TNF (ligand) superfamily, } \\
\text { member 11 }\end{array}$ & Tnfsf11 & 205.0 & 0.72 & 0.259 & 0.0058 & 0.0453
\end{tabular}

Tabelle 39: Sequenzierdaten von Genen, die mit CSC-Eigenschaften und Pluripotenz assoziiert sind, der Tumorzell-mRNA der Gruppe CAF - Remission normiert gegen Tumorzell-mRNA der unbehandelten Tumore

\begin{tabular}{lcccccc} 
Gen Name & Abkürzung & MNR & Log2FC & SEM & p-Wert & $\begin{array}{c}\text { adjusted } \\
\text { p-Wert }\end{array}$ \\
\hline \hline $\begin{array}{l}\text { Integrin-alpha-6 } \\
\begin{array}{l}\text { aldehyde dehydrogenase fam- } \\
\text { ily 1, subfamily A3 }\end{array}\end{array}$ & Itga6 & 1880.9 & -0.71 & 0.116 & $1.07 \mathrm{E}-09$ & $2.09 \mathrm{E}-08$ \\
$\begin{array}{l}\text { ATP binding cassette sub- } \\
\text { family G member 2 }\end{array}$ & Aldh1a3 & 20.3 & 1.43 & 0.345 & $3.41 \mathrm{E}-05$ & 0.0003 \\
\hdashline $\begin{array}{l}\text { nanog homeobox } \\
\text { SRY (sex determining region }\end{array}$ & Nanog & 103.9 & 1.96 & 0.248 & $2.68 \mathrm{E}-15$ & $1.12 \mathrm{E}-13$ \\
$\begin{array}{l}\text { Y)-box 2 } \\
\text { Sox2 }\end{array}$ & 10.2 & 1.24 & 0.400 & 0.0014 & 0.0065 \\
\hline-0.447 & 0.0054 & 0.0210
\end{tabular}

Tabelle 40: Sequenzierdaten von Genen, die mit CSC-Eigenschaften und Pluripotenz assoziiert sind, der Tumorzell-mRNA der Gruppe CAF - Progression normiert gegen Tumorzell-mRNA der unbehandelten Tumore

\begin{tabular}{|c|c|c|c|c|c|c|}
\hline Gen Name & Abkürzung & $M N R$ & $\log 2 \mathrm{FC}$ & SEM & $\mathrm{p}$-Wert & $\begin{array}{c}\text { adjusted } \\
\mathrm{p}-\text { Wert }\end{array}$ \\
\hline Integrin-alpha-6 & Itga6 & 1880.9 & -0.30 & 0.116 & 0.0082 & 0.0586 \\
\hline $\begin{array}{l}\text { aldehyde dehydrogenase fam- } \\
\text { ily } 1 \text {, subfamily } A 3\end{array}$ & Aldh1a3 & 20.3 & 1.12 & 0.345 & 0.0012 & 0.0132 \\
\hline $\begin{array}{l}\text { ATP binding cassette sub- } \\
\text { family } G \text { member } 2\end{array}$ & $A b c g 2$ & 103.9 & 1.41 & 0.248 & $1.36 \mathrm{E}-08$ & $6.82 \mathrm{E}-07$ \\
\hline nanog homeobox & Nanog & 13.9 & 1.19 & 0.400 & 0.0028 & 0.0258 \\
\hline $\begin{array}{l}\text { SRY (sex determining region } \\
\text { Y)-box } 2\end{array}$ & Sox 2 & 10.2 & 0.56 & 0.447 & 0.2093 & 0.5031 \\
\hline
\end{tabular}

